Andriele Ferreira Muri

\title{
Letramento Científico no Brasil e no Japão a partir dos resultados do PISA
}

Tese apresentada como requisito parcial para obtenção do grau de Doutor pelo Programa de Pós-graduação em Educação do Departamento de Educação do Centro de Teologia e Ciências Humanas da PUC-Rio

Orientadora: Prof ${ }^{a}$. Alicia Maria Catalano de Bonamino Co-orientador: Prof. Tufi Machado Soares 


\section{Pontifícia U UIVersidade $C_{\text {Atólica }}$

Andriele Ferreira Muri

\section{Letramento Científico no Brasil e no Japão a partir dos Resultados do PISA}

Tese apresentada como requisito parcial para obtenção do grau de Doutor pelo Programa de pósGraduação em Educação do Departamento de Educação do Centro de Teologia e Ciências Humanas da PUC-Rio. Aprovada pela Comissão Examinadora abaixo assinada.

\section{Prof $\stackrel{a}{a}$ Alicia Maria Catalano de Bonamino Orientadora Departamento de Educação - PUC-Rio \\ Prof. Tufi Machado Soares \\ Co-orientador Departamento de Estatística - UFJF \\ Profa. Silvana Soares de Araujo Mesquita Departamento de Educação - PUC-Rio}

Profa. Rosália Maria Duarte Departamento de Educação - PUC-Rio

Profa. Maria Isabel Ramalho Ortigão Departamento de Formação de Professores - UERJ

Prof ${ }^{a}$. Marta Feijó Barroso - UFRJ Instituto de Física - UFRJ

Prof ${ }^{\mathrm{a}}$ Monah Winograd Coordenadora Setorial do Centro de Teologia e Ciências Humanas PUC-Rio

Rio de Janeiro, 17 de abril de 2017. 
Todos os direitos reservados. É proibida a reprodução total ou parcial do trabalho sem autorização do autor, do orientador e da universidade.

\section{Andriele Ferreira Muri}

Graduou-se em Ciências Biológicas na Universidade do Grande Rio (UNIGRANRIO) em 2003. Cursou um programa de treinamento para professores na Universidade Gakugei de Tóquio, no Japão. É mestre em Educação, Cultura e Comunicação pelo Programa de Pós Graduação em Educação, Cultura e Comunicação da Faculdade de Educação da Baixada Fluminense da UERJ. Participou de diversos congressos na área de Avaliação Educacional e Ciências Biológicas. É autora do livro "A formação científica no Brasil e o PISA". Foi professora substitua da UERJ na cadeira de Metodologia do Ensino de Ciências e professora regente de Ciências e Biologia na Educação Básica.

Ficha Catalográfica

Muri, Andriele Ferreira

Letramento científico no Brasil e no Japão a partir dos resultados do PISA / Andriele Ferreira Muri ; orientadora: Alicia Maria Catalano de Bonamino ; co-orientador: Tufi Machado Soares. - 2017.

238 f. : il. color. ; $30 \mathrm{~cm}$

Tese (doutorado)-Pontifícia Universidade Católica do Rio de Janeiro, Departamento de Educação, 2017.

Inclui bibliografia

1. Educação - Teses. 2. Letramento científico. 3. DIF. 4. TRI. 5. Avaliação educacional. 6. PISA. I. Bonamino, Alicia Maria Catalano de. II. Soares, Tufi Machado. III. Pontifícia Universidade Católica do Rio de Janeiro. Departamento de Educação. IV. Título. 


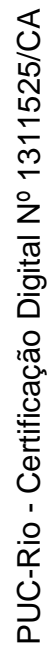

Para minha avó Iolanda. 


\section{Agradecimentos}

À Deus, autor e consumador da minha fé.

À minha orientadora, Professora Alicia Bonamino, pela acolhida e por ter acreditado e investido na viabilidade do meu projeto. Pela forma como conduziu a minha orientação, pela palavra de incentivo e amiga que nunca deixou faltar, pelas lições acadêmicas e de vida. Muito obrigada por tudo!

Aos meus co-orientadores, Professor Tufi Machado Soares e Professor Masahiro Kamata, pelo estímulo e parceria para a realização deste trabalho.

Às escolas e professores, do Brasil e do Japão, que abriram as portas da sala de aula para observação. Sem esse apoio e participação o trabalho não poderia ser realizado. Muito obrigada!

Aos professores especialistas, Dr. Yasushi Ogura e Dr. Masakata Ogawa, por atenciosamente me receberem e pelas valiosas entrevistas concedidas.

As gerentes do PISA no Brasil e no Japão, Maria Helena Guimarães de Castro e Akiko Ono, respectivamente, por me cederem parte do seu tempo e pela impressiva contribuição a partir de suas entrevistas.

À CAPES e à PUC-Rio, pelos auxílios concedidos, sem os quais este trabalho não poderia ter sido realizado.

À minha mãe, pela educação, atenção e carinho de todas as horas.

Ao meu marido e melhor amigo, Diego Courty, pelas importantes contribuições e palavras de apoio.

À Yumi Izuyama que comigo observou e analisou todas as aulas gravadas no Japão.

Ao meus amigos do LAEd por todo apoio e incentivo.

Aos meus colegas de doutorado da PUC-Rio.

Aos professores que participaram da Comissão examinadora.

À todos os professores e funcionários do Departamento de Educação pelos ensinamentos e pela ajuda.

Aos amigos mais chegados que irmãos que me ajudaram em oração.

À todos os amigos e familiares que de uma forma ou de outra me estimularam ou me ajudaram. 


\section{Resumo}

Muri, Andriele Ferreira; Bonamino, Alicia Maria Catalano de. Letramento Científico no Brasil e no Japão a partir dos Resultados do PISA. Rio de Janeiro, 2017. 238p. Tese de Doutorado - Departamento de Educação, Pontifícia Universidade Católica do Rio de Janeiro.

Este estudo compara o Letramento Científico dos estudantes brasileiros e japoneses, com base nos resultados do PISA e procura responder às seguintes as questões de pesquisa: a) Há diferenças de competência cognitiva em Ciências entre os alunos brasileiros e dos outros países, sobretudo os do Japão no PISA?; b) Existem itens do PISA 2006 que apresentam comportamento diferencial, tendo o Brasil como referência?; e c) É possível, a partir dos dados do PISA e da adoção complementar de uma abordagem qualitativa, identificar diferentes ênfases curriculares e/ou práticas pedagógicas no Ensino de Ciências de Brasil e Japão que contribuam para a compreensão das diferenças de desempenho entre seus estudantes? Para responder a primeira questão, comparamos os resultados do Brasil e do Japão nas edições 2006 e 2015 do PISA, em que o foco foi Ciências. O Brasil se mostra em situação de desvantagem em relação a quase todos os países que participaram do Programa, o que é em parte explicado pela repetência. $\mathrm{Na}$ escala de desempenho, o Brasil permanece no nível 1 e o Japão, no nível 3 em 2006, passou para o nível 4 em 2015. Para responder à segunda questão, utilizamos a análise de Differential Item Functioning (DIF) nos itens da prova de Ciências de 2006 e concluímos que há grande presença de DIF nesses itens comparativamente entre o Brasil e o Japão. Apesar de não serem capazes de comprometer o processo avaliativo privilegiando um grupo em detrimento do outro, esses itens sugerem diferentes ênfases curriculares em Ciências. Levando em conta essa hipótese e para responder à terceira questão adotamos uma abordagem qualitativa, com observação do uso do tempo das aulas; registro das ênfases curriculares e da ocorrência de atividades relacionadas à "interação", "investigação", "experimentação" e "aplicação" na perspectiva dos alunos, professores e da observação; e entrevistas com especialistas e gestores. Os resultados mostraram que mais de $20 \%$ do tempo oficial de aula observados no Brasil são desperdiçados com questões outras que não o ensino efetivo de Ciências; 10 vezes mais que no Japão. No Brasil, há ênfase curricular mais 
acentuada nas Ciências Naturais e Biológicas. O currículo é distribuído mais homogeneamente no Japão e é seccionado no Brasil. Segundo os estudantes japoneses, não são freqüentes as atividades de interação, investigação, experimentação e aplicação. As atividades mais recorrentes observadas e percebidas pelos professores japoneses são as de experimentação e interação; no Brasil, as de interação e aplicação. Entrevistas realizadas com especialistas em Ensino de Ciências e gestoras do PISA, no Brasil e no Japão, mostraram que o sucesso do Japão nessa avaliação é associado à existência de um currículo nacional comum e à formação continuada de professores em serviço, bem como às reformas do sistema educacional japonês suscitadas pelos resultados do PISA. O baixo desempenho dos estudantes brasileiros no PISA estaria, por sua vez, relacionado com o despreparo dos estudantes, com a falta de familiaridade destes com o teste, com a deficiente formação dos professores e com o limitado uso das evidências produzidas pelas avaliações em larga escala.

\section{Palavras-chave}

Letramento Científico; DIF; TRI; Avaliação Educacional; PISA; Brasil; Japão; Ênfases Curriculares; Estudo Comparado 


\section{Abstract}

Muri, Andriele Ferreira; Bonamino, Alicia Maria Catalano de (Advisor). Scientific Literacy in Brasil and Japan through PISA's Results. Rio de Janeiro, 2017. 238p. PhD Thesis - Departamento de Educação, Pontifícia Universidade Católica do Rio de Janeiro.

This study compares the Scientific Literacy of Brazilian and Japanese students, based on the results of PISA and seeks to answer the following research questions: a) Are there differences of cognitive competence in Science among Brazilian students and those from other countries, especially Japan, in the PISA ?; B) Are there items of PISA 2006 that present differential functioning, with Brazil as a reference ?; and c) Is it possible, based on the PISA data and the complementary adoption of a qualitative approach, to identify different curricular emphases and / or pedagogical practices in Science Education in Brazil and Japan that contribute to the understanding of differences in performance among their students? To answer the first question, we compared the results of Brazil and Japan in the 2006 and 2015 editions of PISA, where the focus was Science. Brazil is disadvantaged compared to almost all the countries that participated in the Program, which is partly explained by the repetition. In the performance scale, Brazil remains at level 1 and Japan at level 3 in 2006 has moved to level 4 in 2015. In order to answer the second question, we used the Differential Item Functioning (DIF) analysis in the 2006 test's Science items and we conclude that there is a large presence of DIF in these items comparatively between Brazil and Japan. Although they are not able to compromise the evaluation process by favoring one group over the other, these items suggest different curricular emphases in Science. Taking into account this hypothesis and to answer the third question we adopted a qualitative approach, with observation of the use of class time; record of curricular emphases and the occurrence of activities related to "interaction", "investigation", "experimentation" and "application" from the perspective of students, teachers and observation; and interviews with experts and PISA managers. The results showed that more than $20 \%$ of official classroom time observed in Brazil is wasted with questions other than effective teaching of science; 10 times more than in Japan. In Brazil, there is a more pronounced curricular emphasis in Natural and Biological Sciences. The curriculum is 
distributed more homogeneously in Japan and is sectioned in Brazil. According to Japanese students, activities of interaction, investigation, experimentation and application are not frequent. The most recurrent activities observed and perceived by Japanese teachers are those of experimentation and interaction; In Brazil, those of interaction and application. Interviews with experts in Science Education and PISA managers in Brazil and Japan have shown that Japan's success in this assessment is associated with the existence of a common national curriculum and the teachers' ongoing in-service training as well as the educational system reforms raised by the PISA results. The low performance of Brazilian students in PISA would, in turn, be related to the lack of preparation of the students, their lack of familiarity with the test, poor teacher training and the limited use of the evidence produced by the large scale evaluations.

\section{Keywords}

Scientific Literacy; DIF; IRT; Educational Assessment; PISA; Brazil; Japan; Curricular Emphasis; Comparative Study 


\section{Sumário}

1 Introdução

19

2 Letramento Científico 25

2.1 Letramento Científico versus Alfabetização Científica? 26

2.2 A definição de Letramento Científico ao longo do tempo 27

2.3 Os diferentes significados e funções atribuídos ao Letramento 35 Científico

2.4 O conceito de Letramento no PISA 37

2.4.1 Os diferentes significados e funções atribuídos ao 38 Letramento Científico no PISA

2.4.2 A evolução da definição de Letramento Científico no PISA 42

3 Abordagem Metodológica $\quad 46$

3.1 A análise exploratória dos resultados de Brasil e Japão no 47 PISA

3.2 A análise do DIF

49

3.3 Análise das ênfases curriculares e práticas pedagógicas no

Ensino de Ciências de Brasil e Japão

3.3.1 As escolas

53

3.3.2 A pauta de observação

57

3.3.2.1 O uso do tempo

58

3.3.2.2. As ênfases curriculares 58

3.3.2.3 As práticas docentes $\quad 59$

3.3.3 O questionário do professor 60

3.3.4 A análise da prática pedagógica 62

4 Resultados de Brasil e Japão no PISA 66

4.1 Aspectos gerais do Sistema Educacional de Brasil e Japão 68

4.2 A defasagem idade-série $\quad 71$

4.3 A média geral em Ciências $\quad 75$

$\begin{array}{ll}4.4 \text { Os Níveis de proficiência do PISA } & 79\end{array}$ 
4.5 As competências em Ciências $\quad 86$

4.6 O conhecimento das diferentes áreas de Ciências 90

5 A análise do DIF 95

5.1 A Teoria da Resposta ao Item - TRI 95

5.1.1 O modelo de Rasch 97

5.1.2 O modelo de dois parâmetros $\quad 98$

5.1.3 O modelo de três parâmetros 99

5.2 O Funcionamento Diferencial do Item - DIF 101

5.2.1 Alguns Estudos de DIF 101

5.2.2 Métodos de detecção de itens com DIF 103

5.2.3 Investigando os itens com DIF 106

5.2.4 DIF segundo as competências 114

5.2.5 DIF segundo a área do conhecimento do item 118

5.2.6 DIF segundo a área de aplicação do item 123

5.2.7 DIF segundo o âmbito ou contexto do item 128

5.2.8 DIF segundo o tipo de item 129

5.2.9 DIF segundo o idioma do item 130

6 Letramento Científico no Brasil e Japão 132

6.1 Caracterização dos professores observados 132

6.2 O tempo dedicado ao Ensino de Ciências 140

6.3 As ênfases curriculares 148

6.3.1 As ênfases curriculares nas aulas observadas $\quad 161$

6.4 As práticas de ensino e aprendizagem de Ciências 163

6.4.1 Os métodos de ensino do PISA 166

6.5 O uso dos resultados do PISA no Brasil e no Japão 182

6.6 Em suma, o que podemos aprender da experiência do 196 Japão?

7 Conclusão 
9 Anexos

225

9.1 Anexo A

225

9.2 Anexo B

226

9.3 Anexo C

229

9.4 Anexo D

233

9.5 Anexo E

237

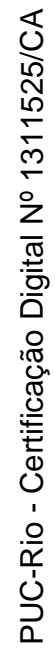




\section{Lista de Figuras}

Figura 1 - Ênfases curriculares no Ensino de Ciências em função 35 de contextos sócio históricos a partir da década de 1950 na concepção de Santos (2007)

Figura 2 - Matriz da avaliação de Letramento Científico do PISA 2006

Figura 3 - Matriz da avaliação de Letramento Científico do PISA 2015

Figura 4 - Mapa do Japão em perspectiva com localização das cidades das três escolas japonesas

Figura 5 - Sistema Educacional Básico de Japão e Brasil

Figura 6 - O "pool" global de top performers na perspectiva do PISA 2015

Figura 7 - Curva característica de três itens

Figura 8 - Curva característica do item

Figura 9 - Curva característica do item segundo o modelo de dois parâmetros

Figura 10 - Curva característica do item segundo o modelo de 100 três parâmetros

Figura 11 - Unidade Roupas, Questão 2. Código S213Q02

Figura 12 - Curva característica do item S213Q02

Figura 13 - Curva característica do item S426Q03

Figura 14 - Unidade Grand Canyon, Questão 3. Código S426Q03

Figura 15 - Curva característica do item S485Q02

Figura 16 - Unidade Chuva Ácida, Questão 2. Código S485Q02

Figura 17 - Unidade Exercício Físico, Questão 1. Código

Figura 18 - Curva característica do item S493Q01

Figura 19 - Frequência dos professores nas diferentes atividades 135 de formação continuada 
Figura 20 - Descrição do Lesson Study por Darling-Hammond, 139 Chung Wei \& Andree, 2010

Figura 21 - Capas da coleção Ciências de Carlos Barros e Wilson 153

Paulino. São Paulo: Editora Ática. $6^{\text {a }}$ edição. 2015

Figura 22 - Frequência dos métodos de Ensino de Ciências do 167 PISA na perspectiva dos estudantes participantes de Brasil e Japão - PISA 2006

Figura 23 - Respostas dos alunos brasileiros e japoneses ao item 29 do questionário do estudante-PISA 2006

Figura 24 - Frequência de atividades na perspectiva dos 175 professores brasileiros e japoneses

Figura 25 - Frequência de ocorrência de atividades nas aulas de 176 Ciências observadas no Japão

Figura 26 - PISA 2003/2006 shock in Japan 189 


\section{Lista de Tabelas}

Tabela 1 - Área e população, total e densidade, das três cidades em Tóquio e do Rio de Janeiro no Brasil

Tabela 2 - Indicadores econômicos e sociais de Brasil e Japão

Tabela 3 - Distribuição percentual dos estudantes nos anos escolares avaliados no PISA 2006 e 2015: Brasil e Japão

72

Tabela 4 - Médias e desvio padrão do Brasil, Japão e OCDE, em Ciências - PISA 2006 e 2015

Tabela 5 - Coeficientes de regressão e $R^{2}$ referente ao modelo Proficiência $=\beta_{0}+\beta_{1}$ (defasado) + e para o Brasil no PISA 2006 e 2015

Tabela 6 - Distribuição percentual dos alunos brasileiros e japoneses nos níveis de desempenho de Ciências no PISA 2006 e 2015

Tabela 7 - Média e desvio padrão de Brasil, Japão e OCDE nas competências de Ciências avaliadas no PISA 2006

Tabela 8 - Média e desvio padrão de Brasil, Japão e OCDE nas competências de Ciências avaliadas no PISA 2015

Tabela 9 - Médias de Brasil, Japão e ODCE nos conhecimentos científicos requeridos no PISA 2006 e 2015

Tabela 10 - Itens de Ciências do PISA 2006 que apresentam DIF no parâmetro a (discriminação) entre Brasil e Japão

Tabela 11 - Itens de Ciências do PISA 2006 que apresentam DIF no parâmetro $b$ (dificuldade) entre Brasil e Japão

Tabela 12 - Direção e intensidade do DIF, entre Brasil e Japão, segundo as competências no parâmetro a nos itens de Ciências do PISA 2006

Tabela 13 - DIF, entre Brasil e Japão, segundo as áreas do conhecimento no parâmetro $b$ dos itens de Ciências do PISA 2006

Tabela 14 - Direção e intensidade do DIF, entre Brasil e Japão, segundo as áreas do conhecimento no parâmetro a nos itens de 120 Ciências do PISA 2006 
Tabela 15 - Direção e intensidade do DIF, entre Brasil e Japão, segundo as áreas do conhecimento no parâmetro $b$ nos itens de Ciências do PISA 2006

Tabela 16 - DIF, entre Brasil e Japão, segundo as áreas de aplicação no parâmetro a nos itens de Ciências do PISA 2006

Tabela 17 - Direção e intensidade do DIF, entre Brasil e Japão, segundo as áreas de aplicação no parâmetro $b$ nos itens de Ciências do PISA 2006

Tabela 18 - DIF, entre Brasil e Japão, segundo as situações e 129 contextos no parâmetro b nos itens de Ciências do PISA 2006

Tabela 19 - DIF, entre Brasil e Japão, segundo o idioma no parâmetro a nos itens de Ciências do PISA 2006

Tabela 20 - Faixa etária dos professores observados

Tabela 21 - Distribuição percentual dos alunos em relação ao tempo médio de aulas regulares de Ciências na Escola - PISA 2006 e PISA 2015

Tabela 22 - Proporção média de tempo que professores atribuem as atividades

Tabela 23 - Distribuição do tempo, em minutos e percentual, nas aulas observadas no Brasil e no Japão

Tabela 24 - Evolução da matriz referencial do PISA

Tabela 25 - Frequência de observação de aulas por escola e ano escolar

Tabela 26 - Frequência de ênfases observadas nas aulas por escola e ano escolar 


\section{Lista de Quadros}

Quadro 1 - Características dos itens do PISA 2006

Quadro 2 - Características das escolas observadas 56

Quadro 3 - Categorias de análise do Letramento Científico no 63 PISA 2006

Quadro 4 - Descrição das habilidades em Ciências no PISA $2006 \quad 80$

Quadro 5 - Descrição das habilidades em Ciências no PISA 201581

Quadro 6 - Conhecimentos científicos presentes na avaliação de 91 Ciências do PISA 2006

Quadro 7 - Conhecimentos científicos presentes na avaliação de 92 Ciências do PISA 2015

Quadro 8 - Variáveis utilizadas no modelo, suas categorias e o número de itens de ciências alocados em cada uma delas

Quadro 9 - Curso de Estudos japonês para o Ensino de Ciências nas séries finais do Ensino Fundamental

Quadro 10 - A matriz referencial do PISA e sua ocorrência nos anos do EF de Brasil e Japão

Quadro 11 - Objetivos da avaliação relacionados com a accountability, o diagnóstico instrucional/das aprendizagens, 0 gerenciamento e o controle educacional e com a premiação, seleção, classificação ou certificação, no Brasil 


\section{Lista de Abreviaturas e Siglas}

ACER - Australian Council for Educational Research

$\mathrm{CCl}$ - Curva Característica do Item

DCN - Diretrizes Curriculares Nacionais

DIF - Funcionamento Diferencial do Item

INEP - Instituto Nacional de Estudos e Pesquisas Educacionais

MEC - Ministério da Educação do Brasil

MEXT - Ministry of Education, Culture, Sports, Science and Technology of Japan

NARST - National Association for Research in Science Teaching

NIER - National Institute for Educational Research

NSTS - National Science Teachers Association

OCDE - Organização para Cooperação e Desenvolvimento Econômico PCN - Parâmetros Curriculares Nacionais

PCN+ - Parâmetros Curriculares Nacionais: orientações educacionais complementares aos PCNs

PISA - Programa Internacional de Avaliação dos Estudantes

PNE - Plano Nacional de Educação

PNLD - Programa Nacional do Livro Didático

SAEB - Sistema de Avaliação da Educação Básica

TRAE - Tempo Reservado à Ação Educativa

TRI - Teoria de Resposta ao Item 


\section{1 \\ Introdução}

Apesar dos avanços propiciados, no Brasil, pelas políticas públicas educacionais em termos da universalização do Ensino Fundamental e da expansão do acesso ao Ensino Médio e à Educação Infantil ainda persistem, como mostram reiterativamente as avaliações nacionais em larga escala conduzidas pelo Instituto Nacional de Estudos e Pesquisas Educacionais (INEP) do Ministério da Educação (MEC), notadamente o Sistema de Avaliação da Educação Básica (SAEB) Saeb e a Prova Brasil, graves problemas em relação à qualidade de ensino e ao desempenho dos estudantes na Educação Básica.

Embora se considere a importância crescente do conhecimento científico, as avaliações nacionais têm se restringido via de regra às áreas de língua portuguesa e matemática e mesmo que se verifique a concordância de professores de Ciências, cientistas e gestores de políticas públicas sobre a importância do desenvolvimento do Letramento Científico, no sentido de enfatizar as capacidades dos estudantes para fazer uso do conhecimento científico em situações do mundo real, a literatura especializada registra também um desequilíbrio entre o desenvolvimento da Ciência e da Tecnologia e da educação científica dos cidadãos (AAAS, 1990 e 2010; BYBEE, 1993; MAIENSCHEIN et al, 1998; MILLAR et al, 1995; DEBOER, 2000; ROBERTS, 2007; ROBERTS \& BYBEE, 2014).

O PISA - Programme for International Student Assessment - em português Programa Internacional de Avaliação dos Estudantes, desenvolvido e coordenado internacionalmente pela Organização para Cooperação e Desenvolvimento Econômico (OCDE), é uma avaliação internacional que além de Leitura e Matemática também focaliza a área de Ciências. O desempenho dos estudantes no PISA é medido por testes e, em cada ciclo de avaliação, uma dessas três áreas cognitivas é o foco principal, o que significa que a maior parte dos itens avaliados está centrada nessa área (aproximadamente dois terços do total do teste), gerando oportunidades para se estudar, em uma pesrpectiva comparada, o desempenho dos estudantes brasileiros em Ciências.

O PISA avalia estudantes com idade entre 15 anos e três meses (completos) e 16 anos e dois meses (completos) no início do período de aplicação, idade esta 
que pressupõe o término da escolaridade básica obrigatória na maioria dos países; e que estão, no mínimo, cursando o $7^{\mathrm{a}}$ ano escolar.

O Letramento Científico no PISA refere-se tanto à compreensão de conceitos científicos como à capacidade de aplicar esses conceitos e pensar sob uma perspectiva científica. Portanto, está associado à capacidade de ir além da simples aquisição de conhecimentos, demonstrando competência para aplicar esses conhecimentos em situações do dia-a-dia e busca examinar a capacidade dos estudantes para analisar, raciocinar e refletir ativamente sobre seus conhecimentos e experiências, enfocando competências que serão relevantes para suas vidas futuras.

Em 2006 e em 2015 o foco do PISA foi o domínio de Ciências e isto permite uma análise aprofundada do desempenho dos estudantes na área enfatizada e, também, uma análise das tendências nas áreas de menor domínio.

Os instrumentos do PISA (testes e questionários) propiciaram três tipos principais de resultados:

1. Indicadores que fornecem um perfil básico de conhecimentos e habilidades dos estudantes.

2. Indicadores derivados de questionários que mostram como tais habilidades estão relacionadas a variáveis demográficas, sociais, econômicas e educacionais.

3. Indicadores de tendências que acompanham o desempenho dos estudantes e monitoram os sistemas educacionais ao longo do tempo.

Neste estudo, foram utilizados os dados do PISA 2006 e 2015, que nos permitem verificar o desempenho dos estudantes nas competências e conhecimentos avaliados em contextos específicos e buscam evidenciar o Letramento Científico. A visão de Letramento Científico que constitui a base do PISA pode ser resumida na seguinte pergunta: O que é importante que os jovens saibam, valorizem e sejam capazes de realizar em situações que envolvem a Ciência e Tecnologia?

Assim, com o intuito de compreender o desempenho do Brasil em Ciências no PISA, comparamos os resultados do país com os de outros países participantes do programa, especialmente com os dos estudantes japoneses, em razão tanto de uma experiência vivida num programa de treinamento de professores oferecido 
por este país, entre os anos de 2007 e 2009, como em virtude da posição de destaque mantida pelo Japão nos testes comparativos internacionais.

Em avaliações de larga escala como o PISA, essa comparabilidade é muito complexa, tendo em vista que nem todos os itens apresentam o mesmo funcionamento. De acordo com Soares (2005), para possibilitar a comparabilidade dos resultados é essencial que o modelo utilizado na avaliação garanta o pressuposto de que o item apresente o mesmo funcionamento para os diversos grupos populacionais que estão sendo avaliados. Para uma boa comparação entre resultados de grupos tão diferentes de estudantes, como é o caso de estudantes brasileiros e japoneses, é imprescindível uma atenção especial à construção dos itens, a fim de que estes não apresentem o chamado Funcionamento Diferencial do Item (DIF).

Um item apresenta DIF quando estudantes que possuem a mesma habilidade cognitiva não têm a mesma probabilidade de acertá-lo. Assim, na estimação das proficiências, o ideal é evitar a utilização de itens com DIF elevado, isto é, que favoreçam um determinado grupo de estudantes. Todavia, o DIF, quando moderado e restrito a poucos itens, interfere minimamente na estimação da proficiência e sua análise pode ser uma ferramenta de diagnóstico do sistema educacional bastante útil no que se refere às diferenças curriculares, socioculturais e, no caso de estudos internacionais, como o PISA, à diversidade de realidades educacionais e à disparidade de resultado entre países. Por este motivo, escolhemos essa abordagem metodológica para conduzir um estudo comparativo entre dois países de realidades socioeconômicas e culturais tão distintas, como é o caso de Brasil e Japão.

Considerando também que as características que distinguem os sistemas educacionais desses dois países têm consequências nos diversos modos de elaboração e desenvolvimento do currículo e, ainda, que os conteúdos são selecionados pelos professores e abordados com ênfases diferenciadas, procuramos:

a) buscar identificar se o funcionamento diferencial dos itens da prova de Ciências do PISA 2006 daria conta de explicar a distância de desempenho existente entre os estudantes avaliados no Brasil e no Japão; 
b) verificar se o comportamento diferencial dos itens do teste prejudica a comparabilidade dos resultados; e

c) tentar identificar diferentes ênfases curriculares e/ou práticas pedagógicas no Ensino de Ciências de Brasil e Japão que possam explicar o desempenho diferenciado dos estudantes brasileiros e japoneses no PISA.

Esses objetivos desdobraram-se nas seguintes questões de pesquisa:

1. De acordo com os resultados do PISA, há diferenças de competência cognitiva em Ciências entre os estudantes brasileiros e dos outros países, sobretudo os do Japão? Como se expressam especificamente essas diferenças em termos das habilidades contempladas pelas subescalas do PISA?

2. Existem itens do PISA 2006 que apresentam DIF, tendo o Brasil como referência?

3. É possível, a partir dos dados do PISA e da adoção complementar de uma abordagem qualitativa, identificar diferentes ênfases curriculares e/ou práticas pedagógicas no Ensino de Ciências de Brasil e Japão que contribuam para a compreensão das diferenças de desempenho entre estudantes brasileiros e japoneses?

Para responder as questões acima, conduzimos as análises baseando-nos no uso de dados quantitativos e na coleta de dados qualitativos. Inicialmente, realizamos uma análise exploratória e descritiva dos resultados de Brasil e Japão em Ciências no PISA 2006 e 2015 e utilizamos a análise de DIF nos itens da prova de Ciências da edição de 2006. Complementarmente, o tema da identificação de possíveis ênfases curriculares e/ou práticas pedagógicas no Ensino de Ciências de Brasil e Japão que pudessem contribuir para a compreensão das diferenças de desempenho entre estudantes brasileiros e japoneses foi viabilizado por meio de um estágio de doutorado sanduíche com duração de oito meses. No estudo empírico, selecionamos um total de seis escolas, três no Japão e três no Brasil, para observação de aulas de Ciências e aplicação de questionários aos professores observados. Além disso, realizamos entrevistas com especialistas da área de Ciências e com responsáveis pelo PISA nos dois países considerados neste estudo. 
Como nosso interesse específico é o de explorar o conceito de Letramento Científico adotado pelo PISA nos resultados do próprio PISA e em situações reais de sala de aula, dito conceito foi a referência de base de todos os instrumentos utilizados em nossas análises. Empregamos os construtos usados pelo Programa para aceder ao ponto de vista dos estudantes sobre o ensino e a aprendizagem de Ciências e também à perspectiva dos professores participantes nesta pesquisa, bem como para orientar as observações das aulas que conduzimos nos dois países. Buscamos, portanto, obter um maior potencial de interpretação dos resultados quantitativos, notadamente pela agregação da percepção dos sujeitos - estudantes, professores e especialistas - ao desenho da pesquisa.

As entrevistas contribuíram com o levantamento de hipóteses que, na visão de especialistas, podem explicar tamanha diferença de desempenho entre os países envolvidos, bem como das peculiaridades dos distintos sistemas. Em suma, nossos objetivos específicos nessa segunda e final etapa do trabalho foram principalmente: a) observar o uso do tempo das aulas de Ciências das séries finais do Ensino Fundamental; b) observar se nas aulas de Ciências desses países ocorrem, e com que frequência, atividades relacionadas à interação, investigação, experimentação e aplicação; c) buscar entender na perspectiva dos professores observados que atividades, e com que frequência, admitem realizar nas suas aulas; e d) buscar entender, com a ajuda de especialistas e gestores, a tamanha diferença de desempenho entre o Brasil e o Japão no PISA.

A partir desta Introdução, esta tese está estruturada em sete outros capítulos. No Capítulo 2, apresentamos a fundamentação teórica baseada no conceito de Letramento Científico. Apresentamos uma breve discussão em torno de significados que podem ser atribuídos aos vocábulos Letramento e Alfabetização, abordarmos o desenvolvimento do conceito de Letramento ao longo do tempo, mapeamos os diferentes significados e funções atribuídos ao Letramento Científico e, na sequência, realizarmos a análise do conceito adotado pela OCDE e pelo PISA e sua evolução ao longo das seis edições do Programa.

O Capítulo 3 é dedicado às questões de pesquisa e, também, à abordagem metodológica. Apesar de termos dedicado um inteiro capítulo desta tese à abordagem metodológica, esclarecemos que, dada a natureza do trabalho, a discussão dos aspectos metodológicos estará também presente ao longo dos 
demais capítulos, principalmente dos quarto, quinto e sexto capítulos que são dedicados à apresentação e discussão dos resultados.

Em seguida, no Capítulo 4, exploramos os resultados dos estudantes brasileiros e japoneses no PISA 2006 e 2015, edições estas que focaram a área de Ciências. Os resultados nos ajudam a compreender quais as competências, conhecimentos e habilidades avaliadas pelo Programa que são evidenciados pelos estudantes desses dois países e apresentamos, também, algumas das características educacionais dos dois países investigados, principalmente aquela relacionada à política de promoção e reprovação de estudantes.

No quinto capítulo, apresentamos os resultados das análises de DIF. Iniciamos com uma breve introdução sobre a Teoria de Resposta ao Item (TRI) para então discutirmos o DIF e sua utilização. Também é traçado um histórico de estudos de DIF e dos métodos de detecção de itens com DIF, para então passar a investigar os itens de Ciências do PISA 2006 com DIF e a caracterizá-los segundo as competências, áreas do conhecimento, áreas de aplicação, âmbito, tipo e idioma.

$\mathrm{Na}$ sequência, no Capítulo 6, apresentamos os resultados da pesquisa qualitativa, incluindo a caracterização dos professores observados e algumas peculiaridades do processo de formação em serviço pelo qual passam os professores japoneses. A seguir, discutimos os resultados da utilização do tempo nas aulas de Ciências no Brasil e no Japão, tratamos das ênfases curriculares na perspectiva proposta, ensinada e aprendida, o que colabora para a compreensão dos resultados obtidos com as análises de DIF e para a identificação das principais diferenças educacionais existentes nos dois países estudados. Por fim, apresentamos e discutimos as práticas de ensino e aprendizagem de Ciências mais frequentemente utilizadas no Brasil e Japão na perspectiva de estudantes, professores e da decorrente da observação de sala de aula.

Finalizamos, no Capítulo 7, retomando os principais resultados apresentados nos capítulos 4, 5 e 6 e os articulamos em torno das considerações finais e da proposta de futuros caminhos a seguir. 


\section{2 \\ Letramento Científico}

Há muitas concepções de Letramento Científico presentes na literatura. De acordo com Laugsksch (2000) e com Hurd (1958), o termo em si acabou tornando-se um slogan educacional bastante reconhecido internacionalmente. De fato, tornou-se muito proeminente como conceito no campo do Ensino de Ciências, e dentro desta comunidade de pesquisa, sendo incluído como um dos 12 principais temas e tópicos do SciEd Resource Assistant, inicialmente produzido pela ERIC (Education Resources Information Center) ${ }^{1}$ (ROBERTS, 2007).

Em sua acepção mais geral, Letramento Científico "significa aquilo que o público em geral deve saber sobre a Ciência" (DURANT, 1993) e "normalmente implica uma apreciação da natureza, objetivos e limitações gerais da Ciência, juntamente com alguma compreensão das ideias científicas mais importantes" (JENKINS, 1994).

No entanto, apesar de parecer simples e consensual, uma definição precisa de Letramento Científico vem sendo buscada por muitos cientistas, educadores, filósofos e organizações desde o século 20. E o problema de definição de Letramento Científico de uma forma mutuamente aceitável tem perseguido também os movimentos de reforma da educação científica desde o seu início.

$\mathrm{Na}$ revisão de estudos sobre o significado do processo de Letramento Científico, tomamos como referência artigos da literatura inglesa e norte americana que empregam o termo literacy, que pode ser traduzido para o português tanto como Alfabetização ou como Letramento (ou ainda literacia, no português de Portugal).

A seguir apresentamos uma breve discussão em torno de significados que podem ser atribuídos a esses dois vocábulos, embora, nesta tese, empregaremos o termo Letramento Científico na acepção adotada pelo PISA e pela OCDE e que também será exposta no decorrer deste capítulo.

\footnotetext{
${ }^{1}$ ERIC é uma biblioteca on-line de pesquisa e informação educacional, patrocinada pelo Instituto de Ciências da Educação (IES) do Departamento de Educação dos Estados Unidos.
} 


\section{1 Letramento Científico versus Alfabetização Científica?}

As discussões sobre educação científica muitas vezes acabam por priorizar um domínio em relação a outro. Santos (2007), sem querer propor uma dicotomia entre os dois domínios, caracteriza a distinção adotando a mesma categorização que vem sendo usada para Alfabetização e Letramento na linguística e em educação, como é o caso da maioria dos autores que abordam esses termos recorrendo, principalmente, a escritos de Street (1984), Kleiman (1995) e Soares (1998, 2002, 2004).

Para Magda Soares (1998), o termo Alfabetização tem sido empregado com o sentido mais restritivo da ação de ensinar a ler e a escrever, enquanto o termo Letramento refere-se ao estado ou condição de quem não apenas sabe ler e escrever, mas cultiva e exerce práticas sociais que usam a escrita. De acordo com essa conceituação, uma pessoa alfabetizada, que sabe ler e escrever, pode não ser letrada, caso não faça uso da prática social de leitura; ou seja, apesar de ler, essa pessoa não é capaz de compreender o significado de notícias de jornais, avisos, correspondências, ou não é capaz de escrever cartas e recados (SANTOS, 2007). Ao contrário, uma pessoa pode não ser alfabetizada, mas ser letrada se tiver contato diário com as informações do mundo da leitura e da escrita, por meio de pessoas que leem ou escrevem para ela as notícias de jornal, as cartas ou os recados (SOARES, 1998).

No campo do Ensino de Ciências propriamente dito, Mamede e Zimmermann (2005) argumentam que o termo Letramento surge como alternativa para o termo Alfabetização, mas ambos se referem ao preparo para a vida em uma sociedade científica e tecnológica. Ainda assim, reconhecem que há diferenças entre os dois termos. A Alfabetização Científica seria a aprendizagem dos conteúdos e da linguagem científica, enquanto que o Letramento Científico se referiria ao uso, num contexto sócio histórico específico, do conhecimento científico e tecnológico no cotidiano do indivíduo. Essas diferenças devem ser levadas em consideração e podem, possivelmente, justificar a opção dessas autoras pelo termo Letramento Científico.

Por sua vez, Krasilchik e Marandino (2004) consideram que o termo Alfabetização Científica já se consolidou na prática social, apesar da distinção 
existente entre Alfabetização e Letramento. Nesse sentido, para as autoras, a Alfabetização já engloba a ideia de Letramento. Contudo, ao empregar o termo Letramento, busca-se enfatizar a função social da educação científica contrapondo-se ao restrito significado de Alfabetização escolar (SANTOS, 2007). Nesse sentido, a conceituação apresentada por Krasilchik e Marandino (2004) para Alfabetização como capacidade de ler, compreender e expressar opiniões sobre Ciência e Tecnologia corresponderia ao que, quase consensualmente, se entende por Letramento Científico. Essa caracterização é também muito próxima do que Chassot (2000) considera como Alfabetização Científica. O autor a define como um conjunto de conhecimentos que facilitariam aos homens e mulheres fazer uma leitura do mundo onde vivem, atribuindo, assim, um sentido mais amplo e social ao termo, que denota conhecimentos científicos e tecnológicos necessários para o cidadão desenvolver-se na vida diária (CHASSOT, 2003).

Diante do exposto, entendemos que, enquanto a Alfabetização pode ser considerada o processo mais simples do domínio da linguagem científica, o Letramento, além desse domínio, exige também o da prática social, e a educação científica em seu mais amplo grau, envolvendo processos cognitivos e domínios de alto nível. Diante do exposto passaremos a analisar a definição de Letramento Científico adotada nesta tese.

\section{2 \\ A definição de Letramento Científico ao longo do tempo}

De acordo com Laugsksch (2000), o termo "Letramento Científico" foi cunhado na década de 1950, e muito provavelmente apareceu na literatura impressa pela primeira vez quando Paul Hurd (HURD, 1958) o usou em uma publicação intitulada Science Literacy: Its Meaning for American Schools (DEBOER, 1991; ROBERTS, 1983). Já para Bybee (1997), foi James Conant quem primeiro utilizou o conceito de Letramento Científico, em 1952, ao escrever a obra General Education in Science. Consensualmente, admite-se que o conceito tenha sido usado primeiro por Conant, no entanto, ele não teria deixado claro, a partir da definição que propôs, o que o sujeito precisaria saber, ser capaz de fazer e que formas de pensar e atitudes deveria apresentar, para ser considerado 
cientificamente letrado. A definição de Conant foi, de acordo com Bybee (1997), a seguinte:

... Dentro do campo da sua experiência, o sujeito iria entender o mundo moderno; Em suma, ele seria bem educado em Ciência aplicada embora o seu conhecimento fatual das engenharias mecânica, elétrica ou química pudesse ser relativamente pequeno. Ele seria capaz de se comunicar de forma inteligente com aqueles que estariam avançando a Ciência e aplicá-lo, pelo menos, dentro de certos limites. Quanto maior a sua experiência, maior seria seu Letramento Científico. (BYBEE, 1997, p. 47)

Seguindo o trabalho de Conant, Hurd (1958) definiu Letramento Científico em relação a um conhecimento generalizado sobre Ciência e sua aplicação no ambiente social. Para Hurd (1958), a Ciência seria tão importante que nenhum aspecto da vida, fosse ele político, social, econômico ou pessoal, deveria ser considerado a revelia dela. Hurd foi, então, um pouco mais longe do que Conant ao definir o conceito:

Há o problema de se construir no currículo de Ciências alguma profundidade e qualidade de compreensão. É essencial selecionar materiais de aprendizagem que sejam mais férteis no fornecimento de oportunidades para a utilização de métodos científicos. Mais esforços são necessários para escolher experiências de aprendizagem que tenham um valor particular para o desenvolvimento de uma valorização da Ciência como realização intelectual, como um processo de exploração e descoberta, e que ilustram o espírito do empreendimento científico. (HURD, 1958, p. 14-15)

É importante notar que a contribuição de Hurd para a definição do conceito de Letramento Científico veio logo depois do memorável mês de Outubro de 1957. Mês e ano marcados pelo lançamento do Sputinik I, o primeiro satélite artificial a ser lançado pela antiga União Soviética e o primeiro satélite a ser lançado também pela humanidade. Seu lançamento abriu, simbolicamente, a "porta" para o começo da corrida espacial entre os Estados Unidos e a ex União Soviética, passando a direcionar, muito mais intensamente, os holofotes da atenção pública para o Letramento Científico. Nesse contexto, Hurd acabou por colocar a discussão do conceito no centro dos movimentos de reforma do Ensino de Ciências ocorridos a partir da década de 1960. No entanto, o foco das reformas até este momento teria sido direcionado à formação de alguns poucos indivíduos cientificamente letrados, a fim de que pudessem tornar-se os cientistas e engenheiros do futuro. Com o objetivo de vencer a corrida espacial, os Estados Unidos da América fizeram investimentos não apenas financeiros, mas também em recursos humanos, sem paralelo na história da Educação, de modo a produzir 
os então chamados projetos de primeira geração do Ensino de física, química, biologia e matemática para o Ensino Médio. Tamanho empenho por parte dos norte-americanos estava relacionado, à época, à formação de uma elite que garantisse a hegemonia dos Estados Unidos na conquista do espaço.

Waterman (1960) escreveu, em uma revisão dos primeiros 10 anos da National Science Foundation dos Estados Unidos, a respeito do reconhecimento de que o progresso na Ciência dependeria, em grande medida, da compreensão do público e do apoio de um sustentado programa de educação em Ciência e investigação. Paralelamente, os americanos, novamente impelidos pela corrida espacial, passaram a se preocupar com a educação recebida pelas crianças e adolescentes. Preocupava-lhes saber se este tipo de ensino permitiria a essas novas gerações lidar com uma sociedade em crescente sofisticação científica e tecnológica (HURD, 1958). O aumento do nível de Letramento Científico entre os americanos era visto como uma estratégia para abordar, de forma eficaz, ambas as preocupações acima (HURD, 1958; WATERMAN, 1960). A história das propostas de mudanças referentes ao Ensino de Ciências nessas últimas décadas revela, portanto, algumas das transformações do currículo escolar, permitindo relacionar essas mudanças ao papel atribuído às disciplinas científicas na formação dos estudantes (KRASILCHIK, 1987). Krasilchik (2000) em "Reformas e Realidades, o caso do Ensino das Ciências" e DeBoer (2000) em Scientific literacy: another look at its historical and contemporary meanings and its relationship to science education reform fazem uma revisão histórica dessas propostas de reforma da educação relacionando-as à evolução mundial.

Dado o importante contexto de apoio à Ciência e ao Ensino de Ciências, inúmeros autores começaram a promover os mais variados aspectos associados ao conceito de Letramento Científico, por exemplo, as referências citadas em DeBoer (1991) e Roberts (1983). Roberts (1983) caracterizou o intervalo compreendido entre 1957-1963 como o "período de legitimação" do conceito. No entanto, as definições sugeridas para Letramento Científico, neste período, nem sempre forneciam uma definição clara do que os autores pretendiam significar. O período inicial de legitimação foi, assim, seguido por um "período de interpretação", no qual os significados múltiplos e variados de Letramento Científico tornaram-se muito mais aparentes (DEBOER, 1991; ROBERTS, 1983). Certo número de tentativas de consolidar a expressão Letramento Científico como um conceito 
mutuamente aceito foi feito (AGIN, 1974; PELLA, 1976), a partir deste período que Roberts (1983) chamou de período de interpretação.

Dois anos após a publicação de Hurd em 1958, Fred Fitzpatrik editou um trabalho intitulado Policies for Science Education (FITZPATRICK, 1960) através do Projeto Science Manpower, iniciado em 1956 no Teachers College da Universidade de Columbia. Em sua contribuição, Fitzpatrick observou, sobretudo, que as reformas da educação científica em curso não deveriam se ater, de forma tão restritiva, à criação de cientistas e engenheiros, mas deveriam estender-se a todos os cidadãos. Ele escreveu

Ao considerar a necessidade de mão de obra científica, no entanto, não devemos perder de vista o fato de que nenhum cidadão que está envolvido, ou não, em esforços científicos, pode ser alfabetizado no sentido moderno até que ele entenda e aprecie a Ciência e seu trabalho... Se o espírito da época é ser favorável ao empreendimento científico, incluindo programas tanto académicos como industriais, o público deve possuir algum grau de Letramento Científico, pelo menos o suficiente para apreciar a natureza do esforço científico e as suas potenciais contribuições para um melhor modo de vida. (FITZPATRICK, 1960, p. 6)

O físico Polykarp Kusch (1960), apelando para uma visão grandiosa do espírito e da natureza da Ciência, também tentou caracterizar o Letramento Científico numa perspectiva que englobasse todos os cidadãos, quando escreveu:

O cidadão que respeita a estrutura da Ciência, que é capaz de ver os resultados desta como uma declaração crítica e cuidadosa do melhor conhecimento do homem sobre o comportamento da natureza é, para mim, mais capaz de participar efetivamente na condução de assuntos nacionais e internacionais - na verdade em todos os aspectos da nossa vida. (KUSCH, 1960, p. 199)

Philip G. Johnson, dois anos depois de Kusch, em 1962, argumentou que o processo de Letramento Científico deveria também incluir as atitudes e os hábitos oriundos da natureza da própria Ciência. Além da crescente crença de que o Letramento Científico significava mais do que uma familiaridade com uma grande coleção de fatos científicos, Johson (1962) notou que

... alguns objetivos do Letramento Científico tornaram-se tão dominantes que a busca de outros importantes objetivos estava sendo severamente inibida; muitas vezes tem havido uma falha em reconhecer adequadamente as habilidades e necessidades dos cidadãos em geral e, assim, contornar os objetivos do Letramento Científico. (JOHSON, 1962, p. 244)

O ano de 1963, que seguiu às contribuições de Johson e dos seus contemporâneos, foi um ano de grandes aportes para a consolidação do conceito de Letramento Científico. Alma Wittlin, Morris Shamos, a National Science 
Teachers Association (NSTA), Robert Carlton, entre outros, foram essenciais para trazer para o centro da discussão aspectos relacionados à Ciência e à Tecnologia e para destacar a necessidade de um caminho mais humanista para o Letramento Científico das massas. Grosso modo, para esses autores, os educadores de Ciências deveriam se esforçar para criar uma forma de Letramento Científico que formasse indivíduos capazes de se posicionar em relação à Ciência, ainda que em termos não técnicos. Assim, os indivíduos saberiam a diferença entre Ciência e Tecnologia, e compreenderiam grandes esquemas conceituais da Ciência, como, por exemplo, a forma atomística da matéria, as leis de conservação, a teoria dos germes, a hereditariedade e a natureza da Ciência.

No ano seguinte, em 1964, a NSTA declarou formalmente, através da publicação Theory into Action, que o principal objetivo do Ensino de Ciências era a criação de indivíduos cientificamente letrados. Para a Associação, um indivíduo letrado cientificamente seria aquele que sabe algo sobre o papel da Ciência na sociedade, aprecia as condições de cultura em que a Ciência sobrevive e conhece as invenções conceituais e os procedimentos de investigação (NSTA, 1964).

Nos meados dos anos de 1960, a discussão sobre a natureza do Letramento Científico amadureceu e ficou claro que havia certas tendências consistentes de pensamento nas inúmeras definições formuladas até então. $O$ trabalho de Pella et al (1966) representa uma das primeiras tentativas de fornecer uma base empírica para a definição de Letramento Científico. Esses autores, a partir de um estado da arte em 100 textos publicados entre 1946 e 1964, determinaram a frequência de ocorrência do que chamaram de "referências", isto é, temas que foram diretamente associados ao conceito de Letramento Científico nas produções por eles analisadas. Eles concluíram que o indivíduo cientificamente letrado era caracterizado como aquele com um entendimento ou compreensão da(s)/do(s):

a) interrelações entre a Ciência e a sociedade;

b) ética da Ciência;

c) natureza da Ciência;

d) diferença entre Ciência e Tecnologia;

e) conceitos básicos da Ciência; e

f) interrelações da Ciência e das humanidades

Baseado nos resultados do trabalho citado acima, Pella (1967) sintetizou uma definição inclusiva de Letramento Científico. Para o autor, um indivíduo 
cientificamente letrado deveria entender as interrelações entre a Ciência e a sociedade, entender os métodos e processos da Ciência, ter conhecimento dos conceitos fundamentais da Ciência ou de seus esquemas conceituais, e entender as relações entre a Ciência e as humanidades ou olhar para a Ciência como parte das humanidades.

Na década de 1970, a NSTA publicou outro documento relacionado aos objetivos da educação científica. Desta vez, deram à história da Ciência e às questões sociais um lugar de importância na definição de Letramento Científico. Assim, o principal objetivo da educação científica seria o de desenvolver indivíduos cientificamente letrados e pessoalmente preocupados/interessados, com elevada competência para o pensamento e ação racional (NSTA, 1971). O NSTA caracterizou, portanto, o indivíduo cientificamente letrado como alguém que usa o conhecimento da Ciência, suas habilidades e disposições, na tomada de decisões do dia-a-dia, que compreende as relações entre Ciência e Tecnologia e sua relação com a sociedade, incluindo as dimensões histórica, interpessoal e econômica.

O final da década de 1970, e o início da de 1980, foi caracterizado por uma infinidade de definições e interpretações do conceito de Letramento Científico (ROBERTS, 1983). No entanto, a persistente falta de consenso acabou reduzindo a utilidade deste conceito (GRAUBARD, 1983). Os Estados Unidos, que vinham enfrentando desafios importantes nesta mesma época - dado o surgimento do poder econômico do Japão e outros países do Pacífico, a crescente visão da Ciência e Tecnologia como a base fundamental para o progresso econômico e o baixo desempenho dos estudantes americanos nas comparações internacionais de desempenho em Ciências - se viram diante da existência de uma crise na educação científica. Inúmeras reformas do Ensino de Ciências são lançadas para tentar reverter o quadro norte americano, e estas acabaram por contribuir muito fortemente com a retomada da consolidação do conceito de Letramento Científico e por reforçar a importância deste para uma educação efetiva em Ciências.

O final da década de 1980 testemunhou o início do Projeto 2061, juntamente com o seu trabalho principal Science for All Americans (RUTHERFORD \& AHLGREN, 1989). Este trabalho resumiu o significado do Letramento Científico em relação às linhas de conhecimentos, habilidades e disposições, indicando o que todos os estudantes devem conhecer e serem capazes de fazer para serem 
considerados cientificamente letrados. Neste momento, parece haver um consenso crescente e internacional sobre o significado de Letramento Científico. As obras publicadas, sobretudo pelas organizações norte-americanas, parecem ter convergido em uma "multidimensional" (BYBEE, 1997) ou "verdadeira" (SHAMOS, 1995) definição de Letramento Científico que incorporava o conhecimento do conteúdo (vocabulário, fatos e conceitos), as habilidades de processo (de manipulação e intelectuais), as disposições (atitudes e comportamentos), as relações Ciência-Tecnologia-Sociedade, a história e a natureza da Ciência.

Apesar desta convergência geral, concordamos com Roberts (2007) que o Letramento Científico ainda tem de ser clara e consistentemente definido. O pensamento atual sobre os resultados pretendidos com a educação científica está enraizado na confiança de que uma compreensão da Ciência é tão importante que deveria ser uma característica da educação de todos os jovens (AAAS, 1989; CONFEDERACION DE SOCIEDADES CIENTÍFICAS DE ESPAÑA, 2011; FENSHAM，1985; MILLAR \& OSBORNE，1998; NATIONAL RESEARCH COUNCIL，2012; SEKRETARIAT DER STÄNDIGEN KONFERENZ DER KULTUSMINISTER DER LÄNDER IN DER BUNDESREPUBLIK DEUTSCHLAND (KMK), 2005; TAIWAN MINISTRY OF EDUCATION, 1999). De fato, em muitos países, a Ciência é um elemento obrigatório do currículo escolar, desde o jardim de infância até a conclusão do Ensino obrigatório (OCDE, 2016).

Nesse sentido, Roberts (2007), num capítulo inteiramente dedicado à discussão do conceito de Letramento Científico, faz duas observações gerais de grande importância. A primeira é que não há consenso sobre o significado ou até mesmo as partes constituintes do termo Letramento Científico - com uma exceção: todos concordam que os estudantes não podem ser cientificamente alfabetizados se não conhecerem qualquer assunto científico. E a segunda observação geral é que a literatura pode ser apreendida mais facilmente considerando as abordagens, ou metodologias conceituais, que os autores utilizam. Roberts (2007) argumenta que a literatura contém muitas expressões de frustação sobre as implicações da falta de consenso tanto para a pesquisa como para a prática. 
Em 2007, foi lançado um manual de pesquisa que fornece uma síntese abrangente, coerente e atual da pesquisa empírica e teórica do campo de Ensino de Ciências. Os autores, os principais especialistas nas diversas áreas de pesquisa, representam a diversidade internacional e de gênero que existe na comunidade de pesquisadores em Ensino de Ciências e buscam, justamente, encontrar um espaço comum de discussão do campo que traga contribuições importantes tanto para a pesquisa quanto para a prática. A publicação do Handbook of Research on Science Education (ABELL \& LEDERMAN, 2007), no qual está contido o importante capítulo de Roberts (2007), citado por nós no parágrafo acima, demonstra que a educação científica está viva e ilustra a sua vitalidade. A National Association for Research in Science Teaching (NARST), uma organização mundialmente conhecida, voltada para melhorar o Ensino e a aprendizagem das Ciências através da investigação, endossa este manual como uma importante e valiosa síntese do conhecimento atual no campo do Ensino de Ciências.

Apenas sete anos após a publicação do Handbook of Research on Science Education (ABELL \& LEDERMAN, 2007), seus editores consideraram, e com razão, que havia espaço e necessidade de uma edição atualizada, dado o intenso ritmo de desenvolvimento em todas as áreas do Ensino de Ciências. O resultado foi o Handbook of Research on Science Education Volume II (LEDERMAN \& ABELL, 2014), que rapidamente se tornou uma referência inestimável no campo, assim como tinha acontecido com o Volume I.

No volume II do Handbook, o capítulo dedicado ao Letramento Científico foi revisado por Roberts, que escreveu a versão do volume I, e Bybee (ROBERTS \& BYBEE, 2014). A revisão dos autores começa já no título do capítulo, no qual fazem alusão a outras formas tomadas na língua inglesa pelo termo Letramento Científico: Scientific Literacy, Science Literacy, e Science Education. Foram consideradas necessárias atualizações significativas, em razão dos rápidos desenvolvimentos tanto nos enquadramentos teóricos como nos aspectos sociais relacionados com a finalidade e o papel do Letramento Científico.

Diante do exposto é possível perceber que a temática do Letramento Científico surgiu em diferentes contextos e que seus objetivos têm tido grande e crescente abrangência. Neste capítulo, pretendemos mapear os diferentes significados e funções que têm sido atribuídas ao Letramento Científico na 
literatura especializada, com o intuito de levantar referenciais para a análise da concepção desse conceito presente em documentos oficiais do PISA.

\section{3 \\ Os diferentes significados e funções atribuídos ao Letramento Científico}

A Ciência engloba diferentes atores sociais (educadores em Ciência, cientistas sociais, pesquisadores de opinião pública, sociólogos da Ciência, e profissionais envolvidos na educação formal e não formal em Ciências, como professores e profissionais que trabalham com a divulgação da Ciência, jornalistas e profissionais de museus, centros de Ciências, parques ambientais, jardins botânicos etc. (ver LAUGKSCH, 2000), fazendo com que a compreensão desse campo depende da análise das inter-relações entre esses atores.

Enquanto os educadores em Ciências se preocupam com a educação nos sistemas de ensino, os cientistas sociais estão voltados para o interesse do público em geral por questões científicas; os sociólogos, envolvidos com a interpretação diária da Ciência; os comunicadores da Ciência, com a divulgação científica em sistemas não formais; e os economistas, interessados no crescimento econômico decorrente do maior consumo da população por bens tecnológicos mais sofisticados que requerem conhecimentos especializados, como o uso da informática (SANTOS, 2007).

Todos esses argumentos, de alguma forma, estão presentes no currículo escolar e constituem fatores de influência no seu planejamento (SANTOS, 2007). Assim, se a prioridade do Letramento for melhorar o campo de conhecimento científico, preparando novos cientistas, o enfoque curricular será centrado em conceitos científicos; se o objetivo for voltado para a formação da cidadania, o enfoque enfatizará a função social e o desenvolvimento de atitudes e valores (RATCLIFFE \& GRACE, 2003).

Como se pode observar na Figura 1, as ênfases e as funções mapeadas do Ensino de Ciências ao longo do contexto histórico e social, baseadas na concepção particular de Santos (2007), embora não coincidam com enunciados que caracterizam o Letramento Científico, em tese, incluem sempre dois grandes grupos de categorias: um que incorpora aquelas relativas à especificidade do 
conhecimento científico, e outro que abrange as categorias relativas à função social (SANTOS, 2007).

Figura 1. Ênfases curriculares no Ensino de Ciências em função de contextos sócio históricos a partir da década de 1950 na concepção de Santos (2007).

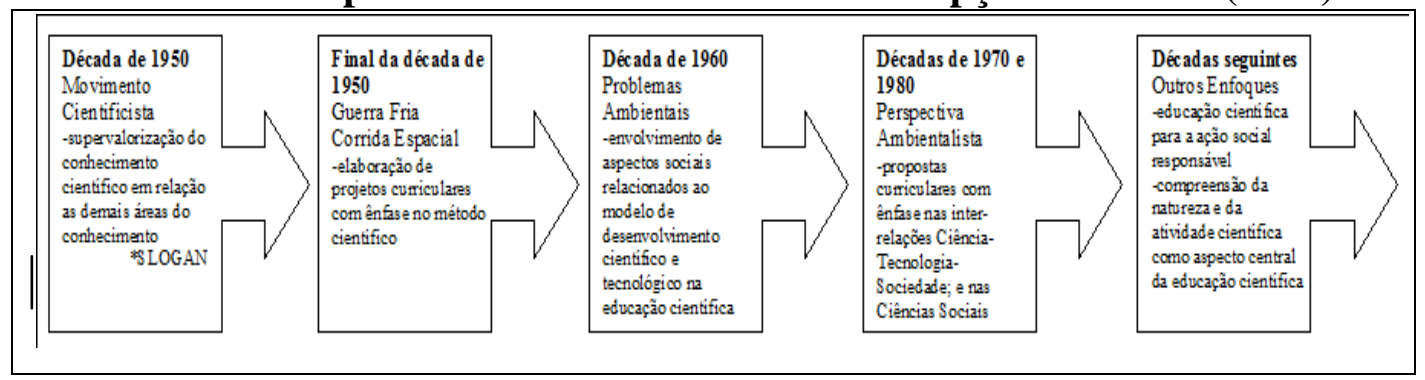

Fonte: elaboração própria a partir dos resultados de SANTOS, 2007.

A década de 1950, marcada pelo movimento cientificista e pela corrida espacial, enfatiza a especificidade do conhecimento científico. As décadas seguintes, de 1960, 1970 e 1980, com a maior visibilidade dos problemas ambientais e do desenvolvimento sustentável, sustentam a abrangência de categorias relativas à função social do Ensino de Ciências. Mais recentemente, encontramos outros enfoques que acabam por reunir esses dois grandes domínios centrados na compreensão do conteúdo científico e da função social da Ciência. Apesar de serem enfatizados de formas diferentes pelos autores que discutem educação científica, eles estão inter-relacionados e imbricados (SANTOS, 2007). Assim, pela natureza do conhecimento científico, não se pode pensar no ensino de seus conteúdos de forma neutra, sem que se contextualize o seu caráter social, nem há como discutir a função social do conhecimento científico sem uma compreensão do seu conteúdo.

Nos últimos anos, as políticas relacionadas com a educação científica têm sido repletas de referências ao Letramento Científico como um objetivo (ATKIN \& HELMS, 1993; JENKINS, 1992). Essas políticas pautam-se, na maioria das vezes e na maioria dos países do mundo, nos resultados de avaliações externas emergidas na década de $1990^{2}$. O conceito de Letramento foi bastante disseminado a partir das matrizes de referência de inúmeros Programas de avaliação. Dentre os quais está o PISA cuja visão de Letramento Científico é uma resposta para a pergunta: O que é importante para os jovens saberem, valorizarem e serem capazes de fazer em situações que envolvem Ciência e Tecnologia?

\footnotetext{
${ }^{2}$ Como, por exemplo, o TIMSS (Trends in International Mathematics and Science Study) da International Association for the Evaluation of Educational Achievement (IEA) e o próprio PISA.
} 
(OCDE, 2016). Nesta tese, nos interessa especificamente o conceito de Letramento Científico adotado pelo Programa, que é a base das nossas análises. Na seção que se segue descrevemos o conceito na acepção do Programa e, portanto, da OCDE.

\section{4 \\ O conceito de Letramento no PISA}

Especialistas internacionais dos países participantes desenvolveram um suporte estrutural e conceitual para cada área de avaliação do PISA, o qual, após consulta, foi adotado em comum acordo pelos governos desses países (OECD, 1999; OECD, 2003; e OECD, 2006). A estrutura começa com o conceito genérico de Letramento, que está relacionado com a capacidade dos estudantes de ir além daquilo que aprenderam e de aplicar seus conhecimentos em novos contextos; e de analisar, argumentar e comunicar, de maneira eficaz, à medida que apresentam, resolvem e interpretam problemas em diversas situações (OCDE, 2007).

De acordo com a OCDE (2007) o conceito de Letramento utilizado no PISA é muito mais amplo do que a noção histórica de Alfabetização como a capacidade de ler e escrever. Além disso, é medido em um processo contínuo, não como algo que um indivíduo tem ou não tem. A aquisição de Letramento é um processo que se desenvolve ao longo de toda a vida - ocorre não só na escola, ou por meio da aprendizagem formal, mas também por meio de interações com a família, os colegas e a comunidade mais ampla (OCDE, 2007). Para a OCDE (2007), não se pode esperar que estudantes de 15 anos de idade tenham aprendido tudo aquilo de que precisarão quando forem adultos, mas eles devem ter uma base de conhecimento sólida em áreas como Leitura, Matemática e Ciências. Para que continuem a aprender essas disciplinas e para que apliquem sua aprendizagem na vida real, esses estudantes também precisam compreender processos e princípios fundamentais, e utilizá-los de maneira flexível em diferentes situações. É por esse motivo que o PISA mede a capacidade de concluir tarefas relacionadas à vida real, que dependem de uma ampla compreensão de conceitos básicos, em vez de limitar a avaliação à compreensão de conhecimentos específicos sobre uma disciplina determinada (OCDE, 2007). Nossa atenção aqui está voltada exclusivamente ao conceito de Letramento Científico que é apresentado na próxima seção. 


\subsection{1 \\ Os diferentes significados e funções atribuídos ao Letramento Científico no PISA}

O Letramento Científico foi o domínio principal das edições de 2006 e 2015 do PISA. A visão do Letramento Científico que constitui sua base é, como vimos, uma resposta para a pergunta: $\mathrm{O}$ que é importante para os jovens saberem, valorizarem e serem capazes de fazer em situações que envolvem Ciência e tecnologia? (OCDE, 2006; 2007; 2013d; 2016).

Em 2006, a construção do Letramento Científico foi definida em termos de um conjunto de competências que se esperava de um indivíduo cientificamente letrado. O PISA 2006 avaliou, dessa forma, a capacidade de realizar tarefas relacionadas a Ciências em uma série de situações que afetam a vida dos estudantes, seja em termos pessoais, seja na sua convivência social (OCDE, 2007). O desempenho dos estudantes foi avaliado em termos de seus conhecimentos e competências (BRASIL, 2008).

As competências avaliadas pelo PISA 2006 foram: identificar questões científicas; explicar fenômenos cientificamente; e usar evidência científica. Essas competências exigem que os estudantes demonstrem, por um lado, o conhecimento, as habilidades cognitivas e, por outro, as atitudes, os valores e as motivações à medida que respondem a questões relacionadas à Ciência (OCDE, 2006).

Os conhecimentos científicos presentes na avaliação do PISA 2006 são de dois tipos: conhecimento de Ciência e conhecimento sobre Ciência. Além disso, também estão presentes na definição do Letramento Científico de 2006 as atitudes relacionadas ao desejo de se engajar em aspectos da vida relativos às Ciências, a valores e grau de interesse conferidos à Ciência, à Tecnologia, ao Meio Ambiente e a outros contextos relevantes (BRASIL, 2008).

Em poucas palavras, as competências avaliadas no PISA 2006 são amplas e incluem aspectos relacionados à utilidade pessoal, à responsabilidade social e ao valor intrínseco e extrínseco do conhecimento científico (OCDE, 2006). Assim, a perspectiva do programa difere daquelas fundamentadas exclusivamente no currículo e na disciplina de Ciências; mas inclui problemas situados em contextos educacionais e também profissionais, e reconhece o lugar essencial dos 
conhecimentos, métodos, atitudes e valores que definem as disciplinas científicas (OCDE, 2006). Portanto, o termo que melhor descreve os propósitos gerais da avaliação científica do PISA 2006 é o Letramento Científico conforme as concepções de Bybee, 1997b, Fensham, 2000, Graber \& Bolte, 1997, Mayer, 2002, Roberts, 1983, UNESCO, 1993.

O termo Letramento Científico foi escolhido, de acordo com a OCDE (2006), por representar os objetivos da educação científica que devem ser aplicados a todos os estudantes, implicando uma amplitude e uma natureza aplicada aos propósitos da educação científica, representando um continuum de conhecimento científico e de habilidades cognitivas associadas à investigação científica, que incorpora múltiplas dimensões e inclui as relações entre Ciência e Tecnologia. Em conjunto, as competências científicas no centro da definição caracterizam a base do Letramento Científico e o objetivo da avaliação científica do PISA 2006 - avaliar o grau de desenvolvimento das competências (BYBEE, 1997a, FENSHAM, 2000, LAW, 2002, MAYER e KUMANO, 2002).

Na edição de 2015 do PISA, compreender e envolver-se em discussões críticas sobre questões que envolvem Ciência e Tecnologia requer três competências específicas: explicar fenômenos cientificamente; avaliar e planejar experimentos científicos; e interpretar dados e evidências cientificamente (OCDE, 2013d; 2016).

Essas competências exigem conhecimento (OCDE, 2013d; 2016). Explicar os fenômenos científicos e tecnológicos, por exemplo, demanda um conhecimento do conteúdo da Ciência - conhecimento de conteúdo. A segunda e terceira competências, no entanto, exigem mais do que um conhecimento do que sabemos, elas dependem de uma compreensão de como o conhecimento científico é estabelecido e o grau de confiança com que é realizado (OCDE, 2016). Reconhecer e identificar os traços que caracterizam a pesquisa científica requer um conhecimento dos procedimentos padrão que embasam os diversos métodos e práticas utilizadas para estabelecer o conhecimento científico, ou seja, um conhecimento procedimental. Finalmente, as competências exigem conhecimento epistemológico - uma compreensão da lógica das práticas comuns à investigação científica, o status das reivindicações de conhecimento que são gerados e o significado dos termos fundamentais, tais como teoria, hipótese e dados (OCDE, 2013d; 2016). 
Segundo a OCDE (2016) as pessoas precisam das três formas de conhecimento científico - conteúdo, procedimental e epistemológico - para executar as três competências de Letramento Científico. Portanto, o PISA 2015 busca avaliar em que medida jovens de 15 anos são capazes de exibir essas competências de forma adequada, dentro de uma gama de contextos pessoais, locais, nacionais e globais. Esta perspectiva, assim como a de 2006, difere da de muitos programas escolares de Ciências, que são, muitas vezes, dominados por conhecimento de conteúdo. Em vez disso, a matriz é baseada em uma visão mais ampla do tipo de conhecimento da Ciência exigido de membros participantes da sociedade contemporânea.

Além disso, a perspectiva baseada em competências também reconhece que há um elemento afetivo na demonstração dessas competências pelo estudante (OCDE, 2006; 2013d; 2016). Esse elemento é representado por suas atitudes ou disposição para a Ciência, o qual irá determinar o seu nível de interesse, sustentar o envolvimento e motivá-lo a atuar (SCHIBECI, 1984). Assim, geralmente a pessoa cientificamente letrada demonstra interesse por assuntos científicos, envolvimento com problemas relacionados à Ciência, preocupação com questões tecnológicas, recursos e ambiente e reflexão sobre a importância da Ciência a partir de uma perspectiva pessoal e social. Estes requisitos não significam que essas pessoas são necessariamente favoráveis à própria Ciência, mas que esses indivíduos reconhecem que a Ciência, a Tecnologia e a investigação neste domínio são um elemento essencial da cultura contemporânea que estrutura muito do nosso pensamento (OCDE, 2013d; 2016).

São essas considerações que levaram às definições de Letramento Científico no PISA 2006 e 2015. Em suma, o PISA, bem como as contribuições mais recentes na busca de uma definição consensual de Letramento Científico, reúne os dois grandes domínios centrados na compreensão do conteúdo científico e da função social da Ciência e da Tecnologia, incluindo atitudes, crenças e interesses que influenciam decisões e ações a partir de uma perspectiva pessoal, social e cultural. 
Figura 2. Matriz da avaliação de Letramento Científico do PISA 2006.

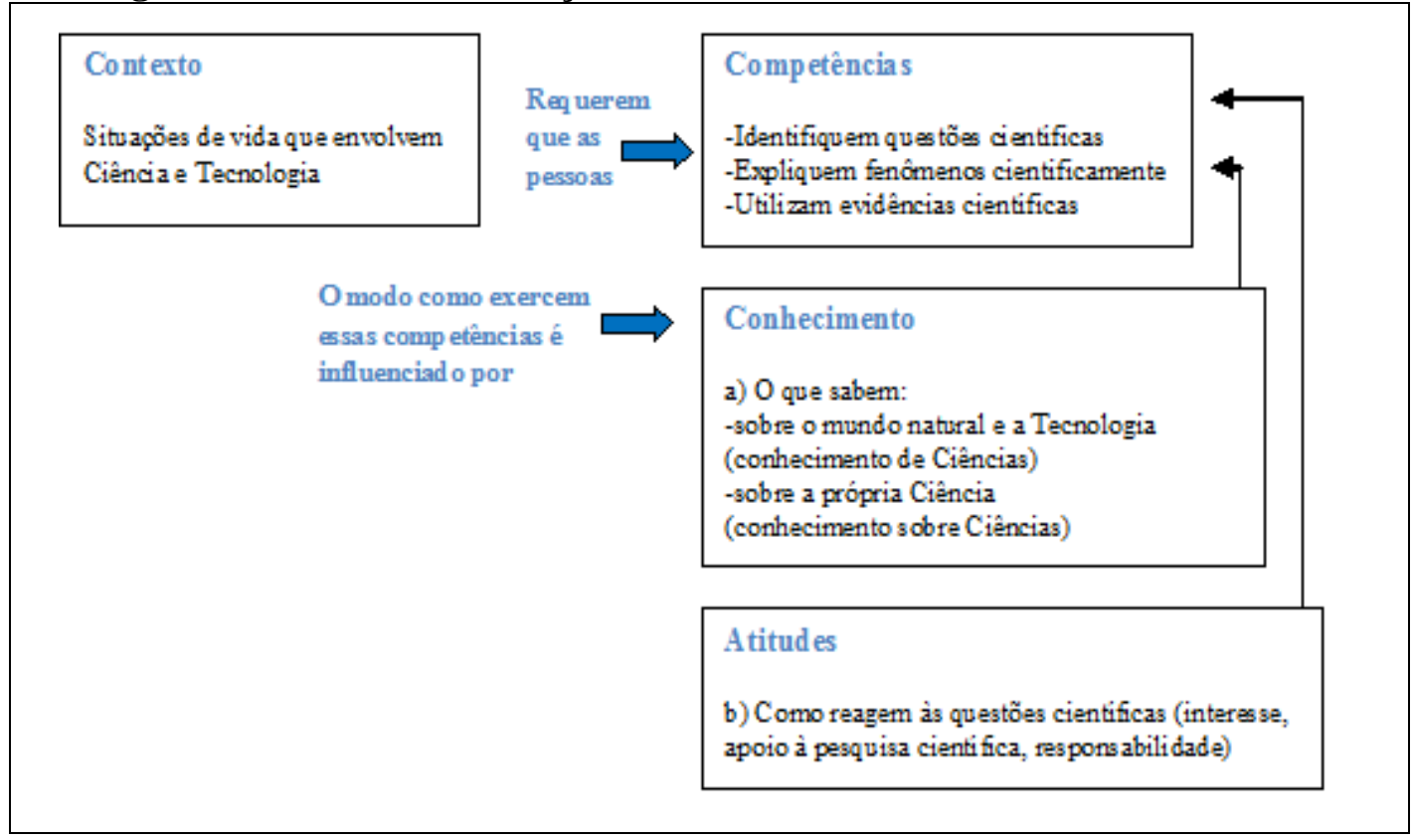

Fonte: adaptado de OCDE, 2007 e BRASIL, 2008.

O PISA 2006 (OCDE, 2007; BRASIL, 2008) desenvolve suas atividades e questões de avaliação de Ciências em uma estrutura composta por quatro aspectos inter-relacionados: os contextos nos quais se inserem as tarefas, as competências que os estudantes necessitam aplicar, as áreas de conhecimento envolvidas e as atitudes do estudante (Figura 2).

Assim como foi em 2006, para fins de avaliação, a definição de Letramento Científico no PISA 2015 pode ser caracterizada como constituída pelo contexto, pelas competências, conhecimentos e atitudes, aspectos que se apresentam interrelacionados (Figura 3). 
Figura 3. Matriz da avaliação de Letramento Científico do PISA 2015

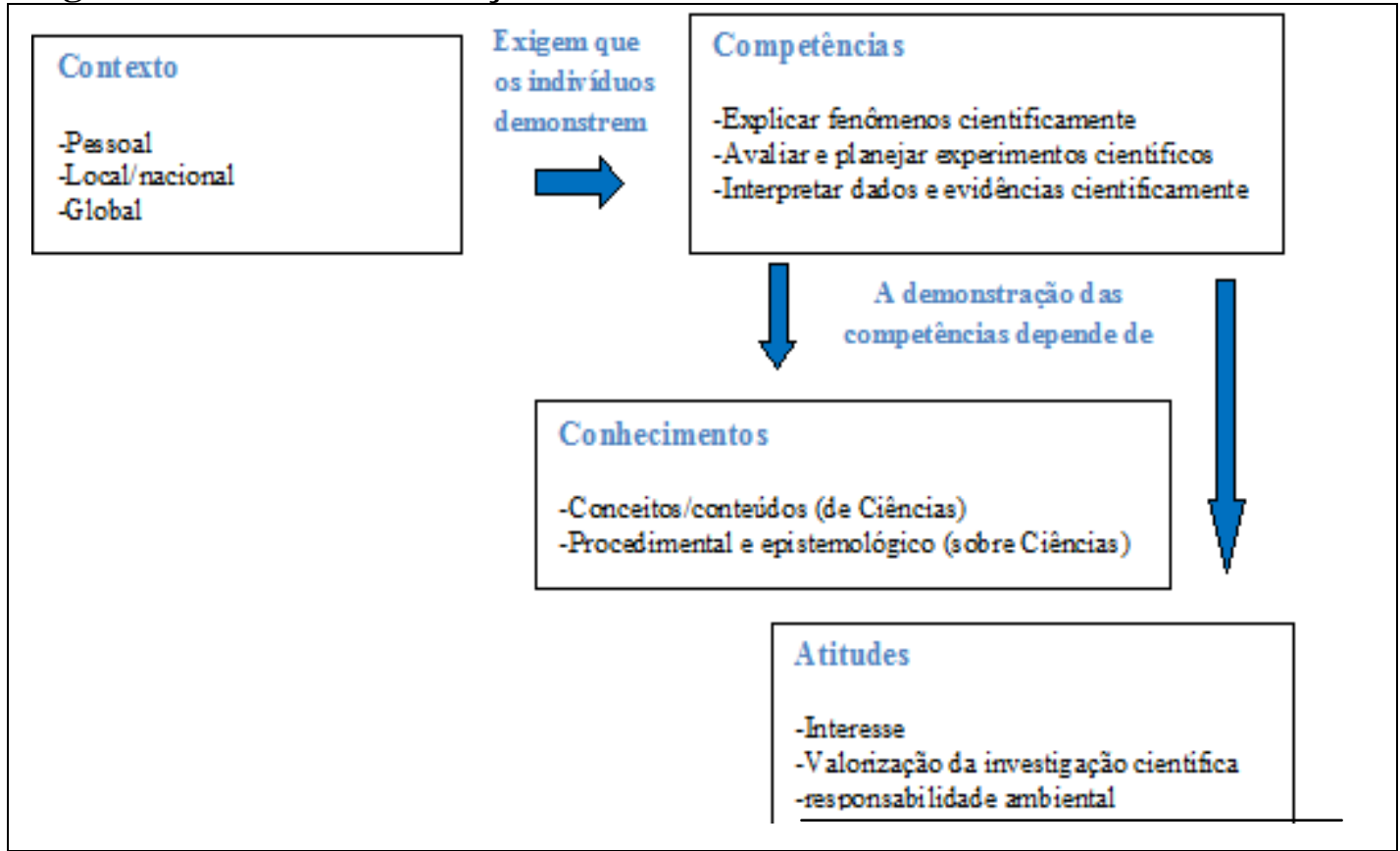

Fonte: adaptado de OCDE, 2016 e BRASIL, 2016.

Comparando as duas figuras podemos perceber que os quatro aspectos interrelacionados que definem o Letramento Científico no PISA permaneceram inalterados nas duas edições do Programa que focaram o domínio de Ciências. O que muda é a forma como esses aspectos são abordados. A evolução das ideias expressas na definição de Letramento Científico é apresentada na subseção a seguir.

\subsection{2}

\section{A evolução da definição de Letramento Científico no PISA}

Nas edições do PISA de 2000 e de 2003 o Letramento Científico foi definido de igual maneira. Nessas duas edições, cujos focos foram o domínio de Leitura e de Matemática, respectivamente, a seguinte definição foi adotada:

Letramento Científico é a capacidade de usar o conhecimento científico para identificar questões e tirar conclusões baseadas em evidências, a fim de compreender e ajudar a tomar decisões sobre o mundo natural e as mudanças feitas a ele por meio da atividade humana. (OECD, 1999, p.60/2003, p. 133).

Em 2000 e 2003, a definição incorporou o conhecimento de Ciências e entendimentos sobre a Ciência dentro do termo "Conhecimento Científico". A definição 2006 separou e elaborou o termo "conhecimento científico" a partir de seu desdobramento em dois componentes: "conhecimento de ciência" e 
"conhecimento sobre ciência" (OECD, 2006). Ambas as definições, no entanto, se referem à aplicação do conhecimento científico para a compreensão e a tomada de decisões sobre o mundo natural.

No PISA 2006, a definição foi reforçada com a adição do conhecimento da relação entre Ciência e Tecnologia - um aspecto que foi assumido, mas não elaborado nas definições de 2000 e 2003 (OCDE, 2013d).

O PISA 2006 define Letramento em Ciências de um indivíduo em termos de:

- Conhecimento científico e utilização desse conhecimento para identificar questões, adquirir novos conhecimentos, explicar fenômenos científicos e estabelecer conclusões sobre questões relacionadas a Ciência baseadas em evidências. Por exemplo, quando os indivíduos lêem sobre um assunto relacionado à saúde, são capazes de separar os aspectos científicos dos não científicos presentes no texto, e de aplicar conhecimento e justificar decisões pessoais?

- Compreensão dos aspectos característicos da Ciência como uma forma de investigação e conhecimento humano. Por exemplo, as pessoas sabem a diferença entre explicações baseadas em evidências e opiniões pessoais?

- Conscientização quanto ao modo como a Ciência e a Tecnologia modelam nossos ambientes material, intelectual e cultural. Por exemplo, os indivíduos conseguem reconhecer e explicar o papel das tecnologias, na medida em que elas influenciam a economia, a organização social e a cultura de uma nação? As pessoas têm consciência das mudanças ambientais e dos efeitos dessas mudanças sobre a estabilidade econômica e social?

- Disposição para envolver-se com questões relacionadas a Ciência e com ideias científicas, como um cidadão reflexivo. Esse aspecto refere-se ao valor que os estudantes dão à ciência, tanto em termos de tópicos como em termos da abordagem científica para entender o mundo e resolver problemas. $\mathrm{O}$ fato de memorizar e reproduzir informações não significa necessariamente que os estudantes vão escolher carreiras científicas ou envolver-se em assuntos relacionados às ciências. $\mathrm{O}$ conhecimento sobre o interesse científico, o apoio à investigação científica e a responsabilidade na resolução de questões ambientais por parte dos jovens de 15 anos de idade fornecem aos formuladores de políticas indicadores antecipados sobre o apoio dos cidadãos às ciências como uma força para o progresso social. (OCDE, 2007, p. 39).

A definição do domínio Letramento Científico não sofreu alterações nas edições de 2009 e 2012, o que era de se esperar porque o foco nessas edições recaiu, respectivamente, nas áreas de Leitura e de Matemática.

A evolução das ideias expressas na definição aparece na edição mais recente do Programa, em 2015, cujo foco foi novamente a área de Ciências. A principal diferença é que a noção de "conhecimento sobre a ciência" foi especificada de forma mais clara e dividida em dois componentes - conhecimento procedimental e conhecimento epistemológico (OCDE, 2013d; 2016). 
Em 2006, a matriz do PISA também foi ampliada para incluir aspectos atitudinais em itens que avaliam os estudantes em questões científicas e tecnológicas no âmbito da construção do Letramento Científico (OCDE, 2013d). Neste mesmo ano, as atitudes foram medidas de duas formas: por meio do questionário contextual do estudante e de itens incorporados no teste (OCDE, 2016). Uma vez que esta incorporação dos itens sobre atitudes estenderam o tamanho do teste em 2006, os aspectos atitudinais, na matriz de 2015, aparecem apenas no questionário do estudante (OCDE, 2013d; 2016).

Quanto aos construtos medidos dentro deste domínio, o primeiro ("Interesse na Ciência") e o terceiro ("Consciência ambiental") continuaram os mesmos de 2006. O segundo, "Apoio à investigação científica", no entanto, foi alterado para uma medida de "Valorização de abordagens científicas para investigação" - o que é, essencialmente, uma mudança de terminologia para melhor refletir o que é medido (OCDE, 2016).

Finalmente, os contextos de avaliação foram alterados de "pessoal, social e global" na avaliação de 2006 para "pessoal, local/nacional e global" em 2015 para tornar os títulos mais coerentes (OCDE, 2016). Em resumo, a definição de 2015 se baseia e se desenvolve a partir da definição de 2006.

Letramento Científico é a capacidade de se envolver com as questões relacionadas com a Ciência e com a ideia da Ciência, como cidadão reflexivo. Uma pessoa letrada cientificamente, portanto, está disposta a participar de discussão fundamentada sobre ciência e tecnologia, o que exige as competências para:

1. explicar fenômenos cientificamente: reconhecer, oferecer e avaliar explicações para fenômenos naturais e tecnológicos;

2. avaliar e planejar investigações científicas: descrever e avaliar investigações científicas e propor formas de abordar questões cientificamente;

3. interpretar dados e evidências cientificamente: analisar e avaliar os dados, afirmações e argumentos, tirando conclusões científicas apropriadas. (BRASIL, 2016, p. 37)

Enfim, segundo o último relatório do PISA sobre os dados de 2015 (BRASIL, 2016), tornar-se letrado cientificamente envolve a ideia de que os propósitos da educação na Ciência devem ser amplos e aplicados; portanto, o conceito de Letramento Científico se refere tanto ao conhecimento da Ciência como ao da Tecnologia pautada na Ciência. A Ciência e a Tecnologia diferem em seus propósitos, processos e produtos: enquanto a Tecnologia visa soluções ótimas para problemas humanos, a Ciência busca a resposta para questões 
específicas sobre o mundo natural. Contudo, ambas estão intimamente relacionadas.

O Letramento Científico requer não apenas o conhecimento de conceitos e teorias da ciência, mas também o dos procedimentos e práticas comuns associados à investigação científica e de como eles possibilitam o avanço da Ciência. De acordo com o programa (OCDE, 2016), indivíduos cientificamente letrados têm o conhecimento das principais concepções e ideias que formam a base do pensamento científico e tecnológico, de como tal conhecimento é obtido e justificado por evidências ou explicações teóricas. Portanto, em 2015, define-se o Letramento Científico em termos da capacidade de uso do conhecimento e da informação de maneira interativa. 


\section{3 Abordagem metodológica}

Neste capítulo, apresentamos o delineamento da pesquisa e as decisões tomadas em seu processo de construção. Como já foi assinalado na Introdução, os objetivos principais desta tese são os seguintes: a) buscar identificar se o funcionamento diferencial dos itens da prova de Ciências do PISA 2006 daria conta de explicar a distância de desempenho existente entre os estudantes avaliados no Brasil e no Japão; b) verificar se o comportamento diferencial dos itens do teste prejudica a comparabilidade dos resultados; e c) tentar identificar diferentes ênfases curriculares e/ou práticas pedagógicas no Ensino de Ciências de Brasil e Japão que possam explicar o desempenho diferenciado dos estudantes brasileiros e japoneses no PISA. Para a realização do estudo, nossos objetivos desdobraram-se nas seguintes questões de pesquisa:

1. De acordo com os resultados do PISA, há diferenças de competência cognitiva em Ciências entre os estudantes brasileiros e dos outros países, sobretudo os do Japão? Como se expressam especificamente essas diferenças em termos das habilidades contempladas pelas subescalas do PISA?

2. Existem itens do PISA 2006 que apresentam DIF, tendo o Brasil como referência?

3. É possível, a partir dos dados do PISA e da adoção complementar de uma abordagem qualitativa, identificar diferentes ênfases curriculares e/ou práticas pedagógicas no Ensino de Ciências de Brasil e Japão que contribuam para a compreensão das diferenças de desempenho entre estudantes brasileiros e japoneses?

Com efeito, para responder as questões acima, conduzimos as análises baseando-nos em duas abordagens: quantitativa e qualitativa. A primeira adota uma análise exploratória e descritiva dos resultados de Brasil e Japão em Ciências no PISA e na utilização da análise de DIF nos itens da prova de Ciências da edição de 2006. Os resultados destas análises serão apresentados e discutidos nos Capítulos 4 e 5 . O segundo tipo de abordagem, a qualitativa, foi realizado por meio de observações de aulas de Ciências, de questionários aplicados aos professores observados, e de entrevistas com especialistas da área de Ciências e 
com responsáveis pelo PISA nos dois países considerados neste estudo. Os resultados, bem como as análises dos dados obtidos através dessa abordagem são apresentados no Capítulo 6.

$\mathrm{Na}$ seção seguinte, apresentamos as estratégias adotadas para responder à primeira questão. Na sequência, descrevemos o método de análise de DIF e, por fim, a abordagem qualitativa da pesquisa.

\section{1}

\section{A análise exploratória dos resultados de Brasil e Japão no PISA}

Para responder a nossa primeira questão de pesquisa, conduzimos uma análise exploratória dos resultados do Brasil e do Japão nas duas edições do PISA cujo foco foi a área de Ciências: 2006 e 2015. Exploramos e comparamos, também, os resultados dos estudantes brasileiros e japoneses com a média dos países membros da OCDE.

A análise dos resultados utiliza-se de estatística descritiva, e compreende análises univariadas e bivariadas. A importância deste tipo de análise reside no fato de nenhuma modelagem estatística de dados pode prescindir de uma análise exploratória, que possibilite ao pesquisador o conhecimento do comportamento das variáveis (BABBIE, 1999).

As variáveis utilizadas ${ }^{3}$ nesta primeira parte do estudo foram selecionadas a partir das bases de estudantes do PISA que encontram-se disponíveis no website da $\mathrm{OCDE}^{4}$. Para as duas últimas edições do Programa, a de 2012 e 2015, a OCDE disponibilizou sistemas de exploração de dados que permitem criar análises e construir relatórios a partir da base de dados do PISA ${ }^{5}$. Na edição de 2006, os dados referentes aos conhecimentos elegidos pelo Programa podiam ser extraídos do website do principal consórcio organizador do PISA - o Australian

\footnotetext{
${ }^{3}$ Proficiência em Ciências (pv1scie); série (st01q01 e st001d01t); proficiência em "explicar fenômenos cientificamente" (pvleps e pv1scep); proficiência em "identificar questões científicas" (pvlisi); proficiência em "usar evidência científica" (pvluse); proficiência em "avaliar e planejar investigações científicas" (pv1sced); proficiência em "interpretar dados e evidências cientificamente" (pv1scid); proficiência em "conhecimento de conteúdo" (pv1skco); proficiência em "conhecimento procedimental e epistemológico" (pv1skpe); proficiência em "sistemas físicos" (pv1ssph); proficiência em "sistemas vivos" (pv1ssli); proficiência em "Terra e sistemas espaciais" (pv1sses); fase (st01q01.rec e st001d01t.rec); níveis (pv1scie.rec).

${ }^{4} \mathrm{http}: / /$ www.oecd.org/PISA/data/

${ }_{5}^{5}$ Para explorar os resultados de 2015, visite: http://PISAdataexplorer.oecd.org/ide/idePISA/. Para os resultados de 2012: https://nces.ed.gov/surveys/PISA/idePISA/.
} 
Council for Educational Research (ACER). No entanto, este website ${ }^{6}$ não está mais disponível.

As variáveis correspondem a nossas unidades de análise dos resultados. Comparamos Brasil, Japão e OCDE quanto a:

1. média geral em Ciências

2. níveis de proficiência

3. competências em Ciências

4. áreas do conhecimento em Ciências

Na comparação do desempenho entre países, optamos também por comparar estudantes defasados, em fase e adiantados no Brasil. O Japão é um dos únicos países da OCDE onde não há reprovação, ou seja, 100\% dos estudantes estão em fase e matriculados no primeiro ano do Ensino Médio. Dadas as diferenças de fluxo dos estudantes no Brasil e no Japão, as médias gerais no PISA, do Japão e do Brasil serão analisadas em quatro dimensões:

1. geral - todos os estudantes participantes do teste

2. estudantes defasados - aqueles matriculados no Ensino Fundamental

3. estudantes em fase - aqueles matriculados na primeira série do Ensino Médio

4. estudantes adiantados - aqueles matriculados nas segunda e terceira séries do Ensino Médio.

Essas dimensões foram obtidas através da recodificação da variável "ano escolar" do PISA, com a criação de novas variáveis denominadas "defasados", "em fase" e "adiantados" que nos permitiram observar os resultados dos estudantes brasileiros em cada situação.

Para fins de comparação, nos baseamos na literatura sobre os efeitos negativos da reprovação para os problemas de ensino-aprendizagem no Brasil (FREITAS, 1947; BRANDÃO, BAETA E ROCHA, 1983; COSTA-RIBEIRO, 1991; ALVES, ORTIGÃO E FRANCO, 2007; CRAHAY, 2002; CORREA, BONAMINO \& SOARES, 2014) e no uso de regressão linear que nos permite investigar o efeito da variável repetência sobre o desempenho em Ciências dos estudantes brasileiros no PISA.

\footnotetext{
${ }^{6}$ http://PISAcountry.acer.edu.au/
} 
Essa abordagem descritiva dos resultados do PISA nos ajuda a responder, principalmente, a segunda parte da nossa primeira questão de pesquisa. Nos ajuda a entender como se expressam especificamente as diferenças, entre Brasil e Japão, em termos das habilidades contempladas pelas subescalas do PISA.

\section{2 \\ A análise do DIF}

Para responder a segunda questão de pesquisa acerca da possível existência de DIF nos itens do PISA 2006, utilizamos o modelo integrado proposto por Soares et al. (2009), que permite a detecção e explicação do DIF simultaneamente, numa só etapa de inferência. O modelo utiliza apenas o pressuposto de que um subconjunto, no total de itens analisados, não possui DIF, sem que seja necessário identificá-los, e é capaz de calcular a probabilidade de cada item possuir DIF, assim como os parâmetros para cada item em cada grupo, e a diferença entre eles. Adicionalmente, o algoritmo calcula as proficiências, médias e desvios-padrão, de cada grupo.

O modelo foi implementado no solver OpenBUGS® ${ }^{7}$ que permite a realização de inferência bayesiana utilizando amostragem de $\operatorname{Gibbs}^{8}$. Os valores das variáveis indicadoras são estimados diretamente no modelo, indicando quais itens apresentam DIF e quais não. O modelo Bayesiano integrado reduz os procedimentos iterativos normalmente utilizados para a purificação e detecção de proficiência e explicação do DIF. Soares et al. (2009), realizaram uma análise do Programa Nova Escola, a partir de dois estudos simulados - um para mostrar as vantagens do modelo integrado sobre aqueles que fixam itens ancora a priori, e outro em que compara o modelo integrado com métodos mais utilizados na

\footnotetext{
${ }^{7}$ BUGS é um pacote de software para a realização de inferência bayesiana utilizando amostragem de Gibbs. O usuário especifica um modelo estatístico, de complexidade arbitrária, simplesmente dizendo as relações entre as variáveis relacionadas. O software inclui um 'sistema especialista', que determina um regime adequado MCMC (cadeia de Markov Monte Carlo), com base no amostrador de Gibbs para analisar o modelo especificado.

${ }^{8}$ Amostragem de Gibbs é um algoritmo iterativo para gerar uma sequencia de amostras a partir de uma distribuição posterior conjunta por amostragem repetida a partir da distribuição condicional plena. Sob condições apropriadas, pode ser demonstrado que a sequência aleatória que representa os desenhos aleatórios sucessivos constituem uma cadeia de Markov que converge para uma distribuição estacionária igual à distribuição posterior conjunta (para mais detalhes, ver GAMERMAN \& LOPES, 2006).
} 
detecção de DIF para diferentes configurações, demonstrando a eficiência do referido método.

Apesar de o PISA ser corrigido utilizando-se o modelo de Rasch, para as análises de DIF do presente estudo ajustamos o modelo da Teoria de Resposta ao Item (TRI) de três parâmetros (3PL). O ajuste deste modelo contempla uma maior flexibilidade das formas da Curva Característica do Item (CCI), bem como possibilita o diagnóstico de DIF no que diz respeito à discriminação do item (parâmetro $a$ ), à dificuldade do item (parâmetro $b$ ) e à probabilidade de acerto ao acaso (parâmetro c), ao passo que o ajuste do modelo Rasch permitiria identificar DIF apenas no parâmetro $b$. Neste estudo, não consideramos a possibilidade de DIF no parâmetro c. Apesar de ser possível, a aplicabilidade desse caso é substancialmente limitada tanto pela sabida dificuldade de estimação deste parâmetro como por restrições práticas.

Utilizamos para a análise de DIF os itens do PISA $2006^{9}$ do Brasil e do Japão que são de domínio público. Trabalhamos apenas com itens dicotômicos, de forma que, de um total de 103 itens de Ciências, foram excluídos da análise seis itens com respostas corrigidas na forma de crédito parcial e um item não comum aos dois países, resultando num total de 96 itens selecionados para a presente análise. A amostra de estudantes do Brasil foi considerada como grupo de referência e a do Japão como grupo focal. Visando utilizar ao máximo sem, no entanto, extrapolar a capacidade de processamento do software OpenBUGS ${ }^{\circledR}$, foi selecionada uma amostra com 3500 casos sendo 2104 estudantes brasileiros e 1396 japoneses, a fim de obter cerca de 1000 respostas para cada item, por amostragem aleatória simples sem reposição, obtendo-se ao final uma média de 1018 respostas para cada item, com um mínimo de 949 e um máximo de 1070 respostas.

Para identificar, nos itens com DIF, as características prevalentes ao longo das covariáveis avaliadas, utilizamos um critério baseado na probabilidade e, a posteriori, os itens com DIF foram identificados. As covariáveis que utilizamos nas análises são aquelas características dos itens quanto a competências, áreas do

\footnotetext{
${ }^{9}$ Dada a recente publicação dos resultados do PISA 2015 (06/12/2016), não nos foi possível analisar os itens desta edição em tempo hábil para a conclusão desta tese. Contudo, é de nosso interesse fazê-lo posteriormente. Ainda assim, reiteramos que os itens de 2006 continuam perfeitamente atuais já que são também utilizados em edições posteriores do PISA. Para se ter ideia, o teste de 2015 continha cerca de 80 itens comuns ao de 2006.
} 
conhecimento, áreas de aplicação, âmbitos, tipos e idiomas. Essas variáveis sinalizam a existência de ênfases curriculares diferenciadas nesses dois países e podem ser observadas no Quadro 1.

Quadro 1. Características dos itens do PISA 2006.

\begin{tabular}{|c|c|}
\hline Covariável & Categorias \\
\hline Competências & $\begin{array}{cc}\checkmark & \text { Identificar questões cientificamente; } \\
\checkmark & \text { Explicar fenômenos cientificamente; } \\
& \checkmark \text { Usar evidência científica. }\end{array}$ \\
\hline Áreas do conhecimento & $\begin{array}{c}\checkmark \quad \text { Conhecimento de Ciências: sistemas vivos, } \\
\text { sistemas físicos, terra e sistemas espaciais, } \\
\text { sistemas tecnológicos; } \\
\checkmark \quad \text { Conhecimento sobre Ciências: explicação e } \\
\text { investigação científica. }\end{array}$ \\
\hline Áreas de aplicação & 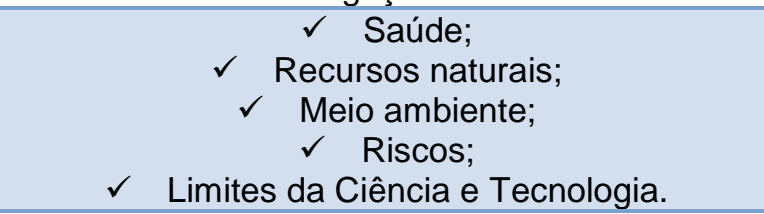 \\
\hline Âmbitos & $\begin{array}{ll}\checkmark & \text { Pessoal; } \\
\checkmark & \text { Social; } \\
\checkmark & \text { Global. }\end{array}$ \\
\hline Tipos & $\begin{array}{cc}\checkmark & \text { Resposta construída aberta; } \\
\checkmark & \text { Resposta construída fechada; } \\
& \checkmark \text { Múltipla escolha; } \\
\checkmark & \text { Múltipla escolha complexa. }\end{array}$ \\
\hline Idiomas & $\begin{array}{lll} & \checkmark & \text { Inglês; } \\
\checkmark & \text { Norueguês; } \\
\checkmark & \text { Coreano; } \\
\checkmark & \text { Japonês; } \\
\checkmark & \text { Alemão; } \\
\checkmark & \text { Francês; } \\
\checkmark & \text { Holandês. } \\
\end{array}$ \\
\hline
\end{tabular}

Fonte: elaboração própria a partir de OCDE, 2007.

Para além dos resultados propiciados pelas análises de DIF, a investigação da existência de ênfases curriculares diferenciadas entre Brasil e Japão foi possível graças à adoção de uma abordagem metodológica mista envolvendo pesquisa qualitativa.

No decorrer da pesquisa e diante dos primeiros achados, sobretudo das análises de DIF, percebemos que itens de determinadas áreas do conhecimento se comportavam diferentemente entre estudantes brasileiros e japoneses. Itens das áreas de Saúde, Meio Ambiente e Recursos Naturais mostraram-se mais fáceis para os estudantes brasileiros em relação aos japoneses; e itens relacionados a Riscos/Catástrofes e Sistemas Tecnológicos mais fáceis para os japoneses em relação aos brasileiros. Estes resultados colocaram a necessidade de um melhor entendimento deste comportamento diferencial e nos levaram a formular uma 
hipótese que considerou a existência de possíveis diferenças de ênfases nos currículos de Ciências praticados no Brasil e no Japão. Para a verificação desta hipótese, recorremos à observação de aulas de Ciências, à aplicação de questionários aos professores observados, e às entrevistas com especialistas da área de Ciências e com os responsáveis pelo PISA no Brasil e no Japão.

\section{3 Análise das ênfases curriculares e práticas pedagógicas no Ensino de Ciências de Brasil e Japão}

Procuramos complementar o estudo quantitativo de DIF com um estudo qualitativo, buscando refinar e ampliar o potencial de interpretação dos resultados quantitativos, notadamente pela agregação da percepção dos sujeitos - estudantes, professores e especialistas - ao desenho da pesquisa. Essa triangulação significou olhar para o mesmo fenômeno, no nosso caso o conceito de Letramento Científico do PISA, a partir de mais de uma perspectiva, uma vez que informações advindas de diferentes ângulos foram utilizadas para iluminar o problema de pesquisa.

$\mathrm{Na}$ literatura especializada, a triangulação não apenas constitui uma das formas de combinar vários métodos qualitativos entre si (FLICK, 2005a; 2005b) e de articular métodos quantitativos e qualitativos (FIELDING \& SCHREIER, 2001; FLICK, 2005c), mas também uma ruptura com a hegemonia metodológica do método único (TASHAKKORI \& TEDDLIE, 1998).

O conceito de Letramento Científico adotado pelo PISA foi a referência de base de todos os instrumentos utilizados em nossas análises. Empregamos os construtos usados pelo Programa em 2006 para aceder ao ponto de vista dos estudantes sobre o ensino e a aprendizagem de Ciências e também à perspectiva dos professores participantes nesta pesquisa, bem como para orientar as observações das aulas.

Além da visão do professor e da observação de aulas de Ciências, para entender como se processa o Letramento Científico nos países estudados, conduzimos entrevistas semiestruturadas com professores especialistas no ensino desta disciplina, no Japão, bem como entrevistas com as pessoas responsáveis, perante a OCDE, pelo PISA, no Japão e no Brasil. Tais entrevistas foram extremamente importantes para a pesquisa de campo, já que contribuíram no 
levantamento de hipóteses que, na visão de especialistas, podem explicar tamanha diferença de desempenho entre os países envolvidos, bem como as peculiaridades dos distintos sistemas de ensino.

Dividiremos essa seção em subseções para melhor abordar a metodologia utilizada. Inicialmente apresentaremos as escolas escolhidas e depois os instrumentos de coleta de dados. Por fim, será apresentado o método de análise da prática pedagógica.

\subsection{1}

\section{As escolas}

Observamos três escolas em cada um dos países envolvidos. No Japão, as três escolas estão centralmente localizadas em Tóquio (Figura 4), porém em diferentes cidades. No Brasil, as três escolas selecionadas estão localizadas no município do Rio de Janeiro.

Figura 4. Mapa do Japão em perspectiva com localização das cidades das três escolas japonesas. Localizador preto $=$ Koganei-shi, vermelho $=$ Setagaya $\mathrm{e}$ azul $=$ Fuchu.

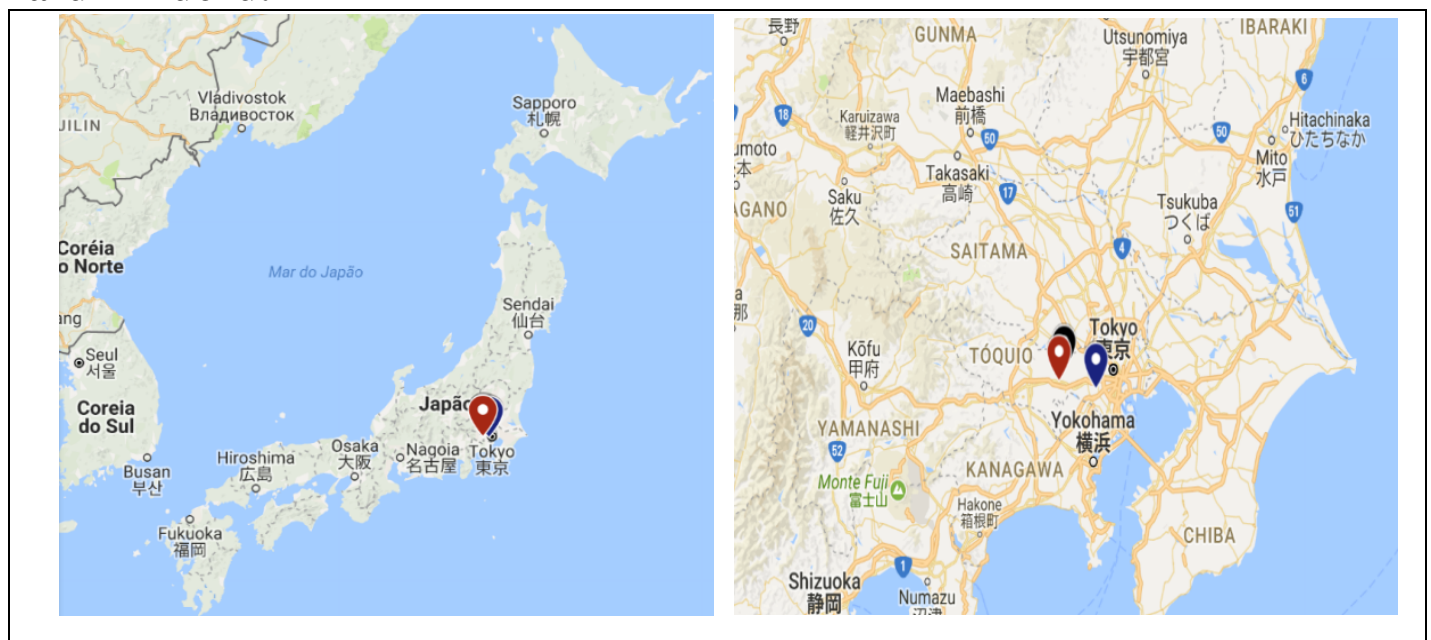

Fonte: Google mapas. 2016.

As três cidades japonesas são Koganei-shi (小金井市), Setagaya-ku (世田谷区) e Fuchu-shi (府中市). Alguns aspectos das cidades como, por exemplo, a população e a área, apenas para fins de contextualização, são apresentadas na Tabela 1, a seguir. 
Tabela 1. Área e população, total e densidade, das três cidades em Tóquio no Japão e do Rio de Janeiro no Brasil.

\begin{tabular}{llllll}
\hline & & Koganei Shi & Setagaya Ku & $\begin{array}{l}\text { Fuchu } \\
\text { Shi }\end{array}$ & $\begin{array}{l}\text { Rio } \\
\text { Janeiro }\end{array}$ \\
\hline Área Total & & $11.33 \mathrm{~km}^{2}$ & $58.08 \mathrm{~km}^{2}$ & $29.34 \mathrm{~km}^{2}$ & $1.200,179 \mathrm{~km}^{2}$ \\
$\begin{array}{l}\text { População } \\
\text { (2013) }\end{array}$ & Total & 120.617 & 892.214 & 257.640 & 6.476 .631 \\
& Densidade & $10.674,07 / \mathrm{km}^{2}$ & $15.361,81 / \mathrm{km}^{2}$ & $8,766 / \mathrm{km}^{2}$ & $5.265,82 / \mathrm{km}^{2}$ \\
\hline
\end{tabular}

Fonte: http://www.toukei.metro.tokyo.jp/tnenkan/tn-eindex.htm. Acesso: 23/02/2016 e, http://www.cidades.ibge.gov.br/xtras/perfil.php?codmun=330455. Acesso: 11/07/2016.

Optamos por estas três escolas japonesas principalmente por conta da facilidade de acesso via parcerias da Universidade Gakugei de Tóquio, onde realizamos o estágio de doutorado sanduíche, e da possibilidade de gravação em vídeo das aulas observadas. De acordo com o Prof. Dr. Masahiro Kamata, orientador desta pesquisa no Japão, é praticamente impossível conseguir autorização para observar escolas aleatoriamente neste país. As missões das escolas públicas e das escolas públicas associadas às universidades são diferentes. Segundo o professor Kamata, as primeiras estão voltadas apenas para o ensino e as segundas para o ensino, a pesquisa e o treinamento de professores. Essa diferença tornaria muito difícil angariar a colaboração na pesquisa das escolas públicas regulares. Para além disso, no entanto, todas as escolas no Japão utilizam o mesmo livro didático e seguem um currículo nacional comum.

As escolas brasileiras foram definidas com base nas características das escolas japonesas, principalmente no que diz respeito à rede, tais como sua associação a universidades e suas políticas de matrícula escolar. De forma a manter o anonimato das escolas e dos professores participantes da pesquisa, as unidades escolares observadas receberam nomes fictício de cientistas brasileiros e japoneses que se destacaram exponencialmente em todo o mundo por contribuições das mais diversas. Chamaremos as japonesas de Hideki Yukawa ${ }^{10}$, Reona Esaki ${ }^{11}$ e Susumu Tonegawa ${ }^{12}$; e as brasileiras de Adolpho Lutz ${ }^{13}$, Carlos Chagas ${ }^{14}$, César Lattes ${ }^{15}$.

\footnotetext{
${ }^{10}$ Hideki Yukawa se tornou o primeiro japonês a receber um Prêmio Nobel em 1949, ganhando um prêmio de física por ter previsto a existência de mesotrons.

${ }^{11}$ Reona Esaki recebeu o Prêmio Nobel de física em 1973.

12 Susumu Tonegawa recebeu o Prêmio Nobel de fisiologia/medicina em 1987.

${ }^{13}$ Adolpho Lutz (1855-1940), médico e sanitarista que combateu doenças graves e descobriu que o leite precisava ser pasteurizado.

${ }^{14}$ Carlos Chagas (1879-1934), médico brasileiro descobridor da doença de Chagas

${ }^{15}$ César Lattes (1924-2005), físico mundialmente famoso que confirmou a existência do méson pi.
} 
Como já dissemos, foram três as escolas japonesas e três as brasileiras participantes da pesquisa qualitativa. Duas das escolas dos dois países são federais, sendo que, no caso do Japão, as duas escolas estão associadas à Universidade e apenas uma delas, no Brasil. A outra escola federal brasileira, apesar de também ser muito cotada para o estágio/formação de futuros professores e objeto de muitas pesquisas educacionais, não está associada à universidade. A terceira escola, tanto no Brasil como no Japão, é pública e municipal.

Embora as políticas de admissão nas escolas segundo o país e a rede sejam diferentes, há alguns aspectos em comum. As escolas federais japonesas requerem um exame de entrada que avalia a Língua Japonesa, Estudos Sociais, Matemática e Ciências. A diferença entre elas é que Hideki Yukawa pede uma carta de referência da direção da escola anterior de origem do estudante/candidato, enquanto que a escola Reona Esaki requere uma carta de motivação do próprio estudante.

No Brasil, a política de acesso à escola Adolpho Lutz está baseada no sorteio público das vagas entre candidatos que estejam cursando o quinto ano escolar no ato da inscrição e que tenham, no mínimo, 10 anos de idade completos. Já a escola Carlos Chagas opera por concurso que avalia os conhecimentos dos candidatos em Língua Portuguesa e Matemática, além de Redação.

As escolas municipais, tanto no Brasil quanto no Japão, têm mecanismos mais simples de admissão. As inscrições na escola brasileira César Lattes são feitas exclusivamente pela internet e os estudantes que já estudam nas escolas da Prefeitura têm a matrícula renovada automaticamente. Ao preencher o cadastro, os pais devem informar no máximo cinco escolas em que gostariam de matricular seus filhos. É preciso, no entanto, registrar o endereço completo para correspondência, inclusive o número do CEP, para que a secretaria de educação informe, posteriormente, a escola designada. Já a escola Susumu Tonegawa, no Japão, considera apenas o endereço do estudante. Cada escola municipal naquele país atende estudantes de determinadas zonas e grupos de endereços do município. ${ }^{16}$ As escolas municipais japonesas têm em geral um alto nível de educação. São muito parecidas entre si e todas elas oferecem ensino integral.

\footnotetext{
${ }^{16}$ Gostaríamos de ressaltar que apesar do tema da segregação educacional não fazer parte do escopo desta pesquisa há na literatura inúmeros estudos que discutem a escolha das escolas pelos pais, a alocação de alunos, etc. (ALVES, BATISTA e ÉRNICA, 2012; BRUEL, 2014;
} 
O Quadro 2, além de resumir os processos de admissão das escolas observadas, apresenta outras características relativas ao tamanho, à infraestrutura, tamanho, etc.

Quadro 2. Características das escolas observadas.

\begin{tabular}{|c|c|c|c|c|c|c|c|}
\hline & \multicolumn{3}{|c|}{ Japão } & \multicolumn{3}{|c|}{ Brasil } \\
\hline & & $\begin{array}{l}\text { Hideki } \\
\text { Yukawa }\end{array}$ & $\begin{array}{l}\text { Reona } \\
\text { Esaki }\end{array}$ & $\begin{array}{l}\text { Susumu } \\
\text { Tonegawa }\end{array}$ & $\begin{array}{l}\text { Adolpho } \\
\text { Lutz }\end{array}$ & $\begin{array}{l}\text { Carlos } \\
\text { Chagas }\end{array}$ & $\begin{array}{l}\text { César } \\
\text { Lattes }\end{array}$ \\
\hline \multicolumn{2}{|c|}{ Ingresso } & $\begin{array}{c}\text {-Ficha de } \\
\text { Inscrição } \\
\text {-Carta de } \\
\text { Recomen- } \\
\text { dação } \\
\text {-Taxa de } \\
\text { Inscrição } \\
\text { ( US\$50) } \\
\text {-Prova }\end{array}$ & $\begin{array}{c}\text {-Ficha de } \\
\text { Inscrição } \\
\text {-Carta de } \\
\text { Motivação } \\
\text {-Taxa de } \\
\text { Inscrição } \\
\text { ( US\$50) } \\
\text {-Prova }\end{array}$ & $\begin{array}{c}\text {-Ser } \\
\text { residente } \\
\text { das } \\
\text { seguintes } \\
\text { zonas: } \\
\text { Shiraitodai, } \\
\text { Oshitate- } \\
\text { cho, } \\
\text { Koyanagi- } \\
\text { cho ou } \\
\text { Koremasa }\end{array}$ & $\begin{array}{c}\text {-Ficha de } \\
\text { Inscrição } \\
\text {-Taxa de } \\
\text { Inscrição } \\
(\sim \operatorname{R} \$ 50) \\
\text {-Sorteio }\end{array}$ & $\begin{array}{c}\text {-Ficha de } \\
\text { Inscrição } \\
\text {-Taxa de } \\
\text { Inscrição } \\
\text { ( R } \$ 50) \\
\text {-Prova }\end{array}$ & $\begin{array}{c}\text {-Inscrição } \\
\text { eletrônica } \\
\text {-Indicação } \\
\text { de } 5 \\
\text { escolas }\end{array}$ \\
\hline \multirow{3}{*}{$\begin{array}{l}\text { Número } \\
\text { de } \\
\text { turmas }\end{array}$} & $\begin{array}{l}70 \\
\text { ano }\end{array}$ & 4 & 4 & 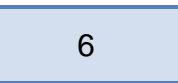 & 2 & 9 & 3 \\
\hline & $\begin{array}{c}80 \\
\text { ano }\end{array}$ & 4 & 4 & 5 & 2 & 11 & 2 \\
\hline & $\begin{array}{c}90 \\
\text { ano }\end{array}$ & 4 & 4 & 5 & 2 & 11 & 1 \\
\hline \multicolumn{2}{|c|}{$\begin{array}{l}\text { Número médio } \\
\text { de estudantes } \\
\text { por turma }\end{array}$} & 40 & 40 & 30 & 30 & 30 & 30 \\
\hline \multicolumn{2}{|c|}{$\begin{array}{c}\text { Laboratório de } \\
\text { Ciências }\end{array}$} & $\sqrt{ }$ & $\sqrt{ }$ & $\sqrt{ }$ & $\sqrt{ }$ & $\sqrt{ }$ & $\sqrt{ }$ \\
\hline \multicolumn{2}{|c|}{$\begin{array}{l}\text { Equipamentos } \\
\text { de laboratório } \\
\text { (vidrarias, } \\
\text { reagentes, etc.) }\end{array}$} & $\sqrt{ }$ & $\sqrt{ }$ & $\sqrt{ }$ & $\sqrt{ }$ & $\sqrt{ }$ & $\sqrt{ }$ \\
\hline \multicolumn{2}{|c|}{$\begin{array}{l}\text { Laboratório de } \\
\text { Informática }\end{array}$} & $\sqrt{ }$ & $\sqrt{ }$ & $\sqrt{ }$ & $\sqrt{ }$ & $\sqrt{ }$ & $\sqrt{ }$ \\
\hline \multicolumn{2}{|c|}{ Multimídia } & $\sqrt{ }$ & $\sqrt{ }$ & $\sqrt{ }$ & $\sqrt{ }$ & $\sqrt{ }$ & $\sqrt{ }$ \\
\hline
\end{tabular}

Fonte: elaboração própria a partir das observações e análise de documentos. 2016.

O PISA avalia as competências e habilidades dos estudantes no terço final da educação básica, examinando a preparação dos jovens de 15 anos para entrar no mercado de trabalho e, em certa medida, a eficácia dos sistemas educativos dos diferentes países. Como, no Brasil, entre os estudantes de 15 anos amostrados no PISA existe significativo atraso escolar, decidimos observar aulas nos três últimos anos do Ensino Fundamental, que, no Japão, antecedem à faixa etária avaliada no PISA. Tais anos correspondem ao $7^{\circ}, 8^{\circ}$ e $9^{\circ}$ anos do Ensino Fundamental, no Brasil, e aos três anos do Junior High School/申学校, no Japão. 
Buscamos observar pelo menos 10 aulas de cada professor que concordou em participar da pesquisa em cada escola. No entanto, por motivos como, por exemplo, incompatibilidade de horário, não autorização para filmagem ou observação das aulas no Japão, longo recesso por conta dos jogos olímpicos do Rio de Janeiro, este número de observações não pode ser contemplado em alguns casos. Praticamente a totalidade das aulas observadas no Japão foram gravadas em vídeo para posterior análise conjunta a um segundo observador nativo da Língua Japonesa, em razão das barreiras postas à pesquisadora pela dificuldade da língua para a perfeita compreensão linguística dos eventos observados nas salas de aulas.

No caso do Brasil, não houve a necessidade de filmagem das aulas observadas, visto que as barreiras linguísticas não se colocam neste caso. A pesquisa contou com o parecer favorável do Comitê de Ética da PUC-Rio, como pode ser consultado no Anexo A desta tese.

\subsection{2}

\section{A pauta de observação}

A construção da ficha de observação se baseou em algumas pesquisas educacionais nacionais e internacionais. O registro de aspectos preliminares da sala de aula e dos atores sociais envolvidos foi adaptado da ficha de observação do projeto Geres ${ }^{17}$. No entanto, as práticas docentes avaliadas na gestão da sala de aula e na promoção da aprendizagem dos estudantes em Ciências tiveram o PISA como referência. Basicamente, o foco da pauta de observação esteve posto em três dimensões principais: a utilização do tempo de aula, a ênfase curricular e o registro das práticas docentes.

\footnotetext{
${ }^{17}$ Trata-se de um estudo longitudinal de painel, com início em 2005, no qual a mesma amostra de escolas e de alunos foi observada ao longo de quatro anos. O Geres envolveu a associação entre cinco centros universitários com tradição em avaliação da educação, a saber: o Laboratório de Avaliação da Educação da PUC-Rio (LAEd), o Grupo de Avaliação e Medidas Educacionais da UFMG (GAME), o Laboratório de Avaliação da UNICAMP (LOED), a Linha de Pesquisa de Avaliação da Educação do Programa de Pós-Graduação em Educação da UFBA, o Centro de Avaliação da Educação da UFJF (CAEd) e a Universidade Estadual do Mato Grosso do Sul (UEMS).
} 


\subsubsection{1}

\section{O uso do tempo}

O questionário contextual dos estudantes no PISA apresenta um item relacionado ao número de aulas semanais de Ciências. Durante as observações, registramos não apenas o número de aulas semanais de cada escola, mas também os horários de início e término, oficial e efetivo, das aulas. As referências principais para a análise desta dimensão estão nos estudos comparados de Marcel Crahay (2002) e de Martin Carnoy (2009) que abordam aspectos relacionados ao uso do tempo.

Do estudo de Crahay (2002), que defende a igualdade de conhecimento como expressão de uma escola justa, tomamos como referência o conceito de Tempo Reservado à Ação Educativa (TRAE). O conceito expressa o tempo real alocado em atividades diretamente relacionadas ao processo de ensinoaprendizagem, descontando-se o tempo perdido com outras questões durante a aula, para nortear a análise dos dados colhidos com base na pauta de observação. A sentença que expressa o conceito é a seguinte:

$$
\text { TRAE }=\text { TO }- \text { TM }- \text { TE }- \text { TS, onde: }
$$

TRAE - Tempo Reservado à Ação Educativa

TO - Tempo oficial

TM - Tempo morto (Pausa, Inatividade e Interrupções)

TE - Tempo "perdido" na entrada

TS - Tempo "perdido" na saída

\subsubsection{2}

\section{As ênfases curriculares}

Os resultados das análises de DIF sugerem diferentes ênfases curriculares em Ciências, no Brasil e no Japão. Na pauta de observação, consideramos a ênfase curricular presente nas aulas observadas. Assim, buscamos registrar se os assuntos tratados estavam relacionados a:

a) Biologia;

b) Química;

c) Física. 


\subsubsection{3}

\section{As práticas docentes}

As práticas docentes observadas na gestão da sala de aula e na promoção da aprendizagem dos estudantes também tiveram sua origem no PISA. Essas práticas referem-se à frequência com a qual determinadas atividades têm lugar nas aulas de Ciências. Essas atividades dizem respeito, especificamente, à frequência com a qual:

1. Os estudantes são convidados a expor as suas ideias.

2. Os estudantes fazem experiências no laboratório.

3. O professor pede aos estudantes que imaginem como determinada questão científica poderia ser investigada em laboratório.

4. O professor pede aos estudantes que apliquem um conceito científico a problemas quotidianos.

5. Os estudantes são convidados a dar a sua opinião acerca dos temas tratados.

6. O professor pede aos estudantes que tirem conclusões de uma experiência por eles realizada.

7. O professor explica como uma noção científica se pode aplicar a vários fenômenos (por ex., ao movimento dos corpos ou a substâncias com propriedades idênticas).

8. Os estudantes têm permissão para conceber as suas próprias experiências.

9. Há um debate ou troca de ideias na aula.

10. As experiências são feitas pelo professor, a título de demonstração.

11. Os estudantes podem escolher os seus trabalhos de pesquisa.

12. O professor usa a Ciência para ajudar os estudantes a compreender o mundo exterior.

13. Os estudantes debatem os temas tratados.

14. Os estudantes fazem experiências seguindo as instruções do professor.

15. O professor explica de modo claro a importância dos conceitos científicos na vida de todos.

16. O professor pede aos estudantes que façam uma pesquisa para testarem as suas próprias ideias. 
17. O professor dá exemplos de aplicações tecnológicas para mostrar como a Ciência é importante para a sociedade.

A pauta de observação, na íntegra, pode ser vista no Anexo B deste documento.

\subsection{3 \\ O questionário do professor}

Inicialmente, a construção desse instrumento se referenciou nos modelos de questionários utilizados por avaliações externas nacionais e internacionais, como Saeb/Prova Brasil ${ }^{18}$, SARESP ${ }^{19}$, Geres e PISA. Nesse contexto, e baseado nas referências apresentadas a seguir, ficou estabelecido que o questionário contemplaria, entre outros, aspectos da formação, o tempo de serviço e forma de contratação, a idade, o sexo etc. dos professores.

Segundo Silva \& Lopes (2015) a certificação, apesar de ser um indicador importante da qualidade do professor, não consegue apontar evidências sobre a eficácia de sua prática pedagógica. $\mathrm{O}$ mesmo acontece com o número de anos de experiência docente, dado que a eficácia de um professor está referenciado num conjunto muito mais complexo de características que superam ou ultrapassam a qualidade da certificação profissional e o tempo de experiência em sala de aula.

Para variados autores, por exemplo, Hattie \& Timperley (2007), Marzano (2003), Danielson (2007), os professores são a mais poderosa influência no ensino e, por isso, o sistema educacional precisa ser concebido para assegurar a formação de professores eficazes. Contudo, resultados obtidos por vários autores, por exemplo, Joslin (1980), Harrison (1980) e Wade (1985), a partir da análise de programas de formação de professores, revelaram existir uma relação menor do que seria de esperar entre a aprendizagem dos professores, durante o desenvolvimento profissional, a sua prática e, consequentemente, a melhoria da

\footnotetext{
${ }^{18}$ A Prova Brasil e o Sistema Nacional de Avaliação da Educação Básica (Saeb) são avaliações para diagnóstico, em larga escala, desenvolvidas pelo Instituto Nacional de Estudos e Pesquisas Educacionais Anísio Teixeira (Inep/MEC). Têm o objetivo de avaliar a qualidade do ensino oferecido pelo sistema educacional brasileiro a partir de testes padronizados e questionários socioeconômicos.

${ }^{19}$ O Sistema de Avaliação de Rendimento Escolar do Estado de São Paulo (SARESP) é aplicado pela Secretaria da Educação do Estado de São Paulo com a finalidade de produzir um diagnóstico da situação da escolaridade básica paulista, visando orientar os gestores do ensino no monitoramento das políticas voltadas para a melhoria da qualidade educacional.
} 
aprendizagem dos estudantes. Os resultados obtidos por estes autores revelam que o desenvolvimento profissional tem elevadas probabilidades de alterar a aprendizagem do professor (82\%), mas que os saberes adquiridos têm menor efeito sobre o seu comportamento (73\%) e ainda menor influência (65\%), apesar de ainda bastante positiva na aprendizagem dos estudantes. De acordo com Guskey \& Yoon (2009), a síntese das investigações sobre esta temática confirma a dificuldade em traduzir o desenvolvimento profissional em ganhos na aprendizagem dos estudantes, o que conduz os autores a salientar a necessidade de os responsáveis pela planificação e implementação do desenvolvimento profissional dos professores avaliarem criticamente a formação que oferecem, além de refletirem sobre o que realmente apresenta evidências positivas para a aprendizagem dos estudantes. Esta constatação tem conduzido ao desenvolvimento de investigações sobre as características da formação que se revelam mais eficazes na alteração do conhecimento profissional dos professores, com o objetivo de conseguir que os conhecimentos e competências por eles adquiridos e/ou reconstruídos, nessa formação, tenham uma maior repercussão na superação de práticas menos eficazes e na melhoria da aprendizagem dos estudantes (LOPES \& SILVA, 2010; SILVA \& LOPES, 2015).

De acordo com Timperley, Wilson, Barrar \& Fung (2007), a formação que assegura resultados eficazes decorre de períodos de tempo alargados e caracterizase pelo envolvimento direto dos professores em atividades que lhes possibilitam aprofundar os seus conhecimentos e desafiar o seu discurso e as suas concepções acerca da aprendizagem, no sentido e os desafiam a de aprender como ensinar de forma eficaz.

A necessidade de desenvolvimento profissional do professor, entendido como uma atividade deliberada e com objetivos explícitos de renovação de ideias e de práticas, é considerada fundamental para a melhoria da qualidade do ensino (GUSKEY \& HUBERMAN, 1995). Neste processo, é fundamental o professor dedicar tempo para reflexão com os seus pares, a fim de melhorar o seu próprio repertório de competências (FLEISCHMAN, 2012). Isto porque, segundo esses autores, o mais eficaz desenvolvimento profissional não tem origem na implementação de um determinado conjunto de práticas, por mais que elas sejam consideradas melhores que as anteriores, mas decorre da adaptação cuidadosa de 
práticas variadas ao conteúdo específico a ensinar e aos elementos do contexto escolar e social (GUSKEY \&YOON, 2009).

Isto envolve a oferta de condições para que os professores, de uma forma colaborativa, investiguem, experimentem, analisem de forma reflexiva a sua prática e tomem decisões conjuntas sobre o que e como fazer para melhorar a aprendizagem dos seus estudantes. Este trabalho colaborativo e em equipe, com vistas ao desenvolvimento profissional, precisa, segundo esses autores, ser desenvolvido no seio de Comunidades de Prática ou Comunidades de Aprendizagem (DUFOUR \& EAKER, 1998; HORD, 1997; WENGER, 1998).

Levando em conta também estas referências, além das do PISA, o questionário do professor foi dividido em três blocos. O primeiro, com o objetivo de traçar o perfil dos professores participantes, coleta informações dos professores, tais como: sexo, idade, graduação, experiência e modo de contratação. Em seguida, apresentamos aos professores algumas questões relativas à sua participação em vários tipos de formação continuada e o impacto dessas atividades na sua prática.

O terceiro bloco é dedicado ao recolhimento de informações sobre o Letramento Científico e é, portanto, nele que resgatamos os itens do PISA listados na subseção anterior e enfatizados nas nossas análises.

Assim como a ficha de observação, o questionário do professor também está disponível nos anexos deste documento (Anexo C).

\subsection{4}

\section{A análise da prática pedagógica}

O passo inicial para a análise dos dados obtidos a partir das observações e do questionário do professor foi a leitura cuidadosa da estrutura conceitual do PISA, como visto no capítulo 1 . O processo de ensino e aprendizagem de Ciências no PISA é investigado com foco nas estratégias de ensino utilizadas na escola e em sua variação nos diferentes tipos de educação e escolas participantes do Programa. Para tanto, o Programa criou quatro escalas a partir das 17 atividades descritas anteriormente, que permitem caracterizar o processo de Letramento Científico dos estudantes. As categorias utilizadas pelo Programa e também por 
nós na análise dos dados foram as seguintes: Interação, Experimentação, Investigação e Aplicação.

A categoria Interação envolve, sobretudo, as atividades relacionadas à participação ativa dos estudantes na aula. A Experimentação tem como referência o exercício dos experimentos, uso do laboratório de Ciências etc. A dimensão Investigação visa a investigar o grau de autonomia dos estudantes para buscar e construir conhecimento. Por fim, a Aplicação está mais relacionada ao uso da Ciência e, consequentemente, com sua importância para a sociedade. A distribuição das atividades entre as categorias elencadas pelo Programa pode ser mais bem visualizada no quadro a seguir (Quadro 3).

Quadro 3. Categorias de análise do Letramento Científico no PISA 2006.

\begin{tabular}{|c|c|c|}
\hline \multicolumn{2}{|l|}{ Índice } & Atividades \\
\hline $\begin{array}{l}\text { Interação } \\
\text { Scinteract }\end{array}$ & - & $\begin{array}{l}\text { 1. Os estudantes são convidados a expor as suas ideias. } \\
\text { 2. Os estudantes são convidados a dar a sua opinião } \\
\text { acerca dos temas tratados. } \\
\text { 3. Há um debate ou troca de ideias na aula. } \\
\text { 4. Os estudantes debatem os temas tratados. }\end{array}$ \\
\hline $\begin{array}{l}\text { Hands-on } \\
\text { Schands }\end{array}$ & - & $\begin{array}{l}\text { 1. Os estudantes fazem experiências no laboratório. } \\
\text { 2. O professor pede aos estudantes que imaginem como } \\
\text { determinada questão científica poderia ser investigada } \\
\text { em laboratório. } \\
\text { 3. O professor pede aos estudantes que tirem conclusões } \\
\text { de uma experiência por eles realizada. } \\
\text { 4. As experiências são feitas pelo professor, a título de } \\
\text { demonstração. } \\
\text { 5. Os estudantes fazem experiências seguindo as } \\
\text { instruções do professor. }\end{array}$ \\
\hline $\begin{array}{l}\text { Investigação } \\
\text { Scinvest }\end{array}$ & - & $\begin{array}{l}\text { 1. O professor pede aos estudantes que apliquem um } \\
\text { conceito científico a problemas quotidianos. } \\
\text { 2. Os estudantes têm permissão para conceber as suas } \\
\text { próprias experiências. } \\
\text { 3. Os estudantes podem escolher os seus trabalhos de } \\
\text { pesquisa. } \\
\text { 4. O professor pede aos estudantes que façam uma } \\
\text { pesquisa para testarem as suas próprias ideias. }\end{array}$ \\
\hline $\begin{array}{l}\text { Aplicação } \\
\text { Scapply }\end{array}$ & - & $\begin{array}{l}\text { 1. O professor explica como uma noção científica se pode } \\
\text { aplicar a vários fenômenos (por ex., ao movimento dos } \\
\text { corpos ou a substâncias com propriedades idênticas). } \\
\text { 2. O professor usa a Ciência para ajudar os estudantes a } \\
\text { compreender o mundo exterior. } \\
\text { 3. O professor explica de modo claro a importância dos } \\
\text { conceitos científicos na vida de todos. } \\
\text { 4. O professor dá exemplos de aplicações tecnológicas } \\
\text { para mostrar como a Ciência é importante para a } \\
\text { sociedade. }\end{array}$ \\
\hline
\end{tabular}

Fonte: elaboração própria a partir de OCDE, 2007. 2015. 
Uma escala de quatro pontos, que envolvem as seguintes categorias de resposta "em todas as aulas", "na maioria das aulas", "em algumas aulas" e "nunca ou quase nunca", foi usada para cada um desses itens. No PISA, os quatro construtos estão positivamente correlacionados entre si, mas as correlações mais elevadas são encontradas, no entanto, entre SCINTACT e SCINVEST e entre SCHANDS e SCINVEST. A consistência interna de todas as quatro escalas é satisfatória em todos os países e assume valores entre 0,70 e 0,80 (OCDE, 2009).

Os mesmos construtos e categorias de análise foram utilizados nas análises dos dados obtidos a partir das observações e do questionário do professor. Em suma, nossos objetivos específicos nessa segunda e final etapa do trabalho foram principalmente: a) observar o uso do tempo das aulas de Ciências das séries finais do Ensino Fundamental; b) observar se nas aulas de Ciências desses países ocorrem, e com que frequência, atividades relacionadas à interação, investigação, experimentação e aplicação; c) buscar entender na perspectiva dos professores observados que atividades, e com que frequência, admitem realizar nas suas aulas; e d) buscar entender, com a ajuda de especialistas e gestores, a tamanha diferença de desempenho entre o Brasil e o Japão no PISA.

Sendo assim, com o trabalho de campo buscamos responder as seguintes questões:

1. A partir das observações, qual é o Tempo Reservado à Ação Educativa de Ciências no Brasil e no Japão?

2. A frequência com que ocorrem, do ponto de vista dos estudantes participantes do PISA, as atividades de ensino aprendizagem de Ciências afetam o desempenho dos estudantes brasileiros e japoneses em Ciências no Programa?

3. Com que frequência essas atividades acontecem nas aulas de Ciências observadas no Brasil e no Japão? As aulas de Ciências desses dois países concentram mais atividades características de alguma das escalas elaboradas pelo PISA (interação, experimentação, investigação e aplicação)?

4. Os professores observados assumem fazer uso dessas atividades nas suas aulas? Com que frequência?

5. Por que o desempenho do Brasil e do Japão no Pisa é tão diferente? Que lições podem ser extraídas da experiência japonesa? 
Para responder as questões postas acima, buscamos conduzir as análises sob duas lógicas principais: uma descritiva e outra explicativa. A primeira está guiada principalmente pela discussão dos resultados do PISA, ou seja, pelas respostas dos estudantes às questões propostas no questionário contextual do estudante na avaliação internacional. Neste caso, investigamos as correlações das frequências dos métodos/práticas pedagógicos com o desempenho dos estudantes e o tempo dedicado ao Ensino de Ciências. Na segunda dimensão, buscando explicar os resultados encontrados na pesquisa, a partir da observação das aulas e dos questionários respondidos pelos professores; e, buscando verificar se as práticas que impactam o desempenho dos estudantes no PISA são especialmente frequentes nas aulas de Ciências observadas nesses dois países e se são assumidas pelos professores nos questionários.

Os resultados de todas as análises, das análises de DIF que deram início aos questionamentos delineados nesta tese até a análise qualitativa, nos ajudam a explicar o comportamento diferencial dos itens de Ciências do PISA, bem como as marcantes diferenças de desempenho nesta avaliação entre estudantes brasileiros e japoneses e são apresentadas nos três capítulos seguintes. No capítulo quatro, apresentaremos e compararemos os resultados do Brasil e do Japão nas duas edições do PISA que deram maior ênfase à área de Ciências. Serão abordados a média geral em Ciências, os Níveis de proficiência do PISA, médias nas competências e áreas do conhecimento. No capítulo cinco, serão apresentados os resultados das análises de DIF e, por fim, no capítulo seis, os resultados da pesquisa de campo. 


\section{4 \\ Resultados de Brasil e Japão no PISA}

O objetivo principal deste capítulo é comparar o desempenho dos estudantes brasileiros com o desempenho de outros estudantes participantes do PISA 2006 e 2015, sobretudo com o dos estudantes japoneses. Utilizamos aqui os dados dessas duas edições da avaliação internacional devido ao fato de, nesses anos, a área de Ciências ter sido contemplada mais detalhadamente. Ou seja, além da escala global, foi possível verificar, a partir dos dados produzidos pelo PISA, o desempenho dos estudantes também em diferentes competências em Ciências.

Para a edição de 2006 do Programa, em particular, foram considerados elegíveis os estudantes nascidos entre $1^{\circ}$ de maio de 1990 e 30 de abril de 1991. Para a de 2015 aqueles num intervalo de 15 anos e três meses e 16 anos e dois meses que tivessem completado pelo menos seis anos de escolaridade quando da aplicação do teste. Levando-se em consideração que os jovens brasileiros de 15 anos no primeiro semestre deveriam, de acordo com o MEC, estar matriculados no $1^{\circ}$ ano do Ensino Médio, considera-se aqueles de mesma idade matriculados em séries anteriores como defasados.

O PISA avaliou, no Brasil, estudantes da $7^{\mathrm{a}}$ série $/ 8^{\circ}$ ano do Ensino Fundamental até o $3^{\circ}$ ano do Ensino Médio em 2006. À época da aplicação do teste, prevalecia no Brasil o Ensino Fundamental de oito anos escolares. Sendo assim, os estudantes brasileiros matriculados no $9^{\circ}$ ano, nesta edição do Programa, correspondem aos estudantes do $1^{\circ}$ ano do Ensino Médio.

Esta é uma das razões do descompasso entre o Brasil e outros países da OCDE, uma vez que na maioria deles o último ano, o que encerra a educação básica, é o $10^{\circ}$ ano escolar. Essa também foi a razão do descompasso do Japão, país no qual o $10^{\circ}$ ano escolar corresponde ao $1^{\circ}$ ano do Ensino Médio brasileiro, uma vez que aquele país há muito possui Ensino Fundamental com duração de nove anos.

Os estudos de avaliação educacional partem da premissa de que a escolarização é um produto desigualmente distribuído, que responde às condições socioeconômicas e culturais e ao contexto regional (BRASIL, 2001). A próxima seção é dedicada à apresentação das principais diferenças nos aspectos mais gerais dos sistemas educacionais do Brasil e do Japão. 
Antes de abordarmos aspectos específicos dos sistemas educacionais, apresentaremos muito sucintamente os principais indicadores socioeconômicos desses dois países. Para caracterizar o desenvolvimento socioeconômico do Brasil e do Japão, assim como feito no relatório nacional do PISA 2000 (BRASIL, 2001), faremos uso de três indicadores, a saber: o Produto Interno Bruto (PIB) per capita ajustado pelo poder de compra ${ }^{20}$, o Índice de Desenvolvimento Humano $(\text { IDH })^{21}$ e o índice de Gini para a distribuição de renda ${ }^{22}$ (Tabela 2).

Tabela 2. Indicadores econômicos e sociais de Brasil e Japão

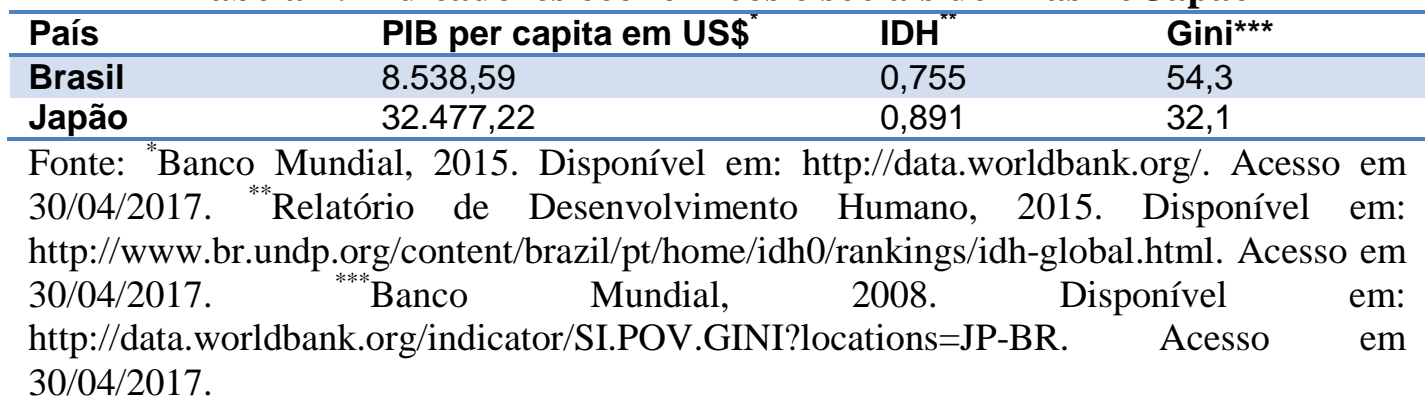

O PIB per capita do Japão, ou seja, o valor total da produção de bens e serviços deste país, é quase quatro vezes maior do que o do Brasil.

O Japão é considerado um país de alto desenvolvimento humano. O IDH é representado pela longevidade da população, seu grau de conhecimento e sua renda. O índice do Japão é de 0,891 enquanto que o do Brasil, país com grau médio de desenvolvimento humano, é de 0,755.

A distância entre os dois países fica mais clara quando se leva em conta o índice de Gini, que mede a desigualdade na distribuição de renda. O Brasil é um dos países com maior desigualdade na distribuição de renda, com índice de Gini

\footnotetext{
${ }^{20}$ PIB per capita é o valor total da produção de bens e serviços de um país. Os dados são calculados

com base no poder de compra da moeda local e são convertidos para o poder de compra do dólar americano (BRASIL, 2001).

${ }^{21}$ O Índice de Desenvolvimento Humano (IDH), calculado segundo metodologia do Programa das Nações Unidas para o Desenvolvimento (PNUD), representa três características desejáveis e esperadas do processo de desenvolvimento humano: 1) a longevidade da população - expressa pela esperança de vida; 2) seu grau de conhecimento - traduzido por duas variáveis educacionais: a taxa de alfabetização de adultos e a taxa combinada de matrícula nos três níveis de ensino; e 3) sua renda ou PIB per capita, ajustada para refletir a paridade do poder de compra entre países. O índice situa-se entre os valores 0 (zero) e 1 (um). Segundo a classificação internacional utilizada, os países são agrupados em três categorias: países de alto desenvolvimento humano, quando o índice for superior a 0,800; países com grau médio de desenvolvimento humano, para valores de 0,500 a 0,800; e os países com baixo grau de desenvolvimento humano, quando o IDH for inferior a 0,500 (BRASIL, 2001).

${ }^{22} \mathrm{O}$ índice de Gini mede a desigualdade na distribuição de renda. Apresenta valores no intervalo 0 (perfeita igualdade) a 100 (máxima desigualdade), quando então é interpretado como se toda a renda fosse apropriada por uma única pessoa (BRASIL, 2001).
} 
bastante elevado (51,5 em 2015), mostrando-se muito alto em comparação não apenas com o Japão mas também com os padrões internacionais.

\section{1}

\section{Aspectos gerais do Sistema Educacional de Brasil e Japão}

A educação básica brasileira é obrigatória dos 4 aos 17 anos de idade e compreende a Educação Infantil, o Ensino Fundamental, o Ensino Médio e a Educação de Jovens e Adultos. No Japão, a frequência nas escolas só é obrigatória a partir dos 6 anos de idade e restrita apenas ao Ensino Fundamental, que tem duração de 9 anos. Isto significa que a educação básica no Japão se restringe ao Ensino fundamental, enquanto no Brasil incorpora o Ensino Médio. Apesar de a obrigatoriedade escolar no Japão abranger apenas o Ensino Fundamental, mais de 98\% de todos os estudantes que concluem este nível ingressam no Ensino Médio. A Figura 5 compara esquematicamente os sistemas educacionais de Brasil e Japão.

Figura 5. Sistema Educacional Básico de Japão e Brasil.
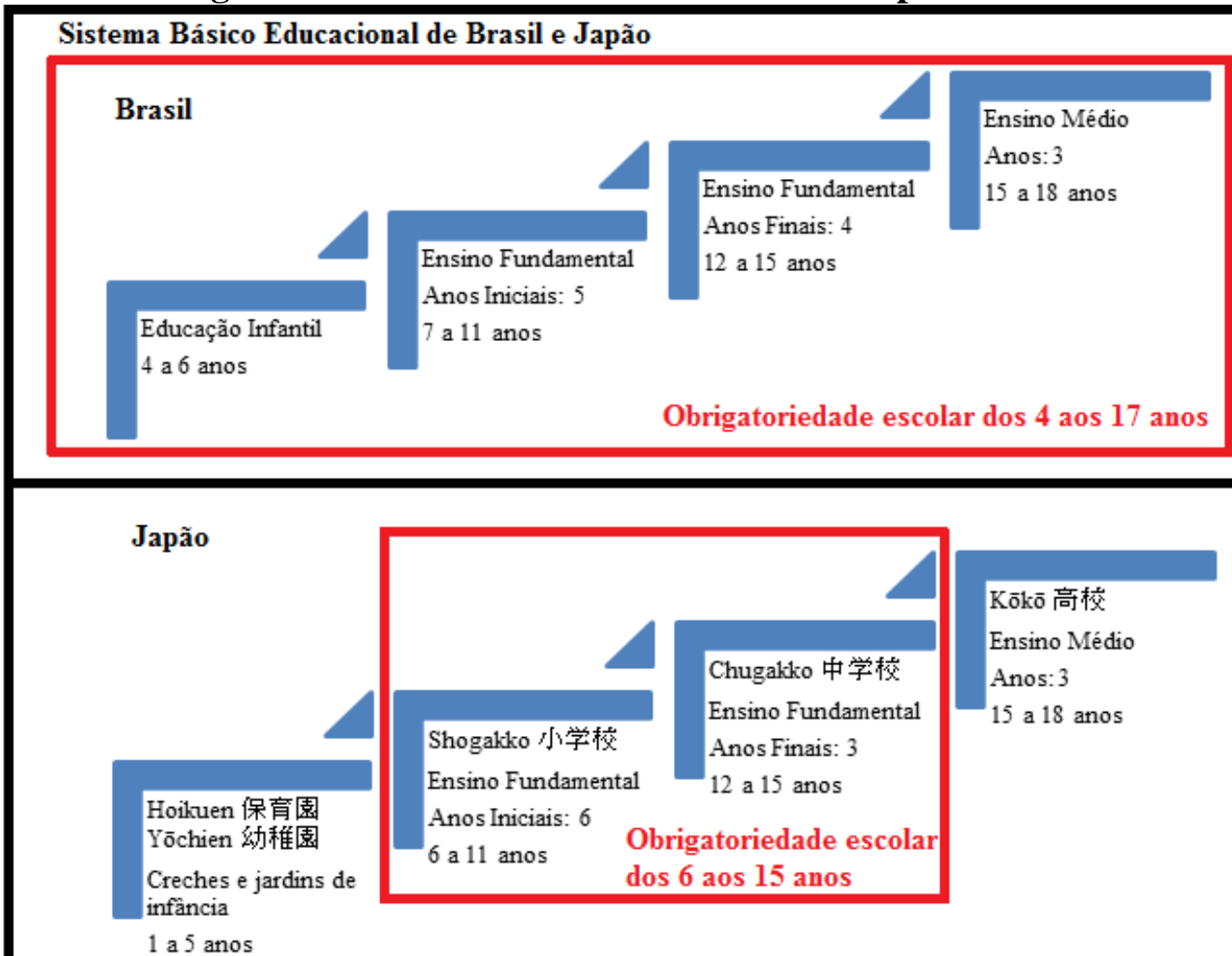

Fonte: Elaboração própria a partir da análise de documentos. 2016. 
Como podemos observar, a partir da Figura 5, a educação prévia ao ensino primário, no Japão, é fornecida nos jardins de infância (yochien) e creches (hoikuen). As creches públicas e privadas aceitam crianças de 1 a 5 anos de idade, e suas propostas para as crianças de 3 a 5 anos são semelhantes às dos jardins de infância brasileiros. De acordo com informações disponíveis no site da embaixada do Japão no Brasil ${ }^{23}$, aproximadamente $60 \%$ de todos os jardins de infância japoneses são particulares. A frequência total de crianças de 5 anos nos jardins de infância e creches é de mais de 95\%. Assim como no Brasil, a proposta educacional nos jardins de infância japoneses varia consideravelmente, indo de ambientes sem estrutura definida e com foco em brincadeiras, até ambientes altamente estruturados com foco no treinamento cognitivo.

O Ensino Fundamental, tanto no Brasil quanto no Japão tem nove anos de duração. No entanto, no Brasil, os "anos iniciais" do Ensino Fundamental somam 5 anos, enquanto no Japão eles são chamados de Shōgakkō (小学校), em japonês, ou Elementary School em inglês, e têm duração de 6 anos. Os "Anos Finais" no Brasil compreendem, portanto, os últimos 4 anos do Ensino Fundamental, nomeadamente o $6^{\circ}, 7^{\circ}, 8^{\circ}$ e $9^{\circ}$ ano escolar. No Japão são 3 anos, do $1^{\circ}$ ao $3^{\circ}$ ano escolar do Chūgakkō (中学校) ou Junior High School.

Em razão da idade dos estudantes avaliados pelo PISA, o foco das nossas análises se centrará no segundo segmento do Ensino Fundamental dos dois países. Mais especificamente, nos três últimos anos desta etapa do ensino que a OCDE considera como o final da escolarização básica. Consideramos também que o PISA avalia o conhecimento adquirido ao longo de todo o Ensino Fundamental já que aplica o teste aos estudantes matriculados, em sua maioria, no primeiro ano do Ensino Médio, no início do ano letivo.

O currículo padrão japonês das séries finais do Ensino Fundamental inclui as seguintes matérias obrigatórias: língua japonesa, estudos sociais, matemática, ciências, uma língua estrangeira (quase sempre inglês), música, belas artes, saúde e educação física, e artes industriais ou serviços domésticos. As exigências curriculares também incluem atividades extraclasse, um curso de educação moral e estudos integrados.

\footnotetext{
${ }^{23}$ http://www.br.emb-japan.go.jp/cultura/educacao.html. Acesso em 03/08/2016.
} 
No Brasil, os Parâmetros Curriculares Nacionais incluem língua portuguesa, matemática, ciências naturais, geografia, história, arte, educação física, língua estrangeira e alguns temas transversais como pluralidade cultural, meio ambiente, saúde e orientação sexual ${ }^{24}$.

O ano letivo da educação básica no Brasil tem a duração de 200 dias, normalmente distribuídos nos meses de fevereiro a dezembro, com férias escolares em julho e janeiro. No entanto, o ano letivo não precisa necessariamente iniciar e terminar no mesmo ano civil, podendo completar os 200 dias letivos no ano civil/fiscal subsequente.

Já o ano letivo japonês, assim como o ano fiscal, começa em abril e termina em março do ano seguinte. Em agosto, os japoneses têm as férias de verão, que duram, em média, seis semanas. Na primavera e inverno, tem férias mais curtas que duram, em média, duas semanas cada uma.

Ao contrário do Brasil, em que o ano letivo divide-se em 4 bimestres, no Japão, o ano letivo é dividido em três períodos: Ichigakki (abril a julho), Nigakki (setembro a dezembro) e Sangakki (janeiro a março), que são intercalados com as férias de verão, inverno e primavera. A jornada escolar no Ensino Fundamental brasileiro inclui, pelo menos, quatro horas de trabalho diário em sala de aula, enquanto no Japão, essa jornada tem duração de 6 horas.

Por fim, e talvez a maior e mais marcante diferença entre os sistemas educacionais do Brasil e do Japão, está a política de promoção e reprovação de estudantes. Iniciaremos nossa apresentação dos resultados do PISA pela abordagem da defasagem idade-série que constitui uma das dimensões das desigualdades educacionais e, junto com o desempenho, um dos problemas mais visados pelas políticas públicas federais, estaduais e municipais. E Também pelo fato de a literatura especializada mostrar que a reprovação não é a melhor solução para os problemas de ensino-aprendizagem no Brasil, além de se mostrar uma medida negativa para o desempenho em Ciências no PISA, principalmente porque esses estudantes não teriam tido a oportunidade de aprender o que é tipicamente avaliado pelo PISA entre jovens de 15 anos de idade.

\footnotetext{
${ }^{24}$ Para o Ensino Médio está em discussão no Brasil a Base Nacional Curricular Comum (BNCC) que vai definir o conteúdo mínimo e as disciplinas obrigatórias que estarão obrigatoriamente nesse segmento de ensino. A reforma do Ensino Médio, contudo, foi aprovada em 08/02/2017 pelo Senado e o texto, sancionado pelo presidente em exercício Michel Temer em 16/02/2017, foi inicialmente colocado em vigor como Medida Provisória (MP 746). O texto final manteve todos os eixos do original.
} 


\section{2}

\section{A defasagem idade-série}

Somente na década de 90, o Brasil conseguiu completar o processo de universalização do Ensino Fundamental. Ao lado dos recentes progressos reais, tanto na multiplicação quanto no uso dos recursos educacionais, um olhar retrospectivo revela o caráter discriminatório do desenvolvimento da escola de massa no Brasil. A alta taxa de reprovação, por exemplo, é um problema que há muito assola a educação brasileira (FREITAS, 1947; BRANDÃO, BAETA E ROCHA, 1983; COSTA-RIBEIRO, 1991; ALVES, ORTIGÃO E FRANCO, 2007; CORREA, BONAMINO \& SOARES, 2014). Ainda que este problema tenha diminuído no Brasil, em especial durante parte da década de 1990, a não aprovação (reprovação e abandono) tem persistido com patamares extremamente elevados. Os resultados do PISA 2009, por exemplo, colocaram o Brasil em forte evidência ao revelar que $40 \%$ dos estudantes brasileiros repetem ao menos uma vez ao longo da educação básica (OCDE, 2010).

Relatórios mais atuais do PISA sugerem que a repetência é uma política dispendiosa, que às vezes é usada como uma forma de punição para sancionar o mau comportamento na escola, e que pode reforçar as desigualdades na educação, porque estudantes sócio-economicamente desfavorecidos repetem com mais frequencia do que os mais favorecidos (OCDE, 2013a; OCDE, 2013b; OCDE, 2015). Apesar de o percentual de estudantes que relataram ter repetido um ano letivo ter diminuído durante a última década, os percentuais ainda são altos. Em 2003, na média dos países da OCDE, 20\% dos estudantes avaliados declararam ter repetido um ano escolar pelo menos uma vez, enquanto em 2012 a percentagem de repetentes auto-relatados caiu para 12\% (OECD, 2013a).

No Brasil, a edição de 2012 revelou que mais de um em cada três estudantes de 15 anos de idade (36\%) tinha repetido uma série pelo menos uma vez, registrando, assim, uma das mais altas taxas de repetência entre os países que participam no PISA (OCDE, 2012). Entre as edições de 2003 e 2012, a proporção de estudantes brasileiros de 15 anos de idade que haviam repetido uma série no Ensino Fundamental diminuiu, mas a prevalência de repetência aumentou no Ensino Médio, mantendo, assim, a média geral estável. 
Na edição de 2006 do PISA, avaliada detalhadamente nesta Tese, 40,9\% dos estudantes brasileiros participantes da avaliação estavam matriculados na série correspondente a sua faixa etária, ou seja, o $9^{\circ}$ ano escolar que, na época de aplicação do teste, correspondia ao $1^{\circ}$ ano do Ensino Médio no país (Tabela 3).

Tabela 3. Distribuição percentual dos estudantes nos anos escolares avaliados no PISA 2006 e 2015: Brasil e Japão

\begin{tabular}{ccccccc}
\hline \multirow{2}{*}{ Países } & \multicolumn{7}{c}{ Ano Escolar } \\
\cline { 2 - 7 } Brasil (2006) & $\mathbf{7}^{\mathbf{0}}$ & $\mathbf{8}^{\mathbf{0}}$ & $\mathbf{9}^{\mathbf{0}}$ & $\mathbf{1 0}^{\mathbf{0}}$ & $\mathbf{1 1}^{\mathbf{0}}$ & $\mathbf{1 2}^{\mathbf{0}}$ \\
Brasil (2015) & 3,7 & 26,3 & $\mathbf{4 0 , 9}$ & 17,7 & 0,8 & $\mathrm{X}$ \\
Japão & 6,5 & 12,4 & $\mathbf{3 7 , 7}$ & 37,2 & 3,3 \\
(2006 e 2015) & 0 & 0 & 0 & $\mathbf{1 0 0}$ & 0 & 0 \\
\hline
\end{tabular}

Fonte: elaboração própria a partir dos resultados do PISA 2006 e 2015.

Levando-se em consideração apenas os dois anos de escolaridade que antecedem o $9^{\circ}$ ano, que é a série em que deveria estar matriculada a totalidade dos estudantes brasileiros de 15 anos de idade, a Tabela 2 mostra que o Brasil somava, na edição de $2006,40,6 \%$ de estudantes ainda matriculados no $7^{\circ}$ e no $8^{\circ}$ ano do Ensino Fundamental ${ }^{25}$. Estudantes defasados em mais de dois anos, isto é retidos nos anos escolares anteriores ao $7^{\circ}$ ano escolar, não são, portanto, contemplados pelo PISA, embora dados do Censo Escolar mostrem que 29\% dos jovens de 15 anos estavam fora da escola e cerca de 50\% estavam defasados na época (BRASIL, 2006).

Em 2015, já com o Ensino Fundamental de 9 anos em pleno funcionamento no Brasil (Lei no 11.274, de 6 de fevereiro de 2006), os estudantes em fase, isto é, aqueles matriculados no $1^{\circ}$ ano do Ensino Médio, equivalente ao $10^{\circ}$ ao escolar, somam $37,7 \%$ dos 23.141 estudantes participantes. O percentual de estudantes defasados é de $22,5 \%$, ainda muito alto, mas bem menor do que o observado em 2006.

O INEP (BRASIL, 2016) afirma que ao longo dos 15 anos passados desde a primeira aplicação do PISA no Brasil, o país tem melhorado significativamente a qualidade das estatísticas oficiais em educação. "Até 2006, por exemplo, a unidade básica da coleta de dados do Censo Escolar era a escola" (BRASIL, 2016,

\footnotetext{
${ }^{25} \mathrm{~A}$ distorção idade-série é a proporção de alunos com mais de dois anos de atraso escolar. Atualmente, no Brasil, a criança deve ingressar no $1^{\circ}$ ano do ensino fundamental aos seis anos de idade, permanecendo no Ensino Fundamental até o $9^{\circ}$ ano, com a expectativa de que conclua os estudos nesta modalidade até os 14 anos de idade. O cálculo da distorção idade-série é realizado a partir de dados coletados no Censo Escolar. Todas as informações de matrículas dos alunos são capturadas, inclusive a idade deles.
} 
p. 27). Segundo o INEP (BRASIL, 2016), com a adoção do Educacenso ${ }^{26}$, que estabelece como unidades de investigação, além da escola, o estudante e o professor, passaram a ser utilizadas informações mais precisas sobre os estudantes de 15 anos elegíveis para o PISA.

Com a ampliação do Ensino Fundamental para nove anos de duração (Lei ${ }^{\circ}$ 11.274, de 6 de fevereiro de 2006), a amostra do PISA em 2015 incluiu estudantes com idade elegível a partir do $7^{\circ}$ ano escolar. A transição do Ensino Fundamental de oito para nove anos abrangeu três ciclos do PISA, mas não se observam diferenças expressivas na distribuição de estudantes nesses ciclos mesmo com a inclusão do $7^{\circ}$ ano na amostra de 2015 (BRASIL, 2016).

De fato, o percentual de matrículas de jovens de 15 anos nas séries avaliadas pelo PISA e a taxa de cobertura, isto é, o número de estudantes participantes na avaliação dividido pelo número total estimado de brasileiros com 15 anos aumentou consideravelmente em cada edição do PISA no Brasil (BRASIL, 2016). "Enquanto, em 2003, um total de 2.359.854 jovens de 15 anos estavam matriculados a partir da $7^{\mathrm{a}}$ série $/ 8^{\circ}$ ano do Ensino Fundamental, em 2015, mais de 2,8 milhões cursavam as séries elegíveis para a avaliação (BRASIL, 2016, p. 28).

Ainda de acordo com os dados da Tabela 3, é possível perceber um aumento considerável de estudantes brasileiros matriculados nas séries finais do Ensino Médio. Eram 18,5\% em 2006 e 40,5\% em 2015; mais que o dobro. Essa diferença, no entanto, pode ser explicada através da mudança no mês de aplicação do teste do PISA que implica em uma mudança da composição dos alunos em relação às diversas séries. A primeira edição do PISA (2000) no país foi aplicada em outubro, as duas seguintes (2003 e 2006) em agosto e, desde 2009 o Brasil tem aplicado o PISA no mesmo mês, em Maio. Essa mudança teria feito com que mais alunos na faixa etária de 15 anos estivessem matriculados em séries mais avançadas. Como destacado por Klein (2011), a estabilidade das datas de aplicação da avaliação é importante para melhor comparabilidade dos resultados e um fiel diagnóstico da composição do alunado entre as séries avaliadas no PISA. Segundo o autor, "o mais apropriado seria selecionar os alunos pela idade escolar de 15 anos do país considerado e realizar a aplicação em um número fixo de

\footnotetext{
${ }^{26}$ Portaria MEC n ${ }^{\circ} 316$, de 4 de abril de 2007.
} 
meses após o início do ano letivo. Essa regra deveria valer para todos os países e para todos os anos.” (KLEIN, 2011, p.719).

Apesar do "avanço", de acordo com o INEP (BRASIL, 2016) os números também refletem que o trabalho educacional de inclusão de jovens de 15 anos no sistema escolar ainda é um desafio ao país. "Com base nos dados de 2015, em torno de $17 \%$ deles estavam fora da escola ou matriculados no $6^{\circ}$ ano ou em séries inferiores" (BRASIL, 2016, p. 28). De fato, numa perspectiva internacional (OCDE, 2007; 2016), em termos de reprovação, o Brasil ocupava a segunda pior posição entre todos os países avaliados pelo PISA 2006 e ocupa a terceira pior entre os países avaliados na edição de 2015.

De maneira geral, os países que apresentam menor média em avaliações internacionais são, justamente, aqueles que apresentam os maiores índices de defasagem escolar. Os altos índices de atraso saem caro para países como o Brasil, não apenas por implicar em custos, inclusive a despesa de um ano escolar adicional para o estudante, mas também para a sociedade e, ainda, como reforça a OCDE (2011), por atrasar o cidadão em, pelo menos, um ano no tocante à finalização da escolaridade básica e ao acesso ao mundo do trabalho.

No Japão não há reprovação. 100\% dos estudantes japoneses em ambas as edições do Programa estavam devidamente matriculados no $10^{\circ}$ ano escolar, ou seja, no $1^{\circ}$ ano do Ensino Médio.

Nas subseções a seguir apresentaremos os resultados do PISA 2006 e 2015, enfatizando as médias gerais da OCDE, do Japão, e do Brasil em quatro dimensões:

1. geral: todos os estudantes participantes do teste

2. estudantes defasados: aqueles matriculados no Ensino Fundamental

3. estudantes em fase: aqueles matriculados na primeira série do Ensino Médio

4. estudantes adiantados: aqueles matriculados nas segunda e terceira séries do Ensino Médio. 


\section{3}

\section{A média geral em Ciências}

Diferentemente do Japão, durante a maior parte do século XX, o Brasil apresentou indicadores educacionais bastante desfavoráveis, não só em comparação com países europeus, mas também em comparação com a maior parte dos países latino-americanos (FRANCO et al, 2007).

A comparação dos resultados obtidos pelos estudantes brasileiros coloca o país em situação de desvantagem em relação a quase todos os países que participam do PISA. Os resultados dos desempenhos no Programa em cada domínio do conhecimento são fornecidos em uma escala na qual a média das médias dos países da OCDE é padronizada em 500, com 100 de desvio padrão. Isso significa que, aproximadamente, dois terços dos estudantes participantes obtiveram uma pontuação entre 400 e 600 pontos. Para calcular essa média, considerou-se como se todos os países tivessem mil estudantes participantes, a fim de evitar que a média da OCDE se inclinasse para os países com maior número de estudantes.

Ao compararmos a média obtida pelo Brasil (390) com a dos demais países participantes do PISA 2006, é possível perceber que o Brasil está entre os países com desempenho mais baixo, ocupando o $52^{\circ}$ lugar entre os 57 países submetidos ao exame nesta edição. O país ficou posicionado à frente apenas da Colômbia $\left(53^{\circ}\right.$ colocado), entre os países Sul-Americanos que apresentam realidades socioeconômicas análogas às suas.

A média do Brasil na área de Ciências se manteve estável desde 2006. Tivemos uma elevação aproximada de 10 pontos nas notas, que passaram de 390 pontos em 2006 para 401 em 2015, mas isto não representa uma mudança estatisticamente significativa (OCDE, 2016). Estes resultados são semelhantes à evolução histórica observada entre os países da OCDE onde um leve declínio na média de 498 pontos em 2006 para 493 pontos em 2015 também não representa uma mudança estatisticamente significativa (BRASIL, 2016).

Em primeiro lugar no PISA 2006 apareceu a Finlândia com 563 pontos de média na avaliação e, em último, o Quirguistão com 322. Com uma média de 531 pontos, o Japão, um dos países do mundo mais bem sucedidos na produção de 
Ciência e cientistas ${ }^{27}$, e que nos interessa particularmente aqui, ocupou a $6^{\text {a }}$ posição no ranking geral, um resultado bastante expressivo, que corrobora o bom aproveitamento dos estudantes japoneses visto em praticamente todas as comparações internacionais de desempenho escolar em que participam (SCHUMER, 1999).

Os estudantes japoneses continuam apresentando excelente desempenho em 2015. Com uma pontuação média de 538 pontos em Ciências, nesta edição, os estudantes japoneses foram superados apenas pelos de Cingapura (556 pontos). A média em Ciências do Japão também se manteve estatisticamente inalterada (531 pontos em 2006 e 538 pontos em 2015), no entanto, o país assumiu a segunda posição entre os países avaliados pelo Programa (OCDE, 2016).

O relatório nacional produzido pelo INEP para tratar os dados do PISA 2006 está baseado em indicadores de nível socioeconômico e cultural e afirma não ser razoável esperar que o desempenho dos estudantes brasileiros fosse similar à média de todos os estudantes da OCDE, mas que, em Ciências, deveria ser cerca 30 pontos maior (30\% do desvio padrão) para ficar dentro do esperado para seu nível médio. Segundo o INEP (BRASIL, 2008), a associação positiva entre os indicadores de nível socioeconômico e cultural dos estudantes mostra que muitos sistemas educacionais têm dificuldades para superar os determinantes da origem socioeconômica dos estudantes. O grande desafio dos sistemas educacionais é garantir bons desempenhos para os mais pobres econômica e culturalmente. $\mathrm{O}$ Brasil é o país da América Latina com índice mais baixo, cerca de 20 pontos abaixo do esperado.

Baseando-se exclusivamente na condição idade-série ajustada, ou seja, levando em consideração somente os estudantes brasileiros em fase na edição de 2006, matriculados no primeiro ano do Ensino Médio, a marca esperada para o nível socioeconômico e cultural do Brasil ainda não consegue ser atingida. A

\footnotetext{
${ }^{27}$ Em 1949, Hideki Yukawa se tornou o primeiro japonês a receber um Prêmio Nobel, ganhando um prêmio de física por ter previsto a existência de mesotrons. Ele foi sucedido por Reona Esaki com um prêmio de física em 1973, Susumu Tonegawa com um prêmio de fisiologia/medicina em 1987, e Kenzaburo Oe com um prêmio em literatura em 1994. Mais recentemente, japoneses ganharam Prêmios Nobel em sequência na área de Ciências naturais. Em 2002, Masatoshi Koshiba, da Universidade de Tóquio, ganhou um prêmio de física; Akira Suzuki, da Universidade de Hokkaido, e Eiichi Negishi, da Universidade de Tóquio, ganharam prêmios de química em 2010; e Shinya Yamanaka, da Universidade de Kyoto, ganhou um prêmio de fisiologia/medicina em 2012, pelo desenvolvimento da célula iPS. Em 2008 e 2010 apenas, um total de seis japoneses receberam prêmios de física e química, a maior honra para cientistas naturais, ressaltando o objetivo do Japão em se tornar um líder mundial em Ciência e Tecnologia.
} 
média dos estudantes brasileiros em fase é de 408 pontos e, portanto, 12 pontos aquém do esperado.

A marca dos 420 pontos, esperada para o nível socioeconômico e cultural do Brasil, só é atingida pelos estudantes brasileiros considerados adiantados. Ou seja, com uma média de 447 pontos, os estudantes brasileiros com pelo menos um ano de escolaridade a mais que os estudantes da OCDE e do Japão conseguem ascender a uma pontuação média que, na visão da OCDE, é aquela correspondente ao patamar necessário para que os jovens possam exercer plenamente sua cidadania. Ainda assim, mesmo comparando nossos estudantes adiantados aos estudantes japoneses (todos sem exceção matriculados no $1^{\circ}$ ano do Ensino Médio), nossa média em Ciências é quase um desvio padrão menor, com 84 pontos de diferença (Tabela 4).

Tabela 4. Médias e desvio padrão do Brasil, Japão e OCDE, em Ciências PISA 2006 e 2015.

\begin{tabular}{cccc}
\hline Edição & Países & Média & $\begin{array}{c}\text { Desvio } \\
\text { Padrão }\end{array}$ \\
\hline \multirow{2}{2006}{} & Brasil geral & 390 & 89.3 \\
& Brasil defasado & 333 & 69,7 \\
& Brasil em fase & 408 & 82,2 \\
& Brasil adiantado & 447 & 85,5 \\
& Japão & 531 & 100,1 \\
\hline \multirow{2015}{*0}{} & Média OCDE & 498 & 104,1 \\
& Brasil geral & 401 & 89,2 \\
& Brasil defasado & 335 & 63,6 \\
& Brasil em fase & 393 & 78,0 \\
& Brasil adiantado & 438 & 81,9 \\
& Japão & 538 & 93,1 \\
& Média OCDE & 493 & 94,1
\end{tabular}

Fonte: elaboração própria a partir dos resultados do PISA 2006 e 2015.

Em 2015 a diferença entre os estudantes brasileiros permaneceu estável, porém, os estudantes em fase apresentaram uma média em Ciências menor que aquela da amostra geral. Menor também que a média de 2006.

Por sua vez, os estudantes tidos como adiantados, apesar de em maior proporção nesta edição do Programa, também apresentaram uma média menor em Ciências em comparação com a de 2006. Em suma, na edição de 2015, bem como na de 2006, somente os estudantes brasileiros matriculados nas séries finais do Ensino Médio, isto é, com escolaridade maior do que os estudantes japoneses 
conseguem atingir os patamares iniciais considerados pela OCDE como essenciais para uma participação ativa na sociedade (Tabela 4).

Não poderíamos encerrar esta seção sem deixar de olhar para o desempenho dos estudantes brasileiros defasados. O fato de ter passado pela experiência da reprovação joga a média dos estudantes brasileiros pelo menos meio desvio padrão para baixo da média geral. Interessados na intensidade ou impacto da associação entre a proficiência em Ciências e a situação dos estudantes brasileiros defasados, implementamos o seguinte modelo por meio de regressão linear:

$$
\text { Proficiência }=\beta_{0}+\beta_{1}(\text { defasado })+e, \text { onde }
$$

$\beta_{0}$ é a média dos estudantes que não passaram pela experiência da reprovação e $\beta_{1}$ indica o quanto os resultados de Ciências de estudantes defasados difere daqueles ditos não defasados. Assim, a Tabela 5 mostra em até quantos pontos a média de um estudante brasileiro avaliado no PISA, em 2006 e 2015, pode ser reduzida quando se leva em consideração sua reprovação.

Tabela 5. Coeficientes de regressão e $\mathbf{R}^{2}$ referente ao modelo Proficiência = $\beta_{0}+\beta_{1}($ defasado $)+e$ para o Brasil no PISA 2006 e 2015 .

\begin{tabular}{ccccc}
\hline $\begin{array}{c}\text { Edição do } \\
\text { PISA }\end{array}$ & Modelo & $\begin{array}{c}\text { Coeficiente de } \\
\text { Regressão }\end{array}$ & Erro padrão & $\mathbf{R}^{2}$ \\
\hline $\mathbf{2 0 0 6}$ & (Constante) & 420,98 & 1,066 & .227 \\
& Defasado & $-87,475$ & 1,674 & \\
\hline 2015 & (Constante) & 417,077 & 0,592 & .155 \\
& Defasado & $-81,388$ & 1,248 & \\
\hline
\end{tabular}

Fonte: elaboração própria a partir dos resultados do PISA 2006 e 2015.

De acordo com os dados apresentados na tabela acima, podemos afirmar que o fato de ser defasado pode diminuir a média em Ciências de um estudante brasileiro avaliado pelo PISA 2006 em até 87,475 pontos. Em 2015, essa diminuição pode ser de até 81,388 pontos. Além disso, a experiência da reprovação explica em aproximados $22 \%$ a variância da proficiência em Ciências dos nossos estudantes na edição de $2006\left(\mathrm{R}^{2}=.227\right)$ e em cerca de $15 \%$ na de 2015 $\left(\mathrm{R}^{2}=.155\right)$.

A repetência escolar é um fenômeno muito complexo em cuja produção interagem características da escola, do estudante, da família, da condição socioeconômica, etc. (ALVES, ORTIGÃO \& FRANCO, 2007). A preocupação com o "fracasso escolar", principalmente dos estudantes socioeconomicamente 
menos favorecidos, deu origem a diversas pesquisas. Patto (1996), com base em ampla revisão da literatura, mostra, criticamente, que as explicações dadas para esse "fracasso" ao longo da história apresentam diferentes ênfases, destacando-se as deficiências do estudante (de origem médica ou psicológica), os fatores intraescolares e a carência cultural do ambiente em que vive, sendo que esta última prevalece, ainda que sob diferentes aspectos, até os dias de hoje. Isso coloca os estudantes brasileiros em situação de extrema desvantagem e abaixo do que seria o menor nível de desempenho estabelecido pelo PISA como veremos em detalhe na seção a seguir.

\section{4}

\section{Os Níveis de proficiência do PISA}

Para facilitar a interpretação dos resultados, o PISA estabeleceu, em cada domínio ou área de avaliação, níveis de desempenho baseados na classificação da pontuação associada às habilidades que os estudantes devem possuir para alcançar a pontuação correspondente. Segundo a $\operatorname{OCDE}(2007 ; 2016)$, a classificação possui dois objetivos: catalogar o desempenho dos estudantes e descrever o que são capazes de fazer (Quadros 4 e 5). 
Quadro 4. Descrição das habilidades em Ciências no PISA 2006.

\begin{tabular}{|c|c|}
\hline Nível/Média & O que os estudantes em geral podem fazer em cada nível \\
\hline $\begin{array}{c}\text { Nível 1 } \\
\text { De } 334,9 \text { a } \\
409,5\end{array}$ & $\begin{array}{l}\text { Os estudantes têm limitado conhecimento científico, de forma tal que } \\
\text { só conseguem aplicá-lo em algumas poucas situações familiares. Eles } \\
\text { são capazes de apresentar explicações científicas óbvias e tirar } \\
\text { conclusões de evidências explicitamente apresentadas. }\end{array}$ \\
\hline $\begin{array}{c}\text { Nível } 3 \\
\text { De 484,1 a } \\
558,7\end{array}$ & $\begin{array}{l}\text { Os estudantes têm conhecimentos científicos razoáveis para fornecer } \\
\text { explicações científicas em contextos familiares ou para tirar } \\
\text { conclusões baseadas em investigações simples. São capazes de } \\
\text { refletir de forma direta e de fazer interpretações literais de resultados } \\
\text { de pesquisas científicas ou de soluções de problemas tecnológicos. } \\
\text { Os estudantes são capazes de identificar questões científicas } \\
\text { claramente definidas em uma série de contextos. Podem selecionar } \\
\text { fatos e conhecimentos para explicar fenômenos e aplicar modelos } \\
\text { simples e estratégias de pesquisa. Podem interpretar e usar conceitos } \\
\text { científicos de diferentes disciplinas e aplicá-los diretamente. Podem, } \\
\text { ainda, dissertar sobre os fatos e tomar decisões baseadas em } \\
\text { conhecimento científico. }\end{array}$ \\
\hline $\begin{array}{c}\text { Nível } 4 \\
\text { De 558,7 a } \\
633,3\end{array}$ & $\begin{array}{l}\text { Os estudantes são capazes de trabalhar efetivamente com situações e } \\
\text { questões que envolvam fenômenos explícitos que requerem deles a } \\
\text { capacidade de fazer inferências sobre o papel da Ciência e da } \\
\text { Tecnologia. Eles são capazes de selecionar e integrar explicações de } \\
\text { diferentes disciplinas de Ciência ou Tecnologia e relacioná-las } \\
\text { diretamente a aspectos de situação da vida. Podem refletir sobre suas } \\
\text { ações e comunicar decisões usando conhecimento e evidência } \\
\text { científica. }\end{array}$ \\
\hline $\begin{array}{c}\text { Nível } 5 \\
\text { De } 633,3 \text { a } \\
707,9\end{array}$ & $\begin{array}{l}\text { Os estudantes são capazes de identificar componentes científicos em } \\
\text { muitas situações complexas da vida, de aplicar tanto conceitos } \\
\text { científicos como conhecimento sobre Ciências a essas situações, e } \\
\text { conseguem comparar, selecionar e avaliar evidências científicas } \\
\text { apropriadas para responder a situações da vida. Os estudantes neste } \\
\text { nível podem utilizar habilidades de pesquisa bem-desenvolvidas, de } \\
\text { relacionar apropriadamente conhecimentos e de refletir criticamente } \\
\text { sobre as situações. São capazes, também, de construir explicações } \\
\text { baseadas em evidências e argumentos baseados em sua análise } \\
\text { crítica. }\end{array}$ \\
\hline $\begin{array}{l}\text { Nível } 6 \\
\text { Acima de } 707,9\end{array}$ & $\begin{array}{l}\text { Os estudantes podem identificar com segurança, explicar e aplicar } \\
\text { conhecimentos científicos e conhecimento sobre Ciências em uma } \\
\text { grande variedade de situações complexas de vida. Eles são capazes } \\
\text { de relacionar diferentes fontes de informação e de usar evidência } \\
\text { retirada de tais fontes para justificar decisões. Eles demonstram } \\
\text { claramente e de forma consistente uma capacidade de reflexão } \\
\text { científica avançada, e demonstram vontade de usar seu conhecimento } \\
\text { científico para resolver questões científicas e tecnológicas novas. Os } \\
\text { estudantes neste nível podem, ainda, usar o conhecimento científico e } \\
\text { desenvolver argumentos para embasar recomendações e decisões } \\
\text { centradas em situações pessoais, sociais e globais. }\end{array}$ \\
\hline
\end{tabular}

Fonte: Adaptação livre de Brasil, 2008.

A escala de Ciências para o PISA 2015 foi dividida em oito níveis de proficiência (Quadro 5), seis deles alinhados com os níveis definidos em 2006 (Quadro 4). A descrição de cada nível define os conhecimentos e habilidades necessários para completar as tarefas e foi feita com base nas demandas cognitivas exigidas.

Os estudantes com proficiência abaixo do nível 1, em 2006, e do nível 1a em 2015, provavelmente conseguem resolver as tarefas desse nível, mas têm 
baixa probabilidade de completar as dos níveis superiores da escala. O nível 6 inclui as tarefas mais desafiadoras em termos de conhecimentos e habilidades. Os estudantes com valores de proficiência localizados nesse nível têm alta probabilidade de realizar as tarefas desse e dos outros níveis da escala.

Quadro 5. Descrição das habilidades em Ciências no PISA 2015.

\begin{tabular}{cc}
\hline Nível/Média & O que os estudantes em geral podem fazer em cada nível \\
\hline Nível abaixo de & A OCDE não especifica as habilidades desenvolvidas. \\
1b & \\
De 334,9 a & \\
409,5 &
\end{tabular}

409,5

Nível 1b

De 334,9 a 409,5

Os estudantes podem usar conhecimento científico básico ou cotidiano para reconhecer aspectos de fenômenos simples e conhecidos. Conseguem identificar padrões simples em fontes de dados, reconhecer termos científicos básicos e seguir instruções explícitas para executar um procedimento científico.

Os estudantes conseguem usar conhecimento de conteúdo e procedimental básico ou cotidiano para reconhecer ou identificar explicações de fenômenos científicos simples. Com apoio,

Nível 1a

De 334,9 a 409,5

Nível 2

De 409,5 a 484,1

Nível 3

De 484,1 a 558,7

Nível 4

De 558,7 a 633,3 conseguem realizar investigações científicas estruturadas com no máximo duas variáveis. Conseguem identificar relações causais ou correlações simples e interpretar dados em gráficos e em imagens que exijam baixo nível de demanda cognitiva. Os estudantes do nível 1a podem selecionar a melhor explicação científica para determinado dado em contextos global, local e pessoal.

Os estudantes conseguem recorrer a conhecimento cotidiano e a conhecimento procedimental básico para identificar uma explicação científica adequada, interpretar dados e identificar a questão abordada em um projeto experimental simples. Conseguem usar conhecimento científico básico ou cotidiano para identificar uma conclusão válida em um conjunto simples de dados. Os estudantes do nível 2 demonstram ter conhecimento epistemológico básico ao conseguir identificar questões que podem ser investigadas cientificamente.

Os estudantes podem recorrer a conhecimento de conteúdo de moderada complexidade para identificar ou formular explicações de fenômenos conhecidos. Em situações mais complexas ou menos conhecidas, podem formular explicações desde que com apoio ou dicas. Podem recorrer a elementos de conhecimento procedimental e epistemológico para realizar um experimento simples em contexto restrito. Os estudantes do nível 3 conseguem fazer distinção entre questões científicas e não científicas e identificar a evidência que apoia uma afirmação científica.

Os estudantes conseguem usar conhecimento de conteúdo mais complexo e mais abstrato, proporcionado ou recordado, para construir explicações de eventos e processos mais complexos ou pouco conhecidos. Podem conduzir experimentos que envolvam duas ou mais variáveis independentes em contextos restritos. Conseguem justificar um projeto experimental recorrendo a elementos de conhecimento procedimental e epistemológico. Os estudantes do nível 4 podem interpretar dados provenientes de um conjunto moderadamente complexo ou de contexto pouco conhecido, chegar a conclusões adequadas que vão além dos dados e justificar suas escolhas. 


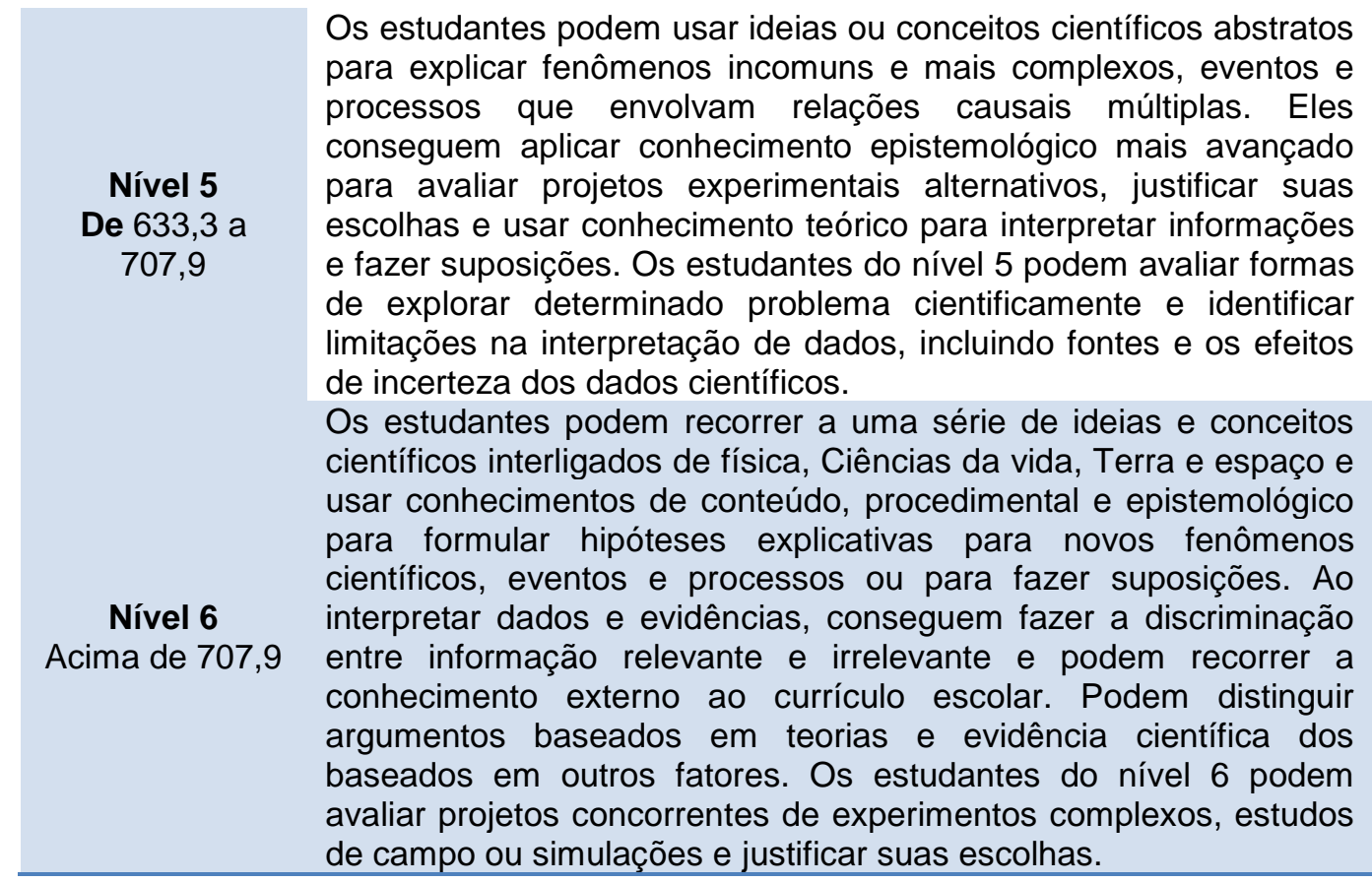

Fonte: Adaptação livre de Brasil, 2016.

A Tabela 6, abaixo, mostra a distribuição dos estudantes brasileiros e japoneses nos níveis de proficiência do PISA. A escala do PISA, como já dissemos, apresenta seis níveis, do nível 1 ao 6, em 2006 e oito níveis, do nível abaixo de 1 b ao nível 6, em 2015. Por iniciativa própria, incluímos o nível 0, que representa o grupo de estudantes que não atinge o nível 1 de proficiência estabelecido pelo PISA em qualquer das edições. Assim, no nível 0, estão os estudantes que não conseguiram, tanto em 2006 quanto em 2015, alcançar uma média em Ciências de, no mínimo, 334,9 pontos.

Tabela 6. Distribuição percentual dos estudantes brasileiros e japoneses nos níveis de desempenho de Ciências no PISA 2006 e 2015.

\begin{tabular}{|c|c|c|c|c|c|c|c|c|}
\hline & \multicolumn{7}{|c|}{ Níveis de Proficiência } \\
\hline & & $\begin{array}{c}\text { Nível } \\
\mathbf{0} \\
\text { (abaixo } \\
\text { de } \\
334,9 \text { ) }\end{array}$ & $\begin{array}{c}\text { Nível } \\
\mathbf{1} \\
(\mathrm{de} \\
334,9 \mathrm{a} \\
409,5)\end{array}$ & $\begin{array}{c}\text { Nível } \\
\mathbf{2} \\
(\mathrm{de} \\
409,5 \mathrm{a} \\
484,1)\end{array}$ & $\begin{array}{c}\text { Nível } \\
\mathbf{3} \\
(\mathrm{de} \\
484,1 \mathrm{a} \\
558,7)\end{array}$ & $\begin{array}{c}\text { Nível } \\
\mathbf{4} \\
(\mathrm{de} \\
558,7 \mathrm{a} \\
633,3)\end{array}$ & $\begin{array}{c}\text { Nível } \\
\mathbf{5} \\
(\mathrm{de} \\
633,3 \mathrm{a} \\
707,9)\end{array}$ & $\begin{array}{c}\text { Nível } \\
\mathbf{6} \\
(\text { acima } \\
\text { de } \\
707,9)\end{array}$ \\
\hline \multirow[t]{6}{*}{2006} & Brasil geral & 27,9 & 33,3 & 23,7 & 11,2 & 3,4 & 0,5 & 0,0 \\
\hline & Brasil defasado & 51,8 & 34,7 & 11,7 & 1,6 & 0,2 & 0,0 & 0,0 \\
\hline & Brasil em fase & 18,6 & 34,6 & 28,3 & 13,7 & 4,4 & 0,4 & 0,0 \\
\hline & Brasil adiantado & 8,2 & 26,2 & 32,4 & 23,3 & 8,2 & 1,6 & 0,1 \\
\hline & Japão & 3,1 & 8,8 & 18,4 & 27,8 & 26,9 & 12,4 & 2,6 \\
\hline & Média OCDE & 5,1 & 14,0 & 24,0 & 27,7 & 20,3 & 7,7 & 1,2 \\
\hline \multirow[t]{6}{*}{2015} & Brasil geral & 24,3 & 32,4 & 25,4 & 13,1 & 4,2 & 0,6 & 0,0 \\
\hline & Brasil defasado & 51,6 & 35,2 & 11,8 & 1,3 & 0,1 & 0,0 & 0,0 \\
\hline & Brasil em fase & 22,6 & 39,0 & 25,9 & 9,7 & 2,5 & 0,3 & 0,0 \\
\hline & Brasil adiantado & 9,8 & 28,1 & 33,6 & 20,7 & 6,6 & 1,1 & 0,1 \\
\hline & Japão & 1,9 & 7,7 & 18,1 & 28,2 & 28,8 & 12,9 & 2,4 \\
\hline & Média OCDE & 5,5 & 15,7 & 24,8 & 27,2 & 19 & 6,7 & 1,1 \\
\hline
\end{tabular}

Fonte: elaboração própria a partir dos resultados do PISA 2006 e 2015. 
Observa-se, na tabela acima, que os maiores percentuais de estudantes brasileiros na amostra geral, que considera todos os estudantes participantes do país, encontram-se nos níveis mais baixos da escala (27,9\% no nível 0 e 33,3\% no nível 1 em 2006 e 24,3\% no nível 0 e 32,4\% no nível 1 em 2015), o que significa um total de, aproximadamente, $60 \%$ dos estudantes brasileiros alocados nos dois níveis mais baixos do Programa nas duas avaliações.

Em avaliações de larga escala, como é o caso do PISA, é previsível que poucos estudantes atinjam os níveis mais altos. O esperado é que a maioria dos estudantes consiga alcançar os Níveis 2 ou 3 da escala de proficiência (OCDE, 2007). Isto pode ser observado entre os países membros da OCDE, onde mais da metade dos estudantes $(51,7 \%$ em 2006 e 52\% em 2015) estão alocados nos Níveis intermediários 2 e 3 . Infelizmente, esta não é a realidade da amostra geral brasileira, e tampouco dos estudantes em fase, com $42 \%$ concentrados nos Níveis 2 e 3 em 2006 e apenas 35,6\% em 2015. Ou seja, bem menos da metade dos estudantes em fase no Brasil conseguem atingir o patamar que a OCDE estabelece como necessário para que os jovens possam exercer plenamente sua cidadania. Apenas os estudantes brasileiros matriculados nos $2^{\circ}$ e $3^{\circ}$ anos do Ensino Médio são capazes de atingir o patamar estabelecido pela OCDE (55,7\% deles em 2006 e $54,3 \%$ em 2015). No caso do Japão, mais de 50\% dos estudantes se concentram nos níveis 3 e 4 da escala de proficiência, tanto em 2006 quanto em 2015. Os estudantes japoneses reconhecidamente aparecem entre os mais bem sucedidos do mundo nos testes comparativos internacionais, sobretudo no que diz respeito a temas ligados a Ciência e a Tecnologia.

Os resultados da edição de 2006 colocam o Brasil no nível 1 e o Japão no nível 3 da escala de proficiência do PISA. Segundo a OCDE (2007), no nível 1, os estudantes têm limitado conhecimento científico, de forma tal que só conseguem aplicá-lo em algumas poucas situações familiares. Eles são capazes de apresentar explicações científicas óbvias e de tirar conclusões de evidências explicitamente apresentadas. Já no nível 3, os estudantes são capazes de identificar questões científicas claramente definidas em uma série de contextos. Podem selecionar fatos e conhecimentos para explicar fenômenos e aplicar modelos simples e estratégias de pesquisa. Podem interpretar e usar conceitos científicos de diferentes disciplinas e aplicá-los diretamente. Podem, ainda, dissertar sobre os fatos e tomar decisões baseadas em conhecimento científico. 
Em 2015, por uma diferença de seis pontos percentuais, o Japão ascendeu um nível no PISA, passando a ocupar o nível 4, no qual os estudantes conseguem usar conhecimento de conteúdo mais complexo e mais abstrato, proporcionado ou recordado, para construir explicações de eventos e processos mais complexos ou pouco conhecidos. Podem conduzir experimentos que envolvam duas ou mais variáveis independentes em contextos restritos. Conseguem justificar um projeto experimental recorrendo a elementos de conhecimento procedimental e epistemológico. Os estudantes do nível 4 podem interpretar dados provenientes de um conjunto moderadamente complexo ou de contexto pouco conhecido, chegar a conclusões adequadas que vão além dos dados e justificar suas escolhas.

O Brasil também consegue ascender um nível no PISA em 2006 e em 2015, mas à custa de, pelo menos, um ou dois anos de escolaridade a mais do que os estudantes japoneses. Ainda assim, nossos estudantes adiantados, matriculados nos $2^{\circ}$ e $3^{\circ}$ anos do Ensino Médio, alcançam o nível 2 em ambas as edições do Programa, permanecendo um nível abaixo dos japoneses em 2006 e dois níveis em 2015. Os estudantes adiantados do Brasil que se encontram no nível 2, de acordo com a OCDE, conseguem recorrer a conhecimento cotidiano e a conhecimento procedimental básico para identificar uma explicação científica adequada, interpretar dados e identificar a questão abordada em um projeto experimental simples. Conseguem usar conhecimento científico básico ou cotidiano para identificar uma conclusão válida em um conjunto simples de dados e, demonstram ter conhecimento epistemológico básico ao conseguir identificar questões que podem ser investigadas cientificamente.

A situação dos estudantes defasados no Brasil, ou seja, daqueles matriculados no Ensino Fundamental é muito complexa e acabamos por convergir com os achados de Muri (2015) que sugerem que a defasagem escolar inviabiliza a obtenção de melhores resultados em Ciências. Mais de 50\% dos estudantes brasileiros que já passaram pela reprovação não conseguem atingir o nível mais básico estabelecido pelo PISA. Eles representavam 51,8\% dos estudantes brasileiros no nível 0 em 2006 e 51,6 em 2015. Os estudantes defasados não conseguem avançar na escala de proficiência: nas duas edições do Programa, em que Ciências foi o foco central da avaliação, os estudantes defasados se concentraram nos níveis 0 e 1 da escala e pouco mais de $10 \%$ deles conseguiram atingir o nível 2. 
Apenas uma pequena proporção de estudantes de todos os países participantes do PISA atinge os níveis mais altos de proficiência (níveis 5 ou 6). Ainda assim, os estudantes japoneses (cerca de 15\%, tanto em 2006 quanto em 2015) representam quase o dobro dos estudantes da OCDE nesses dois níveis. Estudantes posicionados nesses níveis são capazes de identificar, explicar e aplicar o conhecimento científico e o conhecimento sobre a Ciência em uma variedade de situações de vida complexas. Tais habilidades excepcionais podem fornecer uma vantagem significativa em uma economia global competitiva baseada no conhecimento científico. Os dados do PISA 2015 revelam que mais de metade de todos os estudantes de alto desempenho no PISA vivem em apenas quatro países: Estados Unidos, China, Alemanha e Japão. A Figura 5 descreve apenas o número de estudantes de 15 anos de idade que são proficientes nos níveis 5 ou 6 na escala de Ciências do PISA, por país, sem levar em conta que o tamanho da população de estudantes e da amostra de estudantes que participam do PISA varia entre os países.

No entanto, tanto a proporção de um país e o tamanho dos países são importantes quando se estabelece a contribuição destes para o conjunto global de estudantes. Embora a proporção de estudantes de alto desempenho em Ciências seja comparativamente pequena nos Estados Unidos, este país representa pouco mais de um quinto do total mostrado na Figura 6 (que, é claro, considera apenas os países que participam no PISA), simplesmente por causa da dimensão do país e do número total de estudantes de 15 anos de idade que avaliaram no Programa.

Figura 6. O “pool” global de top performers na perspectiva do PISA 2015.

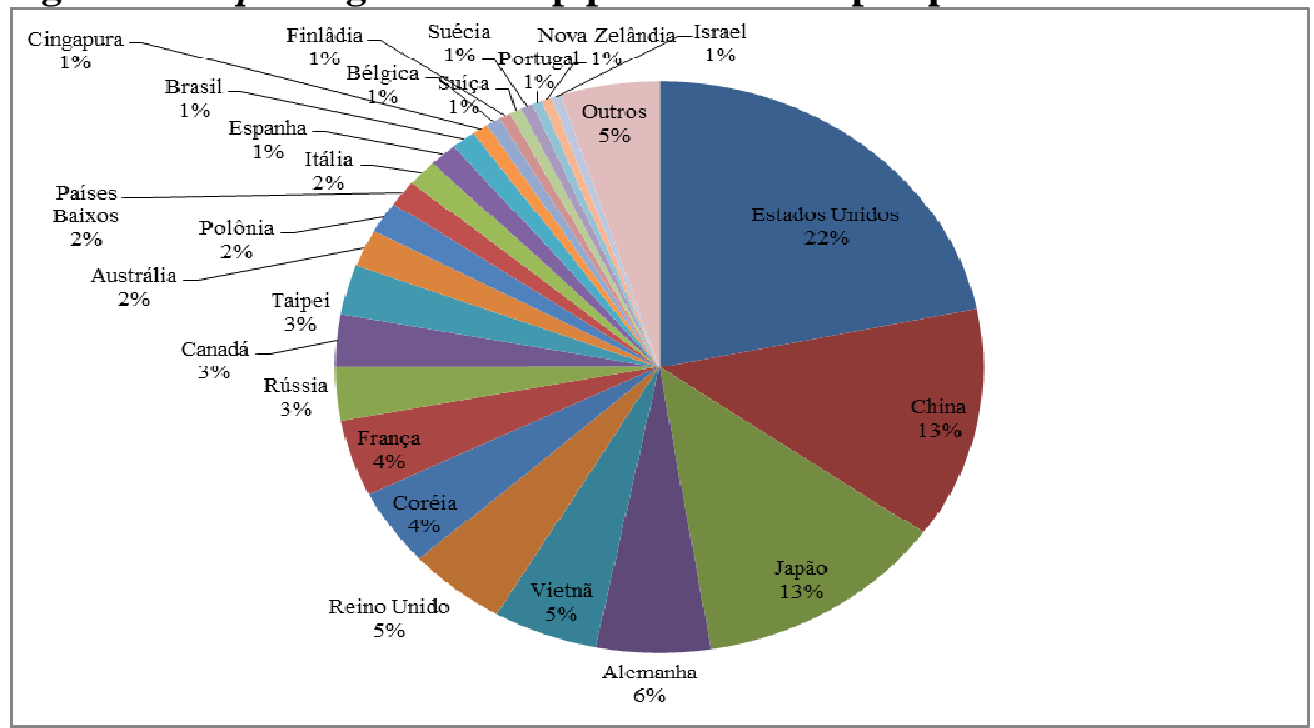

Fonte: adaptação livre de OCDE, 2016. 
Assim, o fato de o Japão contribuir com aproximados $15 \%$ de estudantes nos Níveis mais altos do Programa é ainda mais considerável, visto que se trata de um país pequeno e com uma amostra bem menor do que a Americana e a Chinesa. Em contrapartida, o Brasil aparece com 1\%, mas essa participação está relacionada ao tamanho da população estudada.

Ainda conforme mostrado na Figura 7, dez países, em 2015, abrangem mais de 75\% do pool global de melhores desempenhos em Ciência no PISA. Além dos quatro países com o maior grupo de estudantes de alto desempenho, o Reino Unido e Vietnã contribuem cada um com 5\%, França e Coréia com aproximadamente 4\%, e Canadá e Rússia com cerca de 3\% para o pool global de estudantes de alto desempenho. Quando analisados em conjunto, os 35 países da OCDE representam $72 \%$ do conjunto global de estudantes de alto desempenho, e os 28 membros da União Europeia representam 26\% desse conjunto (OCDE, 2016).

A seguir, analisaremos os resultados dos estudantes brasileiros e japoneses de acordo com as competências em Ciências no PISA.

\section{5 As competências em Ciências}

Os estudantes de cada país tiveram resultados mais altos ou mais baixos em determinadas competências medidas pelo PISA. Em 2006, o PISA avaliou a capacidade dos estudantes nas seguintes competências: "identificar questões científicas"; "explicar fenômenos cientificamente"; e "usar evidência científica".

A competência "identificar questões científicas" envolve reconhecer e comunicar questões que podem ser investigadas cientificamente, e saber o que está envolvido nessas investigações. Inclui reconhecer questões de cunho científico como, por exemplo, o que deve ser comparado, quais variáveis devem ser alteradas ou controladas, quais informações adicionais são necessárias, ou que ações devem ser realizadas para que dados relevantes sejam coletados. Também envolve o reconhecimento de características relevantes da investigação científica e a identificação de palavras-chave para pesquisar questões científicas.

$\mathrm{Na}$ competência "explicar fenômenos cientificamente", os estudantes demonstram sua compreensão aplicando conhecimentos científicos adequados em 
uma situação determinada. Esta competência inclui a descrição ou a explicação científica para fenômenos e a previsão de mudanças e pode envolver, também, reconhecimento ou identificação de descrições, explicações e previsões apropriadas.

Por fim, "usar evidência científica" significa entender descobertas científicas como evidências para demandas ou conclusões. Implica a capacidade para avaliar a informação científica e chegar a conclusões baseadas em provas científicas, e sua futura comunicação. Além disso, inclui a habilidade de selecionar conclusões alternativas em relação a evidências e informá-las; a exposição de razões contra ou a favor de determinada conclusão, com base nos dados fornecidos; a identificação de suposições feitas para se chegar a uma conclusão; e a reflexão sobre as implicações sociais da Ciência e do desenvolvimento tecnológico.

Como vimos, a definição de Letramento Científico em 2015 se baseia e desenvolve a definição de 2006. Em 2015, os estudantes participantes do PISA também foram avaliados em três competências, mas a terminologia de duas das três competências mudou em relação à edição de 2006. Apenas a competência "explicar fenômenos cientificamente" se manteve inalterada. Os relatórios técnicos da OCDE não trazem nenhum registro sobre a mudança nos títulos das competências, no entanto, registram que outras mudanças, por exemplo, a elaboração dos conceitos de conhecimento procedural e epistêmico, representam uma especificação mais detalhada de aspectos particulares que foram embutidos ou assumidos em definições anteriores (OCDE, 2013d). As competências avaliadas em 2015 foram:

1. explicar fenômenos cientificamente: reconhecer, oferecer e avaliar explicações para fenômenos naturais e tecnológicos;

2. avaliar e planejar investigações científicas: descrever e avaliar investigações científicas e propor formas de abordar questões cientificamente;

3. interpretar dados e evidências cientificamente: analisar e avaliar os dados, afirmações e argumentos, tirando conclusões científicas apropriadas.

Assim como os outros países, Brasil e Japão também mostraram desempenhos distintos nas diferentes competências em Ciências avaliadas pelo 
Programa. A Tabela 7 apresenta as médias dos dois países, bem como da OCDE, nas diferentes competências avaliadas em 2006.

Tabela 7. Média e desvio padrão de Brasil, Japão e OCDE nas competências de Ciências avaliadas no PISA 2006.

\begin{tabular}{|c|c|c|c|c|c|c|}
\hline & \multicolumn{6}{|c|}{ Competências } \\
\hline & \multicolumn{2}{|c|}{$\begin{array}{c}\text { Explicar } \\
\text { fenômenos } \\
\text { cientificamente }\end{array}$} & \multicolumn{2}{|c|}{$\begin{array}{l}\text { Identificar } \\
\text { questões } \\
\text { científicas }\end{array}$} & \multicolumn{2}{|c|}{$\begin{array}{l}\text { Usar evidência } \\
\text { científica }\end{array}$} \\
\hline & Média & $\begin{array}{l}\text { Desvio } \\
\text { Padrão }\end{array}$ & Média & $\begin{array}{l}\text { Desvio } \\
\text { Padrão }\end{array}$ & Média & $\begin{array}{l}\text { Desvio } \\
\text { Padrão }\end{array}$ \\
\hline Brasil geral & 390 & 93,8 & 398 & 94,6 & 378 & 107,9 \\
\hline Brasil defasado & 338 & 71,7 & 343 & 78,5 & 308 & 83,5 \\
\hline Brasil em fase & 406 & 85,6 & 415 & 85,8 & 401 & 94,5 \\
\hline Brasil adiantado & 446 & 90,2 & 450 & 86,6 & 447 & 95,5 \\
\hline Japão & 527 & 96,0 & 522 & 103,9 & 544 & 113,9 \\
\hline Média OCDE & 500 & 101,9 & 498 & 97,8 & 499 & 110,2 \\
\hline
\end{tabular}

Fonte: elaboração própria a partir dos resultados do PISA 2006.

A competência em que o Brasil apresenta melhores resultados, seja na amostra geral ou nos grupos de estudantes defasados, em fase e adiantados, é a de "identificar questões cientificamente". No entanto, os resultados brasileiros ficam aquém dos japoneses e da média dos países da OCDE. "Identificar questões cientificamente" é a competência na qual o Japão e a OCDE apresentam a menor média. Contudo, essas médias chegam a ser até 100 pontos maiores que as do Brasil, mesmo quando considerado apenas o grupo de estudantes em fase no país.

$\mathrm{Na}$ competência "explicar fenômenos cientificamente", o desempenho médio do Brasil é idêntico à média geral do país em Ciências (390). Esta é a competência na qual, via de regra, os estudantes dos países da OCDE se saem melhor, em média. Os menores resultados obtidos pelos estudantes brasileiros se relacionam com o uso prático das evidências que a Ciência oferece. Nesta competência, em que o Japão atinge sua média mais alta (544,34 pontos), o Brasil apresenta seu pior desempenho, com 12 pontos abaixo de sua média geral. Mesmo os estudantes brasileiros adiantados ficam atrás do Japão praticamente 100 pontos, ou seja, um desvio padrão.

A realidade dos estudantes brasileiros defasados se repete ao longo das competências como ocorreu entre os níveis de proficiência estabelecidos pelo PISA. As médias são também mais baixas do que as da amostra geral bem como das dos grupos dos estudantes em fase e adiantados. 
O fato de ter reprovado diminui a competência de um estudante brasileiro de "explicar fenômenos cientificamente", "identificar questões científicas" e "usar evidência científica" em pelo menos 52, 55 e 70 pontos, respectivamente.

Em 2015, os estudantes brasileiros, de maneira geral, se saíram melhor na competência de "explicar fenômenos cientificamente" (Tabela 8), e o mesmo acontece entre os estudantes que compõem os grupos de defasados, em fase e adiantados. Ou seja, em todas as dimensões, os estudantes brasileiros tem um desempenho levemente maior na competência "explicar fenômenos cientificamente".

Tabela 8. Média e desvio padrão de Brasil, Japão e OCDE nas competências de Ciências avaliadas no PISA 2015.

\begin{tabular}{ccccccc}
\hline & \multicolumn{5}{c}{ Competências } \\
\cline { 2 - 7 } & \multicolumn{2}{c}{$\begin{array}{c}\text { Explicar } \\
\text { fenômenos } \\
\text { cientificamente }\end{array}$} & \multicolumn{2}{c}{$\begin{array}{c}\text { Avaliar e planejar } \\
\text { investigações } \\
\text { científas }\end{array}$} & $\begin{array}{c}\text { Interpretar dados e } \\
\text { evidências } \\
\text { cientificamente }\end{array}$ \\
& Média & $\begin{array}{c}\text { Desvio } \\
\text { Padrão }\end{array}$ & Média & $\begin{array}{c}\text { Desvio } \\
\text { Padrão }\end{array}$ & Média & $\begin{array}{c}\text { Desvio } \\
\text { Padrão }\end{array}$ \\
\hline Brasil geral & 403 & 92,3 & 398 & 91,5 & 398 & 90,0 \\
Brasil defasado & 337 & 68,4 & 335 & 70,8 & 332 & 66,9 \\
Brasil em fase & 395 & 84,3 & 386 & 84,5 & 386 & 81,4 \\
Brasil adiantado & 441 & 89,4 & 432 & 89,9 & 437 & 85,8 \\
\hline Japão & 539 & 97,8 & 536 & 95,9 & 541 & 97,2 \\
\hline Média OCDE & 493 & 99,9 & 493 & 103,1 & 493 & 101,4 \\
\hline
\end{tabular}

Fonte: elaboração própria a partir dos resultados do PISA 2015.

Os estudantes japoneses, por sua vez, apresentam melhor desempenho nos itens que deles requeriam "interpretar dados e evidências cientificamente" (541 pontos). As médias da OCDE são as mesmas nas três competências avaliadas e os estudantes japoneses as ultrapassam sempre em uma média de 40 pontos.

Novamente, mesmo quando comparamos o grupo brasileiro de estudantes de maior proficiência, dos estudantes adiantados, na sua melhor competência "explicar fenômenos cientificamente" com 441 pontos - os nossos estudantes ficam aquém dos japoneses quase um desvio padrão, com uma diferença de 98 pontos e uma média de 539 pontos.

Nas demais competências, as diferenças ultrapassam 100 pontos, e entre os estudantes defasados as diferenças chegam a mais de 200 pontos em relação ao Japão (acima de dois desvios padrão) e a aproximadamente 150 pontos em relação a OCDE (um e meio desvio padrão). Mesmo o grupo brasileiro de estudantes em fase, iguais em anos de escolaridade aos japoneses e membros da OCDE fica pelo 
um desvio padrão abaixo dos estudantes da OCDE e um e meio desvio padrão abaixo dos estudantes japoneses em qualquer das competências avaliadas pelo PISA 2015.

Comparativamente, não há em 2006, nem tampouco em 2015, nenhum padrão claro que evidencie a variação das médias dos países nas competências avaliadas pelo PISA. Contudo, além das competências, foi possível observar, também, o desempenho dos estudantes no conhecimento das diferentes áreas de Ciências, como será visto na seção seguinte.

\section{6}

\section{O conhecimento das diferentes áreas de Ciências}

O conteúdo a ser avaliado no PISA é selecionado a partir dos campos principais da Física, Química, Ciências Biológicas e Ciências da Terra e do espaço, de acordo com três critérios, a saber: "utilidade do conhecimento científico na vida diária"; "relevância das Ciências e da política educacional durante os próximos anos"; e "necessidade de combinar o conhecimento com alguns processos científicos".

As tarefas previstas no teste do PISA em 2006 envolviam conhecimentos científicos de dois tipos: (a) Conhecimento sobre Ciências, que foi dividido em Investigação Científica e Explicações Científicas; e (b) Conhecimento de Ciências, que focaliza o conhecimento do mundo natural em áreas de conteúdo, tais como: Sistemas Físicos, Sistemas Vivos, Terra e Sistemas Espaciais e Sistemas Tecnológicos. Essas subdivisões podem ser mais bem visualizadas no Quadro 6. 
Quadro 6. Conhecimentos científicos presentes na avaliação de Ciências do PISA 2006.

\begin{tabular}{|c|c|c|}
\hline Conhecimento & Áreas & Conteúdos \\
\hline De Ciências & Sistemas Físicos & $\begin{array}{c}\text { Estrutura e propriedades da matéria, } \\
\text { mudanças químicas da matéria, força e } \\
\text { movimento, energia e interação entre } \\
\text { energia e matéria. }\end{array}$ \\
\cline { 2 - 3 } & Sistemas Vivos & $\begin{array}{c}\text { Células, seres humanos, populações, } \\
\text { ecossistemas e biosfera. }\end{array}$ \\
\cline { 2 - 3 } & $\begin{array}{c}\text { Terra e Sistemas } \\
\text { Espaciais }\end{array}$ & $\begin{array}{c}\text { Estruturas da Terra e seus sistemas, } \\
\text { energia e mudanças nos sistemas da } \\
\text { Terra, história da Terra e a Terra no } \\
\text { espaço. }\end{array}$ \\
\cline { 2 - 3 } & Sistemas Tecnológicos & $\begin{array}{c}\text { Relações entre Ciência e Tecnologia, o } \\
\text { papel da Tecnologia científica, conceitos } \\
\text { e princípios importantes. }\end{array}$ \\
\hline Sobre Ciências & Investigação Científica & $\begin{array}{c}\text { Origem, objetivos, experimentos, tipos de } \\
\text { dados, métodos e características dos } \\
\text { resultados. }\end{array}$ \\
\cline { 2 - 3 } & Explicações Científicas & Tipos, formatos, regras e resultados. \\
\hline
\end{tabular}

Fonte: elaboração própria a partir dos resultados do PISA 2006.

Como já dissemos, a principal diferença entre o PISA 2006 e o PISA 2015 é que a noção de "conhecimento sobre Ciências" foi explicitada com base em sua divisão em dois componentes: "conhecimento procedimental" e "conhecimento epistemológico". Assim, as três competências requeridas para o Letramento Científico em 2015 exigem, também, três formas de conhecimento:

1. "Conhecimento de conteúdo" que se refere ao conhecimento dos fatos, conceitos, ideias e teorias sobre o mundo natural estabelecido pela Ciência e que equivale ao "Conhecimentos de Ciências" da edição de 2006.

2. "Conhecimento procedimental" que é o conhecimento dos procedimentos padrão que os cientistas usam para obter dados confiáveis e válidos.

3. "Conhecimento epistemológico" que se trata de um conhecimento que define as características essenciais para o processo de construção do conhecimento científico.

Os exemplos listados no Quadro 7 indicam as características gerais das três formas de conhecimento avaliadas na edição de 2015. 
Quadro 7. Conhecimentos científicos presentes na avaliação de Ciências do PISA 2015.

\begin{tabular}{|c|c|}
\hline Conhecimento & Conteúdos \\
\hline \multirow[t]{3}{*}{ De Conteúdo } & 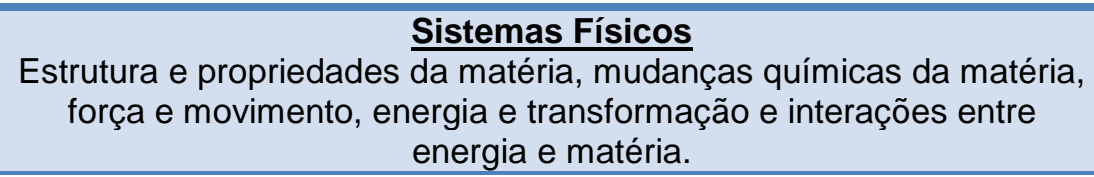 \\
\hline & $\begin{array}{c}\text { Sistemas Vivos } \\
\text { Células, conceito de organismo, seres humanos, populações, } \\
\text { ecossistemas e biosfera. }\end{array}$ \\
\hline & $\begin{array}{c}\text { Terra e Sistemas Espaciais } \\
\text { Estruturas da Terra e seus sistemas, energia e mudanças nos } \\
\text { sistemas da Terra, história da Terra, a Terra no espaço e história e } \\
\text { escala do Universo. }\end{array}$ \\
\hline Procedimental & $\begin{array}{l}\text { - Conceitos de variáveis dependentes e independentes; } \\
\text { - Conceitos de medidas: qualitativas e quantitativas, escalas, } \\
\text { variáveis contínuas e discretas; } \\
\text { - Formas de avaliar e minimizar incertezas: repetições, medidas } \\
\text { médias; } \\
\text { - Mecanismos para gerar replicação; } \\
\text { - Ferramentas de representação de dados: gráficos, tabelas, mapas, } \\
\text { histogramas; } \\
\text { - Controle de variáveis: desenho experimental, randomização; } \\
\text { - Natureza de desenhos específicos: observação, busca de padrões, } \\
\text { experimentação. }\end{array}$ \\
\hline \multirow[t]{2}{*}{ Epistemológico } & $\begin{array}{l}\text { - Os construtos e recursos da ciência } \\
\text { - Natureza das observações científicas, fatos, hipóteses, modelos e } \\
\text { teorias; } \\
\text { - Propósitos e objetivos das observações científicas: produção de } \\
\text { explicações do mundo natural, produção de soluções para as } \\
\text { necessidades humanas (Tecnologia); } \\
\text { - Valores da ciência: compromisso, objetividade, eliminação de viés; } \\
\text { - Natureza do raciocínio científico: dedução, indução, inferência, } \\
\text { analogias e uso de modelos. }\end{array}$ \\
\hline & $\begin{array}{l}\text { O papel dos construtos e recursos para justificar a produção do } \\
\text { - Como afirmações científicas são apoiadas por dados e raciocínio na } \\
\text { ciência; } \\
\text { - Função das diferentes formas de investigação para produção de } \\
\text { conhecimentos; } \\
\text { - Como as medidas de erro afetam o grau de confiabilidade do } \\
\text { conhecimento científico; } \\
\text { - Uso e limites de uso dos modelos físicos, sistêmicos e abstratos; } \\
\text { - Papel dos pares no estabelecimento de confiabilidade nas } \\
\text { comunidades científicas; } \\
\text { - Papel do conhecimento científico e de outras formas de } \\
\text { conhecimento na identificação de questões sociais e tecnológicas. }\end{array}$ \\
\hline
\end{tabular}

Fonte: elaboração própria a partir dos resultados do PISA 2015.

Alguns países obtiveram desempenho substancialmente mais alto em "Conhecimento sobre Ciências", ou seja, conhecimento sobre os propósitos e a natureza da investigação científica e das explicações científicas, do que em "Conhecimento de Ciências", conhecimento do mundo natural e da forma como este se articula com diferentes disciplinas científicas (Tabela 9). 
Tabela 9. Médias de Brasil, Japão e ODCE nos conhecimentos científicos requeridos no PISA 2006 e 2015.

\begin{tabular}{|c|c|c|c|c|c|}
\hline \multirow[b]{2}{*}{ Edição } & & \multirow[b]{2}{*}{$\begin{array}{l}\text { Conhecimento sobre } \\
\text { Ciências/ Conhecimento } \\
\text { procedimental e } \\
\text { epistemológico }\end{array}$} & \multicolumn{3}{|c|}{ Conhecimento de Ciências } \\
\hline & & & $\begin{array}{l}\text { Sistema } \\
\text { Físicos }\end{array}$ & $\begin{array}{c}\text { Sistemas } \\
\text { Vivos }\end{array}$ & $\begin{array}{c}\text { Terra e } \\
\text { Sistemas } \\
\text { Espaciais }\end{array}$ \\
\hline \multirow{3}{*}{2006} & Brasil & 394 & 385 & 403 & 375 \\
\hline & Japão & 531 & 530 & 526 & 530 \\
\hline & $\begin{array}{l}\text { Média } \\
\text { OCDE }\end{array}$ & 500 & 500 & 502 & 500 \\
\hline \multirow{3}{*}{2015} & Brasil & 401 & 396 & 404 & 395 \\
\hline & Japão & 538 & 538 & 538 & 541 \\
\hline & $\begin{array}{l}\text { Média } \\
\text { OCDE }\end{array}$ & 493 & 493 & 492 & 494 \\
\hline
\end{tabular}

Fonte: http://PISAcountry.acer.edu.au/ e http://gpseducation.oecd.org/Home

Ainda que não tenha conseguido atingir a média dos países da OCDE, o Brasil conseguiu ultrapassar a barreira dos 400 pontos no tocante ao "Conhecimento de Ciências", mas especificamente no conhecimento dos "sistemas vivos" tanto em 2006 quanto em 2015.

No caso do Japão, em 2006, foi na área dos "sistemas físicos" que os estudantes alcançaram média maior. De fato, como veremos nas análises das aulas observadas neste país, é possível apontar ênfase maior nos conteúdos relativos aos “sistemas físicos". Em 2015, o Japão apresentou um desempenho bastante uniforme nas diferentes áreas, sendo este levemente maior na área "Terra e sistemas espaciais". Nas médias da OCDE, os resultados tendem, também, ainda que muito sutilmente, a ser melhores nas questões que demandam o "Conhecimento de Ciências" e, assim como no Brasil, em 2006, o conteúdo com melhores médias de desempenho é o relativo à categoria "sistemas vivos" (502) e, em 2015, à "Terra e sistemas espaciais" (494). O relatório do PISA (OCDE, 2007) reporta que um melhor desempenho em "Conhecimento de Ciências" sugere que o currículo tem dado ênfase ao ensino de conhecimento científico específico.

No caso do Brasil, se compararmos as médias das sub-escalas "Conhecimento de Ciências" e "Conhecimento sobre Ciências", podemos observar, a partir da Tabela 10, que diferentemente da OCDE e do Japão, os nossos estudantes obtém um melhor desempenho geral nas questões ligadas ao "Conhecimento sobre Ciências". O mesmo abrangia, em 2006, questões relacionadas à compreensão da natureza, do trabalho científico e da reflexão científica e, em 2015, o conhecimento dos procedimentos padrão que os cientistas 
usam para obter dados confiáveis e válidos que definem as características essenciais para o processo de construção do conhecimento científico.

Infelizmente, neste caso, não foi possível apresentar dados dos estudantes brasileiros defasados, em fase e adiantados. Os dados de 2006 foram extraídos do website do principal consórcio organizador do PISA - o Australian Council for Educational Research (ACER) - e os de 2015 do website "GPS education" da OCDE. As limitações dessas ferramentas não nos permitiram calcular as médias para esses grupos de estudantes. Do mesmo modo, não estão disponíveis na base de dados do ACER as médias referentes aos sistemas tecnológicos que também compunham o "Conhecimento de Ciências" em 2006. 


\section{A análise do DIF}

A necessidade e relevância da padronização ou uniformização das condições de aplicação dos instrumentos de medida é um dos pressupostos mais importantes da avaliação, seja no âmbito psicológico ou educativo (ANASTASI, 1988; PASQUALI, 2000). O estudo do DIF está intimamente ligado ao suposto da padronização das condições de aplicação dos instrumentos de medida de um teste avaliativo. "Deve-se ter claro que a presença de DIF num teste é um fator que pode tornar o processo avaliativo injusto" (ANDRIOLA, 2001).

A comparação de resultados nos testes educacionais, entendidos como o resultado dos escores que medem a proficiência dos estudantes, é possível graças à utilização da Teoria de Resposta ao Item (TRI). A seguir, e antes de abordar o DIF propriamente dito, a fim de melhorar a compreensão dos tipos de DIF que passarão a ser apresentados, descrevem-se e retomam-se alguns conceitos e potencialidades desta teoria.

\section{1 \\ A Teoria da Resposta ao Item - TRI}

A comparabilidade de resultados em diferentes testes educacionais realizados em grupos diferentes de estudantes é possível graças à utilização da TRI. Tal comparabilidade decorre do fato de a TRI utilizar modelos estatísticos em que a dificuldade dos itens é parametrizada na mesma escala de proficiência das habilidades cognitivas dos estudantes. Além disso, é necessário empregar-se itens comuns aos diferentes testes e que apresentem o mesmo funcionamento nos diferentes grupos de estudantes para que uma boa comparabilidade possa ser alcançada. Em avaliações internacionais de larga escala como o PISA, essa comparabilidade é muito mais crítica, tendo em vista que nem todos os itens apresentam o mesmo funcionamento. No caso do PISA, a TRI possibilita a comparação entre estudantes de diferentes países, uma vez que o modelo empregado nos itens é conhecido, esses estão na mesma escala e há itens comuns nos testes aplicados aos diferentes estudantes dos países participantes. 
A TRI consiste em um conjunto de modelos estatísticos que permitem produzir medidas cognitivas por meio de estímulos, neste caso, os testes de aprendizagem. No contexto da avaliação educacional, os traços latentes são as competências cognitivas dos estudantes e, nesta tese, o Letramento Científico. De acordo com Valle (2001), o que esta metodologia sugere são algumas formas de representar a relação entre a probabilidade de um estudante responder corretamente a um item e seus traços latentes ou habilidade na área de conhecimento avaliada.

Para se compreender a contribuição da TRI para a pesquisa educacional, é preciso, primeiramente, reconhecer que esta abordagem toma como unidade de análise o item e não o teste. O teste é um conjunto de itens, todos, entretanto, normalmente referenciados a uma mesma competência. Para se elaborar adequadamente um teste, é preciso conhecer o funcionamento de cada item, ou seja, a CCI, que estabelece a relação entre o escore ou proficiência do estudante e a probabilidade dele de acertar o item.

Pressupõe-se aqui que todas as curvas características de itens são crescentes, ou seja, quanto maior a proficiência do estudante, maior a chance de acertar o item. A Figura 7 mostra a curva de três itens, ilustrando o fato de que há inúmeros comportamentos possíveis para a curva característica de um item. Verifica-se, na Figura 7, que é possível ter itens para os quais a probabilidade de acerto é alta, mesmo para estudantes de proficiências baixas, como é o caso do item 1, e itens em que a chance de acerto é substancial apenas para valores altos da proficiência, como é o caso do item 3.

Figura 7. Curva característica de três itens.

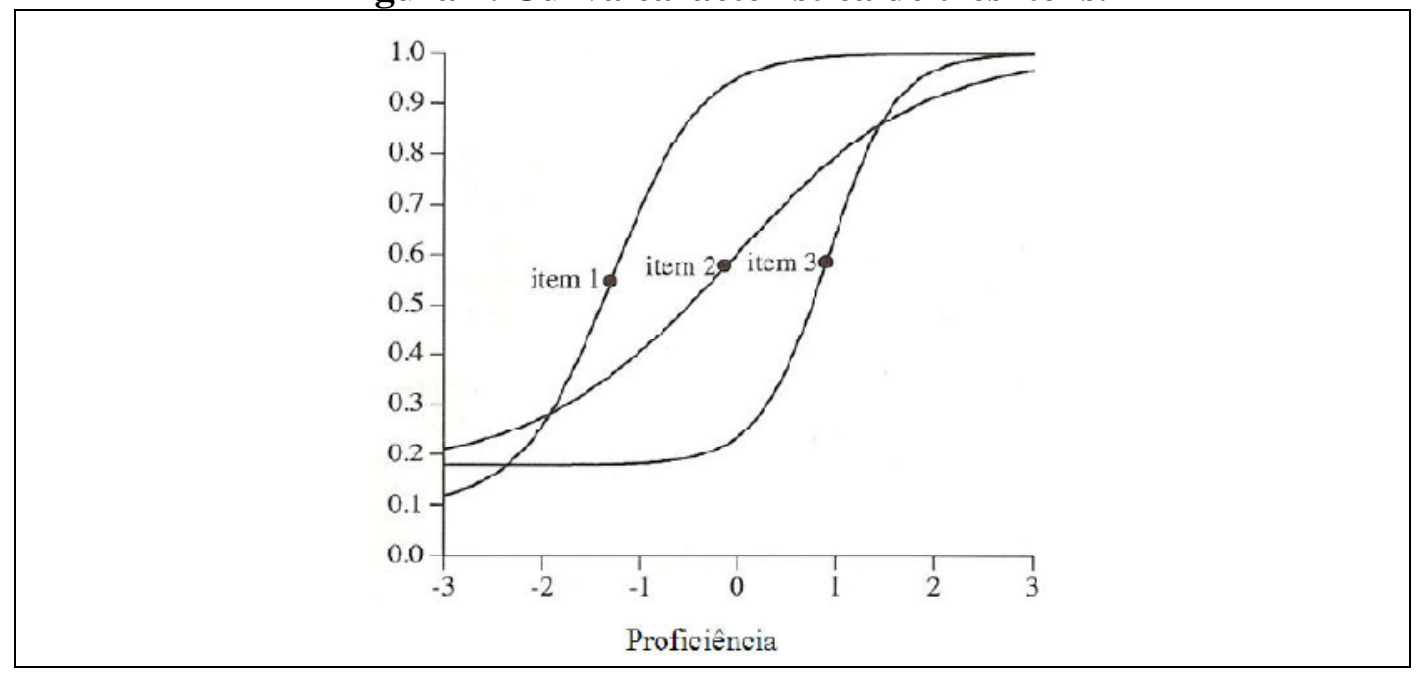

Fonte: Ubriaco, 2009. 
A TRI é composta de um conjunto de modelos estatísticos que representam, grosso modo, a probabilidade de determinada resposta a um item ser escolhida como uma função das características dos itens (dificuldade e discriminação, por exemplo) e das características dos respondentes, principalmente, o nível correspondente do trato latente (no caso a proficiência cognitiva) que está sendo medido. Existem modelos da TRI para diferentes tipos de itens: dicotômicos, politômicos ou para respostas contínuas. Nesta tese, atém-se aos modelos dicotômicos que se diferenciam pelo número de parâmetros analisados: os modelos de um parâmetro, conhecido como modelo de Rasch, considera a dificuldade do item; o modelo de dois parâmetros, também chamado de modelo de Lord, considera a dificuldade e a discriminação do item; e o modelo de três parâmetros considera, além da dificuldade e da discriminação, a probabilidade de acerto casual.

\subsection{1 \\ O modelo de Rasch}

O modelo de Rasch, uma referência ao nome de seu idealizador, George Rasch (1960), é o mais simples para itens dicotômicos, sobretudo devido à sua parcimônia de medida e à simplicidade de sua lógica. Esse modelo é representado pela função logística de um único parâmetro, a qual considera que as respostas de um sujeito a um conjunto de itens dependem apenas de sua habilidade e da dificuldade dos respectivos itens.

Um item é considerado tanto mais difícil quanto maior for o nível de proficiência que o sujeito necessita apresentar para acertá-lo. O modelo logístico unidimensional de um parâmetro é representado pela equação:

$$
P_{i}\left(Y_{i j}=1 / \theta \mathrm{j}\right)=\frac{\mathrm{e}^{(\theta \mathrm{j}-\mathrm{bi})}}{1+\mathrm{e}^{(\theta \mathrm{j}-\mathrm{bi})}}
$$

Onde $\mathrm{Y}_{\mathrm{ij}}$ é o indicador de acerto do item (i) pelo indivíduo (j); $\theta \mathrm{j}$ é a proficiência do indivíduo (j); bi é o parâmetro que indica a dificuldade do item (i). Pode-se verificar imediatamente porque o parâmetro bi é interpretado como sendo a dificuldade do item. Note o que é representado na Figura 2: quando a proficiência do estudante $(\theta j)$ é igual à dificuldade do item bi $(\theta j=b i)$, a probabilidade de acerto ao item fica igual a 0,5. Assim, itens mais difíceis 
requerem maior valor de proficiência para que a probabilidade de acerto atinja 0,5. Representa-se abaixo um exemplo de uma curva característica para um item segundo o modelo de Rasch (Figura 8).

Figura 8. Curva característica do item.

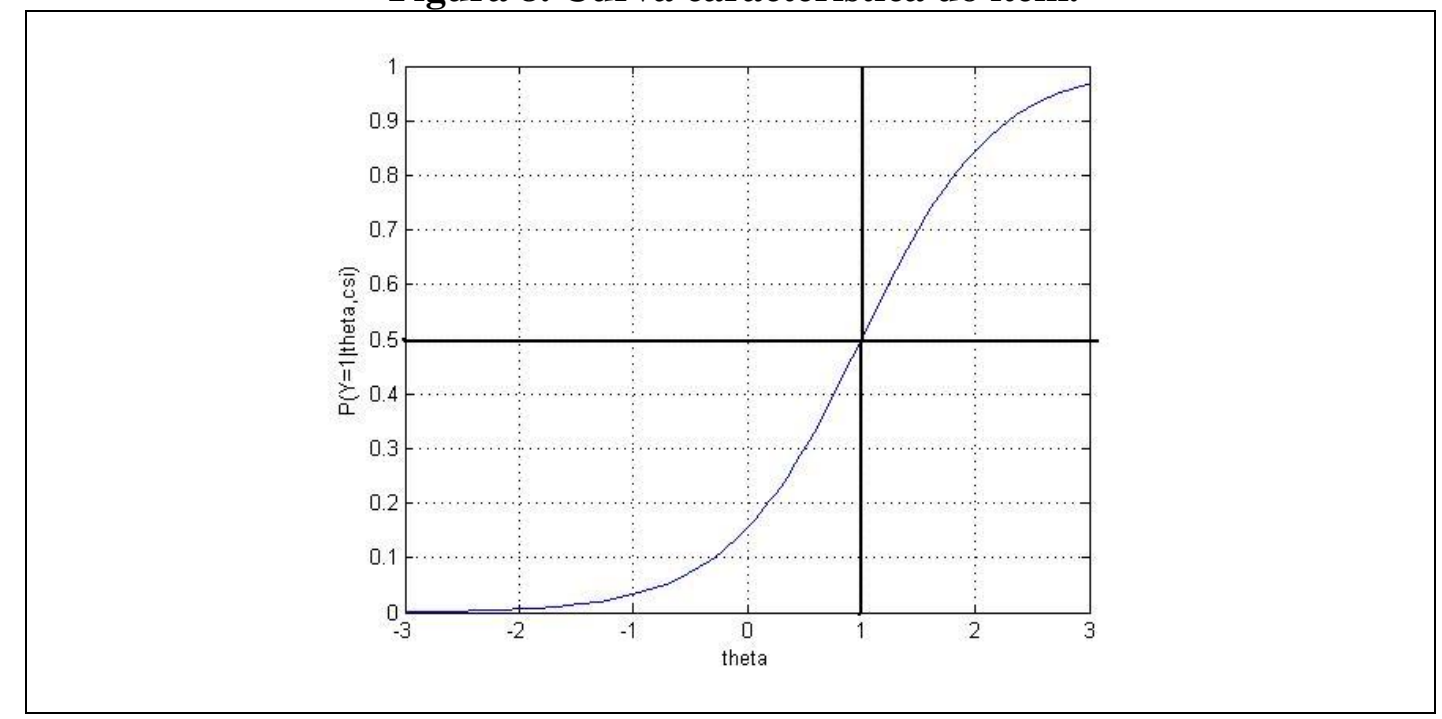

Fonte: elaboração própria a partir do software Matlab. 2017.

\section{1 .2}

\section{O modelo de dois parâmetros}

Este modelo foi inicialmente proposto por Lord em 1952 (LORD, 1980) com base na distribuição normal acumulada, mas em seguida teve o suporte alterado para a função logística por Birnbaum (1968). O modelo de dois parâmetros leva em conta, além do parâmetro de dificuldade, o parâmetro de discriminação do item. Este parâmetro, num certo sentido, representa o quanto o item consegue diferenciar indivíduos com diferentes níveis de proficiência. Se a discriminação do item for baixa, sujeitos de maior e menor habilidade terão probabilidades mais próximas de acertar o item. O modelo logístico unidimensional de dois parâmetros expressa a relação entre a variável latente $\theta$ e a resposta dada ao item da seguinte forma:

$$
P_{i}\left(Y_{i j}=1 ; \theta \mathrm{j}, \mathrm{a}_{\mathrm{i}}, \mathrm{b}_{\mathrm{i}}\right)=\frac{\mathrm{e}^{\mathrm{Da}(\theta-\mathrm{bi})}}{1+\mathrm{e}^{\mathrm{Da} \mathrm{i}_{\mathrm{i}}(\theta-\mathrm{bi})}}
$$

Onde o índice $i$ representa o item; $a_{i}$ é o parâmetro de discriminação do item; e $b_{i}$ é o parâmetro de dificuldade do item. $D$ é um fator de escala, constante, e normalmente igual a 1,7, usado para aproximar a curva logística da distribuição 
normal. Como se pode notar, o parâmetro $b_{i}$ representa o ponto na escala da variável latente $\theta$, para o qual há $50 \%$ de chance de escolha da resposta representada por $\mathrm{Y}=1$ pelo indivíduo (SOARES et al, 2005). Representa-se abaixo um exemplo de uma curva característica para um item segundo o modelo de dois parâmetros (Figura 9).

Figura 9. Curva característica do item segundo o modelo de dois parâmetros.

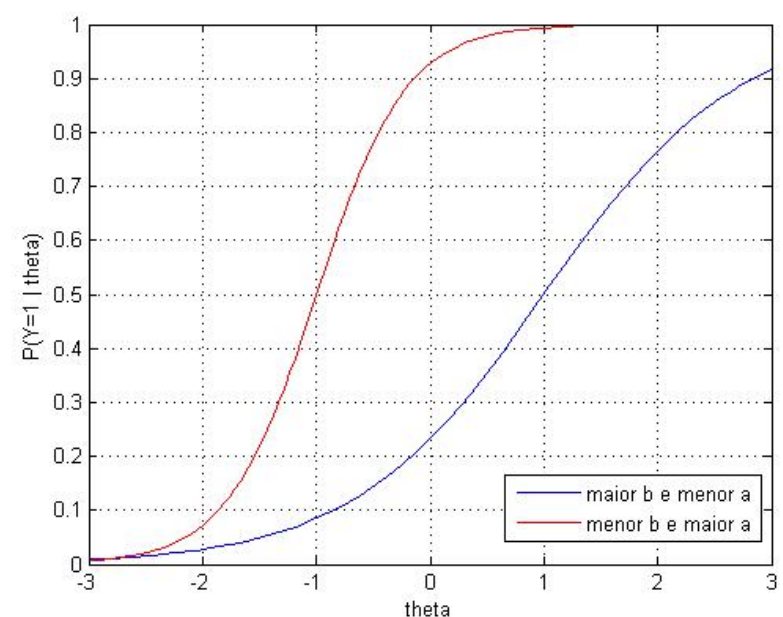

Fonte: elaboração própria a partir do software Matlab. 2017.

A curva vermelha é característica de um item mais fácil, ou seja, onde indivíduos de proficiência mais baixa tem alta probabilidade de acertar o item; e é bastante inclinada, indicando um alto grau de discriminação do item. Já a curva azul, possui menor inclinação e, portanto, indica um parâmetro de discriminação menor, ao passo que representa, também, um item mais difícil, tendo em vista que em proficiências mais baixas as probabilidades de acertar o item são inferiores a do primeiro, representado pela curva vermelha.

\subsection{3}

\section{O modelo de três parâmetros}

Este modelo resulta da incorporação do parâmetro $c_{i}$, que representa a probabilidade de acerto ao acaso, ao modelo de dois parâmetros. O acerto casual pode representar, inclusive, a influência de um "chute" nos testes de múltipla escolha, relacionando, inclusive, a uma resposta dada devido a outro traço que não 
exatamente aquele avaliado no teste ou ainda à resposta aleatória. O modelo logístico unidimensional de três parâmetros é representado pela seguinte equação:

$$
P_{i}\left(Y_{i j}=1 / \theta \mathrm{j}\right)=\mathrm{c}_{\mathrm{i}}+\frac{1-\mathrm{c}_{\mathrm{i}}}{1+\mathrm{e}^{-\mathrm{Da} \mathrm{a}_{\mathrm{i}}(\theta \mathrm{j}-\mathrm{bi})}}
$$

Esta equação corresponde à probabilidade do indivíduo (j) responder corretamente ao item (i), dado que tem habilidade $\theta j$. $C_{i}$ é o parâmetro que corresponde à probabilidade de acerto ao acaso do item (i) e D é uma constante equivalente a 1 para a curva logística ou a 1,7 para se obter uma aproximação da distribuição normal acumulada. Representa-se abaixo um exemplo de uma curva característica para um item segundo o modelo de três parâmetros (Figura 10).

Figura 10. Curva característica do item segundo o modelo de três parâmetros.

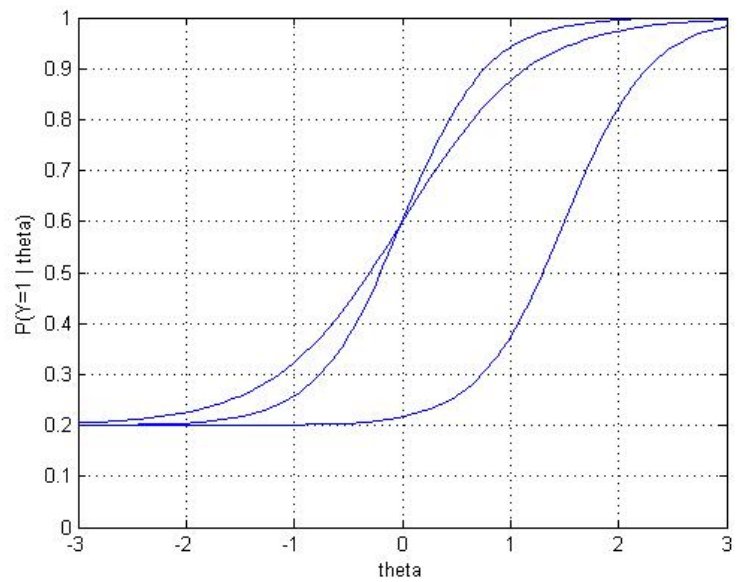

Fonte: elaboração própria a partir do software Matlab. 2017.

De acordo com Soares (2005), para possibilitar a comparabilidade dos resultados é essencial que o modelo utilizado na avaliação garanta o pressuposto de que o item apresente o mesmo funcionamento para os diversos grupos populacionais que estão sendo avaliados. Para uma boa comparação entre resultados de grupos tão diferentes de estudantes, como é o caso de estudantes brasileiros e japoneses, é imprescindível uma atenção especial à construção dos itens, a fim de que estes não apresentem um funcionamento diferencial. 


\section{2 \\ O Funcionamento Diferencial do Item - DIF}

Um item apresenta DIF quando estudantes que possuem a mesma habilidade cognitiva não têm a mesma probabilidade de acertá-lo. Assim, na estimação das proficiências, o ideal é evitar a utilização de itens com DIF elevado, isto é, que favoreçam um determinado grupo de estudantes. Todavia, o DIF, quando moderado e restrito a poucos itens, interfere minimamente na estimação da proficiência e sua análise pode ser uma ferramenta de diagnóstico do sistema educacional bastante útil no que se refere às diferenças curriculares, socioculturais e, no caso de estudos internacionais, como o PISA, à diversidade de realidades educacionais e à disparidade de resultado entre países. Por este motivo principal, justifica-se a escolha do emprego dessa abordagem metodológica para conduzir um estudo comparativo entre dois países de realidades socioeconômicas e culturais tão distintas como é o caso de Brasil e Japão.

Estudos visando identificar itens que sejam favoráveis a um determinado grupo, em detrimento de outros, ganham destaque no campo da psicometria, pois ajudam a assegurar que os testes sejam tão imparciais quanto possível (AGUIAR, 2008). Nesse sentido, Soares (2005) destaca que a preocupação com o funcionamento diferencial do item antecede ou, ainda, extrapola o contexto da TRI, na qual a ausência do DIF é requisito para uma boa equalização entre resultados de grupos diferentes de estudantes.

\section{2 .1}

\section{Alguns Estudos de DIF}

As análises de DIF tem sido de grande importância na pesquisa educacional desde a década de 60. Autores consagrados como O’Neil \& McPeek (1993), Schmitt \& Bleistein (1987), Berberoglu (1995), entre outros, mostraram a importância dessas análises em estudos que comparam os itens de testes educacionais aplicados a diferentes grupos.

Historicamente, a preocupação com o DIF está fortemente associada ao desejo de se construírem questões de teste que não sejam afetadas por características étnico-culturais dos grupos submetidos aos testes de avaliação 
educacional (COLE, 1993). A partir de achados em estudos sobre o viés ${ }^{28}$ de itens e testes realizados em 1951 por pesquisadores da Universidade de Chicago, que haviam encontrado variações nos itens em aspectos peculiares, tais como conteúdo e formato, surgem os primeiros dados a respeito dos problemas técnicos presentes em determinados itens utilizados na avaliação da aprendizagem (HAMBLETON, SWAMINATHAN, ROGERS, 1991). Segundo Aguiar (2008), um desses problemas técnicos diz respeito ao uso indevido da linguagem escrita; muitas vezes, termos empregados nos testes são mais familiares a determinado grupo em detrimento de outro. O`Neil \& McPeek (1993), Schmitt \& Bleistein (1987), Berberoglu (1995) e Gierl, Bisanz, Bisanz \& Boughton (2003) mostraram que as diferenças entre os grupos podem também estar relacionadas às características étnicas, de sexo e de nível socioeconômico.

Soares et al (2005) apresentam uma análise do comportamento diferencial dos itens de geografia aplicados aos estudantes da 4a série no Programa de Avaliação da rede Pública de Educação Básica, o Proeb-2001 nas diferentes regiões do Estado de Minas Gerais. Os resultados sugerem que itens relacionados a questões ambientais são mais fáceis para os estudantes da região metropolitana de Belo Horizonte do que para os estudantes do interior do Estado. Por outro lado, os itens que avaliam a relação entre o espaço urbano e o espaço rural se mostram mais fáceis para os estudantes do interior.

Barroso e Franco (2008) realizaram uma análise comparativa entre países participantes do PISA 2000 com foco em linguagem, utilizando a Teoria da Resposta ao Item e a identificação de questões que apresentavam DIF. O objetivo dos autores era o de verificar se o desempenho dos estudantes brasileiros teria ou não características diferentes de estudantes de outros países, e se estas características poderiam revelar diferentes ênfases curriculares no Ensino de Ciências, apesar de o foco da edição investigada ter sido linguagem. Os resultados obtidos indicaram a existência de itens com DIF, mas não permitiram a explicação deste comportamento com base nos parâmetros escolhidos associados às ênfases curriculares. Isso se deveu, segundo os autores, ao pequeno número de itens disponíveis no ano 2000, apenas 34, que apontavam para a então necessidade de

\footnotetext{
${ }^{28}$ Um item é enviesado se sujeitos e habilidades iguais, mas de culturas diferentes, não tem a mesma probabilidade de acertar um item (LINN \& DRASGOW, 1993).
} 
técnicas estatísticas mais elaboradas e a utilização dos dados do PISA 2006 para avançar nesta avaliação.

Aguiar (2008), a partir dos dados do PISA 2003, comparou as diferenças nas ênfases curriculares em Matemática no Brasil e Portugal. Os resultados deste estudo mostraram que alguns itens de Matemática apresentam funcionamento diferencial entre estudantes brasileiros e portugueses. Para o autor, os aspectos que explicam esta ocorrência estão relacionados com ênfases diferenciadas não apenas em determinados conteúdos da Matemática, mas também a processos cognitivos e ao formato do item.

Gamerman et al (2010) realizaram uma análise Bayesiana na Teoria de Resposta ao Item aplicada ao PISA 2003 e identificaram uma série de indicadores que diferenciam os sistemas educativos dos países de língua inglesa participantes do Programa (Grã-Bretanha, Canadá, Austrália, Irlanda, Estados Unidos e Nova Zelândia). Estes indicadores, segundo os autores, podem ajudar a compreender a natureza e as possíveis origens da diferença entre esses países e mostrar um possível caminho para a incorporação de práticas benéficas, atualmente disponíveis, nesses sistemas de ensino.

Esses resultados ratificam a importância das análises de DIF, na identificação de diferenças em testes de habilidades. Segundo Aguiar (2008), essa análises nos sugerem que, ao invés de entendermos o item do teste como a única causa do desempenho diferencial, devemos considerar, também, questões de equidade educacional em nossas escolas e em nossa sociedade. $\mathrm{O}$ perfeito entendimento dos resultados de DIF passa, necessariamente, pelo reconhecimento dessas desigualdades sócio educacionais. Aliado a isso, a gama de evidências empíricas produzidas pelos já citados entre tantos outros trabalhos de análise de DIF, muitos métodos estatísticos foram desenvolvidos no intuito de dar maior suporte a este tipo de abordagem.

\section{2 .2}

\section{Métodos de detecção de itens com DIF}

Existem vários procedimentos formais para se estudar o comportamento diferencial dos itens. Grosso modo, esses procedimentos podem ser divididos em dois grupos: 
1. os clássicos que dependem, direta ou indiretamente, de uma estimativa prévia da proficiência, por exemplo, o método de Mantel-Haenszel (HOLLAND \& THAYER, 1988) e o método de regressão logística (SWAMINATHAN E ROGERS, 1990);

2. os baseados nos modelos da TRI que utilizam os parâmetros desta teoria e, apesar de não precisarem de uma proficiência já conhecida, demandam um critério alternativo para a equalização dos indivíduos, a priori, um subconjunto de itens que não possuam DIF, genericamente chamados de itens âncora. Exemplos bastante conhecidos desses métodos são o IRT-D ${ }^{2}$ (THISSEN, 2001), o IRT-LR (THISSEN, STEINBERG \&WAINER, 1993), e o BILOGMG (ZIMOWSKI, MURAKI, MISLEVY \& BOCK, 1996).

Outros métodos ainda podem ser encontrados em Clauser \& Mazor (1998) e em Andriola (2001). Dentre os métodos mais conhecidos estão os dois exemplos clássicos citados anteriormente. O método de Mantel-Haenszel foi desenvolvido por N. Mantel e W. Haenszel no ano de 1959, e aplicado ao estudo do DIF por P. W. Holland e D. T. Thayer em 1988 (ANGOFF, 1993; DORANS \& HOLLAND, 1993). Consiste, basicamente, na comparação das frequências observadas e esperadas de acertos e erros nos grupos que geralmente os estudos para determinação de DIF utilizam, denominados de referência e focal, de acordo com os distintos níveis de habilidade escolhidos pelo investigador (ANDRIOLA, 2001). Nesta tese, o Brasil é o grupo de referência e o Japão o grupo focal.

Uma crítica ao método de Mantel-Haenszel é que ele não é sensível ao DIF não uniforme ${ }^{29}$, ou seja, não é capaz de detectar DIF quando há uma interação entre o nível de proficiência e o desempenho no item. Nesse tipo de DIF é inapropriado examinar-se globalmente os dados, como prevê o método de MantelHaenszel, pois tal procedimento poderia ocultar sua presença uma vez que a variabilidade do DIF se verifica em diferentes zonas da variável latente. Este problema, segundo Aguiar (2008), motivou a busca por técnicas de detecção de

\footnotetext{
${ }^{29}$ Existem, basicamente, dois tipos de DIF. O primeiro é o DIF uniforme ou consistente, que ocorre quando as CCIs do item estudado para os grupos focal e de referência são diferentes, indicando que o item favorece uniformemente um dos grupos em detrimento do outro. Em outras palavras, as curvas não se cruzam em nenhum ponto, ao longo da variável latente, neste caso, a proficiência. O segundo tipo de DIF, denominado DIF não uniforme DIF ou inconsistente ocorre quando há uma interação entre o nível de proficiência e o desempenho no item, de modo que a direção do item muda ao longo da escala de proficiência. (AGUIAR, 2008).
} 
DIF que superassem essa limitação, como é o caso do método da regressão logística.

O modelo para predizer a probabilidade de ocorrência de uma resposta correta a um item, mais conhecido como método da regressão logística, como destaca Bock (1975), é um procedimento estatístico para predizer uma variável dependente, de natureza dicotômica, a partir de algumas variáveis independentes, no caso desta proposta, proficiência e grupo. O método de regressão logística é um dos mais utilizados para detectar o DIF (SWAMINATHAN \& ROGERS, 1990; ROGERS \& SWAMINATHAN, 1993; ZUMBO, 1999). Contudo, o método de Mantel-Haenszel ainda é o mais utilizado para a análise de DIF, inclusive no Educational Testing Service (ETS), nos exames do National Assessment for Educational Progress (NAEP); e aqui no Brasil, na análise do Sistema de Avaliação da Educação Básica (Saeb).

Alguns métodos baseados em modelos da TRI, como IRT-D2 e IRT-LR (THISSEN, 2001; THISSEN, STEINBERG, \& WAINER, 1993), impõem que alguns do itens (genericamente chamados de itens âncora) não apresentem DIF. Segundo Soares et al (2009) eles consideram dois modelos:

1. o modelo compacto, em que os parâmetros de todos ou de parte dos itens têm necessariamente que ser os mesmos para os grupos estudados;

2. o modelo ampliado, onde os parâmetros dos itens para os quais o DIF é considerado podem variar para os grupos estudados.

De acordo com Soares et al (2009) a detecção dos itens com DIF é um passo importante na análise de DIF, mas uma análise completa também requer alguns outros passos importantes. Isso inclui uma satisfatória classificação do DIF encontrado, a identificação dos fatores a ele associados e, possivelmente, uma análise confirmatória das hipóteses. Schmitt, Holland \& Dorans (1993) sugerem que estudos especialmente planejados devem ser utilizados para confirmar as hipóteses formuladas a partir do estudo dos fatores de DIF. Neste contexto, é natural a construção de modelos de regressão que associam covariáveis, relacionadas com os itens, à magnitude do DIF. As covariáveis representariam os fatores de DIF de tal maneira que os resultados da análise de regressão podem confirmar ou não as hipóteses formuladas.

Esses métodos comparam os modelos em fases sucessivas utilizando a razão de verossimilhança nos testes. Em alguns deles os itens de ancoragem podem 
permanecer constantes ou variar em estágios diferentes, dependendo dos resultados dos testes (WANG E YEH, 2003). Em qualquer caso, todas estas propostas envolvem diferentes fases de detecção de parâmetros de DIF e decisão sobre quais itens têm DIF ou não.

Soares et al. (2009) descreveu um modelo Bayesiano integrado para detecção e análise de DIF que elimina a necessidade de utilização dessas etapas separadas. O modelo proposto, inicialmente, assume que um subconjunto de itens âncora é conhecido e que os parâmetros dos demais itens podem variar entre os grupos de indivíduos. Contudo, ele também pode ser usado quando não se tem certeza se um item apresenta ou não DIF, isto é, quando não se tem certeza absoluta de que um item não tem DIF e pode ser usado como âncora. Estudos simulados mostraram uma boa recuperação dos parâmetros gerados, e um exemplo real mostrou a viabilidade da utilização do modelo em situações práticas com resultados satisfatórios e consistentes. Por essas, entre outras vantagens, nesta tese, utilizou-se este modelo agregado que elimina etapas, dado que uma análise de regressão associada aos parâmetros do DIF é introduzida no modelo de tal forma que, além de confirmar a ocorrência, também se pode, simultaneamente, explicar o DIF.

\subsection{3 \\ Investigando os itens com DIF}

Antes de iniciarmos a investigação dos itens com DIF é importante que os seguintes conceitos sejam definidos:

1. $d a_{j}$ representa a diferença entre o parâmetro $a_{j}$ do grupo de focal menos tal parâmetro no grupo de referência, ele indica o quanto o item $j$ discrimina mais no grupo focal (Japão) em relação ao de referência (Brasil).

2. $d b_{j}$ representa a diferença entre o parâmetro $b_{j}$ do grupo de focal menos tal parâmetro no grupo de referência, ele indica o quanto o item $j$ se apresenta mais difícil no grupo focal (Japão) em relação ao de referência (Brasil).

3. $Z a_{j}$ mede a probabilidade de ocorrência de DIF no parâmetro $a_{j}$ no item $j$.

4. $Z b_{j}$ mede a probabilidade de ocorrência de DIF no parâmetro $b_{j}$ no item $j$.

Nesta pesquisa consideramos como tendo DIF todos os itens que apresentavam tanto nos parâmetros $Z a$ quanto nos parâmetros $Z b$ valores maiores 
que 0,6 , ou seja, que apresentavam mais que $60 \%$ de chance do item ter DIF nos parâmetros $a$ ou $b$. Este é um percentual bastante aceito e utilizado na literatura. Soares et al (2009) consideraram como tendo DIF aqueles itens que apresentam um $\mathrm{Z}$ maior do que 0,5 .

Do total de 96 itens analisados, 62 apresentaram DIF independentemente do parâmetro avaliado; oito dos quais apresentaram DIF tanto no parâmetro $a$ como no parâmetro $b$, levando-se em consideração Brasil e Japão. São 20 os itens que apresentam DIF somente no parâmetro $a$ e 50 aqueles que apresentam comportamento diferencial somente no parâmetro b. As Tabelas que se seguem identificam os códigos dos itens para os quais houve DIF, apresentam os parâmetros do DIF e os percentuais válidos de acerto no Brasil, Japão e OCDE. Há duas planilhas anexadas a esta tese. Uma contém as características dos itens de Ciências do PISA 2006 que utilizamos aqui e a outra traz os parâmetros do DIF e os percentuais de acertos desses mesmos itens (Anexos D e E).

Tabela 10. Itens de Ciências do PISA 2006 que apresentam DIF no parâmetro $a$ (discriminação) entre Brasil e Japão.

\begin{tabular}{|c|c|c|c|c|c|c|c|c|}
\hline \multirow{2}{*}{$\begin{array}{l}\text { Código } \\
\text { do Item }\end{array}$} & \multirow[t]{2}{*}{$Z a$} & \multirow[t]{2}{*}{$a 1$} & \multirow[t]{2}{*}{$a 2$} & \multirow[t]{2}{*}{ d.a } & \multirow{2}{*}{$\begin{array}{l}\text { Discrimina } \\
\text { mais no }\end{array}$} & \multicolumn{3}{|c|}{$\begin{array}{l}\text { Percentual válido de } \\
\text { respostas corretas }\end{array}$} \\
\hline & & & & & & Brasil & Japão & OCDE \\
\hline S213Q01 & 0,824 & 1,444 & 0,945 & $-0,417$ & BR & 16,9 & 53,1 & 47,9 \\
\hline S213Q02 & 0,988 & 1,004 & 0,498 & $-0,703$ & BR & 44,9 & 81,2 & 77,6 \\
\hline S256Q01 & 0,885 & 0,249 & 0,454 & 0,587 & $J P$ & 76,3 & 94,2 & 87,2 \\
\hline S268Q06 & 0,732 & 1,543 & 0,946 & $-0,446$ & BR & 31,3 & 59,5 & 54,0 \\
\hline S416Q01 & 0,971 & 1,479 & 0,817 & $-0,588$ & BR & 14,1 & 64,3 & 44,7 \\
\hline S421Q03 & 0,878 & 1,474 & 0,805 & $-0,599$ & BR & 31,0 & 61,7 & 63,5 \\
\hline S425Q02 & 0,675 & 1,631 & 1,116 & $-0,366$ & $\mathrm{BR}$ & 28,1 & 60,4 & 45,5 \\
\hline S426Q03 & 0,627 & 1,302 & 0,674 & $-0,527$ & BR & 31,0 & 68,0 & 66,3 \\
\hline S426Q05 & 0,862 & 0,848 & 1,315 & 0,440 & JP & 49,0 & 84,5 & 74,7 \\
\hline S437Q06 & 1,000 & 1,508 & 0,714 & $-0,747$ & $\mathrm{BR}$ & 35,3 & 69,6 & 74,1 \\
\hline S438Q01 & 0,891 & 1,052 & 0,658 & $-0,484$ & $\mathrm{BR}$ & 53,9 & 79,6 & 82,6 \\
\hline S438Q02 & 0,998 & 0,565 & 1,315 & 0,848 & JP & 42,6 & 71,9 & 66,1 \\
\hline S447Q02 & 0,981 & 0,365 & 0,865 & 0,865 & JP & 37,7 & 45,6 & 41,4 \\
\hline S478Q01 & 0,836 & 0,686 & 0,335 & $-0,716$ & $\mathrm{BR}$ & 26,8 & 36,0 & 43,1 \\
\hline S485Q02 & 0,973 & 1,545 & 0,875 & $-0,566$ & BR & 32,4 & 54,6 & 57,8 \\
\hline S493Q01 & 0,618 & 0,649 & 0,419 & $-0,446$ & BR & 27,3 & 37,9 & 50,4 \\
\hline S498Q03 & 0,855 & 0,500 & 0,924 & 0,602 & $J P$ & 36,3 & 45,13 & 43,0 \\
\hline S508Q03 & 0,957 & 0,667 & 1,187 & 0,589 & JP & 45,5 & 78,8 & 71,8 \\
\hline S510Q01 & 0,664 & 0,730 & 0,483 & $-0,424$ & BR & 30,6 & 62,4 & 52,1 \\
\hline S527Q03 & 0,676 & 0,969 & 0,563 & $-0,495$ & $\mathrm{BR}$ & 32,3 & 74,6 & 57,4 \\
\hline
\end{tabular}

Fonte: Elaboração própria a partir dos resultados das análises de DIF, com dados do PISA 2006.

A Tabela 10 lista os itens de Ciências do PISA de 2006 que apresentam DIF no parâmetro $a$ de discriminação entre Brasil e Japão. Os itens em negrito são 
públicos e serão descritos e discutidos mais adiante. Na primeira coluna da tabela estão os códigos de identificação dos itens tal com aparecem no PISA. As quatro colunas que se seguem apresentam os parâmetros do DIF. $\mathrm{Za}$ indica a probabilidade de um item apresentar DIF. Visto que nesta tese foram considerados possuidores de DIF todos os itens que apresentavam médias maiores que 0,6, ou seja, que apresentavam mais que $60 \%$ de chance de obter DIF. Neste sentido, todos os itens listados na tabela 10 apresentam Za superior a 0,6.

As colunas $a 1$ e $a 2$ indicam, respectivamente, o parâmetro $a$ do grupo focal, o Japão, e do grupo de referência, o Brasil. A coluna da representa a diferença entre o parâmetro $a$ do grupo focal menos tal parâmetro no grupo de referência, indicando, portanto, o quanto o item discrimina mais no grupo focal em relação ao de referência. Os coeficientes médios de $d a$ se negativos indicam uma maior discriminação nos itens de Ciências para o Brasil e os coeficientes em média positivos o fazem para o Japão. A penúltima coluna da Tabela 10 traz esta informação. Como se pode observar, a maioria dos coeficientes médios é negativo, 14 de 20, e, portanto, discriminam mais os itens para os estudantes brasileiros em relação aos japoneses. Na tripla e última coluna estão os percentuais válidos de resposta correta aos itens.

Na mesma lógica da Tabela 10, a Tabela 11 lista os itens de Ciências do PISA de 2006 que apresentam DIF no parâmetro $b$ de dificuldade entre Brasil e Japão. Nesta Tabela, assim como na anterior, os itens em negrito são públicos e serão descritos e discutidos mais adiante. Aqueles em vermelho possuem DIF também no parâmetro $a$ e já tiveram seus parâmetros listados na Tabela anterior. Na primeira coluna da Tabela 11 estão os códigos de identificação dos itens tal com aparecem no PISA. As quatro colunas que se seguem apresentam os parâmetros do DIF. Tal qual na Tabela anterior esses parâmetros funcionam de igual maneira sendo que eles fazem referência à dificuldade do item. Todos os itens listados na Tabela 11 apresentam $\mathrm{Zb}$ superior a 0,6 e, por isso, foram considerados possuidores de DIF. Os coeficientes médios de $d b$ se negativos indicam uma maior dificuldade dos itens de Ciências para o Brasil e os coeficientes em média positivos o fazem para o Japão. A penúltima coluna da Tabela 11 indica quais itens foram mais fáceis para estudantes brasileiros e japoneses e a última os percentuais válidos de acerto. Dos 50 itens com DIF em $b$, 
22 foram mais fáceis para os estudantes brasileiros e 28 para os estudantes japoneses.

Tabela 11. Itens de Ciências do PISA 2006 que apresentam DIF no parâmetro $b$ (dificuldade) entre Brasil e Japão.

\begin{tabular}{|c|c|c|c|c|c|c|c|c|}
\hline \multirow{2}{*}{$\begin{array}{l}\text { Código do } \\
\text { item }\end{array}$} & \multirow[t]{2}{*}{$\mathrm{Zb}$} & \multirow[t]{2}{*}{ b1 } & \multirow[t]{2}{*}{ b2 } & \multirow[t]{2}{*}{ déb. } & \multirow{2}{*}{$\begin{array}{l}\text { Mais fácil } \\
\text { para }\end{array}$} & \multicolumn{3}{|c|}{$\begin{array}{l}\text { Percentual válido de } \\
\text { respostas corretas }\end{array}$} \\
\hline & & & & & & Brasil & Japão & OCDE \\
\hline S114Q05 & 1,000 & 1,897 & 3,226 & $-1,329$ & BR & 16,6 & 18,0 & 19,2 \\
\hline S131Q04 & 0,805 & 1,625 & 1,966 & $-0,340$ & BR & 19,4 & 39,9 & 31,4 \\
\hline S213Q02 & 1,000 & 0,554 & $-0,691$ & 1,247 & JP & 44,9 & 81,2 & 77,6 \\
\hline S269Q01 & 0,979 & 0,587 & 0,115 & 0,471 & $J P$ & 33,9 & 84,1 & 56,5 \\
\hline S269Q03 & 1,000 & 1,526 & 0,159 & 1,366 & $J P$ & 13,7 & 80,6 & 39,9 \\
\hline S269Q04 & 1,000 & 2,312 & 1,247 & 1,066 & $J P$ & 18,6 & 57,4 & 33,9 \\
\hline S304Q03a & 1,000 & 1,002 & 1,668 & $-0,666$ & $\mathrm{BR}$ & 21,5 & 42,4 & 38,7 \\
\hline S326Q01 & 0,874 & 0,887 & 1,265 & $-0,377$ & $\mathrm{BR}$ & 40,7 & 64,7 & 60,0 \\
\hline S326Q02 & 1,000 & 0,572 & 1,236 & $-0,663$ & $\mathrm{BR}$ & 40,4 & 64,8 & 63,1 \\
\hline S326Q03 & 0,836 & 1,330 & 1,037 & 0,293 & $J P$ & 26,8 & 68,4 & 56,4 \\
\hline S408Q03 & 0,964 & 2,644 & 3,541 & $-0,897$ & $\mathrm{BR}$ & 12,9 & 16,2 & 31,2 \\
\hline S408Q04 & 1,000 & 0,852 & 2,009 & $-1,157$ & $\mathrm{BR}$ & 40,6 & 44,8 & 47,7 \\
\hline S413Q04 & 0,889 & 2,116 & 1,497 & 0,618 & $J P$ & 16,5 & 52,9 & 40,3 \\
\hline S415Q07 & 0,953 & 0,718 & 1,406 & $-0,687$ & $\mathrm{BR}$ & 53,8 & 63,6 & 72,8 \\
\hline S415Q08 & 0,755 & 1,161 & 0,798 & 0,362 & $J P$ & 36,9 & 73,0 & 57,7 \\
\hline S416Q01 & 1,000 & 1,613 & 0,874 & 0,738 & JP & 14,1 & 64,3 & 44,7 \\
\hline S425Q05 & 1,000 & 0,912 & $-0,085$ & 0,997 & $J P$ & 48,4 & 84,4 & 69,4 \\
\hline S426Q03 & 1,000 & 2,235 & 1,001 & 1,234 & JP & 31,0 & 68,0 & 66,3 \\
\hline S426Q07 & 0,892 & 1,294 & 2,176 & $-0,882$ & BR & 50,5 & 53,6 & 62,4 \\
\hline S437Q01 & 1,000 & 1,251 & 0,416 & 0,834 & $J P$ & 46,1 & 82,5 & 70,6 \\
\hline S437Q03 & 1,000 & 1,052 & 1,839 & $-0,786$ & $\mathrm{BR}$ & 37,3 & 51,1 & 48,2 \\
\hline S447Q03 & 1,000 & 0,672 & 1,361 & $-0,689$ & BR & 41,5 & 60,4 & 55,8 \\
\hline S458Q01 & 1,000 & 1,620 & 2,812 & $-1,192$ & BR & 14,8 & 16,0 & 15,9 \\
\hline S458Q02 & 0,844 & 1,278 & 0,878 & 0,399 & JP & 26,0 & 66,0 & 57,1 \\
\hline S466Q05 & 0,996 & 1,994 & 1,002 & 0,992 & JP & 33,5 & 66,0 & 52,8 \\
\hline S466Q07 & 1,000 & 0,986 & $-0,145$ & 1,132 & JP & 26,8 & 86,6 & 75,0 \\
\hline S476Q01 & 0,719 & 0,648 & 0,270 & 0,377 & JP & 46,5 & 79,4 & 70,7 \\
\hline S476Q03 & 0,804 & 0,847 & 0,520 & 0,327 & JP & 36,5 & 75,0 & 58,7 \\
\hline S477Q02 & 0,998 & 0,078 & 0,921 & $-0,843$ & BR & 61,4 & 71,9 & 76,8 \\
\hline S477Q03 & 1,000 & 0,050 & 0,805 & $-0,754$ & BR & 58,8 & 76,0 & 74,5 \\
\hline S477Q04 & 0,991 & 0,709 & 0,069 & 0,640 & JP & 37,1 & 85,1 & 60,1 \\
\hline S478Q01 & 0,862 & 2,215 & 3,591 & $-1,376$ & BR & 26,8 & 36,0 & 43,1 \\
\hline S478Q03 & 1,000 & 0,194 & 1,154 & $-0,960$ & BR & 57,6 & 66,4 & 66,1 \\
\hline S485Q02 & 1,000 & 0,593 & 1,263 & $-0,669$ & BR & 32,4 & 54,6 & 57,8 \\
\hline S485Q03 & 0,999 & 0,701 & 0,125 & 0,576 & JP & 43,5 & 83,4 & 66,1 \\
\hline S493Q01 & 0,669 & 2,009 & 2,618 & $-0,608$ & BR & 27,3 & 37,9 & 50,4 \\
\hline S493Q03 & 0,992 & $-0,396$ & 0,309 & $-0,705$ & BR & 71,0 & 79,9 & 82,7 \\
\hline S493Q05 & 0,903 & 1,907 & 1,482 & 0,425 & JP & 13,8 & 51,2 & 44,6 \\
\hline S495Q01 & 0,670 & 1,699 & 1,443 & 0,255 & JP & 18,0 & 51,4 & 42,1 \\
\hline S495Q03 & 1,000 & 0,992 & 1,414 & $-0,421$ & BR & 20,6 & 48,5 & 39,3 \\
\hline
\end{tabular}




\begin{tabular}{lllllllll}
\hline S495Q04 & 0,625 & 1,569 & 1,332 & 0,237 & JP & 24,4 & 58,5 & 54,4 \\
S498Q02 & 0,978 & 1,406 & 2,051 & $-0,645$ & BR & 37,1 & 46,4 & 46,5 \\
\hline S510Q01 & 0,704 & 1,569 & 1,124 & 0,444 & JP & 30,6 & 62,4 & 52,1 \\
S514Q03 & 0,735 & 1,561 & 1,255 & 0,305 & JP & 24,2 & 60,8 & 46,3 \\
\hline S514Q04 & 1,000 & 1,496 & 0,954 & 0,541 & JP & 22,5 & 68,4 & 52,2 \\
S521Q02 & 0,741 & 2,337 & 1,789 & 0,547 & JP & 31,4 & 57,6 & 55,1 \\
\hline S521Q06 & 1,000 & $-0,468$ & 0,419 & $-0,887$ & BR & 68,3 & 80,1 & 88,9 \\
\hline S524Q06 & 0,999 & 1,152 & 0,640 & 0,511 & JP & 36,4 & 72,2 & 64,5 \\
\hline S527Q03 & 1,000 & 1,974 & 0,441 & 1,533 & JP & 32,3 & 74,6 & 57,4 \\
S527Q04 & 0,639 & 1,947 & 1,598 & 0,348 & JP & 28,9 & 56,8 & 53,7 \\
\hline
\end{tabular}

Fonte: Elaboração própria a partir dos resultados das análises de DIF, com dados do PISA 2006.

Na sequência, recorrendo a um item público, liberado para divulgação pelo consórcio que administra o PISA, exemplificamos, resumidamente, os procedimentos adotados na identificação do DIF. Esclarecemos que o mesmo procedimento foi adotado com todos os demais itens de Ciências do teste e que os itens públicos possuidores de DIF em ambos os parâmetros $a$ e $b$ serão, também, apresentados, descritos e discutidos mais adiante. Eles somam um total de 4 itens e tomamos inicialmente como exemplo o item S213Q02 (Figura 11). 
Figura 11. Unidade Roupas, Questão 2. Código S213Q02

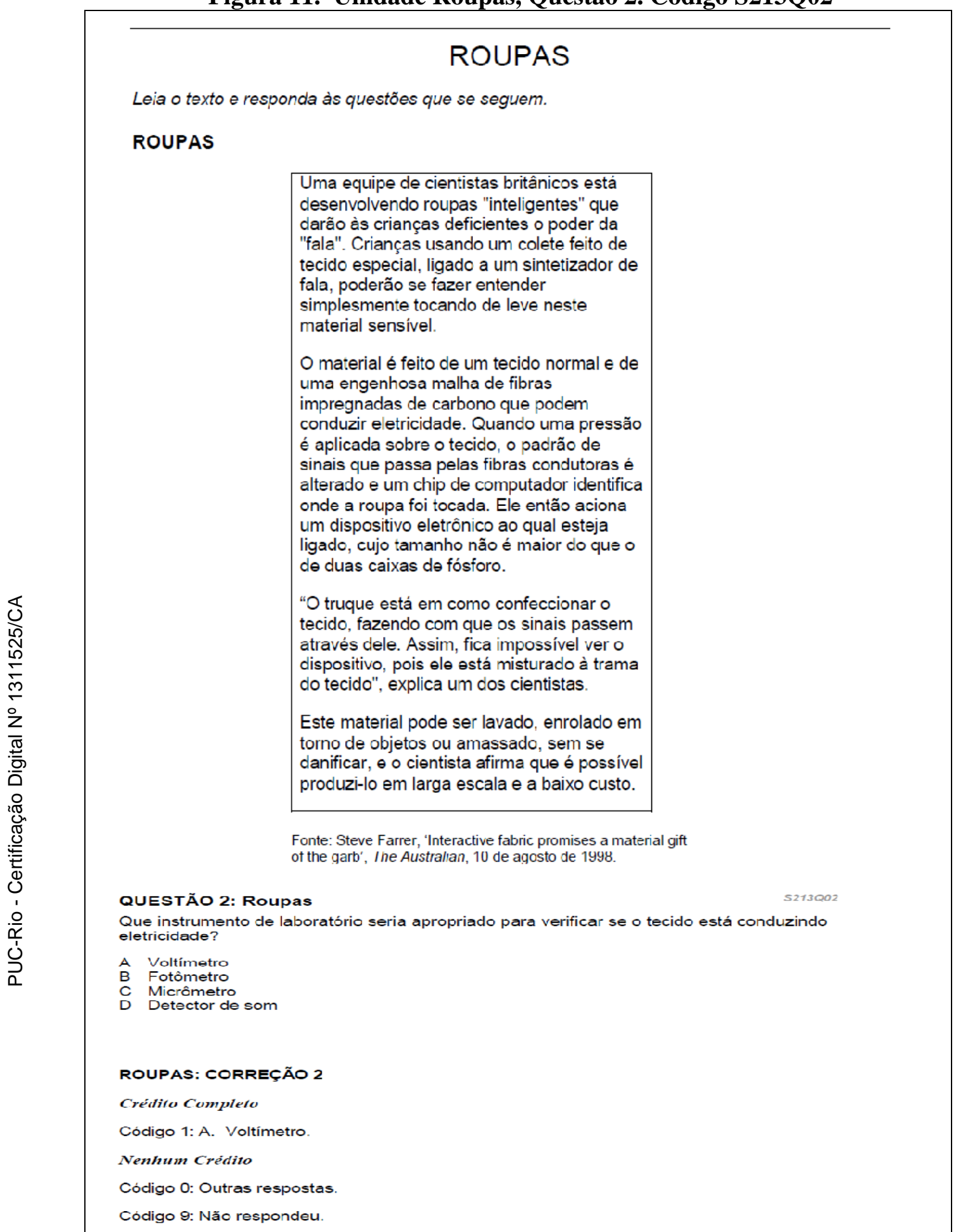

Fonte: BRASIL, 2008.

Como se pode observar na figura acima, o item S213Q02 é de múltipla escolha. Ele está inserido na área de aplicação "limites da ciência e da tecnologia", num contexto pessoal e acessa a área do conhecimento de "sistemas 
tecnológicos". Ele avalia a competência de "explicar fenômenos cientificamente" e foi desenvolvido na Austrália originalmente em Inglês. Calculados os parâmetros de discriminação e dificuldade deste item, é possível afirmar que ele é mais fácil para os estudantes japoneses em relação aos brasileiros, com um coeficiente médio positivo de 1,247 (Tabela 10), e mais discriminante na população de estudantes brasileiros em relação aos estudantes japoneses. O valor médio do $d . a$, ou seja, a diferença entre o parâmetro $a$ do grupo focal menos tal parâmetro no grupo de referência é negativo (-0,7036, ver Tabela 9) indicando que o item é mais discriminante entre os estudantes brasileiros. Abaixo apresentamos a CCI deste item para Brasil e Japão (Figura 12).

Figura 12. Curva característica do item S213Q02.

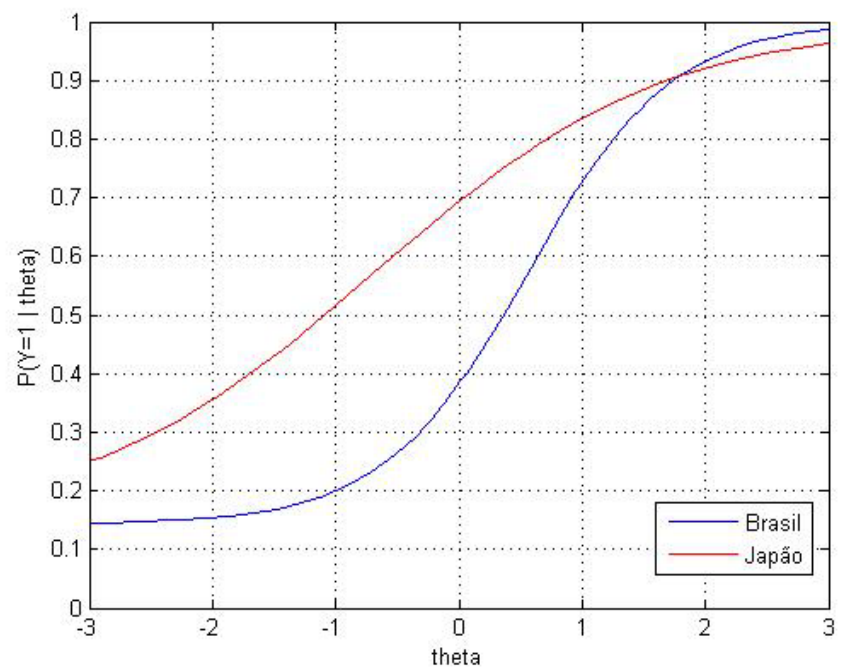

Fonte: Elaboração própria a partir do software Matlab. 2017.

A partir da análise gráfica da Figura 12 podemos perceber a presença do DIF tanto na dificuldade (diferença no parâmetro b) quanto na discriminação (diferença no parâmetro a). Inicialmente, a Figura nos mostra que as curvas de Brasil e Japão são diferentes. A do Brasil é mais acentuada do que a do Japão indicando que o item discrimina mais os estudantes brasileiros. A probabilidade de acerto ao item, no entanto, é mais alta entre os estudantes japoneses indicando que para quase todas as faixas de proficiências o item é mais fácil para o Japão. Contudo, esse é um caso de DIF não uniforme, pois, não favorece uniformemente os estudantes japoneses em detrimento dos brasileiros. Em algumas (poucas) 
faixas de proficiência o item se torna mais fácil para o Brasil, ou seja, a direção do DIF muda ao longo da escala.

O item S213Q02 é considerado extremamente fácil no PISA. Ele está alocado no primeiro nível (Nível 1) da escala de proficiência do Programa tanto que os estudantes japoneses apresentam um alto percentual válido de acerto neste item, mais de $81 \%$. A proporção de respostas corretas dos estudantes da OCDE é de $77,6 \%$ e a do Brasil de 44,9\%. Aqui, solicita-se ao estudante lembrar o nome de um instrumento utilizado na determinação da condutividade elétrica de tecidos, o voltímetro. Apesar de a maioria dos estudantes brasileiros estarem alocados no nível 1 de proficiência do PISA, como vimos, menos da metade conseguiu identificar corretamente o instrumento solicitado Naturalmente, este item que mobiliza a competência "explicar fenômenos científicos" e a área de "sistemas tecnológicos" notoriamente tende a favorecer os estudantes japoneses. Aparentemente os estudantes japoneses estão mais familiarizados a temas relacionados à tecnologia do que os estudantes brasileiros e o estímulo sobre uma roupa supostamente inteligente se aproxima mais da realidade dos estudantes do Japão. Além disso, via de regra, os estudantes brasileiros não têm aula de laboratório, nem tampouco prática de laboratório que lhes permitam conhecer os equipamentos descritos nas possibilidades de resposta do item anteriormente descrito.

Normalmente, os itens que apresentam DIF elevados e sistemáticos são identificados em pré-testes e análises estatísticas preliminares, realizados antes de serem utilizados para a produção da proficiência do estudante. São dedicados esforços e recursos substanciais para alcançar amplitude e equilíbrio culturais e linguísticos dos instrumentos da avaliação. Aplicam-se mecanismos rigorosos de garantia de qualidade na tradução, na amostragem e na coleta de dados. Não se espera, em princípio, que se encontrem itens com padrões bem definidos associados à existência de DIF. No entanto, ainda assim, alguns itens que exibem algum grau de comportamento diferencial, como o mostrado acima, podem trazer alguma informação adicional relevante para entender algumas das possíveis diferenças educacionais existentes entre os países analisados.

$\mathrm{Na}$ sequência, descrevemos cada uma das características associadas aos itens buscando associá-las com o sentido e a magnitude do DIF. Essas 
características foram definidas pelo próprio PISA e estão listadas no quadro a seguir (Quadro 8).

Quadro 8. Variáveis utilizadas no modelo, suas categorias e o número de itens de ciências alocados em cada uma delas. PISA 2006.

\begin{tabular}{|c|c|c|}
\hline Variável & Categorias & $\begin{array}{l}\text { Itens } \\
\text { (n) }\end{array}$ \\
\hline \multirow{3}{*}{$\begin{array}{l}\text { Competências } \\
\text { Referem-se às escalas definidas } \\
\text { pelo PISA }\end{array}$} & Identificar questões científicas & 21 \\
\hline & Explicar fenômenos cientificamente & 49 \\
\hline & Usar evidência científica & 26 \\
\hline \multirow{6}{*}{$\begin{array}{l}\text { Áreas do Conhecimento } \\
\text { Indicam o tema principal do } \\
\text { conteúdo dos itens }\end{array}$} & Sistemas físicos & 17 \\
\hline & Sistemas vivos & 22 \\
\hline & Terra e sistemas espaciais & 11 \\
\hline & Sistemas tecnológicos & 8 \\
\hline & Investigação científica & 22 \\
\hline & Explicações científicas & 16 \\
\hline \multirow{6}{*}{$\begin{array}{l}\text { Áreas de Aplicação } \\
\text { Indicam as áreas gerais nas } \\
\text { quais os itens estão inseridos }\end{array}$} & Saúde & 25 \\
\hline & Recursos naturais & 17 \\
\hline & Meio ambiente & 15 \\
\hline & Acidentes ou problemas & 13 \\
\hline & Limites da Ciência e da tecnologia & 24 \\
\hline & Outras & 2 \\
\hline \multirow{3}{*}{$\begin{array}{l}\text { Âmbito } \\
\text { Indica a dimensão na qual o item } \\
\text { está inserido }\end{array}$} & Pessoal & 26 \\
\hline & Social & 54 \\
\hline & Global & 16 \\
\hline \multirow{4}{*}{$\begin{array}{l}\text { Tipo } \\
\text { Indica o formato do item }\end{array}$} & Resposta Construída Aberta & 28 \\
\hline & Resposta Construída Fechada & 4 \\
\hline & Múltipla Escolha & 37 \\
\hline & Múltipla Escolha Complexa & 27 \\
\hline \multirow{8}{*}{$\begin{array}{l}\text { Idioma } \\
\text { Indica a língua em que o item foi } \\
\text { escrito originalmente }\end{array}$} & Inglês & 34 \\
\hline & Norueguês & 16 \\
\hline & Coreano & 3 \\
\hline & Japonês & 4 \\
\hline & Alemão & 9 \\
\hline & Francês & 14 \\
\hline & Inglês/Grego & 1 \\
\hline & Holandês & 15 \\
\hline
\end{tabular}

Fonte: elaboração própria a partir dos relatórios técnicos do PISA 2006.

\section{2 .4}

DIF segundo as competências

Considerando os dois países em questão, encontramos DIF em todas as competências avaliadas pelo PISA 2006. A competência com maior concentração de DIF no parâmetro discriminação $-a$ - foi "identificar questões científicas" 
(28,6\% dos itens desta competência apresentam DIF em $a$ comparada a 24,5\% e 7,7\% dos itens das competências de "explicar fenômenos cientificamente" e "usar evidência científica", respectivamente). No que diz respeito à dificuldade do item $-b-$ a competência em que os itens mais se comportam de maneira diferente para estudantes brasileiros e japoneses é "explicar fenômenos cientificamente" (57,1\% dos itens desta competência apresentam DIF em $b$ comparada a 42,9\% e 50,0\% dos itens das competências de "identificar questões científicas" e "usar evidência científica", respectivamente).

A competência que menos apresenta DIF no parâmetro $a$ é "usar evidência científica". A probabilidade dos itens desta competência estarem concentrando mais índices com DIF foi de 92,3\%. Para testar se essa hipótese se confirmaria, construiu-se uma tabela $2 \times 2$ apenas considerando a correlação entre a distribuição de se ter DIF ou não, no parâmetro $a$, para a competência "usar evidência científica" com a distribuição das outras duas competências agregadas. O teste $\chi^{2}$ de Pearson por associação confirma a hipótese com um p-valor de 0,053, sugerindo uma inclinação bem menor à ocorrência de DIF $(7,7 \%)$, no parâmetro $a$, em itens alocados nesta competência do que nas demais.

$\mathrm{Na}$ Tabela 12, apresentamos os resultados referentes à direção e à intensidade do DIF, em $a($ d.a $)$.

Tabela 12. Direção e intensidade do DIF, entre Brasil e Japão, segundo as competências no parâmetro a nos itens de Ciências do PISA 2006

\begin{tabular}{|ccccc|}
\hline Competência & $\mathbf{N}$ & Média & $\begin{array}{r}\text { Desvio } \\
\text { Padrão }\end{array}$ & $\begin{array}{r}\text { Erro } \\
\text { Padrão }\end{array}$ \\
$\begin{array}{c}\text { Explicar fenômenos } \\
\text { cientificamente }\end{array}$ & 49 &,- 1322 &, 25601 &, 03657 \\
$\begin{array}{c}\text { Identificar questões } \\
\text { científicas }\end{array}$ & 21 &,- 0246 &, 17434 &, 03804 \\
Usar evidência científica & 26 &,- 0238 &, 16701 &, 03275 \\
\hline
\end{tabular}

Fonte: Elaboração própria a partir dos resultados das análises de DIF, com dados do PISA 2006. * Pearson Chi-Square $(\mathrm{p}=, 059)$.

Se houvessem valores em média positivos, eles indicariam que os itens alocados em determinada competência seriam mais discriminantes no Japão. Contudo, todos os coeficientes médios são negativos e, portanto, discriminam mais os itens para os estudantes brasileiros em relação aos japoneses. Este resultado é estatisticamente significativo $(\mathrm{p}=0,059)$. Sendo assim, em poucas palavras, os itens da prova de Ciências do PISA 2006, segundo as competências avaliadas no PISA, são mais eficazes em diferenciar estudantes brasileiros, em 
relação aos japoneses, com níveis distintos de proficiência. O teste post hoc demonstra que a diferença das médias também é significativa ao nível de 0,05: a começar pelos itens que usam evidência científica, seguido daqueles que identificam questões científicas até chegar naqueles que explicam fenômenos cientificamente, de modo geral, os itens com DIF no parâmetro $a$, segundo a competência, discriminam mais a população de estudantes brasileiros.

As diferenças no parâmetro $b$ não são tão significativas quanto às apresentadas no parâmetro $a$. As faixas percentuais de presença e ausência de DIF no parâmetro b segundo a competência do item estão distribuídas quase que uniformemente, em torno de 50\%, indicando que, considerando-se a dificuldade, praticamente não há comportamento diferencial dos itens que favoreça ou prejudique algum dos dois grupos analisados. Todas as competências apresentam, portanto, a mesma prevalência de DIF $(\mathrm{p}=0,532)$.

Outro exemplo de item público que apresenta DIF em ambos os parâmetros $a$ e $b$ levando em consideração os estudantes de Brasil e Japão é o S426Q03. A seguir apresentamos a CCI deste item para Brasil e Japão (Figura 13).

Figura 13. Curva característica do item S426Q03.

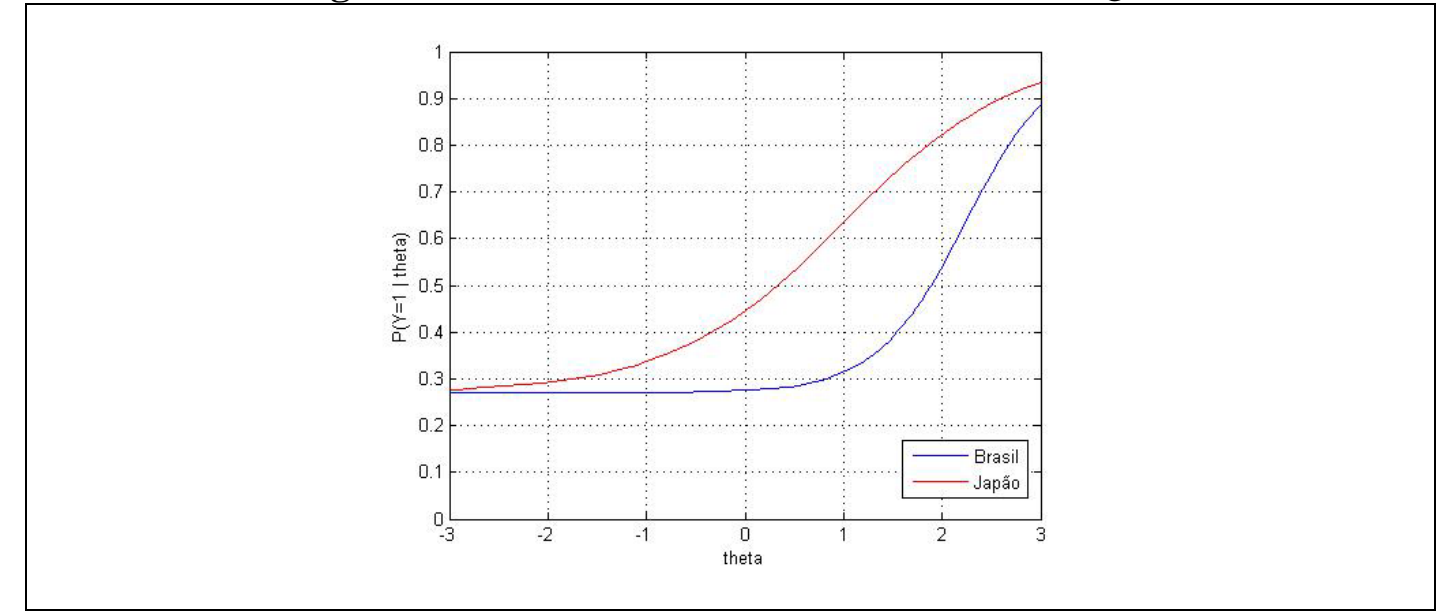

Fonte: Elaboração própria a partir do software Matlab. 2017.

A partir da Figura 13 podemos perceber a presença do DIF nos parâmetros $a$ e $b$. Assim como no item anterior, a Figura nos mostra que as curvas de Brasil e Japão são diferentes. Contudo, esse é um caso de DIF uniforme, ou seja, as curvas não se cruzam e, portanto não há mudança de direção do DIF ao longo da escala. A curva do Brasil é novamente mais acentuada do que a do Japão indicando que o item discrimina mais os estudantes brasileiros $($ d. $a=-0,5274)$; e a probabilidade 
de acerto ao item é mais alta entre os estudantes japoneses, ou seja, o item é mais fácil para os japoneses $(d . b=1,234)$. O item S426Q03 pertence a unidade "Grand Canyon" que, de maneira geral, está relacionada ao estudo do solo e das rochas (Figura 14).

Figura 14. Unidade Grand Canyon, Questão 3. Código S426Q03.

\section{O GRAND CANYON}

O Grand Canyon está localizado em um deserto nos Estados Unidos. Ele é um cânion grande e profundo formado por muitas camadas de rochas. No passado, os movimentos na crosta terrestre ergueram estas camadas. Atualmente, o Grand Canyon apresenta 1,6 $\mathrm{km}$ de profundidade em determinadas partes. O Rio Colorado percorre todo o fundo do cânion.

Veja a foto abaixo do Grand Canyon tirada da margem sul. Várias camadas diferentes de rochas podem ser vistas nas paredes do cânion.

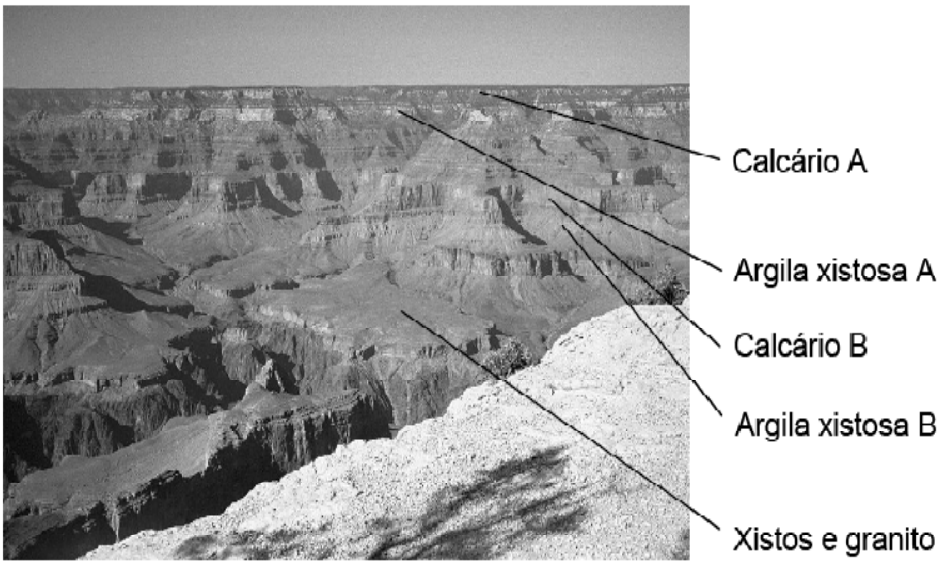

\section{QUESTÃO 3: O GRAND CANYON}

A temperatura no Grand Canyon varia de menos de $0{ }^{\circ} \mathrm{C}$ a mais de $40{ }^{\circ} \mathrm{C}$. Embora ele esteja localizado em uma área desértica, as fendas das rochas, algumas vezes, contêm água. De que maneira essas mudanças de temperatura e a água contida nas fendas das rochas ajudam a acelerar a decomposição das rochas?
A A água congelada dissolve as rochas quentes.
B A água consolida as rochas entre si.
C O gelo torna lisa a superfície das rochas.
D A água congelada se expande nas fendas das rochas.

Fonte: BRASIL, 2008.

O item S426Q03 é de múltipla escolha e trata o tema do "meio ambiente" no âmbito "social". A competência envolvida aqui é a de "explicar fenômenos cientificamente" sobre tudo no que diz respeito ao conhecimento de "terra e sistemas espaciais". Este item foi elaborado pelo instituto australiano ACER originalmente em inglês. 
A resposta correta dessa questão - letra $\mathrm{D}$ - requer que o estudante saiba que a água congela quando a temperatura está abaixo de zero grau, assim como conheça a propriedade da água de se expandir ao congelar, relacionando um fenômeno físico com um efeito geológico visível. Novamente se pode observar um nítido contraste entre o percentual válido de respostas certas do Brasil em comparação com o Japão - 31\% para o Brasil e $68 \%$ para o Japão. Os técnicos no Relatório Nacional do INEP apontam como fator favorável aos estudantes da OCDE, cujo percentual de acerto foi um pouco menor do que o do Japão - 66,3\% - a maior convivência deles com as características do fenômeno de congelamento da água, devido ao clima frio. Esse fator também pode ser atribuído aos estudantes japoneses, para os quais este item é mais fácil como vimos.

\subsection{5 \\ DIF segundo a área do conhecimento do item}

Os conhecimentos científicos presentes na avaliação do PISA 2006 eram de dois tipos: a) conhecimento de Ciência; e b) conhecimento sobre Ciência. Os conhecimentos de Ciências relacionam-se diretamente ao conhecimento dos estudantes sobre o mundo natural e foram selecionados a partir dos principais campos da física, química, biologia, Ciências da terra e do espaço, e Tecnologia. O conhecimento sobre Ciência tem mais relação com a Ciência propriamente dita. A primeira categoria, "investigação científica", centra-se no inquérito como o processo central da Ciência e os vários componentes desse processo, ou seja, como os cientistas obtêm os dados. A segunda categoria, intimamente relacionada com a investigação, é "explicações científicas" e se refere mais aos resultados da investigação científica e à forma como os cientistas utilizam os dados colhidos.

Encontramos DIF em todas as áreas de conhecimento avaliadas pelo PISA 2006 considerando Brasil e Japão. Na área do conhecimento de Ciência, o descritor com maior concentração de DIF no parâmetro discriminação $-a-$ foi "terra e sistemas espaciais" (36,4\% dos itens desta área apresentaram DIF em $a$ comparada às demais áreas). Nenhuma das outras áreas contempladas atingiu mais do que $25 \%$ de probabilidade de concentrarem DIF em $a$. No que diz respeito à dificuldade do item - $b$ - a concentração ocorreu em "sistemas vivos" (68,2\% dos itens deste descritor apresentaram DIF). Diferente do que aconteceu 
no parâmetro $a$, todas as áreas do conhecimento apontaram probabilidades, se não superiores bem próximas a 50\%, de concentrarem DIF. Quando o conhecimento aferido é "sobre ciência", os DIFs se concentram em "investigações científicas" (27,30\% dos itens apresentam DIF nesta área comparados a 12,50\% dos itens na área de "explicações científicas") no parâmetro $a$ e em "explicações científicas" (43,80\% comparados a 40,90\% de presença em "investigações científicas") no parâmetro $b$.

Os itens com DIF estão distribuídos homogeneamente. Não há concentrações tão representativas que sugiram uma incidência maior ou menor a ocorrência de DIF em determinada área de conhecimento nem no parâmetro $a$ nem tampouco no parâmetro $b$. Ainda assim, pelo fato de $68 \%$ dos itens alocados na área do conhecimento "sistemas vivos" apresentarem DIF no parâmetro b, testamos a hipótese desse descritor estar concentrando mais itens com DIF do que os demais, podendo, assim, estar favorecendo um grupo de estudantes em detrimento do outro. Para tanto, construímos uma tabela $2 \times 2$ apenas considerando a correlação entre a distribuição de se ter DIF ou não, no parâmetro $b$, para a área do conhecimento sobre Ciência "Sistemas Vivos" com a distribuição dos outros descritores agregados, inclusive aqueles do conhecimento sobre Ciência, conforme pode ser visto na Tabela 13.

Tabela 13. DIF, entre Brasil e Japão, segundo as áreas do conhecimento no parâmetro $b$ dos itens de Ciências do PISA 2006

\begin{tabular}{ccc}
\hline & Apresenta DIF em b & Total de itens \\
\hline Outros & 35 & 74 \\
& $47,30 \%$ & $100,00 \%$ \\
Sistemas Vivos & 15 & 22 \\
& $68,20 \%$ & $100,00 \%$ \\
Total & 50 & 96 \\
& $52,10 \%$ & $100,00 \%$ \\
\hline
\end{tabular}

Fonte: Elaboração própria a partir dos resultados das análises de DIF, com dados do PISA 2006. * Pearson Chi-Square $(\mathrm{p}=, 069)$.

O teste $\chi^{2}$ de Pearson por associação, contudo, não confirmou tal hipótese encontrando-se um p-valor de 0,069 , não se podendo afirmar que haja uma maior ocorrência de DIF em itens alocados na área de conhecimento "sistemas vivos", ainda que esta tenha uma quantidade representativa de itens com DIF.

De igual forma, no parâmetro $a$, a área de conhecimento dos itens de Ciências do PISA 2006 não privilegiou Brasil ou Japão. Apesar de todos os descritores apresentarem valores em média negativos no parâmetro $a$ (Tabela 14), 
o que tornaria os itens um pouco mais discriminantes no Brasil, as diferenças em relação ao Japão não são estatisticamente significativas $(\mathrm{p}=0,564)$.

Tabela 14. Direção e intensidade do DIF, entre Brasil e Japão, segundo as áreas do conhecimento no parâmetro a nos itens de Ciências do PISA 2006

\begin{tabular}{ccccc}
\hline $\mathbf{N}$ & Média $\boldsymbol{d . a}$ & $\begin{array}{c}\text { Desvio } \\
\text { Padrão }\end{array}$ & $\begin{array}{c}\text { Erro } \\
\text { Padrão }\end{array}$ \\
\hline $\begin{array}{c}\text { Terra e Sistemas } \\
\text { Espaciais }\end{array}$ & 11 & $-0,1093$ &, 27709 & 0,08355 \\
$\begin{array}{c}\text { Sistemas Vivos } \\
\text { Sistemas Físicos } \\
\text { Investigação } \\
\text { Científica }\end{array}$ & 22 & $-0,0973$ & 0,21894 & 0,04668 \\
$\begin{array}{c}\text { Explicações } \\
\text { Científicas }\end{array}$ & 17 & $-0,1219$ & 0,28297 & 0,06863 \\
$\begin{array}{c}\text { Sistemas } \\
\text { Tecnológicos }\end{array}$ & 16 & $-0,0241$ & 0,17015 & 0,03628 \\
$\quad$ Total & 96 & $-0,0287$ & 0,1908 & 0,0477 \\
\hline
\end{tabular}

Fonte: Elaboração própria a partir dos resultados das análises de DIF, com dados do PISA 2006. * Pearson Chi-Square $(\mathrm{p}=, 0564)$.

No parâmetro $b$, inicialmente, apenas os itens alocados nos conhecimentos de "terra e sistemas espaciais" e "sistemas tecnológicos" estariam favorecendo um pouco os estudantes japoneses. Todos os demais, por apresentarem valores em média negativos, seriam mais fáceis para os estudantes brasileiros (Tabela 15). Contudo, essas diferenças encontradas no parâmetro $b$, assim como aquelas encontradas no parâmetro $a$, entre Brasil e Japão, não são estatisticamente significativas $(p=0,470)$ e, portanto, não se pode afirmar que este ou aquele descritor esteja favorecendo um grupo em detrimento do outro.

Tabela 15. Direção e intensidade do DIF, entre Brasil e Japão, segundo as áreas do conhecimento no parâmetro $b$ nos itens de Ciências do PISA 2006

\begin{tabular}{ccccc}
\hline & N & Média $\boldsymbol{d . b}$ & $\begin{array}{c}\text { Desvio } \\
\text { Padrão }\end{array}$ & $\begin{array}{c}\text { Erro } \\
\text { Padrão }\end{array}$ \\
\hline $\begin{array}{c}\text { Terra e } \\
\text { Sistemas }\end{array}$ & 11 & 0,0887 & 0,63643 & 0,19189 \\
$\begin{array}{c}\text { Espaciais } \\
\text { Sistemas Vivos } \\
\quad \text { Sistemas }\end{array}$ & 22 & $-0,3131$ & 0,81572 & 0,17391 \\
$\begin{array}{c}\text { Físicos } \\
\text { Investigação } \\
\text { Científica }\end{array}$ & 17 & $-0,0564$ & 0,47605 & 0,11546 \\
$\begin{array}{c}\text { Explicações } \\
\text { Científicas }\end{array}$ & 16 & $-0,0726$ & 0,55554 & 0,11844 \\
$\begin{array}{c}\text { Sistemas } \\
\text { Tecnológicos }\end{array}$ & 8 & $-0,0466$ & 0,33442 & 0,0836 \\
\hline Total & 96 & 0,0222 & 0,44956 & 0,15894 \\
\hline
\end{tabular}

Fonte: Elaboração própria a partir dos resultados das análises de DIF, com dados do PISA 2006.* Pearson Chi-Square $(\mathrm{p}=, 470)$. 
O próximo item que descreveremos tem como tema a Chuva Ácida e contém em seu estímulo uma notícia sobre as milenares estátuas do museu da Acrópole de Atenas, que estavam sendo destruídas por conta deste fenômeno. Assim como os dois itens descritos anteriormente e como o que descreveremos a seguir, o item S485Q02 apresenta DIF nos dois parâmetros (Figura 15).

Figura 15. Curva característica do item S485Q02.

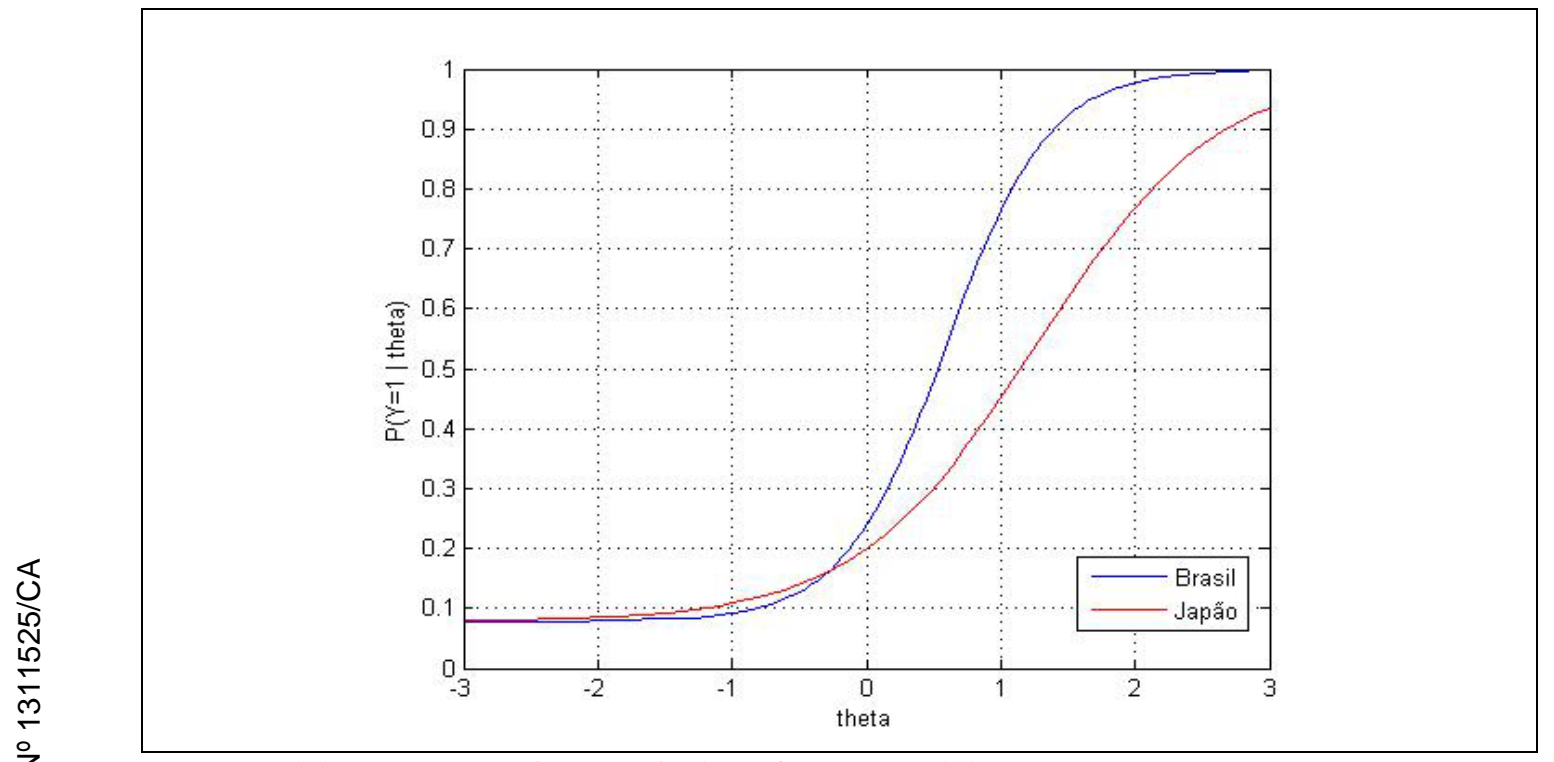

Fonte: Elaboração própria a partir do software Matlab. 2017.

Assim como os itens anteriores, este também discrimina mais os estudantes brasileiros no PISA quando vistos em relação aos japoneses (d.a=-0,5664 e a curva do Brasil mais acentuada do que a do Japão), no entanto, se mostra mais fácil para os estudantes brasileiros de mesma proficiência que os japoneses ( $d . b=-$ 0,6696) na maior parte da escala. Assim o é, por se tratar de um caso de DIF não uniforme onde o DIF muda de direção ao longo da escala.

O item requer uma explicação sobre as causas da chuva ácida e sua área de aplicação é notoriamente a de "acidentes e problemas ambientais". É uma questão que exige o entendimento dos processos que originam a presença de gases de enxofre e nitrogênio como agentes de contaminação atmosférica, resultantes tanto da oxidação da maior parte dos combustíveis fósseis quanto da atividade vulcânica. Os temas da poluição e da chuva ácida já estão em livros e currículos há algum tempo, no Brasil. Esse conteúdo está enquadrado na unidade temática "problemas ambientais brasileiros e o desenvolvimento sustentável" proposta no tema estruturador "interação entre os seres vivos" do PCN+ (Parâmetros 
Curriculares Nacionais: orientações educacionais complementares aos PCNs) (BRASIL, 2002).

Para obter o crédito completo do item S485Q02 (Figura 16), o estudante deveria mencionar qualquer uma das seguintes fontes de óxido de enxofre e nitrogênio: gases de escapamento de carros, as emissões de gás das fábricas, a queima de combustíveis fósseis, tais como petróleo e carvão, os gases provenientes de vulcões ou outras fontes semelhantes. Os técnicos do PISA consideraram que atribuir tais gases a uma contaminação não específica (crédito parcial), como poluição, por exemplo, também é uma resposta aceitável, dado que as análises realizadas evidenciaram pouca diferença de proficiência entre ambos os grupos. Como já mencionado, aqui consideramos para fins de análise, como resposta certa, apenas aquelas as quais foram atribuídas crédito total.

Este é um item de resposta aberta, construída e para convertê-lo o estudante precisa demonstrar competência em "explicar fenômenos cientificamente". A categoria de conhecimento envolvida é "conhecimentos de ciências" - sistemas físicos - e o nível ao qual este item está alocado é o 3. Mais da metade dos estudantes japoneses e da OCDE acertaram este item, 54,6\% e 57,8\% respectivamente. O percentual de acerto dos estudantes brasileiros foi de apenas $32,4 \%$. Ainda assim, como vimos, este é um item que se comporta de maneira diferencial e se mostra mais fácil para os estudantes brasileiros de mesma proficiência que os estudantes japoneses. 
Figura 16. Unidade Chuva Ácida, Questão 2. Código S485Q02.

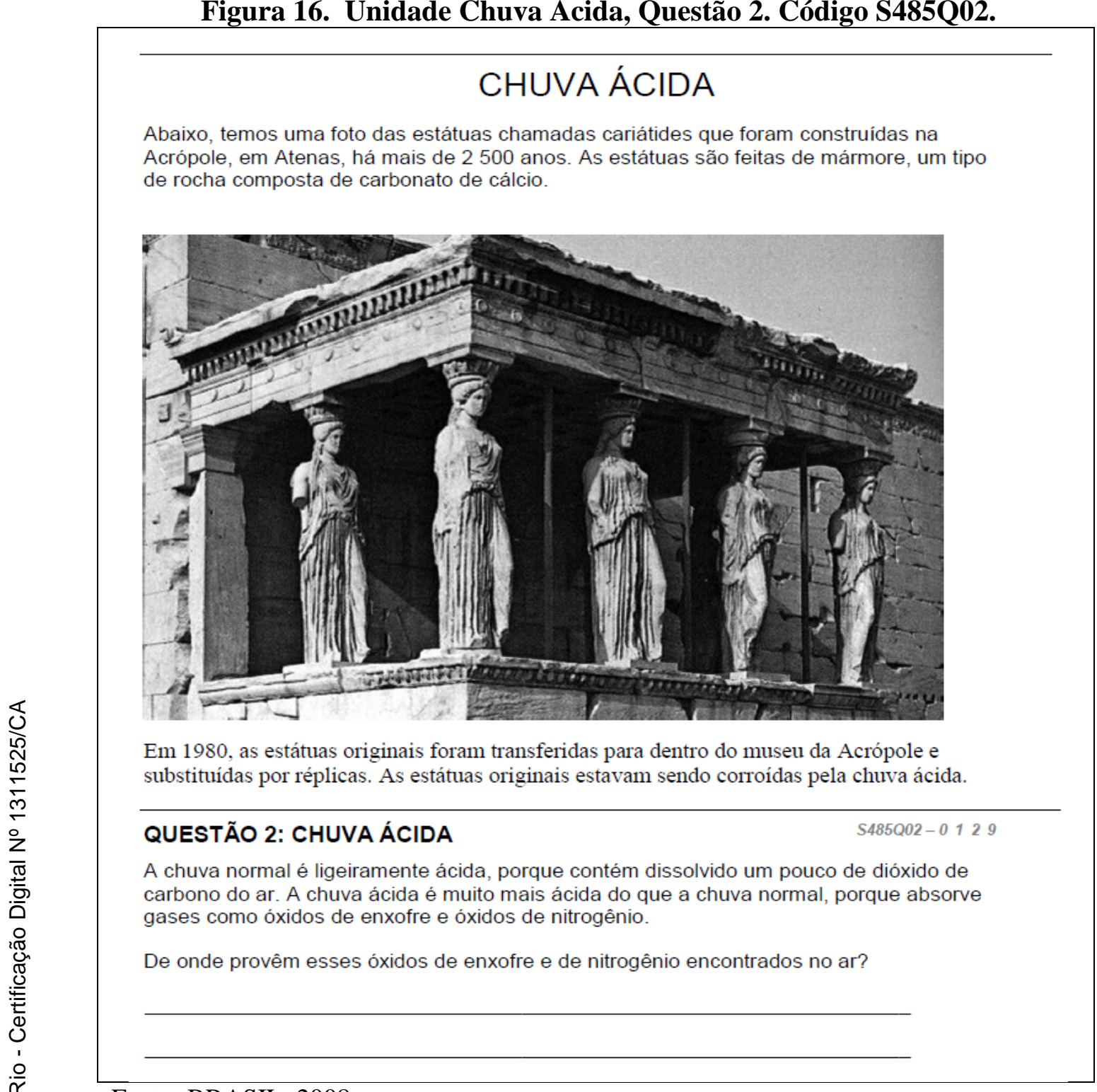

Fonte: BRASIL, 2008.

\section{2 .6}

DIF segundo a área de aplicação do item

Além das competências e das áreas do conhecimento, outra característica pública dos itens de Ciências do PISA 2006 é a área de aplicação. A área de aplicação dos itens está centrada em seu emprego em relação a contextos pessoais, sociais e globais como: "saúde", "recursos naturais", "meio ambiente", "riscos" e "limites da ciência e da tecnologia".

Tanto no parâmetro $a$ quanto no parâmetro $b$ há ocorrência de itens com DIF em todas as áreas avaliadas. Contudo, no parâmetro $a$, os itens com DIF estão mais concentrados nas áreas de "meio ambiente" e "limites da ciência e da 
tecnologia", 33,3\% dos itens em ambos os casos. Já no parâmetro $b$, são as áreas de "riscos" e "saúde" que concentram mais itens com DIF, 76,9\% e 72\%, respectivamente.

Para testar a hipótese de que "meio ambiente" e "limites da ciência e da tecnologia" estariam concentrando itens com DIF no parâmetro $a$, recodificamos a variável "área de aplicação" em "área de aplicação.rec", ou seja, numa nova variável onde o conjunto de áreas de aplicação diferentes de "meio ambiente" e "limites da ciência e da tecnologia" foi agregada. Consideramos, portanto, apenas a correlação entre a distribuição de se ter DIF ou não, no parâmetro $a$ para essas duas áreas, com a distribuição das demais áreas agregadas, conforme pode ser visto na Tabela 16. O teste $\chi^{2}$ de Pearson por associação confirma a hipótese com um p-valor de 0,045 , sugerindo uma inclinação maior à ocorrência de DIF, no parâmetro $a$, em itens alocados nestas áreas de "meio ambiente" e "limites da ciência e da tecnologia" do que nas demais.

Apesar de concentrarem os itens com DIF no parâmetro $a$, as áreas de "meio ambiente" e "limites da ciência e da tecnologia" não fazem distinção entre brasileiros e japoneses, ou seja, do ponto de vista estatístico, não se pode afirmar que os itens alocados nessas duas ou nas demais áreas de aplicação de Ciências do PISA 2006 discriminem mais os estudantes brasileiros do que os japoneses e viceversa $(\mathrm{p}=0,801)$. Decidimos filtrar a categoria "outras", por esta apresentar apenas dois itens, mas ainda assim não se encontrou um p-valor que permitisse sustentar a hipótese que itens de qualquer das áreas discriminassem mais no Brasil ou no Japão $(\mathrm{p}=0,071)$.

Tabela 16. DIF, entre Brasil e Japão, segundo as áreas de aplicação no parâmetro a nos itens de Ciências do PISA 2006

\begin{tabular}{ccc}
\hline & Apresenta DIF em a & Total de itens \\
\hline Meio Ambiente & 5 & 15 \\
& $33,3 \%$ & $100,0 \%$ \\
Limites da Ciência e da & 8 & 24 \\
Tecnologia & $33,3 \%$ & $100,0 \%$ \\
Outras & 7 & 57 \\
& $12,3 \%$ & $100,0 \%$ \\
Total & 20 & 96 \\
& $20,8 \%$ & $100,0 \%$ \\
\hline
\end{tabular}

Fonte: Elaboração própria a partir dos resultados das análises de DIF, com dados do PISA 2006.

Os resultados da ocorrência de DIF no parâmetro $b$, segundo as áreas de aplicação, apontam uma concentração de itens com DIF nas áreas de "riscos" e 
"saúde". Diferentemente do que se observou no parâmetro $a$, no que diz respeito à dificuldade (parâmetro $b$ ), os itens de fato se comportam de maneira diferente para estudantes brasileiros e japoneses. O teste $\chi^{2}$ de Pearson por associação confirma o DIF segundo a área de aplicação no parâmetro $b$ com um p-valor de 0,020. Filtramos a categoria "outras", novamente por esta apresentar apenas dois itens, mas ainda assim se encontrou um p-valor que sustenta a hipótese que as diferentes áreas concentram itens com DIF $(\mathrm{p}=0,071)$.

A fim de verificar a direção e a intensidade do DIF, em $b(d . b)$, construímos a Tabela 17 considerando a correlação entre a distribuição da direção e da intensidade do DIF das áreas de aplicação, excluindo-se a categoria outras, com apenas dois itens. Três das áreas de aplicação, "meio ambiente", "saúde" e "recursos naturais", tendem a apresentar valores em média negativos, enquanto as demais, "limites da ciência e da tecnologia" e "riscos", apresentam, em média, valores positivos. Como vimos, os valores em média positivos indicam que os itens alocados em determinada competência seriam mais fáceis para o Japão. Ao contrário, aqueles negativos mais fáceis para os estudantes brasileiros em relação aos japoneses. Este resultado é estatisticamente significativo $(\mathrm{p}=0,050)$.

Tabela 17. Direção e intensidade do DIF, entre Brasil e Japão, segundo as áreas de aplicação no parâmetro $b$ nos itens de Ciências do PISA 2006

\begin{tabular}{ccccc}
\hline & N & Média & $\begin{array}{c}\text { Desvio } \\
\text { Padrão }\end{array}$ & $\begin{array}{c}\text { Erro } \\
\text { Padrão }\end{array}$ \\
\hline $\begin{array}{c}\text { Meio Ambiente } \\
\text { Limites da } \\
\text { Ciência e da } \\
\text { Tecnologia }\end{array}$ & 15 & $-0,0805$ & 0,57094 & 0,14742 \\
$\quad 24$ & 0,0797 & 0,52475 & 0,10711 \\
$\quad$ Riscos & 13 & 0,2019 & 0,7074 & 0,1962 \\
$\begin{array}{c}\text { Saúde } \\
\text { Recursos } \\
\text { Naturais }\end{array}$ & 25 & $-0,2607$ & 0,63613 & 0,12723 \\
$\quad 17$ & $-0,2964$ & 0,40617 & 0,09851 \\
Total & 94 & $-0,0875$ & 0,5912 & 0,06098 \\
\hline
\end{tabular}

Fonte: Elaboração própria a partir dos resultados das análises de DIF, com dados do PISA 2006.* Pearson Chi-Square $(\mathrm{p}=, 050)$.

Cada um dos itens públicos que descrevemos e discutimos até aqui pertence a uma área de aplicação diferente. O item S213Q02, sobre roupas inteligentes, é da área de "limites da ciência e da tecnologia", o S426Q03, que fala do Grand Canyon, é de "meio ambiente", o S426Q03, sobre a chuva ácida, é de "riscos" e, por fim, o item S493Q01, que descreveremos a seguir, é de "saúde".

A Unidade do item S493Q01 é intitulada "Exercício Físico" e contém em seu estímulo vantagens da prática de atividade física regular e moderada. O 
contexto, a área do conhecimento e a competência deste item são, respectivamente, âmbito "pessoal", "sistemas vivos" e "explicar fenômenos cientificamente", respectivamente. Esse item foi submetido pelo governo Suíço e originalmente elaborado em Francês. Como se pode observar na Figura 17, o item é de múltipla escolha complexa e requer que o estudante circule "sim" ou "não" para cada uma das afirmativas colocadas. É uma questão que exige o conhecimento dos benefícios advindos da prática regular de exercício físico. Temas como este, relacionado à saúde humana, não apenas aparecem como conteúdo em livros didáticos, como também aparecem como temas estruturadores do ensino fundamental (Ser Humano e Saúde) e médio (Qualidade de Vida das populações humanas) no Brasil e no Japão. Esse assunto é também bastante abordado em projetos e igualmente sugerido como tema transversal no Brasil e, a prática regular de exercícios físicos faz parte da rotina escolar no Japão. Para obter o crédito completo deste item, o estudante deveria circular as quatro respostas corretamente, na seguinte ordem: Sim, Não, Não e Sim. O item está posicionado no nível 3 de proficiência do PISA com uma média de 544,9 na escala de dificuldade. 
Figura 17. Unidade Exercício Físico, Questão 1. Código S493Q01.

\section{EXERCÍCIO FÍsICO}

Praticar exercicios físicos regularmente, porém com moderação, é bom para a saúde.

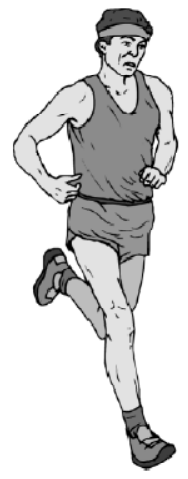

QUESTÃO 1: EXERCíCIO FÍsICO

Quais as vantagens do exercício físico regular? Faça um círculo em "Sim" ou "Não" em cada uma das afirmações.

\begin{tabular}{|l|c|}
\hline Esta é uma vantagem do exercício físico regular? & Sim ou Não? \\
\hline O exercício físico ajuda a evitar doenças cardiacas e circulatórias. & Sim / Não \\
\hline O exercício físico impede que os vírus entrem no corpo. & Sim / Não \\
\hline O exercício físico leva a uma dieta saudável. & Sim / Não \\
\hline O exercício físico ajuda a evitar o excesso de peso. & Sim / Não \\
\hline
\end{tabular}

Fonte: BRASIL, 2008.

Entre os países da OCDE cerca de 50\% dos estudantes responderam esta questão corretamente. Em contrapartida, apenas 27,3\% dos estudantes brasileiros conseguiram converter este item comparados a 37,9\% dos estudantes japoneses. Esse item, de maneira geral, não se mostrou fácil para os estudantes brasileiros, nem tampouco para os estudantes japoneses, que desta vez, ficaram alguns pontos abaixo da média percentual da OCDE. Esse resultado pode estar relacionado a dificuldade dos estudantes, tanto brasileiros como japoneses, de selecionar informação relevante a partir de dados variados e de tirar conclusões ou de fazer a sua própria avaliação de uma determinada situação.

Assim com os demais itens públicos descritos aqui, este também discrimina mais a população de estudantes brasileiros $($ d.a=0,4461) e, apesar, de ter se mostrado difícil para ambos brasileiros e japoneses, para estudantes de mesma proficiência, este item favorece, em geral, os estudantes brasileiros $(d . b=-0,6088)$. 
A partir da análise da CCI do item S493Q01 (Figura 18) podemos perceber a presença do DIF na discriminação (diferença no parâmetro a) onde a curva do Brasil se mostra mais acentuada do que a do Japão indicando que o item discrimina mais os estudantes brasileiros; e a presença de DIF na dificuldade (diferença no parâmetro b). A probabilidade de acerto ao item na análise gráfica, no entanto, não favorece uniformemente os estudantes brasileiros em detrimento dos japoneses conforme indicado no cálculo dos parâmetros. Esse é, novamente, um caso de DIF não uniforme ou inconsistente que ocorre quando há uma interação entre o nível de proficiência e o desempenho no item, de modo que a direção do DF do item muda ao longo da escala de proficiência.

Figura 18. Curva característica do item S493Q01.

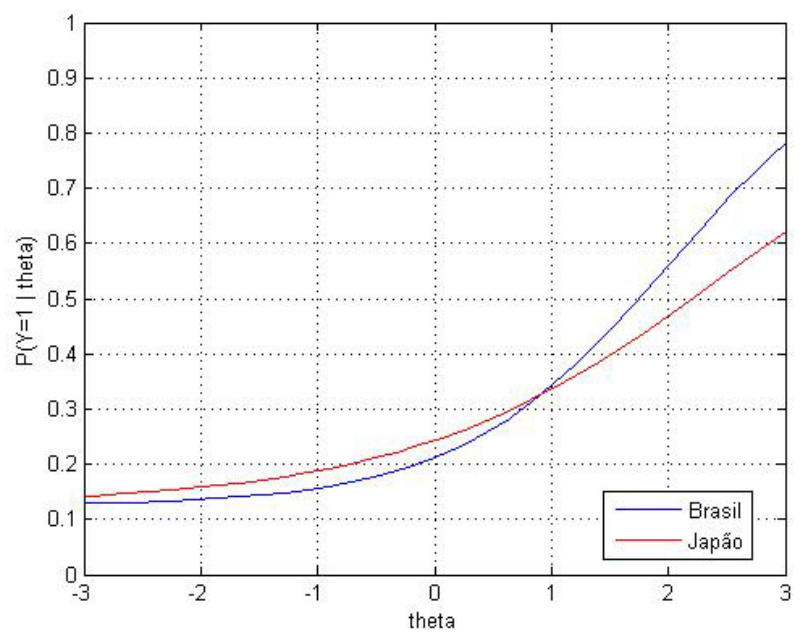

Fonte: Elaboração própria a partir do software Matlab. 2017.

\subsection{7}

DIF segundo o âmbito ou contexto do item

No PISA 2006, as situações da vida real que demandam do estudante posicionamento ou conhecimentos que podem corresponder a três âmbitos ou círculos concêntricos de abrangência da questão: pessoal, social e/ou global. O contexto que mais apresentou DIF no parâmetro $a$ foi o "Pessoal". Contudo, nenhum dos contextos apresenta mais de $25 \%$ de DIF no parâmetro $a$. Já no parâmetro $b$, observa-se uma maior predominância de DIF no contexto "Global" $(68,8 \%)$ seguido do contexto "Pessoal" $(61,5 \%)$ e, por fim, mais de $40 \%$ no contexto "Social". 
De fato, os dois primeiros contextos descritos anteriormente, Global e Pessoal, tendem a concentrar mais DIF no parâmetro de dificuldade do item $(b)$ do que o contexto Social $(\mathrm{p}=0,035)$. Esta hipótese foi testada a partir de uma tabela de contingência $2 \times 2$ que agregou os contextos Global e Pessoal associando-os ao contexto Social responsável pela maior quantidade de itens no teste, 54 no total, contra 42 dos outros dois contextos juntos (Tabela 18). Isso quer dizer que, mesmo em menor número no teste e juntos, os itens alocados nos contextos Global e Pessoal concentram mais comportamento diferencial do que aqueles construídos no âmbito Social.

Tabela 18. DIF, entre Brasil e Japão, segundo as situações e contextos no parâmetro $b$ nos itens de Ciências do PISA 2006

\begin{tabular}{|c|c|c|c|}
\hline & & Apresenta DIF em b & Total de itens \\
\hline \multirow{5}{*}{$\begin{array}{l}\text { Contexto do } \\
\text { Item }\end{array}$} & & 27 & 42 \\
\hline & Outro & $64,3 \%$ & $100,0 \%$ \\
\hline & & 23 & 54 \\
\hline & Social & $42,6 \%$ & $100,0 \%$ \\
\hline & & 50 & 96 \\
\hline Total & & $52,1 \%$ & $100,0 \%$ \\
\hline
\end{tabular}

Fonte: Elaboração própria a partir dos resultados das análises de DIF, com dados do PISA 2006.

Não se encontraram diferenças estatisticamente significativas entre as médias dos coeficientes de $d . a$ e $d . b$, de intensidade do DIF na dificuldade e/ou discriminação dos itens. Isso significa que o DIF aparentemente está uniformemente distribuído entre os itens dos diferentes contextos, e não privilegia nem prejudica nenhum dos dois países. Apesar da maioria das médias dos coeficientes terem sido negativas e, assim, sugerirem uma maior discriminação e/ou facilidade dos itens para o Brasil, os p-valores encontrados não foram estatisticamente significativos ( $\mathrm{p}$ valor de 0,927 para a diferença no parâmetro a (d.a) e de 0,350 para o parâmetro b (d.b)).

\section{2 .8}

\section{DIF segundo o tipo de item}

Os tipos de itens empregados no teste de Ciências do PISA 2006 foram de múltipla escolha e resposta construída. Os itens de múltipla escolha eram, no entanto, padronizados com quatro alternativas de respostas, a partir das quais os estudantes eram obrigados a selecionar a melhor; ou complexos, apresentando 
várias declarações para cada um, entre as quais os estudantes deviam escolher uma das várias possíveis respostas (sim / não, verdadeiro / falso, correto / incorreto etc.). Os itens de resposta construída também foram classificados de forma diferenciada pelo PISA. Nos itens de resposta construída fechada, era necessário que os estudantes construíssem uma resposta numérica dentro de restrições muito limitadas, ou apenas uma palavra ou uma curta frase como resposta. Os itens de resposta construída aberta exigiam respostas mais completas ou extensas que frequentemente abarcavam alguma explicação ou justificativa.

Todos os tipos de item apresentaram DIF. No entanto, a ocorrência de comportamento diferencial no parâmetro $a(50 \%)$ não foi tão expressiva quanto no parâmetro $b(70,4 \%)$. O DIF encontrado na dificuldade e na discriminação dos itens não se mostrou associado ao tipo de item, de tal forma que este aspecto não torna um item mais ou menos discriminante, mais fácil ou mais difícil, para os estudantes de nenhum dos dois países. Em outras palavras, não se encontraram diferenças significativas entre as médias de intensidade do DIF na dificuldade do item para os diferentes tipos de itens ( $\mathrm{p}$-valor de 0,516), nem tampouco entre as médias de intensidade do DIF na discriminação do item para os diferentes tipos de itens de Ciências do PISA 2006 (p-valor de 0,107). Isso quer dizer que, embora existam itens com DIF, não há indícios suficientes de que o DIF esteja privilegiando um grupo em detrimento do outro, facilitando ou discriminando mais, por exemplo, o desempenho dos estudantes brasileiros e/ou dos japoneses.

\section{2 .9}

\section{DIF segundo o idioma do item}

Os itens de Ciências do PISA 2006 foram originalmente escritos em 10 idiomas distintos. No entanto, mais de $30 \%$ do total foi escrito originalmente em inglês e 11 itens em inglês apresentam DIF no parâmetro $a$ e 12 no parâmetro $b$. Contudo, itens que apresentam DIF em $a$ não necessariamente apresentam DIF em $b$ e vice-versa $(\mathrm{p}=0,283)$. Os itens escritos, originalmente, na língua inglesa apresentam mais DIF no parâmetro $a$ do que os itens escritos nos demais idiomas (correlação testada estatisticamente pelo teste qui-quadrado para associação entre variáveis, tendo-se encontrado um p-valor de 0,007). Isso pode ser observado na Tabela 19 de contigência $2 \times 2$ apresentada a seguir. No entanto, comparando-se a 
intensidade e direção do DIF, por meio dos coeficientes $d . a$ calculados para cada item, não se encontram diferenças significativas entre as suas médias $(-0,2938$ para os itens escritos em outros idiomas e $-0,0865$ para os escritos em inglês), segundo um teste $t$ para diferenças entre médias para o qual se encontrou um pvalor de 0,439 .

Tabela 19. DIF, entre Brasil e Japão, segundo o idioma no parâmetro a nos itens de Ciências do PISA 2006

\section{Apresenta DIF em a Total de itens}

\begin{tabular}{ccc}
\hline Outros Idiomas & 9 & 67 \\
Inglês & $13,4 \%$ & $100,0 \%$ \\
& 11 & 29 \\
Total & $37,9 \%$ & $100,0 \%$ \\
& 20 & 96 \\
\hline
\end{tabular}

Fonte: Elaboração própria a partir dos resultados das análises de DIF, com dados do PISA 2006. * Pearson Chi-Square $(\mathrm{p}=, 007)$

Os DIFs encontrados no parâmetro $b$ dos itens também não se mostraram associados ao idioma (p-valor de 0,477 ), de tal forma que o idioma não torna mais fácil ou mais difícil um item para os estudantes de nenhum dos dois países. Da mesma forma, não se encontrou diferenças significativas entre as médias de intensidade do DIF na dificuldade do item para os diferentes idiomas ( $\mathrm{p}$-valor de 0,283). Isso quer dizer que embora existam itens com DIF segundo o idioma, não há indícios suficientes de que o DIF esteja privilegiando um grupo em detrimento do outro, facilitando, por exemplo, o desempenho dos estudantes brasileiros e/ou dos japoneses. 


\section{6 \\ Letramento Científico no Brasil e Japão}

Como vimos até aqui, o desempenho dos estudantes japoneses em Ciências no PISA é bem melhor do que o dos estudantes brasileiros. Apesar da ocorrência de DIF em alguns itens do teste, não podemos dizer que tamanha diferença de desempenho seja explicada única e exclusivamente pelo comportamento diferencial dos itens, ou seja, pelo fato de os itens estarem favorecendo o Japão em detrimento do Brasil. Dentre inúmeros outros fatores, tais como a condição socioeconômica dos estudantes, o nível de escolaridade de seus pais etc., a literatura aponta que professores eficazes trazem impactos significativos para a aprendizagem dos estudantes (HANUSHEK \& WOSSMANN, 2010; HATTIE, 2003, 2009, 2012; THE LEARNING CURVE, 2012; HANUSHEK, 2002; TAYLOR, ROEHRIG, HENSLER, CONNOR \& SCHATSCHNEIDER, 2010). A identificação dos componentes que o professor incorpora na sua prática de ensino podem, portanto, fazer a diferença na aprendizagem e no desempenho dos estudantes e, ainda, resultar em medidas que promovam a eficácia escolar e uma melhoria substancial da qualidade do ensino.

Observamos no Japão e no Brasil, entre os meses de Novembro de 2015 e Outubro de 2016, um total de 147 aulas de Ciências dos três últimos anos do Ensino Fundamental. Foram acompanhados 16 professores no total, oito em cada país.

Antes de entrarmos efetivamente na análise da utilização do tempo, das ênfases curriculares e das práticas pedagógicas no Ensino de Ciências de Brasil e Japão, apresentamos e caracterizamos os professores observados.

\section{1}

\section{Caracterização dos professores observados}

Foram observados 16 professores: oito deles no Brasil e oito no Japão e $15^{30}$ professores responderam a um questionário envolvendo:

\footnotetext{
${ }^{30}$ Um dos professores japoneses saiu da escola observada antes que pudéssemos recolher o questionário. Fizemos algumas tentativas de tentar localizá-lo, mas não obtivemos sucesso.
} 
1.Características pessoais e profissionais: sexo, idade, graduação, experiência e modo de contratação.

2. Formação continuada

3. Prática pedagógica

Nesta sessão de caracterização utilizaremos apenas as informações pessoais, profissionais e de formação continuada. Nas sessões que se seguem, apresentamos os resultados da prática pedagógica.

Dentre os 16 professores observados, 9 são do sexo feminino e 7 do masculino. A proporção de homens e mulheres nas amostras de Brasil e Japão se inverte. No Japão, a maioria dos professores observados é do sexo masculino (5 de 8) e, no Brasil, a maioria é do sexo feminino (6 de 8).

No que diz respeito à idade, os professores são mais velhos no Japão. Na Tabela 20 apresentamos a frequência de idade entre os professores observados.

Tabela 20. Faixa etária dos professores observados

\begin{tabular}{|c|c|c|}
\hline Faixa Etária & País & Frequência \\
\hline \multirow[t]{2}{*}{ De 25 a 29 anos } & Brasil & 3 \\
\hline & Japão & 0 \\
\hline \multirow[t]{2}{*}{ De 30 a 39 anos } & Brasil & 3 \\
\hline & Japão & 2 \\
\hline \multirow[t]{2}{*}{ De 40 a 49 anos } & Brasil & 1 \\
\hline & Japão & 1 \\
\hline \multirow[t]{2}{*}{ De 50 a 59 anos } & Brasil & 0 \\
\hline & Japão & 3 \\
\hline \multirow[t]{2}{*}{ Mais de 60 anos } & Brasil & 1 \\
\hline & Japão & 1 \\
\hline
\end{tabular}

Como se pode observar, a maior parte dos professores brasileiros por nós observados tem menos de 39 anos (6 dos 8). Já a maior parte dos japoneses (5 de 7) estão acima dos 40 anos. A idade desses professores está intimamente relacionada a seu tempo de experiência como professores de Ciências. Os professores japoneses são mais velhos e também mais experientes. Cinco deles tem mais de 20 anos de experiência na profissão.

No caso do Brasil, dos oito professores observados apenas dois têm mais de 10 anos de experiência e somente um deles não é servidor público. 
Apenas quatro dos professores japoneses observados é servidor, a outra metade trabalha sob regime contratual.

$\mathrm{Na}$ mesma direção, a maioria dos professores brasileiros participantes da pesquisa só leciona na escola observada. Apenas um professor disse dar aulas em mais de uma escola, além da observada, precisamente o único que não é servidor público.

No Japão, só quatro professores, os servidores, não dão aulas em outra escola. Os demais trabalham em mais de um estabelecimento de ensino.

Todos os professores brasileiros observados possuem diplomas de pósgraduação strictu sensu: quatro deles são mestres e quatro doutores.

Não observamos professores doutores no Japão. Ainda que neste país os professores possam solicitar uma licença remunerada para fazer mestrado e que o Ministério da Educação ofereça vários programas de treinamento para formadores de professores, apenas quatro dos professores observados são mestres e os outros três, licenciados/bacharéis.

A formação inicial dos professores brasileiros é uma só: Biologia, com licenciatura que é requisito para os professores de Ciências dos últimos anos do Ensino fundamental no país. No Japão é diferente, lá os professores formados em Física, Química e Geociências, além da Biologia, ficam habilitados a lecionar nesse segmento de Ensino. Como veremos a seguir, essa formação mais diversificada pode ser uma vantagem em termos de ensino e aprendizagem de Ciências para os estudantes japoneses. Em duas das três escolas observadas no Japão, os professores lecionam os conteúdos de acordo com a sua formação e especialidade. Apesar de, assim como no Brasil, os estudantes no Japão terem apenas a disciplina genérica de Ciências no final do Ensino Fundamental, naquele país, cada turma pode ter mais de um professor e este lecionar, para diferentes turmas, apenas os conteúdos nos quais é especializado. Por exemplo, o professor de Ciências com formação em Química leciona os conteúdos de Química para todas as turmas da escola. Assim também o fazem aqueles com formação em Física, Geociências e Biologia.

A formação continuada dos professores brasileiros e japoneses também tem suas peculiaridades. O questionário do professor aplicado na pesquisa focaliza atividades relacionadas a: 
1. Cursos e/ou oficinas, por exemplo, sobre disciplinas ou métodos e/ou outros tópicos relacionados à educação científica/Ensino de Ciências;

2. Conferências ou seminários sobre educação científica/Ensino de Ciências em que professores e/ou os pesquisadores apresentam resultados de suas pesquisas e discutem problemas educacionais;

3. Programas de qualificação como, por exemplo, um curso em nível de graduação ou pós-graduação que ofereça diploma ou certificado;

4. Visitas de observação a outras escolas;

5. Participação em uma rede de professores (network) formada especificamente para seu desenvolvimento profissional;

6. Pesquisa individual ou em colaboração sobre um tópico de interesse profissional;

7. Orientação e/ou observação feita por um colega e supervisão, organizadas formalmente pela escola.

Na Figura 19, apresentamos a frequência dos professores brasileiros e japoneses nessas atividades de formação continuada.

Figura 19. Frequência dos professores nas diferentes atividades de formação continuada.

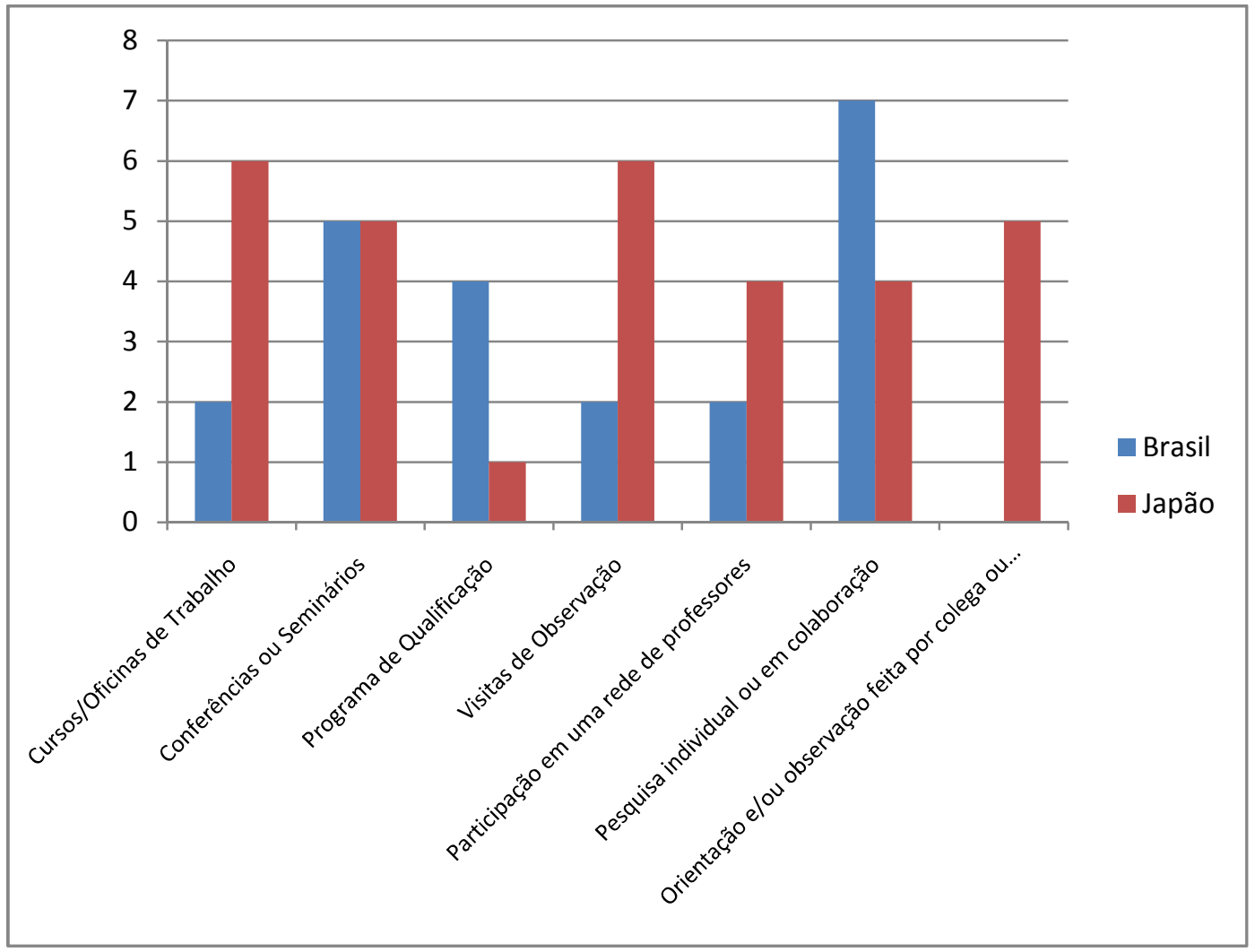

Fonte: elaboração própria a partir dos dados da pesquisa. 2016. 
Como se pode perceber na Figura 20, a formação continuada entre os professores brasileiros observados enfatiza aquelas iniciativas diretamente relacionadas à pesquisa e à extensão. Normalmente essas atividades estão também relacionadas com a frequência aos cursos de pós-graduação. Assim, essas respostas sugerem um maior interesse por parte dos professores brasileiros por atividades que confiram certificação e isso, muito provavelmente, tem relação com os planos de carreira oferecidos na educação pública.

As atividades mais comuns entre os profissionais japoneses são aquelas relacionadas à interação com os pares. Ou seja, aquelas que fazem parte da formação que é realizada em e no serviço. No Japão, os professores são obrigados a renovar sua licença a cada dez anos e a formação acaba se dando no percurso. Por isso, acreditamos que os professores japoneses assumam ter participado de atividades relacionadas a cursos e oficinas, visitas de observação, programas de orientação e observação e conferências ou seminários (Figura 20). Esses resultados encontram suporte nas palavras do Professor Ogawa por nós entrevistado:

The Japanese system has changed and even if you have a certificate you need to renew it every ten years. You have to involve in a certain kind of in service training teacher program. In Japan the teachers always work in peers... If you are into a school, for example, into a low secondary school, maybe 9th graders, and there are three 9th graders, three teachers there, those three teachers group is closely discussing everything. One teacher sometimes drop another teacher class and after finishing the class they discuss what is going on in their classes and then probably start developing a plan, whole year course programs, for example, science programs. How can I say? Course Plan! One year plan. Plan one year class scheduling. It is not developed by one teacher. Always the group is responsible to do that. In some cases, if one class is left behind, probably other teachers will help and support this class teacher. It is a very natural thing, so that, even for the novices teachers or maybe the first freshman teacher they can have much more help and easily manage their science classes because the senior teachers are kindly helping the novice teachers. That kind of human relation is very popular among Japanese school system. If one teacher have problems, she or he announce it through the different means of communication or other devices, other teacher comment or suggest or advice. Always there is a kind of peer group so that there are no teachers standing alone. That is a very good way of doing of teachers. If someone have problems other teachers assist or help them, so that, in return he or she can help other. It is a very popular way. But that kind of thing is a cultural traditional. $^{3}$

\footnotetext{
${ }^{31}$ Tradução livre: O sistema japonês mudou e, mesmo que você tenha um certificado, você precisa renová-lo a cada dez anos. Você tem que se envolver em algum programa de formação de professores em serviço. No Japão os professores sempre trabalham em grupo... Se você está em uma escola, por exemplo, em uma escola secundária, talvez no $9^{\circ}$ ano, e há três turmas de $9^{\circ}$ ano, três professores lá, os três professores do grupo estão discutindo tudo de perto. Um professor, por
} 
No Japão, o trabalho colaborativo como desenvolvimento profissional tem sido um aspecto bem-sucedido do treinamento de professores. Os grupos de pesquisa de professores são um componente da abordagem japonesa para a aprendizagem profissional chamada jyugyo kenkyu ou Lesson Study (FERNADEZ \& YOSHIDA, 2004). Através do Lesson Study, os professores se sentem conectados uns aos outros e com um corpo de conhecimento que eles geram, compartilham e continuamente refinam. É uma atividade altamente valiosa, largamente discutida e apontada na literatura internacional como o motivo principal do sucesso escolar dos japoneses (DARLING-HAMMOND, CHUNG WEI \& ANDREE, 2010; KATO, 2014; CHASSELS \& MELVILLE, 2009; LEWIS, 2011; ERMELING \& GRAFF-ERMELING, 2014; OECD, 2010), que permite que os professores se reúnam para desenvolver seus conhecimentos e habilidades pedagógicas.

O Lesson Study se baseia na observação de aulas por um grupo de professores que coletam dados sobre ensino e aprendizagem e analisam-nos colaborativamente (LEWIS et al., 2006). Durante o estágio de doutorado sanduíche tivemos a oportunidade de acompanhar uma sessão de Lesson Study. Normalmente, o que ocorre é que a direção da escola organiza reuniões para discutir técnicas de ensino e as reuniões em cada escola são complementadas por grupos informais de estudo em todo o distrito, ou seja, abertas a outros professores de outras escolas. Assim, os professores trabalham juntos projetando planos de aula. Ao terminar um plano, um professor do grupo ensina a lição aos seus estudantes enquanto os outros observam. Em seguida, o grupo reúne-se novamente para avaliar o desempenho do professor que deu a aula e fazer sugestões de melhoria.

vezes, pode substituir o outro e depois discutir o que está acontecendo em suas aulas e, em seguida, provavelmente começar a desenvolver um plano, programas de curso de ano inteiro, por exemplo, programas de Ciências. Como posso dizer? Plano de curso! Plano de um ano. Planejar um ano de aulas. Não é desenvolvido por um professor. Sempre o grupo é responsável por fazer isso. Em alguns casos, se uma classe é deixada para trás, provavelmente outros professores irão ajudar e apoiar o professor desta classe. É uma coisa muito natural, de modo que, os professores novatos podem ter muito mais ajuda e gerenciar facilmente suas aulas de Ciências porque os professores seniores estão gentilmente ajudando-os. Esse tipo de relação humana é muito popular no sistema escolar japonês. Se um professor tiver problemas, ele anunciá-o através dos diferentes meios de comunicação ou outros dispositivos, outro professor comenta, sugere ou aconselha. Sempre há um tipo de grupo de pares para que não haja professores sozinhos. Essa é uma maneira muito boa de fazer as coisas. Se alguém tiver problemas, outros professores ajudam, para que, em troca, ele possa ajudar outros. É uma maneira muito popular. Mas esse tipo de coisa é uma tradição cultural. 
Para a OCDE (2010) esta prática está inteiramente consistente com a maneira como as equipes trabalham na indústria privada japonesa. Também reflete a confiança dos japoneses nos grupos para fazer qualquer trabalho, o que acaba tendo um profundo impacto sobre a prática do ensino. Na verdade, é um diferencial para a melhoria contínua e sustentada da prática de ensino.

Para se tornar professor no Japão, os estudantes devem participar de um programa de educação de professores certificado pelo Ministério de Educação em uma universidade ou faculdade. O Japão tem algumas universidades nacionais de formação de professores, como é caso da Tokyo Gakugei University onde realizei meu estágio de doutorado sanduíche.

A prática docente é uma parte comum de todos os programas de formação de professores. As prefeituras, como outros empregadores no Japão, estão preparadas para fazer grandes investimentos em seus novos professores na certeza de que eles adquiram as habilidades necessárias para desempenhar bem seu papel. De acordo com a OCDE (2010), os ógãos educacionais japoneses assumem que os novos profissionais vêm até eles com a necessária inteligência aplicada, mas não necessariamente com as habilidades requeridas ao bom desempenho do trabalho. Assim, eles tomam a responsabilidade de fornecer aos recém-formados um programa de indução que nada mais é do que uma oportunidade sustentada de aprendizagem com professores experientes antes de efetivamente começarem a ensinar em tempo integral. O período de indução dura um ano inteiro, e os professores experientes recebem um ano de folga de seus trabalhos de ensino para supervisionar seus aprendizes.

Enfim, o Lesson Study é um processo de desenvolvimento profissional colaborativo, baseado na escola, pelo qual os professores japoneses procuram melhorar o ensino e a aprendizagem que ocorrem em suas salas de aula (Stigler \& Hiebert, 1999). A ele são creditadas o desenvolvimento contínuo do professor e as mudanças que ocorreram nas salas de aula japonesas nas últimas cinco décadas (Lewis \& Tsuchida, 1997), uma situação que contrasta com a falta aparente de mudança em muitas salas de aula ocidentais (Stigler \& Hiebert, 1999).

Darling-Hammond, Chung Wei \& Andree (2010) em "How High-Achieving Countries Develop Great Teachers" descrevem o Lesson Study como uma prática japonesa altamente desenvolvida que está se espalhando por outras nações. Neste texto, uma breve pesquisa realizada no âmbito do Stanford Center for Opportunity 
Policy in Education, as autoras apresentam um quadro sobre a prática do Lesson

Study, tal como reproduzimos aqui na Figura 20.

\section{Figura 20. Descrição do Lesson Study por Darling-Hammond, Chung Wei \& Andree, 2010.}

Japan's Lesson Study Approach to Professional Development

In Japan kenkyии jugyou (research lessons) are a key part of the learning culture. Every teacher periodically prepares a best possible lesson that demonstrates strategies to achieve a specific goal (e.g. students becoming active problem-solvers or students learning more from each other) in collaboration with other colleagues. A group of teachers observe while the lesson is taught and usually record the lesson in a number of ways, including videotapes, audiotapes, and narrative and/or checklist observations that focus on areas of interest to the instructing teacher (e.g., how many student volunteered their own ideas). Afterwards, the group of teachers, and sometimes outside educators, discuss the lesson's strengths and weakness, ask questions, and make suggestions to improve the lesson. In some cases the revised lesson is given by another teacher only a few days later and observed and discussed again

Teachers themselves decide the theme and frequency of research lessons. Large study groups often break up into subgroups of 4-6 teachers. The subgroups plan their own lessons but work toward the same goal and teachers from all subgroups share and comment on lessons and try to attend the lesson and follow-up discussion. For a typical lesson study, the 10-15 hours of group meetings are spread over three to four weeks. While schools let out between 2:40 and 3:45 p.m., teachers' work days don't end until 5 p.m., which provides additional time for collegial work and planning. Most lesson study meetings occur during the hours after school lets out. The research lessons allow teachers to refine individual lessons, consult with other teachers and get colleagues' observations about their classroom practice, reflect on their own practice, learn new content and approaches, and build a culture that emphasizes continuous improvement and collaboration.

Some teachers also give public research lessons, which expedites the spread of best practices across schools, allows principals, district personnel, and policymakers to see how teachers are grappling with new subject matter and goals, and gives recognition to excellent teachers.

Fonte: Darling-Hammond, Chung Wei \& Andree, $2010^{32}$

\footnotetext{
${ }^{32}$ Tradução livre: A abordagem japonesa de Lesson Study para o desenvolvimento profissional. No Japão, o kenkyuu jugyou (lições de pesquisa) é uma parte fundamental da cultura de aprendizagem. Cada professor prepara periodicamente a melhor lição possível que demonstre estratégias para atingir um objetivo específico (por exemplo, os alunos se tornarem ativos na solução de problemas ou os alunos aprenderem mais uns dos outros) em colaboração com outros colegas. Um grupo de professores observa enquanto a lição é ensinada e geralmente registra a lição de várias maneiras, incluindo gravação de vídeo, áudio e observações de narrativas e / ou de checklist que se concentram em áreas de interesse para o professor instrutor (por exemplo, como muitos estudantes ofereceram suas próprias idéias). Depois, o grupo de professores, e às vezes educadores externos, discutem os pontos fortes e fracos da lição, fazem perguntas e fazem sugestões para melhorá-la. Em alguns casos, a lição revista é dada por outro professor apenas alguns dias depois e observada e discutida novamente.

Os próprios professores decidem o tema e a frequência das lições de pesquisa. Grandes grupos de estudo frequentemente se dividem em subgrupos de 4-6 professores. Os subgrupos planejam suas próprias lições, mas trabalham para o mesmo objetivo e os professores de todos os subgrupos compartilham e comentam as lições e tentam participar da lição e da discussão de acompanhamento. Para um estudo de lição típico, 10-15 horas de reuniões de grupo são distribuídas ao longo de três a quatro semanas. Enquanto o horário escolar se encerra entre 2:40 e 3:45 da tarde, o dia de trabalho dos professores não termina até às 17hs, o que proporciona tempo adicional para o trabalho colegial e planejamento. A maioria das reuniões de estudo de aula ocorre durante as horas após a saída dos alunos. As aulas de pesquisa permitem que os professores refinem lições individuais, consultem outros professores e obtenham observações dos colegas sobre suas práticas de sala de aula, reflitam sobre sua própria prática, aprendam novos conteúdos e abordagens e construam uma cultura que enfatize a melhoria contínua e a colaboração.
} 
Diante do exposto, é possível perceber que o Lesson Study, como parte de um programa de formação de professores, oferece muitos benefícios que poderiam contribuir para uma cultura aprimorada de colaboração profissional proposital em escolas que mantém foco na melhoria contínua do ensino e das aprendizagens necessárias para a participação ativa no mundo em rápida mudança que vivemos hoje. Os japoneses dizem que o Lesson Study desenvolve os olhos do professor para ver as crianças (RICHARDSON, 2000). Certamente uma das chaves mais importantes para a qualidade da educação no Japão é a qualidade dos seus professores e dos seus programas de formação docente. O tempo escolar e seu uso são outros dos fatores importantes para o bom desempenho acadêmico dos estudantes japoneses. Na sessão seguinte trataremos do tempo dedicado ao Ensino de Ciências no Brasil e no Japão, a partir dos dados do PISA e também das aulas por nós observadas nesses dois países.

\section{2 O tempo dedicado ao Ensino de Ciências}

O tempo de aula é um indicador chave da oportunidade de aprender Ciências (BLANK, 2012). Pesquisadores da relação entre tempo e aprendizagem defendem que o tempo de aula precisa ser alocado regularmente durante o dia e a semana escolar e que o tempo de instrução é uma questão-chave de equidade (TRAPHAGEN, 2011, KARWEIT, 1983, NATIONAL CENTER ON TIME AND LEARNING, 2010). Dada a importância do tempo dedicado ao processo de ensino e aprendizagem, estudos internacionais como o PISA, trazem a informação do tempo dedicado às aulas de Ciências pelos países participantes, como pode ser visto na Tabela 21 para os países aqui pesquisados e na OCDE, de modo geral.

Alguns professores também dão lições públicas de pesquisa, o que agiliza a disseminação das melhores práticas nas escolas, permitindo que os diretores, pessoal do distrito e formuladores de políticas vejam como os professores estão lidando com novos temas e metas e dão reconhecimento aos excelentes professores. 
Tabela 21. Distribuição percentual dos estudantes em relação ao tempo médio de aulas regulares de Ciências na Escola - PISA 2006 e PISA 2015.

\begin{tabular}{ccccc}
\hline & & \multicolumn{3}{c}{ Aulas Regulares na Escola (\%) } \\
\hline \multirow{2}{*}{2006} & Brasil & $\begin{array}{c}\text { Menos que duas } \\
\text { horas por } \\
\text { semana }\end{array}$ & $\begin{array}{c}\text { De duas a quatro } \\
\text { horas por } \\
\text { semana }\end{array}$ & $\begin{array}{c}\text { Mais que quatro } \\
\text { horas por } \\
\text { semana }\end{array}$ \\
& Japão & $\mathbf{4 9 , 8}$ & 38,8 & 11,4 \\
\multirow{2}{*}{$\mathbf{2 0 1 5}$} & 26,6 & $\mathbf{6 1 , 2}$ & 12,2 \\
& Média OCDE & 32,7 & $\mathbf{3 8 , 5}$ & 28,8 \\
& Brasil & 13,8 & $\mathbf{6 6 , 5}$ & 19,7 \\
& Japão & 3,3 & $\mathbf{8 0 , 4}$ & 16,3 \\
& Média OCDE & $\mathbf{9 , 5}$ & $\mathbf{4 0 , 2}$ & $\mathbf{5 0 , 3}$ \\
\hline
\end{tabular}

Fonte: elaboração própria com base nos resultados do PISA 2006 e 2015.

A partir da tabela acima podemos observar que aproximadamente $50 \%$ dos estudantes da amostra brasileira, em 2006, afirmavam ter menos de duas horas de aula regular de Ciências por semana, enquanto que a maioria dos estudantes da OCDE, e mais da metade dos japoneses, eram expostos a um período que vai de duas a quatro horas de aula desse conteúdo por semana. Como mais de $40 \%$ dos estudantes brasileiros participantes na edição de 2006 estavam defasados, permanecendo, portanto, retidos e matriculados nos anos finais do Ensino Fundamental, não era de se esperar que a maioria deles informasse ter mais do que duas horas aula de Ciências por semana na escola. O que é preocupante é o tempo dedicado à disciplina, já que duas horas-aula é a carga horária mínima da disciplina na maioria das escolas do país.

Em 2015, a maioria dos estudantes brasileiros, assim como os japoneses, afirmaram ter entre duas e quatro aulas de Ciências por semana. Os dados de 2015, diferentemente dos de 2006, nos permitem avaliar exatamente quantos tempos de aula os estudantes afirmam ter. Mais de um terço dos estudantes brasileiros $(32,5 \%)$ afirma ter duas aulas por semana e mais de um terço dos japoneses $(33,2 \%)$ quatro.

A mudança nos dados do Brasil, entre 2006 e 2015, tem novamente relação com a amostra do país no Programa. Da mesma forma que o período de aplicação do teste influencia na distribuição dos estudantes nas séries, o número de aulas observadas também reflete o número de estudantes matriculados em cada segmento de ensino. Via de regra, estudantes matriculados no Ensino Fundamental, que foram maioria em 2006, têm apenas duas aulas de Ciências por semana, ao passo em que alunos matriculados no Ensino Médio, que foram 
maioria em 2015, têm até seis aulas por semana, que somam os tempos destinados a Biologia, Física e Química.

No Japão, além de os estudantes receberem muito mais horas aulas de Ciências do que os brasileiros, diante do que pudemos observar, as aulas envolvem uma maior mobilização dos conteúdos aprendidos em questões práticas e do dia-a-dia. A importância da Ciência para o desenvolvimento científicotecnológico é muito enfatizada desde as séries iniciais do Ensino Fundamental e grande parte das reformas no Ensino de Ciências no Japão procuraram revisar o número de aulas e a prática pedagógica adotada pelos professores, de forma a alcançar maiores índices de Letramento Científico entre a população como um todo.

A Associação Brasileira de Ciências (ABC, 2007) afirma que o desenvolvimento social, científico e tecnológico do Brasil requer uma reformulação profunda da estrutura educacional em nosso país. Talvez, o repensar da carga horária dedicada ao Ensino de Ciências na escola brasileira possa ser um dos muitos passos em direção ao almejado desenvolvimento científicotecnológico do país.

Para além da importância da carga horária dedicada ao ensino e aprendizagem, de Ciências ou de qualquer outra disciplina, está o uso do tempo. Estudantes brasileiros perdem em média um dia de aula por semana por conta de desperdício de tempo em sala de aula, gasto com atrasos, excesso de tarefas burocráticas (fazer chamada, limpar a lousa e distribuir trabalhos) e em aulas mal preparadas pelo professor. Este tempo deixa de ser gasto com o processo efetivo de ensino e aprendizagem. Essa foi uma das principais conclusões de um estudo recém-lançado pelo Banco Mundial (BRUNS \& JAVIER, 2014) que analisou o trabalho de professores na América Latina e seu impacto sobre a qualidade do aprendizado, a formação dos estudantes e o desempenho desses países em rankings internacionais de educação. Esta situação já havia sido constatada, em 2005, no estudo de Martin Carnoy com Gove e Marshall (CARNOY, GOVE, MARSHALL, 2009) sobre a vantagem acadêmica de Cuba em comparação com o Brasil e com o Chile.

O Banco Mundial (BRUNS \& JAVIER, 2014) avaliou 15,6 mil salas de aula, mais da metade delas no Brasil (classes de Ensino Fundamental e Médio em Minas Gerais, Pernambuco e Rio de Janeiro), e calculou que, em média, apenas 
64\% do tempo de aula é usado para o ensino/aprendizagem, ficando o Brasil 20 pontos percentuais abaixo dos padrões internacionais.

Bárbara Bruns afirmou em entrevista a BBC Brasil que em escolas no leste da Ásia, Japão, Cingapura, Finlândia e Alemanha não é comum observar professores chegarem à sala de aula sem um material pronto ou sem a percepção de que o tempo precisa ser usado para ensinar e manter os estudantes engajados, algo considerado crucial para o aprendizado. De fato, diante da nossa experiência no estágio de doutorado sanduíche no Japão, foi possível perceber que o uso efetivo do tempo de aula nessa sociedade e sistema educacional, notoriamente reconhecido como um dos maiores desempenhos de avaliações internacionais do mundo é algo extremamente importante.

Os resultados da Pesquisa Internacional sobre Ensino e Aprendizagem (TALIS), também da OCDE, de 2013 (OCDE, 2013c), nos permite comparar os dados do Brasil aos do Japão. A Tabela 22 mostra as informações dos professores do segundo segmento do Ensino Fundamental pesquisados sobre a distribuição do tempo em uma aula qualquer no seu horário de aulas semanal. Ela traz informações acerca do percentual de tempo dedicado por esses professores a atividades como: tarefas administrativas, manutenção da ordem na classe e o ensino e aprendizagem efetivo.

Tabela 22. Proporção média de tempo que professores atribuem as atividades $* * *$

\begin{tabular}{ccccccc}
\hline & \multicolumn{2}{c}{$\begin{array}{c}\text { Tarefas } \\
\text { administrativas }\end{array}$} & \multicolumn{2}{c}{$\begin{array}{c}\text { Manutenção da ordem } \\
\text { na sala de aula }\end{array}$} & \multicolumn{2}{c}{$\begin{array}{c}\text { Ensino e } \\
\text { aprendizagem efetivo }\end{array}$} \\
\cline { 2 - 7 } & $\%$ & $\begin{array}{c}\text { Erro } \\
\text { padrão }\end{array}$ & $\%$ & $\begin{array}{c}\text { Erro } \\
\text { padrão }\end{array}$ & $\%$ & $\begin{array}{c}\text { Erro } \\
\text { padrão }\end{array}$ \\
Brasil & 12,2 & 0,1 & 19,8 & 0,3 & 66,7 & 0,3 \\
Japão & 7,0 & 0,2 & 14,6 & 0,3 & 78,3 & 0,5 \\
OCDE & 8,0 & 0,0 & 12,7 & 0,1 & 78,7 & 0,1 \\
\hline
\end{tabular}

Fonte: OCDE, TALIS, 2013c.

*esses dados são reportados por professores e se referem a uma aula aleatoriamente escolhida que eles lecionem durante a semana.

**A soma de tempo investido numa aula média pode não fechar 100\% devido ao fato de respostas que não somaram $100 \%$ terem sido aceitas.

Como se pode observar, os achados do Banco Mundial também aparecem refletidos nos achados do TALIS. Segundo os próprios professores avaliados por este Programa, no Brasil, não se investe nem sequer 70\% do tempo disponível em ensino e aprendizagem efetivo. Muito do nosso tempo acaba sendo destinado a outras questões que chamaremos aqui, genericamente, de Tempos Mortos (TM), 
ou seja, tempo investido em questões outras que não aquelas relacionadas ao ensino aprendizagem de Ciências. O Japão e a OCDE também tem uma perda considerável de tempo com questões outras, contudo, seus professores admitem investir mais de $75 \%$ do tempo no ensino e aprendizagem efetivo de seus estudantes.

Segundo Crahay (2002), para se desenvolver uma competência ou apropriar um conhecimento, é preciso beneficiar-se de ocasiões de aprendizagem apropriadas. Para o autor,

a não ser que se acredite na geração espontânea das competências, parece lógico supor-se que os estudantes só aprendem o que, de uma maneira ou de outra, lhes é dado a ocasião de aprender. Por consequência, se se constata que as ocasiões para dominar os objetivos inscritos nos planos de estudos e, paralelamente, o tempo concedido ao seu ensino variam de aula para aula, compreende-se melhor por que uma importante parte da variância dos resultados dos estudantes é imputável à escola frequentada. Não se pode esperar que estudantes que não se beneficiam de ocasiões de aprendizagem equivalentes atinjam níveis de competência equivalentes. (CRAHAY, 2002, p. 212).

Assim, buscamos, baseados no autor (CHAHAY, 2002), calcular o Tempo Reservado à Ação Educativa (TRAE) de Ciências das aulas observadas no decorrer da pesquisa, no Brasil e no Japão. O autor reúne quantidade significativa de dados empíricos que permitem conceber um ensino ao mesmo tempo mais justo e eficaz. Segundo Crahay, a observação do tempo de ensino constitui um meio indireto de medir as ocasiões de aprender de que os estudantes se beneficiam.

As três escolas observadas no Japão oferecem quatro horas-aula de Ciências por semana a seus estudantes. Entre as brasileiras, a Adolpho Lutz oferece três horas-aula por semana, a Carlos Chagas oferece quatro horas-aula para os $6^{\circ}, 7^{\circ}$ e $8^{\circ}$ anos e cinco horas-aula para os $9^{\circ}$ anos e a César Lattes oferece três horasaula para os $6^{\circ}, 7^{\circ}$ e $8^{\circ}$ anos e quatro horas-aula para as turmas de nono ano.

Um fato chamou nossa atenção na distribuição das aulas japonesas e acabou por se mostrar um aspecto diferencial em relação à organização do horário escolar brasileiro. Nas três escolas japonesas, cada aula, de 50 minutos, é separada uma da outra por um intervalo de 10 minutos. Pesquisadores acreditam que uma razão pela qual os estudantes japoneses parecem mais engajados quando estão na aula do que os estudantes em muitos outros países é que eles recebem mais interrupções do ensino (STEVENSON \& STIGLER, 1992). Esse tempo, no entanto, não é um Tempo Morto, mas um tempo dedicado a outras questões como 
a troca de sala de aula, a entrega de atividades de casa, etc. É, portanto, um tempo em que os professores e os estudantes devem se organizar para a próxima aula de forma a não se perder muito do tempo efetivo de aula. Igualmente, as aulas são ministradas uma a uma, ou seja, não são ministradas no mesmo dia ou de forma seguida como fazemos no Brasil ao juntarmos dois tempos ou duas aulas de Ciências, ou de qualquer outra disciplina, num mesmo dia e horário consecutivo. No Japão, os estudantes têm aula de Ciências, e também de outras disciplinas, em diferentes dias da semana, um tempo por dia.

De Novembro de 2015 a Outubro de 2016 observamos um total de 147 horas-aula de Ciências no Brasil e no Japão. Como já dissemos, foram aulas de Ciências dos três últimos anos do Ensino Fundamental. Foram 64 horas-aula no Japão e 83 horas-aula no Brasil. Tentamos observar 10 horas-aula de cada professor, mas como já dissemos, em alguns momentos isso não foi possível e, por isso, temos um tempo de observação diferente nos dois países.

Tanto no Brasil quanto no Japão, nas escolas observadas a hora-aula é composta por 50 minutos. Sendo assim o nosso Tempo Oficial (TO) total foi de exatos 7350 minutos. Além do TO, para encontrar o Tempo Reservado à Ação Educativa (TRAE), registramos também: o Tempo Morto (TM), o Tempo "Perdido" na Entrada (TE) e o Tempo "Perdido" na Saída (TS). A sentença que expressa o conceito de TRAE, definido por Crahay (2002), é a seguinte:

$$
\mathrm{TRAE}=\mathrm{TO}-\mathrm{TM}-\mathrm{TE}-\mathrm{TS}
$$

As unidades de tempo observadas nos dois países são apresentadas na Tabela 23.

Tabela 23. Distribuição do tempo, em minutos e percentual, nas aulas observadas no Brasil e no Japão

\begin{tabular}{|c|c|c|c|c|}
\hline & \multicolumn{2}{|c|}{ Brasil } & \multicolumn{2}{|c|}{ Japão } \\
\hline & Minutos & $\%$ & Minutos & $\%$ \\
\hline Tempo Oficial (TO) & 4150 & 100 & 3200 & 100 \\
\hline Tempo Morto (TM) & 219 & 5,3 & 31 & 1,0 \\
\hline Tempo Perdido na Entrada (TE) & 397 & 9,6 & 30 & 0,9 \\
\hline Tempo Perdido na Saída (TS) & 138 & 3,3 & 11 & 0,3 \\
\hline $\begin{array}{l}\text { Tempo Reservado à Ação Educativa } \\
\text { (TRAE) }\end{array}$ & 3396 & 81,8 & 3128 & 97,8 \\
\hline
\end{tabular}

Fonte: elaboração própria com base nos resultados da pesquisa. 2016. 
Como se pode observar, a diferença de TM, TE e TS entre os dois países, mais exatamente entre as escolas e aulas observadas, é gigantesca. Foram 31, 30 e 11 minutos, respectivamente, no Japão e de 219, 397 e 138 no Brasil. Assim, o TRAE das aulas observadas, tanto no Brasil quanto no Japão, é igual ao TO menos o TM, o TE e o TS, portanto, 3128 minutos no Japão e 3396 minutos no Brasil.

Aproximadamente uma hora e meia de aula dentre as 64 observadas no Japão foi destinada a questões outras que não o ensino e aprendizagem de Ciências. Isso representa pouco mais de $2 \%$ do total de horas observadas. De fato, o tempo das aulas observadas de Ciências no Japão esteve claramente relacionado a conteúdos de Ciências e à atividade científica. $\mathrm{O}$ intervalo entre as aulas, anteriormente mencionado, parece contribuir substancialmente para este uso efetivo do tempo. Durante as observações, pudemos notar que este intervalo foi utilizado para a resolução de questões administrativas, entrega de materiais etc. Cabe ressaltar, também, que os professores e escolas observadas não apresentam problemas importantes com indisciplina. Os japoneses são culturalmente muito disciplinados e o professor e a profissão docente são muito respeitados naquela sociedade. Os estudantes, no início de todas as aulas, reverenciam seus professores de pé e novamente o fazem antes de deixar a sala ao término da aula agradecendo-os pela instrução.

Já a situação das escolas brasileiras por nós observadas reproduz os achados da grande pesquisa TALIS, do estudo realizado pelo Banco Mundial e também do estudo de Carnoy, Gove e Marshall (2009). Das horas-aula observadas (83) chegamos a perder pelo menos 15 horas-aula, quase que $20 \%$ do tempo total. As escolas brasileiras que observamos aqui desperdiçam 10 vezes mais tempo de aula do que as escolas japonesas.

Sabemos que um bom ensino e uma boa gestão de sala de aula são essenciais para melhorar o engajamento dos estudantes (DARLING-HAMMOND, WISE \& KLEIN, 1999; GETTINGER \& SEIBERT, 2002; OLIVER, WEHBY \& RESCHLY, 2011) e que esta gestão é um desafio à educação brasileira. Obviamente, as condições de ensino no Japão, como já dissemos, são mais propícias ao engajamento dos estudantes do que no Brasil. As escolas lá, por exemplo, funcionam em turno único enquanto as nossas oferecem dois turnos. Só a escola "César Lattes" trabalha em turno único. 
Por aqui, encontramos também muito problema com indisciplina. A maior parte do TM que registramos não se relaciona com atividades burocráticas ou administrativas. Os professores brasileiros gastam muito do tempo de aula mantendo a disciplina na classe, cerca de $20 \%$ do tempo segundo o levantamento internacional da OCDE (OCDE, 2013c). Ou seja, o docente gasta um em cada cinco minutos pedindo silêncio ou chamando a atenção da turma em razão da bagunça. Outra parte do tempo perdido se relaciona com as entradas e saídas das salas de aula pelos professores e estudantes, a atrasos, interrupções etc. O TE, por exemplo, é caracterizado, principalmente, pela troca de professores. Não há um desconto de tempo de deslocamento de uma sala para outra. Recorrentemente acontece que os professores entram atrasados em sala e isso não parece incomodálos, nem tampouco aos estudantes. Observamos também que a falta de materiais de instrução disponíveis imediatamente no início do horário oficial de instrução também acometeu bastante o TE. Os professores brasileiros observados precisavam remover, montar e desmontar o material eletrônico, em cada sala no período de instrução, enquanto esses materiais estavam previamente disponíveis nas salas de aula japonesas. O TS é marcado pelo "quem acabou pode sair" reafirmando nossa limitação na gestão do tempo de instrução.

Fato é que o tempo importa! A perda de tempo de instrução como um indicador de oportunidade educacional está fundamentada em um corpo robusto de pesquisa sobre a importância do tempo de aprendizagem. Há mais de meio século, John Carroll (1963) colocou o tempo no centro de seu modelo para o aprendizado escolar. A ideia genérica de Carroll era de que o que os estudantes aprendem está intimamente relacionado com o tempo que passam aprendendo. Muitas pesquisas subsequentes confirmaram a percepção central de Carroll (BERLINER, 1990; 2007; ROGERS, MIRRA, SELTZER \& JUN, 2014).

Algumas das pesquisas mais extensas sobre a disponibilidade de tempo de aprendizagem foram feitas em países em desenvolvimento como o Brasil e outros países latinos americanos. Estudos internacionais têm focado sua atenção nos fatores institucionais que moldam o tempo de aprendizagem e as oportunidades educacionais. Assim como nossa pesquisa, esses estudos apontam que, em alguns países com renda média relativamente baixa, os estudantes frequentemente recebem instrução apenas para uma fração do tempo total de aprendizagem atribuído (ABADZI, 2007; 2009). Nos países em desenvolvimento, estruturas de 
governança fracas e condições inadequadas de aprendizagem podem ser as causadoras dos atrasos, do absenteísmo dos professores e do mau uso do tempo de aula, por exemplo, quando os materiais de instrução não estão disponíveis (SCHUH et al., 2011).

Assim como David Farbman (2012), pesquisador do Centro Nacional de Tempo e Aprendizagem, observamos que mais tempo, ou uma melhor utilização deste, permitiria que os professores dessem conta do conteúdo e pudessem examinar os tópicos com mais profundidade e mais detalhamento, além de individualizarem e diferenciarem a instrução e poderem responder, com maior tranquilidade, às perguntas dos estudantes.

Outra dimensão que pode explicar as diferenças de desempenho entre os estudantes brasileiros e japoneses no PISA-Ciências são as ênfases curriculares. Esta dimensão será apresentada na seção seguinte.

\section{3 \\ As ênfases curriculares}

A literatura sobre Ensino de Ciências praticamente não registra pesquisas sobre o tema das ênfases curriculares. Roberts (1982 e 1995) propôs, genericamente para o campo, um conceito que julgamos particularmente útil para a análise e planejamento de currículo na área de Ensino de Ciências. Para o autor, ênfase curricular é um conjunto coerente de mensagens sobre Ciências comunicadas, explícita ou implicitamente, ao estudante e essas mensagens constituem objetivos que vão além da aprendizagem de fatos, princípios, leis e teorias da matéria de ensino em si (ROBERTS, 1982).

Segundo Moreira (1986a) para se especificar a substância de uma ênfase curricular no Ensino de Ciências deve-se considerar tanto as mensagens explícitas como as implícitas. Isto é, deve-se dar atenção tanto ao que está escrito sobre a matéria de ensino no material instrucional como ao que não está escrito, mas é ensinado, e ao que é efetivamente aprendido. Apesar da discussão teórica de currículo não fazer parte do escopo da nossa pesquisa, assim como Forquin (1995), consideramos que, no cotidiano escolar, o currículo toma diferentes

formas e, mesmo que possa não existir como documento, está presente nos espaços que se destinam à prática educativa. Dessa forma, currículo é tudo que se 
ensina em sala de aula, e que, muitas das vezes, é diferente daquilo que foi prescrito e pensado.

Forquin (1992) faz uso das denominações currículo formal, currículo ensinado e currículo aprendido como aspectos possíveis de seleção no interior da cultura, conforme o sujeito se coloca do ponto de vista de quem prescreve - os construtores de programas e responsáveis oficiais ou do ponto de vista dos professores em sala de aula, ou ainda na condição de estudantes. Para o autor, aquilo que é realmente aprendido, retido e compreendido pelos estudantes não corresponde exatamente àquilo que os professores ensinam ou acreditam ensinar, pois a recepção da mensagem depende do contexto social e cultural (FORQUIN, 1992).

Para Forquin (1992), elaboração curricular envolve tomada de decisão em relação à seleção, organização e distribuição do conhecimento que toda uma população estará sujeita na sua formação escolar. Sendo assim, o interesse em compreender os processos internos com relação ao currículo de Ciências, nos conduziu ao diálogo com a literatura específica do Ensino de Ciências e suas recomendações atuais ao ensino e à aprendizagem de Ciências no Brasil e no Japão.

Por meio das observações de campo percebemos algumas ênfases curriculares diferentes em Ciências no Brasil e no Japão. Inicialmente, observamos o currículo proposto ou formal, como o define Forquin (1992) nesses dois países.

No Brasil, não há a definição de um currículo nacional comum, como é o caso do Japão, e o que há são os Parâmetros Curriculares Nacionais (PCN) que datam de 1998, que trazem diretrizes, ou como o próprio nome diz, parâmetros para a definição do currículo e que desde sua criação não passaram por nenhum processo de revisão.

O Ministério da Educação, Cultura, Esportes, Ciência e Tecnologia do Japão (MEXT) determina um Curso de Estudo (Course of Study em inglês e 学習指導要領 ou Gakushū shidō yōryō em japonês) com padrões a serem seguidos por todas as escolas, desde o jardim de infância até o Ensino Médio, para organizar os conteúdos com vista a assegurar um padrão comum de educação em todo o país. Os Cursos de Estudo têm sido geralmente revistos a cada 10 anos e a 
última revisão do documento ocorreu em Março de 2008, estando a próxima revisão prevista para 2017.

Os objetivos de Ciências Naturais no Ensino Fundamental brasileiro são concebidos para que o estudante desenvolva competências que lhe permitam compreender o mundo e atuar como indivíduo e como cidadão, utilizando conhecimentos de natureza científica e tecnológica. (BRASIL, 1998). O PCN defende que o Ensino de Ciências Naturais deve se organizar de forma que, ao final do ensino fundamental, os estudantes tenham desenvolvido as seguintes capacidades:

- compreender a natureza como um todo dinâmico e o ser humano, em sociedade, como agente de transformações do mundo em que vive em relação essencial com os demais seres vivos e outros componentes do ambiente;

- compreender a Ciência como um processo de produção de conhecimento e uma atividade humana, histórica, associada a aspectos de ordem social, econômica, política e cultural;

- identificar relações entre conhecimento científico, produção de tecnologia e condições de vida, no mundo de hoje e em sua evolução histórica, e compreender a tecnologia como meio para suprir necessidades humanas, sabendo elaborar juízo sobre riscos e benefícios das práticas científico-tecnológicas;

- compreender a saúde pessoal, social e ambiental como bens individuais e coletivos que devem ser promovidos pela ação de diferentes agentes;

- formular questões, diagnosticar e propor soluções para problemas reais a partir de elementos das Ciências Naturais, colocando em prática conceitos, procedimentos e atitudes desenvolvidos no aprendizado escolar;

- saber utilizar conceitos científicos básicos, associados à energia, matéria, transformação, espaço, tempo, sistema, equilíbrio e vida;

- saber combinar leituras, observações, experimentações e registros para coleta, comparação entre explicações, organização, comunicação e discussão de fatos e informações;

- valorizar o trabalho em grupo, sendo capaz de ação crítica e cooperativa para a construção coletiva do conhecimento. (BRASIL, 1998, p. 33)

O documento japonês, em linhas gerais, aponta para o cultivo nos estudantes de uma espécie de "entusiasmo para a vida" ("Zest for life”) com base expressa nos princípios educativos e nas revisões da Lei de Bases da Educação do país. Os novos Cursos de Estudo do Japão, de acordo com o MEXT, enriquecem o conteúdo do ensino e aumentam o número de classes, enfatizando o equilíbrio entre a aquisição de conhecimentos e competências básicas e essenciais e fomentando a capacidade de pensar, tomar decisões e expressar-se (MEXT, 2016). Essas últimas habilidades estão intimamente relacionas aos objetivos principais do governo japonês para o Ensino de Ciências, a saber: 
- capacitar os estudantes a ter um interesse ativo nas coisas e fenômenos naturais, e para realizar observações e experiências com um senso de propósito, ao mesmo tempo, promovendo bases para a capacidade de realizar investigações científicas e desenvolvendo atitudes positivas na realização dessas investigações.

- capacitar os estudantes para aprofundar a compreensão das coisas e fenômenos naturais, e cultivar formas científicas de olhar e pensar. (MEXT, 2016)

Para a aquisição das capacidades previstas no PCN de Ciências Naturais, do Brasil, e no Curso de Estudos do Japão há em ambos os documentos indicações de conteúdo. A diferença é que, mesmo apresentando mais objetivos e esses mais detalhados, o PCN é apenas uma diretriz e está longe de definir o que, de fato, se deve ensinar e aprender em Ciências no Ensino Fundamental brasileiro, enquanto o documento japonês, a partir dos dois objetivos genéricos, apresenta mais detalhadamente os conteúdos a serem ensinados. Além da lista de conteúdos a serem ministrados, o documento japonês também traz instruções de trabalho com os conteúdos, como, por exemplo, as séries onde devem ser administrados e alguns temas menores, dentro dos temas principais, que não podem deixar de ser abordados. Por fim, o Curso de Estudos japonês também apresenta considerações sobre o design do currículo e da operacionalização dos conteúdos.

O PCN estrutura o conteúdo a ser ministrado em eixos temáticos. De acordo com este documento, os eixos temáticos representam uma organização articulada de diferentes conceitos, procedimentos, atitudes e valores para cada um dos ciclos de escolaridade. Os Eixos Temáticos estabelecidos para o Ensino Fundamental são:

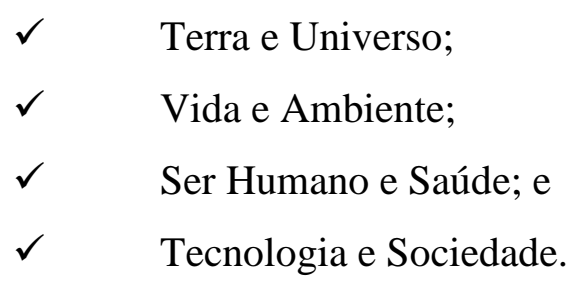

Esses eixos temáticos foram elaborados de modo a ampliar as possibilidades de realização dos PCN de Ciências Naturais, com o estabelecimento, na prática de sala de aula, de diferentes sequências de conteúdos internas aos ciclos; o tratamento de conteúdos em diferentes situações locais e o estabelecimento das várias conexões: entre conteúdos dos diferentes eixos temáticos, entre esses e os 
temas transversais e entre todos eles e as demais áreas do Ensino Fundamental. (BRASIL, 1998).

Os textos de cada eixo temático de Ciências Naturais apontam conexões com vários temas transversais, tais como:

$\checkmark \quad$ Meio Ambiente

$\checkmark \quad$ Saúde

$\checkmark \quad$ Orientação Sexual

$\checkmark \quad$ Trabalho e Consumo, entre outros

No sexto ano do Ensino Fundamental, a maioria dos livros didáticos - que servem de apoio e orientação aos professores para a apresentação dos conteúdos no país - o de Ciências aborda especificamente o eixo temático "Terra e Universo", dentro do qual, encontramos assuntos como aqueles sugeridos pelo PISA no tema "Terra e Sistemas Espaciais", a saber: estruturas da Terra e seus sistemas, energia e mudanças nos sistemas da Terra, história da Terra, a Terra no espaço.

Nos eixos temáticos, "Vida e Ambiente" e "Ser Humano e Saúde", recorrentemente abordados no $7^{\circ}$ e $8^{\circ}$ anos, respectivamente, encontramos frequentemente conteúdos relacionados a células, seres humanos, populações, ecossistemas e biosfera apontados como "Sistemas Vivos" no PISA.

No último eixo temático estabelecido para o Ensino Fundamental, "Tecnologia e Sociedade", conteúdo programático característico do $9^{\circ}$ ano, cobrem-se temas como "Sistemas Físicos" e "Sistemas Tecnológicos" avaliados pelo PISA.

Acreditamos, assim como Moreira (1986b) que, no Brasil, os livros didáticos veiculam determinadas ênfases curriculares. Na verdade, percebemos que o livro didático, não apenas de Ciências, mas também os de outras disciplinas, é o principal orientador do currículo no país ${ }^{33}$. A regência da LDBEN, Lei 9394/1996, se materializa na Educação Básica também por meio das DCN, dos PCN e dos PCN+, com reflexos nos Livros Didáticos, sobretudo a partir de programas nacionais de distribuição, que exigem, em sua análise, sintonia com a política pública educacional vigente. Achamos conveniente conferir o conteúdo

\footnotetext{
${ }^{33} \mathrm{Na}$ literatura estudos demonstram que existe uma parcela de professores que não utiliza o Livro Didático. Há, também, uma produção significativa sobre o tema do livro didático de Ciências. Para mais detalhes, ver, por exemplo, Fracalanza, 1992; Megid Neto \& Fracalanza, 2003 e Fracalanza \& Megid Neto, 2006.
} 
dos livros didáticos de Ciências aprovados Programa Nacional do Livro Didático - PNLD. No website do Programa (http://www.fnde.gov.br/pnld-2017/) é possível visualizar todos os livros aprovados para o ano de 2017.

O conteúdo dos livros didáticos de Ciências aprovados pelo PNLD é basicamente o mesmo. No entanto, nas séries iniciais do Ensino Fundamental esses conteúdos estão distribuídos mais aleatoriamente nos anos escolares. Nas séries finais, que mais nos interessam aqui, a ordem é exatamente a mesma em todas as coleções. Assim, no $6^{\circ}$ ano, o tema mais recorrente é meio ambiente, no $7^{\circ}$ ano são os seres vivos, no $8^{\circ}$ ano é o corpo humano e, por fim, no $9^{\circ}$ ano, os conteúdos de Física e Química.

A título de exemplo, consultamos uma coleção da Editora Ática largamente adotada pelos professores no Brasil (Figura 21).

Figura 21. Capas da coleção Ciências de Carlos Barros e Wilson Paulino. São Paulo: Editora Ática. 6 ${ }^{\mathrm{a}}$ edição. 2015.

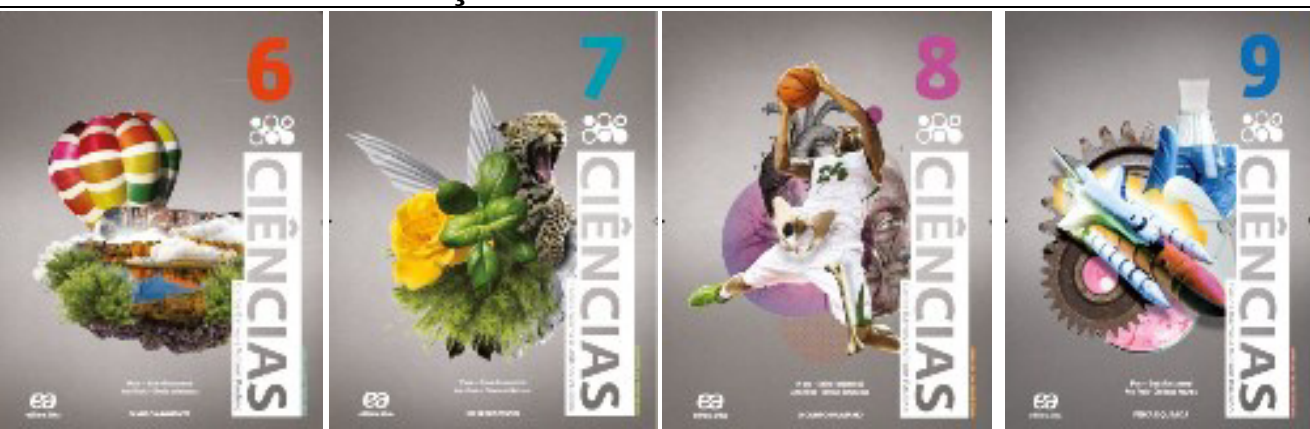

Fonte: http://pnld.aticascipione.com.br/obra/ciencias-o-meio-ambiente/ , 2016.

Os autores, Carlos Barros e Wilson Paulino são consagrados entre os professores de Ciências, principalmente por ocasião da implantação da avaliação rigorosa do PNLD, com aprovação em todas as edições do Programa.

A coleção organiza-se em quatro volumes e cada um tem uma média de 250 páginas. O primeiro volume tem como foco central o estudo do meio ambiente. $\mathrm{O}$ segundo aborda a diversidade dos seres vivos e suas adaptações. O terceiro tematiza o corpo humano. Por fim, o quarto volume apresenta conceitos gerais de Física e de Química. As unidades e capítulos compreendem sequências didáticas e estratégias de ensino em que são desenvolvidos eixos de estudo previstos para o currículo escolar de Ciências nos anos finais do Ensino Fundamental.

No $6^{\circ}$ ano, são seis unidades e 20 capítulos:

Unidade 1- Os seres vivos e o ambiente:

Capítulo 1: Quanta vida na Terra; 
Capítulo 2: Onde a vida acontece;

Capítulo 3: Energia e matéria em um ecossistema;

Capítulo 4: As relações entre os seres vivos;

Capítulo 5: A distribuição da vida na Biosfera;

Capítulo 6: Biomas brasileiros.

Unidade 2 - A Terra por dentro e por fora:

Capítulo 7: Da superfície ao centro da Terra;

Capítulo 8: As rochas;

Capítulo 9: Minérios e jazidas;

Capítulo 10: O solo: piso, pátria, pão;

Capítulo 11: Preservação do solo.

Unidade 3 - A água no ambiente:

Capítulo 12: A água e a vida;

Capítulo 13: A água e seus efeitos físicos;

Capítulo 14: Tratamento de água e de esgoto para todos.

Unidade 4 - $\mathrm{O}$ ar e o ambiente:

Capítulo 15: Atmosfera: a camada gasosa que envolve a Terra;

Capítulo 16: Propriedades do ar.

Unidade 5 - Desequilíbrios ambientais:

Capítulo 17: A poluição ambiental;

Capítulo 18: Lixo: problemas e soluções.

Unidade 6: Universo - $\mathrm{O}$ ambiente maior.

Capítulo 19: Universo, galáxias, estrelas, planetas, satélites...;

Capítulo 20: O Sistema Solar.

No $7^{\circ}$ ano, são quatro unidades e 22 capítulos:

Unidade 1- Diversidade de vida na Terra:

Capítulo 1: Reconhecendo um ser vivo;

Capítulo 2: A origem da vida;

Capítulo 3: A evolução dos seres vivos;

Capítulo 4: Biodiversidade e classificação;

Capítulo 5: Vírus: seres sem organização celular.

Unidade 2 - Os reinos das moneras, dos protoctistas e dos fungos; 
Capítulo 6: Reino das moneras: as bactérias e as arqueas;

Capítulo 7: Reino dos protoctistas: protozoários e algas;

Capítulo 8: Reinos dos fungos;

Unidade 3 - $\mathrm{O}$ reino das plantas:

Capítulo 9: Briófitas e pteridófitas;

Capítulo 10: Gimnospermas;

Capítulo 11: Angiospermas: aspectos gerais - raiz, caule e folha;

Capítulo 12: Angiospermas: flor, fruto e semente.

Unidade 4 - $\mathrm{O}$ reino dos animais:

Capítulo 13: Os poríferos e os cnidários;

Capítulo 14: Os platelmintos e os nematódeos;

Capítulo 15: Os anelídeos e os moluscos;

Capítulo 16: Os artrópodes;

Capítulo 17: Os equinodermos;

Capítulo 18: Os peixes;

Capítulo 19: Os anfíbios;

Capítulo 20: Os répteis;

Capítulo 21: As aves;

Capítulo 22: Os mamíferos.

No $8^{\circ}$ ano, são cinco unidades e 18 capítulos:

Unidade 1 - A organização do corpo humano:

Capítulo 1: Ser humano, com muito prazer;

Capítulo 2: A célula: uma visão geral;

Capítulo 3: A divisão celular;

Capítulo 4: Níveis de organização do corpo humano.

Unidade 2 - A reprodução:

Capítulo 5: O sistema genital;

Capítulo 6: Como nascemos;

Capítulo 7: Corpo e mente: os cuidados na adolescência;

Capítulo 8: A vida continua.

Unidade 3 - As funções de nutrição:

Capítulo 9: A importância dos alimentos;

Capítulo 10: Alimentação saudável; 
Capítulo 11: A digestão;

Capítulo 12: A respiração;

Capítulo 13: A circulação;

Capítulo 14: A excreção.

Unidade 4 - Funções de relação com o ambiente:

Capítulo 15: Locomoção: ossos e músculos;

Capítulo 16: Os sentidos.

Unidade 5 - A coordenação das funções orgânicas:

Capítulo 17: O sistema nervoso;

Capítulo 18: O sistema endócrino.

No $9^{\circ}$ ano são três unidades e 20 capítulos:

Unidade 1 - Conceitos básicos de Física e de Química:

Capítulo 1: Matéria e energia;

Capítulo 2: Medições e unidade de medida;

Capítulo 3: Matéria: estados físicos e propriedades.

Unidade 2 - $\mathrm{O}$ estudo da Física:

Capítulo 4: O movimento;

Capítulo 5: As leis de Newton;

Capítulo 6: A gravitação universal;

Capítulo 7: Máquinas simples e trabalho;

Capítulo 8: Energia mecânica;

Capítulo 9: Temperatura e calor;

Capítulo 10: As ondas e o som;

Capítulo 11: As ondas e a luz;

Capítulo 12: Eletricidade;

Capítulo 13: Magnetismo.

Unidade 3 - O estudo da Química:

Capítulo 14: O átomo: estrutura e identificação;

Capítulo 15: A tabela periódica dos elementos químicos;

Capítulo 16: As ligações químicas;

Capítulo 17: Substâncias e misturas;

Capítulo 18: Funções químicas: ácidos e bases;

Capítulo 19: Funções químicas: sais e óxidos;

Capítulo 20: Reações químicas. 
Em linhas gerais, como veremos a seguir na apresentação da matriz referencial do PISA, as tarefas que os estudantes precisavam cumprir no PISA 2006 requerem conhecimentos de Ciências que estão prescritos no PCN do Ensino Fundamental, assim como nos Livros Didáticos aprovados pelo PNLD.

O mesmo não acontece no Japão, já que a área de aplicação "saúde” não faz parte do currículo de Ciências. Os conteúdos de Ciências determinados no Curso de Estudos japonês para o segundo ciclo do Ensino Fundamental estão listados no quadro a seguir (Quadro 9), por série e divisão dos campos como originalmente descrito no documento.

\section{Quadro 9. Curso de Estudos japonês para o Ensino de Ciências nas séries} finais do Ensino Fundamental.

\section{Ano Campo Conteúdo}

$\checkmark$ Fenômenos físicos familiares: luz e som, força e pressão

$\checkmark$ Matéria na vida diária: as formas das substâncias, soluções aquosas, mudança de estados

$1 \checkmark$ Os seres vivos e a variedade das plantas: observação de seres $2 \quad$ plantas

$\checkmark$ A composição e as mudanças da Terra: vulcões e terremotos, sobreposição de camadas e aspectos do passado

$\checkmark$ Correntes elétricas e seu uso: corrente elétrica, corrente elétrica e campo magnético

$1 \checkmark$ Transformações químicas e átomos/moléculas: composição das substâncias, transformações químicas, transformações químicas e a massa das substâncias

2 A vida dos animais e a transição dos seres vivos: seres vivos e células, estrutura do corpo e função dos animais, grupos dos animais, transição e evolução dos seres vivos

2

$\checkmark$ O clima e suas mudanças: observação do clima, mudanças no clima, o clima do Japão

$\checkmark$ Movimento e energia: regularidade do movimento, energia mecânica

$\checkmark$ Transformações químicas e íons: soluções e íons, ácidos/bases e íons

1

$\checkmark$ Ciência, tecnologia e humanos: energia, desenvolvimento científico e tecnológico, conservação do meio natural e o uso da Ciência e da Tecnologia

3

$\checkmark$ Continuidade da vida: crescimento e multiplicação dos seres vivos, regularidade hereditária e genes

$\checkmark$ A Terra e o Universo: movimentos dos corpos celestes e 2 rotação e translação da Terra, o sistema solar e as estrelas

$\checkmark$ Natureza e Humanos: seres vivos e meio ambiente, recursos naturais e desastres, conservação do meio natural e o uso da Ciência e da Tecnologia

Fonte: adaptação livre de MEXT, 2016.

Os quadros referenciais da OCDE / PISA são desenvolvidos por painéis de peritos. Esses quadros são sempre aprovados pelos governos integrantes da OCDE, por meio do Conselho de Países Participantes. Na Tabela 24, a seguir, 
além de mostrar os conteúdos trabalhados no PISA, apresentamos a evolução da matriz referencial de Ciências ao longo das diferentes edições do Programa, a partir da primeira no ano de execução em 2000. Fica claro a partir da observação da Tabela abaixo que 2006 e 2015 foram os anos em que mais conteúdos de Ciências foram abordados, em razão desta ter sido a área enfatizada nessas duas edições do PISA.

Tabela 24. Evolução da matriz referencial do PISA

\begin{tabular}{|c|c|c|c|c|c|c|c|c|}
\hline & & & 2000 & 2003 & 2006 & 2009 & 2012 & 2015 \\
\hline \multirow{18}{*}{$\begin{array}{l}\text { Sistemas } \\
\text { Físicos }\end{array}$} & \multirow{4}{*}{$\begin{array}{c}\text { Estrutura da } \\
\text { Matéria } \\
\text { Propriedades da } \\
\text { Matéria }\end{array}$} & Modelo de partículas & & & $x$ & $x$ & $x$ & $x$ \\
\hline & & Ligações & & & $x$ & $x$ & $x$ & $x$ \\
\hline & & Mudanças de estado & $x$ & $x$ & $x$ & $x$ & $x$ & $x$ \\
\hline & & $\begin{array}{c}\text { Condutividade térmica e } \\
\text { elétrica }\end{array}$ & $x$ & $x$ & $x$ & $x$ & $x$ & $x$ \\
\hline & \multirow{3}{*}{$\begin{array}{l}\text { Mudanças } \\
\text { Químicas da } \\
\text { Matéria }\end{array}$} & Reações & $x$ & $x$ & $x$ & $x$ & $x$ & $x$ \\
\hline & & $\begin{array}{l}\text { Transferência de } \\
\text { energia }\end{array}$ & & & $x$ & $x$ & $\times$ & $x$ \\
\hline & & Ácidos/Bases & & & $x$ & $x$ & $x$ & $x$ \\
\hline & \multirow{5}{*}{$\begin{array}{c}\text { Movimento e } \\
\text { Forças } \\
\text { Ação em distância }\end{array}$} & Velocidade & $x$ & $x$ & $x$ & & & $x$ \\
\hline & & Fricção & & & $x$ & & & $x$ \\
\hline & & Magnetismo & & & & & & $x$ \\
\hline & & Gravitação & & & & & & $x$ \\
\hline & & Forças eletrostáticas & & & & & & $x$ \\
\hline & \multirow{3}{*}{$\begin{array}{c}\text { Energia e } \\
\text { Transformação }\end{array}$} & Conservação & $x$ & $x$ & $x$ & & & $x$ \\
\hline & & Dissipação & & & $x$ & & & $x$ \\
\hline & & Reações Químicas & & & $x$ & & & $x$ \\
\hline & \multirow[t]{3}{*}{$\begin{array}{l}\text { Interações entre } \\
\text { energia e matéria }\end{array}$} & $\begin{array}{l}\text { Ondas sonoras e } \\
\text { luminosas }\end{array}$ & & & $x$ & & & $x$ \\
\hline & & Som & & & $x$ & & & $x$ \\
\hline & & Ondas Sísmicas & & & $x$ & & & $x$ \\
\hline \multirow{14}{*}{$\begin{array}{l}\text { Sistemas } \\
\text { Vivos }\end{array}$} & \multirow[t]{2}{*}{ Células } & Estrutura e Função & & & $x$ & & & $x$ \\
\hline & & DNA & & & & & & $x$ \\
\hline & Conceito de & Unicelular & & & & & & $x$ \\
\hline & Organismo & Pluricelular & & & & & & $x$ \\
\hline & \multirow[t]{3}{*}{ Seres Humanos } & Saúde & $x$ & $x$ & $x$ & & & $x$ \\
\hline & & Nutrição & $x$ & $x$ & $x$ & & & $x$ \\
\hline & & $\begin{array}{l}\text { Subsistemas digestório, } \\
\text { respiratório, excretor, } \\
\text { reprodutivo e suas } \\
\text { relações }\end{array}$ & & & $x$ & & & $x$ \\
\hline & \multirow[t]{4}{*}{ Populações } & Espécies & $x$ & $x$ & $x$ & & & $x$ \\
\hline & & Diversidade & & & $x$ & & & $x$ \\
\hline & & Variabilidade & & & $x$ & & & $x$ \\
\hline & & Evolução & $x$ & $x$ & $x$ & & & $x$ \\
\hline & \multirow[t]{2}{*}{ Ecossistemas } & $\begin{array}{l}\text { Cadeias e teias } \\
\text { alimentares }\end{array}$ & $x$ & $x$ & $x$ & & & $x$ \\
\hline & & $\begin{array}{c}\text { Fluxo de matéria e } \\
\text { energia }\end{array}$ & & & $x$ & & & $x$ \\
\hline & Biosfera & Sustentabilidade & $x$ & $x$ & $x$ & & & $x$ \\
\hline \multirow{15}{*}{$\begin{array}{c}\text { Terra e } \\
\text { Sistemas } \\
\text { Espaciais }\end{array}$} & \multirow{3}{*}{$\begin{array}{l}\text { Estruturas da } \\
\text { Terra }\end{array}$} & Litosfera & & & $x$ & & & $x$ \\
\hline & & Hidrosfera & & & $x$ & & & $x$ \\
\hline & & Atmosfera & & & $x$ & & & $x$ \\
\hline & \multirow[t]{2}{*}{ Energia na Terra } & Fontes & & & $x$ & & & $x$ \\
\hline & & Clima Global & & & $x$ & & & $x$ \\
\hline & \multirow{3}{*}{$\begin{array}{l}\text { Mudanças na } \\
\text { Terra }\end{array}$} & Placas tectônicas & & & $x$ & & & $x$ \\
\hline & & Ciclos geoquímicos & & & $x$ & & & $x$ \\
\hline & & $\begin{array}{c}\text { Forças Construtivas e } \\
\text { Destrutivas }\end{array}$ & & & $x$ & & & $x$ \\
\hline & \multirow[t]{2}{*}{ História da Terra } & Fósseis & & & $x$ & & & $x$ \\
\hline & & Origem e evolução & & & $x$ & & & $x$ \\
\hline & \multirow[t]{3}{*}{ Terra no Espaço } & Gravidade & & & $x$ & & & $x$ \\
\hline & & Sistema solar & $x$ & $x$ & $x$ & & & $x$ \\
\hline & & Galáxias & & & & & & $x$ \\
\hline & \multirow{2}{*}{$\begin{array}{l}\text { História e Escala } \\
\text { do Universo }\end{array}$} & Ano luz & & & & & & $x$ \\
\hline & & Teoria do Big Bang & & & & & & $x$ \\
\hline
\end{tabular}

Fonte: elaboração própria com dados de OCDE, 1999; 2003; 2006; 2009; 2012; 2016. 
É possível observar certa ênfase dos parâmetros brasileiros em Ciências Naturais e Biológicas. De fato, com base na experiência enquanto professora desta disciplina nas séries finais do Ensino Fundamental, já tive ocasião de observar uma maior dedicação às Ciências Naturais e Biológicas nos $6^{\circ}, 7^{\circ}$ e $8^{\circ}$ anos. Via de regra no Brasil, apenas no $9^{\circ}$ ano, os estudantes são expostos a conteúdos relacionados aos sistemas físicos, químicos e tecnológicos e o conteúdo da maioria expressiva dos livros didáticos brasileiros apoiam esta conclusão, como vimos no exemplo citado anteriormente. Isso também ficou muito claro nas aulas por nós observadas nas escolas brasileiras, como mostraremos na subseção a seguir.

No Japão, apesar de haver uma maior prescrição de conteúdos relacionados às Ciências Naturais e Biológicas em cada ano escolar, não podemos dizer que haja, de fato, uma ênfase nesta área, mas sim uma distribuição mais equilibrada dos conteúdos. Naquele país, a cada ano, os estudantes recebem conteúdos relacionados à Química, à Física e à Biologia. Desde muito cedo, os estudantes japoneses têm contato com temas relacionados ao avanço da Ciência e da Tecnologia e sua importância na vida de todos. O Quadro 10, a seguir, mostra a correspondência entre a matriz de Ciências no PISA e as propostas curriculares dos dois países em cada ano escolar do Ensino Fundamental.

Quadro 10. A matriz referencial do PISA e sua ocorrência nos anos do EF de Brasil e Japão

\begin{tabular}{|c|c|c|c|c|c|c|c|}
\hline \multirow[b]{2}{*}{ PISA } & \multicolumn{4}{|c|}{ Brasil } & \multicolumn{3}{|c|}{ Japão } \\
\hline & $6^{\circ}$ ano & $7^{\circ}$ ano & $8^{\circ}$ ano & $9^{\circ}$ ano & $\begin{array}{l}7^{\circ} \\
\text { ano }\end{array}$ & $\begin{array}{c}8^{\circ} \\
\text { ano }\end{array}$ & $\begin{array}{l}9^{\circ} \\
\text { ano }\end{array}$ \\
\hline Sistemas físicos & & & & $\mathbf{X}$ & $\mathbf{X}$ & $\mathbf{X}$ & $\mathbf{X}$ \\
\hline Sistemas vivos & & $\mathbf{X}$ & $\mathbf{X}$ & & $\mathbf{X}$ & $\mathbf{X}$ & $\mathbf{X}$ \\
\hline Terra e sistemas espaciais & $\mathbf{X}$ & & & & $\mathbf{X}$ & $\mathbf{X}$ & $\mathbf{X}$ \\
\hline Sistemas tecnológicos & & & & $\mathbf{X}$ & & & $\mathbf{X}$ \\
\hline
\end{tabular}

Fonte: elaboração própria, a partir dos resultados da pesquisa. 2016.

Pode-se observar que os diferentes conteúdos presentes na Matriz referencial do PISA são apresentados praticamente em todos os anos escolares aos estudantes japoneses, de forma tal que fica estabelecido um contato contínuo desses estudantes com os diversos temas do Ensino de Ciências ao longo do Ensino Fundamental. Acreditamos que esta continuidade ofereça não apenas um 
maior e mais prolongado contato com os diversos campos das Ciências, mas principalmente que ofereça aos estudantes uma maior oportunidade de consolidação dos conceitos científicos que são retomados ano após ano.

No caso do Brasil, apesar de termos, assim como no Japão, uma cobertura total dos conteúdos propostos na matriz referencial do PISA, percebemos a apresentação desses conteúdos de forma mais seccionada ao longo dos anos do Ensino Fundamental. Acreditamos, que a essa distribuição mais estanque dos conteúdos se some outra dificuldade curricular no Brasil, representada pela ausência de elaboração e implementação de um currículo nacional comum.

Se há um aspecto relevante que pode ser aprendido com a experiência japonesa este se refere à atenção que é dispensada no Japão aos detalhes do currículo nacional e a insistência de que este currículo seja realmente ensinado e aprendido.

De acordo com a OCDE (2010), o currículo japonês é coerente, cuidadosamente focado em tópicos essenciais e numa profunda exploração conceitual, logicamente sequenciado, e definido em um nível muito elevado de desafio cognitivo. Resultado disso é que os egressos do Ensino Médio naquele país têm um nível de domínio dos temas que se equipara ao dos graduados da faculdade em muitos países ocidentais.

O Japão tem uma história de excelência sustentável e está no topo do ranking internacional de pesquisas educacionais desde o início dessas iniciativas. Ryo Watanabe, diretor de Pesquisa Internacional do NIER, em entrevista a OCDE, afirmou que os estudantes japoneses têm tido muito sucesso no PISA por causa do seu currículo. O Japão tem padrões curriculares nacionais, ou cursos de estudo que definem o conteúdo a ser ensinado por grau e disciplina, e que a cada dez anos deve ser atualizado. Segundo Watanabe, em todo o país, os professores ensinam com base nos padrões curriculares nacionais (OCDE, 2010).

Ainda de acordo com a OCDE (2010), o currículo japonês é muito exigente, no entanto, é também altamente coerente, na medida em que progride passo a passo, de forma lógica de ano para ano, concentrando-se a cada ano nos temas que devem ser dominados para compreender o que será apresentado no ano seguinte.

Até aqui apresentamos o currículo formal. A seguir, apresentamos o currículo ensinado e aprendido a partir das aulas que observamos nos dois países. 


\subsection{1}

\section{As ênfases curriculares nas aulas observadas}

Como dissemos, observamos entre os meses de Novembro de 2015 a Outubro de 2016 um total de 147 aulas de Ciências no Brasil e no Japão. Foram 64 horas-aula no Japão e 83 horas-aula no Brasil, distribuídas entre os três últimos anos do Ensino Fundamental. A Tabela 25 mostra a distribuição dessas aulas entre os diferentes anos e escolas observados.

Durante o estágio no Japão, observamos 23 aulas de Ciências no $7^{\circ}$ ano, 32 no $8^{\circ}$ e nove no $9^{\circ}$ ano. O maior número de aulas no $8^{\circ}$ ano, $50 \%$ do total das observações no Japão, é devido, principalmente, às observações realizadas na escola Hideki Yukawa. Nesta escola, fomos autorizados a observar um único professor e apenas as turmas de $8^{\circ}$ ano.

Tabela 25. Frequência de observação de aulas por escola e ano escolar

\begin{tabular}{ccccccc}
\hline \multirow{2}{*}{ País } & \multirow{2}{*}{ Escola } & \multicolumn{4}{c}{ Ano escolar } & Total \\
\cline { 3 - 6 } & Hideki Yukawa & Sétimo Ano & Oitavo Ano & Nono Ano & \\
\hline \multirow{4}{*}{ Japão } & 0 & 17 & 0 & 17 \\
& Reona Esaki & 15 & 10 & 9 & 34 \\
& Susumu Tonegawa & 8 & 5 & 0 & 13 \\
& Total & $\mathbf{2 3}$ & $\mathbf{3 2}$ & $\mathbf{9}$ & $\mathbf{6 4}$ \\
\hline \multirow{3}{*}{ Brasil } & Adolpho Lutz & 8 & 9 & 13 & 30 \\
& Carlos Chagas & 10 & 14 & 16 & 40 \\
& César Lattes & 6 & 6 & 1 & 13 \\
& Total & $\mathbf{2 4}$ & $\mathbf{2 9}$ & $\mathbf{3 0}$ & $\mathbf{8 3}$ \\
\hline
\end{tabular}

Fonte: elaboração própria, a partir dos resultados da pesquisa. 2016.

A distribuição das observações brasileiras é mais uniforme, como se pode observar. Nas escolas brasileiras a autorização para observação era mais genérica e pudemos escolher as turmas, os professores e os horários mais convenientes. No total foram 24 aulas de Ciências no $7^{\circ}$ ano, 29 no $8^{\circ}$ e 30 no $9^{\circ}$.

Durante a observação, registramos e classificamos a área enfatizada em cada aula observada em:

1. Biologia: quando o assunto estava centrado em temas de Ciências Biológicas e Naturais;

2. Química: quando os temas dessa cadeira eram contemplados;

3. Física: quando os temas faziam menção aos sistemas físicos.

Esse tipo de registro possibilitou verificar que a ênfase nas áreas acompanha exatamente as prescrições do currículo brasileiro e japonês apresentado 
anteriormente. A distribuição japonesa é bastante regular e acompanha o Curso de Estudos japonês no sentido que distribui conteúdos de Ciências, Química e Física em todos os anos do Junior High School. Foram observadas lá, no total, 18 aulas relacionadas a temas de Ciências, 25 de Química e 21 de Física.

A tabela 26 mostra que, no $7^{\circ}$ e no $9^{\circ}$ ano escolar no Japão, respectivamente, foram observadas pouquíssimas aulas de Química (4,5\% do total) e nenhuma de Física. Acreditamos que isto se explique pelo fato de nossas observações terem acontecido, no Japão, entre os meses de Novembro de 2015 e Fevereiro de 2016, e que os conteúdos de Química e Física tenham sido apresentados aos estudantes antes ou depois deste período de acompanhamento, uma vez que os mesmos estão prescritos também para o $7^{\circ}$ e o $9^{\circ}$ anos. Como não tivemos acesso aos planos de aula dos professores observados, nem pudemos entrevistá-los para apurar como é feita a distribuição dos conteúdos ao longo do ano letivo, esta explicação funciona apenas como uma hipótese.

Tabela 26. Frequência de ênfases observadas nas aulas por escola e ano escolar

\begin{tabular}{|c|c|c|c|c|c|}
\hline \multirow{2}{*}{ País } & \multirow{2}{*}{ Área } & \multicolumn{3}{|c|}{ Ano escolar } & \multirow{2}{*}{ Tota } \\
\hline & & Sétimo Ano & Oitavo Ano & Nono Ano & \\
\hline \multirow{4}{*}{ Japão } & Biologia & 11 & 5 & 2 & 18 \\
\hline & Química & 1 & 17 & 7 & 25 \\
\hline & Física & 11 & 10 & 0 & 21 \\
\hline & Total & 23 & 32 & 9 & 64 \\
\hline \multirow{4}{*}{ Brasil } & Biologia & 24 & 29 & 0 & 53 \\
\hline & Química & 0 & 0 & 16 & 16 \\
\hline & Física & 0 & 0 & 14 & 14 \\
\hline & Total & 24 & 29 & 30 & 83 \\
\hline
\end{tabular}

Fonte: elaboração própria, a partir dos resultados da pesquisa. 2016.

No Japão, os professores de Ciências do segundo ciclo do Ensino Fundamental dão aulas de todos os conteúdos de Ciências, embora a grande maioria deles seja especializada em determinada área dentro do campo das Ciências. Por exemplo, na escola Hideki Yukawa, o único professor que observamos era especialista em Química e todas as aulas observadas foram dessa matéria. Por se tratar de uma escola associada à universidade, esse professor somente leciona aulas de Química nas diferentes turmas da escola. As turmas, por sua vez, têm mais de um professor de Ciências que pode, ou não, ser especialista em cada área do conhecimento. 
No Brasil, como se pode perceber a partir da Tabela 26, não observamos nenhuma aula com ênfase em Química ou Física nos $7^{\circ}$ e $8^{\circ}$ anos. Os assuntos relacionados a esses campos da Ciência, assim como o que é proposto na maioria dos livros didáticos, só é apresentado aos estudantes brasileiros no $9^{\circ}$ ano. De forma oposta, temas relacionados às Ciências Naturais e Biológicas - Biologia são abordadas exaustivamente nos três anos iniciais do Ensino Fundamental.

Esses resultados nos permitem concluir que, ainda que limitados pelo tempo que pode ser destinado à observação, o currículo formal, tanto no Brasil quanto no Japão, está presente e é ensinado em sala de aula. Quanto à aprendizagem, os resultados dos estudantes brasileiros no PISA sugerem uma resposta negativa no caso do Brasil. O desempenho dos estudantes brasileiros em Ciências está longe do esperado, nossos resultados nos colocam atrás não apenas de um país desenvolvido e industrializado como o Japão, mas de outros países latino americanos com realidades socioeconômicas semelhantes a nossa.

Na sequência, de modo a refinar a nossa compreensão das significativas diferenças de desempenho em Ciências entre os estudantes brasileiros e japoneses, e entendendo que a abordagem didática e a prática pedagógica também constituem fatores importantes da ênfase curricular, analisaremos as práticas pedagógicas e de ensino utilizadas por professores nesses dois países.

\section{4 As práticas de ensino e aprendizagem de Ciências}

A qualidade do ensino e sua eficácia têm sido objeto de vários estudos nacionais e internacionais que procuram destacar as características da atuação pedagógica docente que têm efeito positivo sobre o desempenho dos estudantes (HANUSHEK \& WOSSMANN, 2010; HATTIE, 2003, 2009, 2012; THE LEARNING CURVE, 2012; HANUSHEK， 2002; TAYLOR， ROEHRIG, HENSLER, CONNOR \& SCHATSCHNEIDER, 2010). Çimer (2007) apresenta uma detalhada revisão da literatura sobre ensino eficaz de Ciências e identifica seis princípios que o norteiam.

$\mathrm{O}$ primeiro se relaciona com "lidar com ideias e concepções dos estudantes". Este princípio é importante para que os professores ajudem os estudantes a construir a sua própria compreensão e conhecimento, ativando suas 
ideias e concepções pré-existentes, de modo que, estando ciente delas e à luz do conhecimento cientificamente aceito, possam modificar, alterar ou desenvolver esses aspectos. Para esta finalidade, métodos de ensino e atividades como perguntas e respostas, discussões tanto em pequenos grupos como da classe inteira, atividades em pequenos grupos, trabalhos práticos, utilizando instalações de TIC podem ser empregados.

O segundo princípio é "incentivar os estudantes a aplicar novos conceitos ou habilidades em diferentes contextos”. Para tal, os professores podem lançar mão de trabalhos práticos, estudos de campo, simulações, atividades de escrita e de roleplay ${ }^{34}$.

O terceiro princípio identificado por Çimer (2007) é o de "incentivar a participação dos estudantes nas aulas". O envolvimento pode se dar por meio de um vasto leque de atividades de ensino e aprendizagem, tais como ensino baseado na investigação, grupos de aprendizagem cooperativa, debates, visitas de campo, jogos e assim por diante.

"Encorajar a investigação", "incentivar a aprendizagem cooperativa entre os estudantes" e "oferecer uma avaliação contínua e fornecer feedback" são, respectivamente, os três outros princípios identificados. Na construção dos princípios do ensino eficaz de Ciências, Çimer (2007) se apoia principalmente em ideias construtivistas de ensino e aprendizagem, o que se explica pelo fato de que, nos últimos anos, o construtivismo deu um grande impulso para a reestruturação da educação científica, em aspectos como objetivos, conteúdos, ensino e avaliação.

A teoria de aprendizagem construtivista, que foi descrita pela primeira vez por Von Glasersfeld (1989), vê a aprendizagem não só como um complemento de informações para o conhecimento existente, mas também como uma reconstrução do que já é conhecido. De acordo com o construtivismo, os estudantes aprendem mais e melhor quando eles estão autorizados a construir um entendimento pessoal com base em experiências e a refletir sobre essas experiências. Uma sala de aula construtivista é caracterizada por estudantes que trabalham em grupos e na qual a

\footnotetext{
${ }^{34}$ A técnica de roleplay, traduzida como dramatização, é uma atividade altamente flexível que permite aos alunos praticar a comunicação em diferentes contextos sociais e em diferentes papéis sociais.
} 
aprendizagem é interativa e dinâmica; há também uma ênfase em habilidades sociais e de comunicação e na troca de ideias.

De fato, muitos autores afirmam que a pergunta e, portanto, a investigação, leva a um melhor desempenho dos estudantes em Ciências (KIRSCHER et al, 2006; SECKER, 2002; entre outros). Schneider et al (2002) constataram que estudantes norte-americanos do $10^{\circ}$ e $11^{\circ}$ anos que participaram do currículo do Project Based Science (PBS), cujo objetivo é melhorar a forma como as aulas de Ciências são ministradas por envolver os estudantes na busca de soluções para questões autênticas através da investigação, colaboração e uso da tecnologia, pontuaram significativamente mais alto do que uma sub amostra do NAEP em $44 \%$ dos itens. As maiores pontuações apareciam justamente concentradas nas questões que enfatizavam as investigações científicas. No mesmo ano, Secker (2002) concluiu que práticas pedagógicas baseadas em indagações, fossem individuais ou coletivas, estavam associadas positivamente com o desempenho dos estudantes em um exame padronizado de Ciências.

Em suma, o desenvolvimento de uma mente investigativa e o apoio a estratégias de investigação têm sido considerados os objetivos mais importantes do Ensino de Ciências ao longo dos últimos 50 anos. No PISA 2006, o "conhecimento sobre Ciência" incluiu as categorias de investigação e explicação científicas. Já em 2015, a noção de "conhecimento sobre Ciência" foi especificada de forma mais clara e dividida em dois componentes - conhecimento procedimental e conhecimento epistemológico. Assim, em linhas gerais, para efeitos da avaliação do PISA, as competências são testadas usando o conhecimento que se pode esperar de estudantes de 15 anos de idade em relação aos conceitos e às ideias da Ciência (conhecimento do conteúdo), aos procedimentos e as estratégias utilizadas em todas as formas de investigação científica (conhecimento procedimental), e à maneira pela qual as ideias são justificadas e asseguradas na Ciência (conhecimento epistemológico).

O questionário do estudante no PISA 2006, como já dissemos, inclui itens relacionados às perspectivas dos estudantes sobre o ensino e a aprendizagem que ocorrem nas aulas de Ciências. Em 2006, itens relacionados com as atitudes dos estudantes em Ciências foram incluídos tanto no questionário contextual do estudante como no teste e isso acabou levando à ampliação do tamanho do teste. Assim, na matriz de 2015, os aspectos atitudinais foram medidos por meio apenas 
do questionário do estudante. Dentro desse domínio, os construtos "Interesse na Ciência" e a "Consciência ambiental" continuaram os mesmos de 2006. O "Apoio à investigação científica", no entanto, foi alterado para uma medida de "Valorização de abordagens científicas para investigação" - o que é, essencialmente, uma mudança de terminologia para melhor refletir o que é medido. Tais atividades não apenas podem ser consideradas estratégias orientadas pela investigação como também criam uma oportunidade para examinar quais práticas pedagógicas resultam em um maior desempenho de Letramento Científico.

\subsection{1 \\ Os métodos de ensino do PISA}

O PISA 2006 descreve quatro métodos construtivistas de Ensino de Ciências: interação, hands-on ou experimentação, aplicação e investigação e estes métodos são baseados em 17 práticas pedagógicas distintas, que já foram descritas na abordagem metodológica ${ }^{35}$. Os estudantes foram convidados a responder em que grau estes quatro métodos construtivistas de Ensino da Ciência ocorrem em suas aulas de Ciências. As respostas envolviam as seguintes opções: "em todas as aulas", "na maioria das aulas", "em algumas aulas" e "nunca ou quase nunca". Para descrever a frequência das respostas dos estudantes, agrupamos as opções "em todas as aulas" e "na maioria das aulas", obtendo, assim, as atividades mais frequentemente presentes nas aulas de Ciências dos dois países, tanto na perspectiva dos estudantes quanto dos professores.

\footnotetext{
${ }^{35}$ 1. Os alunos são convidados a expor as suas ideias; 2. Os alunos fazem experiências no laboratório; 3 . O professor pede aos alunos que imaginem como determinada questão científica poderia ser investigada em laboratório; 4 . O professor pede aos alunos que apliquem um conceito científico a problemas quotidianos; 5 . Os alunos são convidados a dar a sua opinião acerca dos temas tratados; 6 . O professor pede aos alunos que tirem conclusões de uma experiência por eles realizada; 7. O professor explica como uma noção científica se pode aplicar a vários fenômenos (por ex., ao movimento dos corpos ou a substâncias com propriedades idênticas); 8. Os alunos têm permissão para conceber as suas próprias experiências; 9. Há um debate ou troca de ideias na aula; 10. As experiências são feitas pelo professor, a título de demonstração; 11. Os alunos podem escolher os seus trabalhos de pesquisa; 12 . O professor usa a Ciência para ajudar os alunos a compreender o mundo exterior; 13 . Os alunos debatem os temas tratados; 14. Os alunos fazem experiências seguindo as instruções do professor; 15. O professor explica de modo claro a importância dos conceitos científicos na vida de todos; 16 . O professor pede aos alunos que façam uma pesquisa para testarem as suas próprias ideias; 17. O professor dá exemplos de aplicações tecnológicas para mostrar como a Ciência é importante para a sociedade.
} 
A primeira escala sobre os métodos de ensino da edição de 2006 é a "interação no ensino e na aprendizagem das Ciências" - escala INTACT -, que indica a frequência com que os diferentes elementos de ensino interativo ocorrem em sala de aula. A escala INTACT tem uma confiabilidade aceitável no PISA (alfa: 0,76).

A ocorrência de oportunidades de investigação científica (INVEST, alpha: 0,73) e a de experimentação (HANDS, alpha: 0.69) são abordagens de ensino de natureza construtivista medidos pela segunda e terceira escala, respectivamente. A última escala se concentra na aplicação da Ciência a situações da vida real (APPLY) e também mostra um índice de confiabilidade aceitável (alpha: 0,71). A frequência da adoção dessas abordagens no Brasil e no Japão, segundo os estudantes participantes do PISA, é apresentada na Figura 22.

Figura 22. Frequência dos métodos de Ensino de Ciências do PISA na perspectiva dos estudantes participantes de Brasil e Japão - PISA 2006

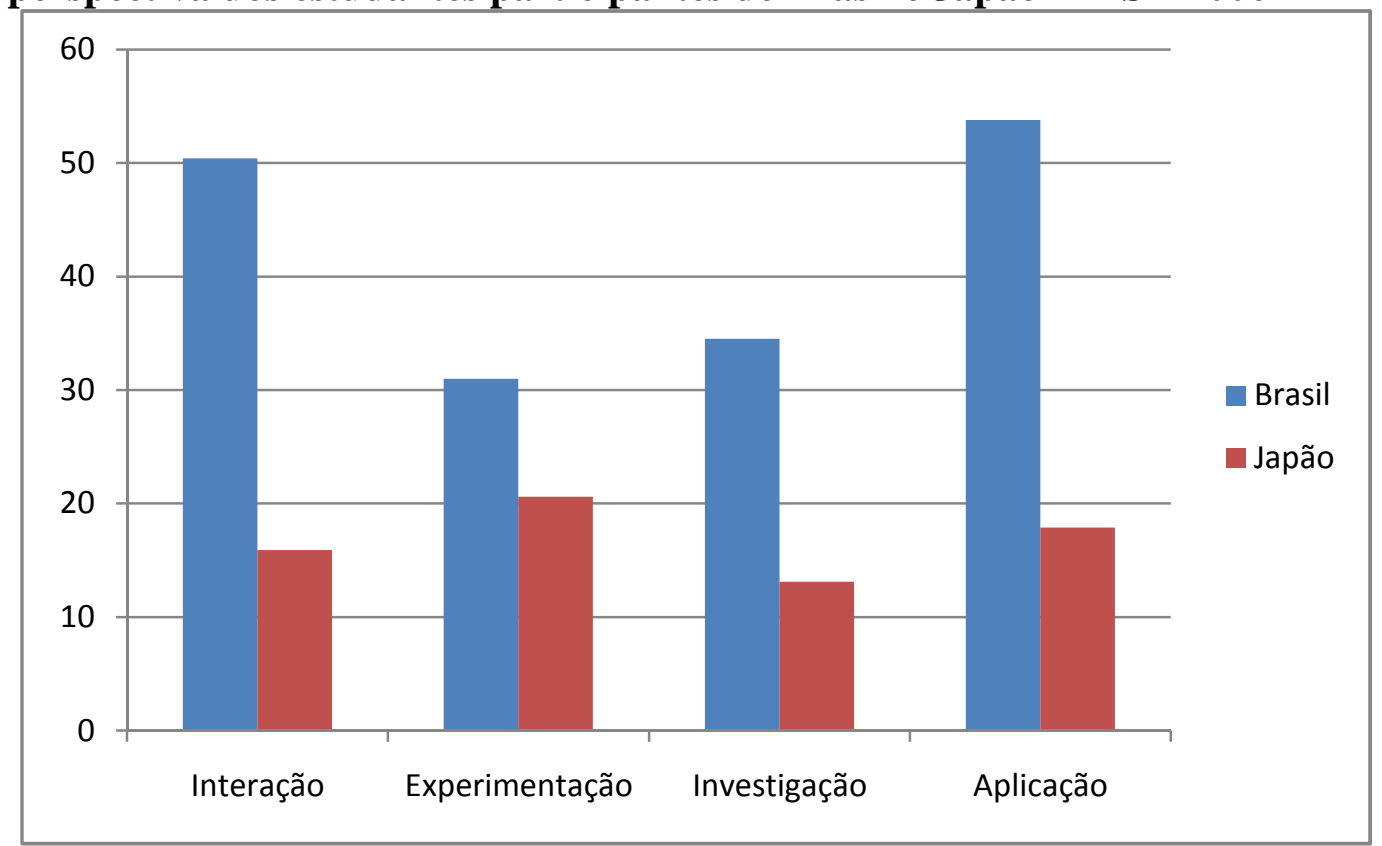

Fonte: elaboração própria, a partir dos resultados da OCDE, 2007.

Os estudantes brasileiros, apesar de não apresentarem um desempenho satisfatório em Ciências no PISA, admitem serem expostos mais frequentemente às práticas de ensino que envolvem investigação, interação, aplicação e experimentação, nessa ordem, principalmente em comparação com os estudantes japoneses. Como pode ser observado na Figura 23, os dados do PISA 2006 revelam algo, no mínimo, curioso, principalmente no caso do Japão. A literatura sobre o tema reforça que abordagens construtivistas do Ensino de Ciências, como 
as descritas pelo PISA, são extremamente importantes para o desenvolvimento das habilidades no âmbito do Letramento Científico. Apesar de o Japão apresentar um dos melhores resultados em Ciências no PISA, quando comparado a outros países da OCDE, os estudantes japoneses raramente admitem uma utilização frequente de estratégias pedagógicas de interação, experimentação, investigação e aplicação pelos professores nas aulas. Eles afirmam que, de modo geral, tais atividades ocorrem em pouco mais de $15 \%$ das aulas. Já os estudantes brasileiros, por exemplo, responderam que a experimentação, atividade de menor frequência, ocorre, pelo menos, em $30 \%$ das aulas.

Pesquisas demonstram que as práticas de ensino baseadas na investigação desempenham um papel significativo na educação científica, com efeito positivo na aprendizagem dos estudantes, em especial, no envolvimento dos estudantes nas dimensões cognitivas da investigação e nas atividades de investigação orientadas pelo professor (FURTAK et al., 2012). As instruções baseadas na investigação parecem não apenas melhorar o desempenho (BLANCHARD et al., 2010), mas também as atitudes em relação ao sujeito e habilidades de pensamento crítico transferíveis (HATTIE, 2009).

Apesar de a pesquisa apontar esses benefícios, os estudantes brasileiros e os japoneses participantes do PISA 2006, não demonstram terem tido acesso de maneira frequente a essas estratégias. Atividades de investigação, na perspectiva dos estudantes no PISA, ocorrem, por exemplo, em pouco mais de $30 \%$ das aulas dos estudantes brasileiros e em pouco menos de $15 \%$ das aulas dos estudantes japoneses. Apesar de haver uma frequência maior destas atividades nas aulas dos estudantes brasileiros, o desempenho do Brasil em Ciências não é bom, ao passo que o do Japão é, reconhecidamente, um dos melhores do mundo.

No caso do Japão, a baixa frequência com que as referidas atividades são realizadas nas aulas de Ciências não impacta negativamente o desempenho nem positivamente as atitudes dos estudantes japoneses sobre Ciências. Em relação a este último aspecto, nos resultados do PISA 2006, o Japão apresenta altos níveis de desempenho nos domínios de Letramento Científico, que contrastam com níveis muito baixos de interesse por Ciências e por carreiras científicas.

A OCDE (2007) desenvolveu um indicador para medir o interesse geral em Ciências dos estudantes participantes. A média do Brasil neste índice foi 0.47, o que quer dizer que quase $50 \%$ dos estudantes brasileiros participantes dessa 
edição do programa demonstravam algum interesse em Ciência e nas carreiras científicas. A média do Japão, por sua vez, foi apenas de 0.21 , o que significa que em torno de $20 \%$ dos estudantes japoneses avaliados em 2006 demonstravam algum interesse em Ciência e nas carreiras científicas (Figura 23).

Figura 23. Respostas dos estudantes brasileiros e japoneses ao item 29 do questionário do estudante-PISA 2006

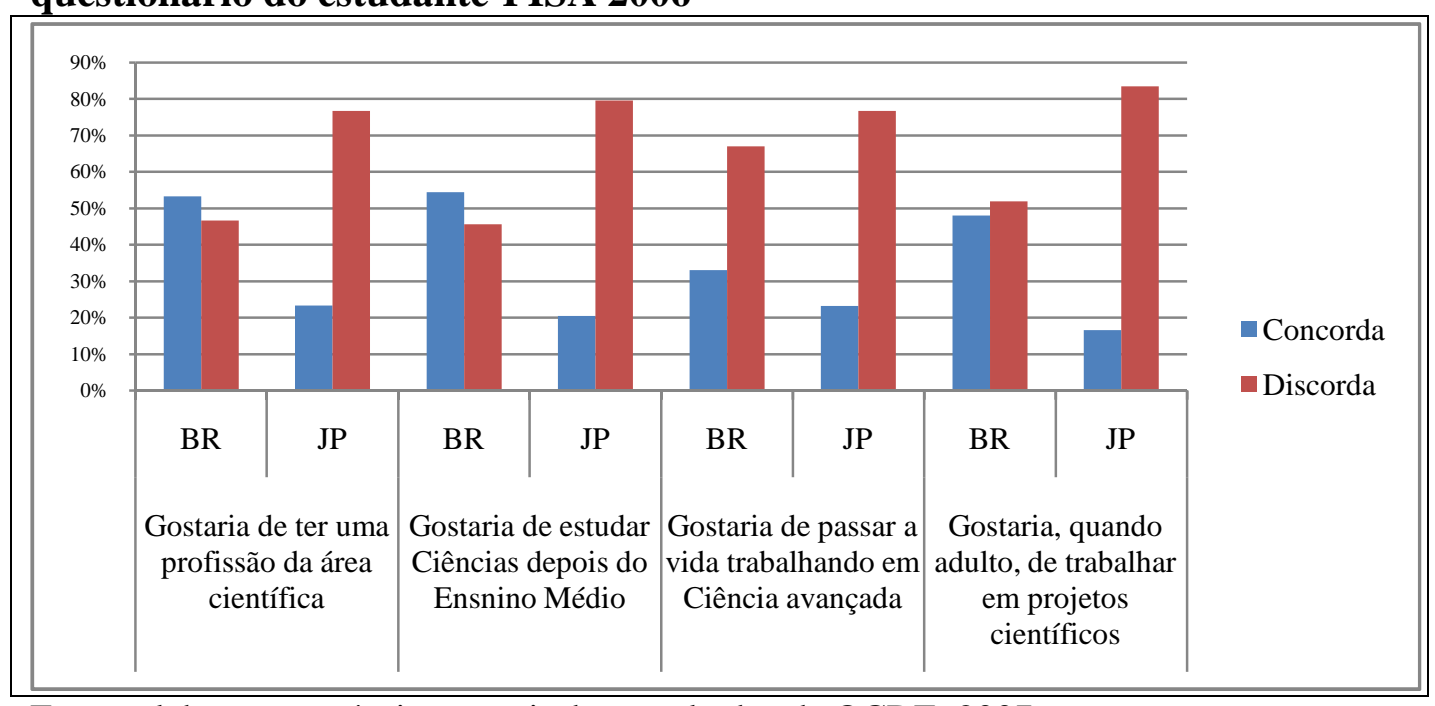

Fonte: elaboração própria, a partir dos resultados da OCDE, 2007.

Tem-se observado em diversos países um desinteresse geral dos jovens em relação à aprendizagem de Ciência na escola, que parece associado à baixa procura por parte dos estudantes de carreiras científicas (AIKENHEAD, 2004; BARAM-TSABARI et al., 2009; EUROPEAN COMMISSION, 2004; 2007; FENSHAM, 2004; JENKINS, 2006; JENKINS \& NELSON, 2005; OSBORNE, SIMON \& COLLINS, 2003; OSBORNE, 2006; OSBORNE \& DILLON, 2008; SHAMOS \& HOWES, 1996; TOMEI, 2008; SCHREINER \& SJØBERG, 2004; VÁZQUEZ \& MANASSERO, 2008).

$\mathrm{Na}$ tentativa de responder a alguns dos dilemas enfrentados pelos pesquisadores da área de Ensino de Ciências, relativos seja à diminuição do interesse dos jovens em seguir carreiras científicas e também pela Ciência ao longo da escolaridade básica, seja à necessidade de se ouvir os estudantes nas propostas educacionais, bem como à posição da educação científica face à diversidade cultural existente na sociedade, pesquisadores da Universidade de Oslo desenvolveram um projeto comparativo internacional denominado de The Relevance of Science Education (Rose) que já foi aplicado em mais de 40 países, dentre os quais Brasil e Japão. 
O Rose é um projeto destinado a lançar luz sobre fatores afetivos de importância para a aprendizagem da Ciência e da Tecnologia. Para isso, as principais instituições internacionais de pesquisa e indivíduos trabalham em conjunto no desenvolvimento de perspectivas teóricas, instrumentos de pesquisa, coleta e análise de dados. A característica chave do Rose é coletar e analisar a informação dos estudantes sobre diversos fatores que influenciam suas atitudes e sua motivação para aprender Ciência e Tecnologia. O Rose desenvolveu, por meio de deliberações internacionais e de oficinas e pilotagem com parceiros de pesquisa, um instrumento que visa traçar perspectivas atitudinais ou afetivas sobre Ciência e Tecnologia na educação e na sociedade, de acordo com estudantes de 15 anos de idade.

Resultados comparativos da aplicação do Rose em 25 países trazem resultados bastante curiosos: enquanto os estudantes de todos os países gostariam de trabalhar com algo importante e significativo, o gosto pela Ciência ensinada na escola, em comparação com outros temas, foi apontado como positivo (pontuação entre 2 e 4 da escala Likert) apenas entre estudantes de países subdesenvolvidos, como Uganda, Gana, Suazilândia, Zimbábue, Botsuana, Filipinas e Bangladesh (SCHREINER e SJØBERG, 2007).

A execução do Rose no Brasil é de responsabilidade dos professores Nélio Bizzo e Luís Caldeira Brant de Tolentino Neto. Tolentino Neto defendeu em 2008, sob a orientação de Bizzo, tese intitulada "Os interesses e posturas de jovens estudantes frente às Ciências: resultados do projeto Rose aplicado no Brasil”. O principal objetivo do trabalho de Tolentino Neto (2008) foi a aplicação de um instrumento internacional que permitisse avaliar os interesses e as posturas de jovens estudantes brasileiros frente à Ciência e Tecnologia (C\&T). Ele aplicou, em 2007, o instrumento a 652 estudantes das cidades de São Caetano do Sul/SP e Tangará da Serra/MT, o que lhe permitiu produzir evidências sobre aspectos da realidade do Ensino de Ciências em contextos brasileiros bem diversos.

O estudo de Tolentino Neto revelou que os jovens estudantes avaliados acham a disciplina de Ciências interessante, embora tenham baixo interesse em exercê-la profissionalmente. As análises do autor evidenciaram, também, a preferência significativa das mulheres por assuntos relacionados à saúde e dos homens por temas relacionados à tecnologia, física e à proteção ambiental. O estudo revelou, também, o desinteresse de estudantes e alunas por questões de 
botânica, agricultura e por desafios ambientais. Os estudantes paulistas, avaliados no estudo, incluíam-se como responsáveis pelas questões do meio ambiente e cobravam maior envolvimento da sociedade na proteção ambiental. Não acreditavam, contudo, que a Ciência e a tecnologia pudessem resolver este tipo de problemas, mas se mostraram muito esperançosos em relação ao futuro do planeta e da humanidade. Os estudantes mato-grossenses, por sua vez, diferentemente dos paulistas, se eximiram das responsabilidades pelos problemas ambientais e colocaram nas mãos dos especialistas a condução das mudanças necessárias. Eles mostraram acreditar no poder da Ciência e da Tecnologia para produzir tais mudanças, embora se declarassem mais céticos em relação a seu possível sucesso.

Enfim, diante das primeiras observações realizadas pela pesquisa de Tolentino Neto (2008) no Brasil, verificou-se a necessidade de se conhecerem os interesses, atitudes e preferências dos jovens em relação à Ciência e à Tecnologia em âmbito nacional. Assim, a partir de 2010, o projeto Rose, passou a ser aplicado no Brasil em uma escala nacional, com financiamento do Conselho Nacional de Desenvolvimento Científico e Tecnológico (CNPq). A amostra brasileira, com representatividade nacional, envolveu 2.365 estudantes, oriundos de 84 escolas.

Os dados obtidos (GOUW, 2013; GOUW \& BIZZO, 2016) revelam que o jovem brasileiro considera a Ciência escolar interessante, apesar de não ter preferência por esta em relação a outras disciplinas. Mostra que há uma atitude geral positiva em relação à disciplina, tanto no que se refere à sua importância como à sua utilidade; apesar disso, tanto meninas quanto meninos têm pouco interesse em ingressar na carreira científica (GOUW, 2013; GOUW \& BIZZO, 2016). Revelam, ainda, que o brasileiro possui grande interesse pelos temas científicos abordados na escola, sendo os temas de maior interesse aqueles relacionados à Biologia Humana, especificamente à evolução biológica, tema bastante controverso no currículo da disciplina, e que os jovens estudantes brasileiros estão abertos a discussões sobre o tema (GOUW, 2013; GOUW, MOTA \& BIZZO, 2013).

No Japão, o projeto Rose é de responsabilidade do Professor Masakata Ogawa, entrevistado no período de estágio do doutorado sanduíche. A amostra japonesa, considerada um estudo de caso, consistiu de 19 escolas e 560 estudantes (OGAWA \& SHIMODE, 2004) e os instrumentos foram aplicados em 2003. Os resultados obtidos revelam que os jovens japoneses não consideram a Ciência 
escolar interessante e não têm preferência pela Ciência em relação a outras disciplinas (OGAWA \& SHIMODE, 2004).

O Japão tem recebido atenção de educadores de Ciências em todo o mundo pela sua prosperidade em inovações científicas e tecnológicas e de desenvolvimento econômico, sustentados ao longo de várias décadas sem perder a própria identidade cultural e, ainda pelo alto desempenho acadêmico dos estudantes em testes internacionais de conhecimento científico, mesmo apresentando índices baixos em indicadores que medem atitudes e interesses em relação ao empreendimento científico e tecnológico (OGAWA \& SHIMODE, 2004). No Japão, os profissionais da educação, assim como o grande público, têm sérias preocupações sobre o desinteresse dos jovens por atividades de aprendizagem em geral e por atividades de aprendizado de Ciências em particular. Antes dos resultados do PISA, os resultados do TIMSS (MARTIN et al., 2000; NIER, 2001; NIER, 2002) desencadearam debates públicos no Japão sobre o assunto e levantaram a pergunta sobre como os estudantes japoneses, apesar de não demonstrarem interesse em Ciência e em carreiras a ela relacionadas e, ainda, de assumirem que não são frequentemente expostos a atividades construtivistas, que, em tese, tornariam as aulas de Ciências mais interessantes, podem mostrar altos níveis de desempenho no PISA e em outras avaliações externas.

Em entrevista, ambos os professores japoneses especialistas na área de Ciências, Ogura e Ogawa, relataram que a resposta a esta pergunta é algo que todo mundo gostaria de saber. A importância do tema é tal que, em 2005, foi realizado um Seminário da OCDE em que o professor Yasushi Ogura discutiu o crescente desinteresse pelos estudos científicos entre os jovens de muitos países, incluindo o Japão. Além disso, o TIMSS 2003 mostrou, assim como o PISA, que um percentual muito pequeno de estudantes japoneses do $8^{\circ}$ ano gostaria de ter um trabalho que envolvesse Ciência.

Segundo o professor Ogura,

it is very much culturally dependent. Not only Japan but also Korean students show the same trend. Maybe Taiwan too... But still, country high score students has better interest than lower score students. Within countries it is correlated to scores. But across countries it is not correlated... And why this happens, it is my opinion, depend on the educational system and in Japan or Korea, entrance examination, study for entrance examination impacts, huge impacts the students learning. Students, our students, need to pass the examinations. Regardless, if they don't work they don't pass. It is not a matter of motivation but obligation... and textbook 
knowledge is the necessity to deep, to pass. Even if they don't like the content they have to study it! ${ }^{36}$

A perspectiva do professor Ogawa também está relacionada com aspectos culturais. Embora não faça qualquer referência à cultura de exames de admissão, como fez o professor Ogura, ele assume que o fato pode perfeitamente estar relacionado ao status socioeconômico do estudante ou ainda a outros variados fatores. $\mathrm{Na}$ verdade, ele argumenta que as tarefas do PISA não são assim difíceis para os estudantes japoneses.

From my point of view the impact of the test item in PISA is very serious to the Japanese government so that some component should be included in the process of revision of the course of study. Not simply memorizing certain kind of knowledge sequence or group of knowledge but much more. That kind of idea is similar to the idea of Japanese educating people because, from my point of view, before starting the PISA program some of the educators in Japan have already realized that some shift on the goal is needed. We call it "ikiruchikara", one of the key slogans of the revision of the Japanese Course of Study. Some of the major idea of this slogan is quite similar with the philosophy of PISA Scientific Literacy. The science teachers are not so much surprised when the PISA items come into the Japanese school, most of them are very understandable and also the student is not so much seriously in problem by working on PISA type tasks. But it is very strange because not only Japan but all of the East Asian regions have good marks and it is very difficult to explain something because also in the Nordic countries are getting excellent results in PISA. ${ }^{37}$

O professor Ogura levantou também outra hipótese como explicação

possível para o desinteresse dos estudantes japoneses pela Ciência. Para ele, o resultado do PISA reflete a experiência atual dos estudantes japoneses no Ensino

\footnotetext{
${ }^{36}$ Tradução livre: É culturalmente dependente. Não só o Japão, mas também os estudantes coreanos mostram a mesma tendência. Talvez Taiwan também... Mas, ainda assim, os estudantes de maior desempenho do país têm maior interesse do que os alunos de menor desempenho. Dentro dos países está correlacionada com o desempenho. Mas entre os países não é correlacionada... E por que isso acontece, na minha opinião, depende do sistema educacional e, no Japão ou Coréia, do exame de admissão, a preparação para o exame de admissão impacta, impacta muito na aprendizagem dos alunos. Os alunos, nossos alunos, precisam passar nos exames. Independentemente disso, se eles não estudam, eles não passam. Não é uma questão de motivação, mas de obrigação e conhecimento de livros didáticos, é a necessidade de aprofundar-se para passar. Mesmo se eles não gostam do conteúdo eles têm que estudá-lo!

${ }^{37}$ Tradução livre: Do meu ponto de vista, o impacto do item do teste do PISA é muito grave para o governo japonês para que alguns componentes devam ser incluídos no processo de revisão do curso de estudo. Não simplesmente memorizando certo tipo de seqüência de conhecimento ou grupo de conhecimento, mas muito mais. Esse tipo de idéia é semelhante à idéia de educar os japoneses porque, do meu ponto de vista, antes de iniciar o PISA alguns dos educadores no Japão já perceberam que alguma mudança na meta é necessária. Nós o chamamos de "ikiruchikara", um dos principais slogans da revisão do Curso de Estudo Japonês. Alguma das melhores idéia deste slogan é bastante semelhante à filosofia de Letramento Científico do PISA. Os professores de Ciências não ficam muito surpresos quando os itens de PISA vêm para a escola japonesa, a maioria deles é muito compreensível e também o aluno não encontra muitos problemas ao trabalhar com tarefas do padrão PISA. Mas é muito estranho porque não só o Japão, mas todas as regiões do Leste Asiático têm boas notas e é muito difícil explicar algo porque também os países nórdicos estão obtendo excelentes resultados no PISA.
} 
Médio. O PISA mostra, de certa forma, o que os estudantes teriam aprendido ao final da escolaridade básica e isso explicaria o bom desempenho japonês. No entanto, a atitude de desinteresse dos estudantes por Ciências estaria relacionada à diferente ênfase pedagógica adotada no Ensino Médio, que, no Japão, é notoriamente mais concentrado no ensino/apendizagem de conteúdo e na preparação para o vestibular e isto explicaria os resultados deste índice no PISA e no TIMSS. Da mesma forma, o fato de os estudantes japoneses participantes do PISA não reconhecerem a presença de atividades construtivistas no ensino de Ciências também se relaciona com sua condição de estudantes do Ensino Médio e não mais do Ensino Fundamental. Para o professor Ogura,

PISA in Japan is very special setting because PISA test is just three months after the students enter the high school. Probably the academic results are mainly the results of Junior High School but emotional area probably they describe about science education in high school, in three months. Our high school teachers do not do experiments or think provoking teaching, much lessons are expositive... Not experimental! Much less motivated and much less interesting. PISA timing is not very good. If we have done PISA six months before... ${ }^{38}$

O professor Ogura testou e validou essa hipótese. Ele conduziu uma pesquisa (OGURA, 2009) que explorou as atitudes dos estudantes japoneses em relação à Ciência no $9^{\circ}$ ano, usando as mesmas questões que foram usadas no PISA 2006. Foram amostrados aleatoriamente 89 escolas e cerca de 3000 estudantes. As principais conclusões a que chegou foram que os estudantes japoneses estão perdendo seu interesse pela Ciência no $10^{\circ}$ ano escolar, ou seja, na entrada no Ensino Médio. Embora o nível de motivação para aprender Ciências no $9^{\circ}$ ano seja pequeno, quando comparado a outros países com realidades análogas a do Japão, esse nível é menor ainda no primeiro ano do Ensino Médio (10 $\mathrm{ano})$. Aparentemente, o que é ensinado aos estudantes de escolas de Ensino Médio, no Japão, não é tão interessante quanto era no ensino fundamental. Além disso, segundo a pesquisa de Ogura (2009), os estudantes japoneses sofrem alto grau de estresse com a realização de exames periódicos várias vezes por ano e, também, com os exames de admissão ao final do $9^{\circ}$ e do $12^{\circ}$. A frequência com que os

\footnotetext{
${ }^{38}$ Tradução livre: O cenário do PISA no Japão é muito especial, porque o teste é aplicado apenas três meses após a entrada dos alunos na escola. Provavelmente os resultados acadêmicos são principalmente os resultados do Ensino Fundamental, mas a área emocional provavelmente descreve a educação científica no ensino médio, em três meses. Nossos professores do ensino médio não fazem experiências ou ensinam provocando o pensar, muitas lições são expositivas... Não experimentais! Muito menos motivadoras e muito menos interessantes. O PISA timing não é muito bom. Se tivéssemos feito o PISA seis meses antes...
} 
estudantes são avaliados em Ciências pareceria estar, de algum modo, privando os estudantes de estímulos para desenvolver o seu interesse e gosto pela disciplina.

Nossas observações, realizadas em turmas dos anos finais do Ensino Fundamental, corroboram a hipótese do professor Ogura. Como veremos a seguir, atividades de experimentação, aplicação e interação são as mais recorrentes em aula, como foi possível identificar em nossas observações de salas de aulas e apreendida dos professores observados. Já atividades envolvendo "investigação" são as menos frequentes. As respostas dos professores participantes, a itens que averiguam a prática pedagógica em Ciências, são apresentados na Figura 24.

\section{Figura 24. Frequência de atividades na perspectiva dos professores} brasileiros e japoneses

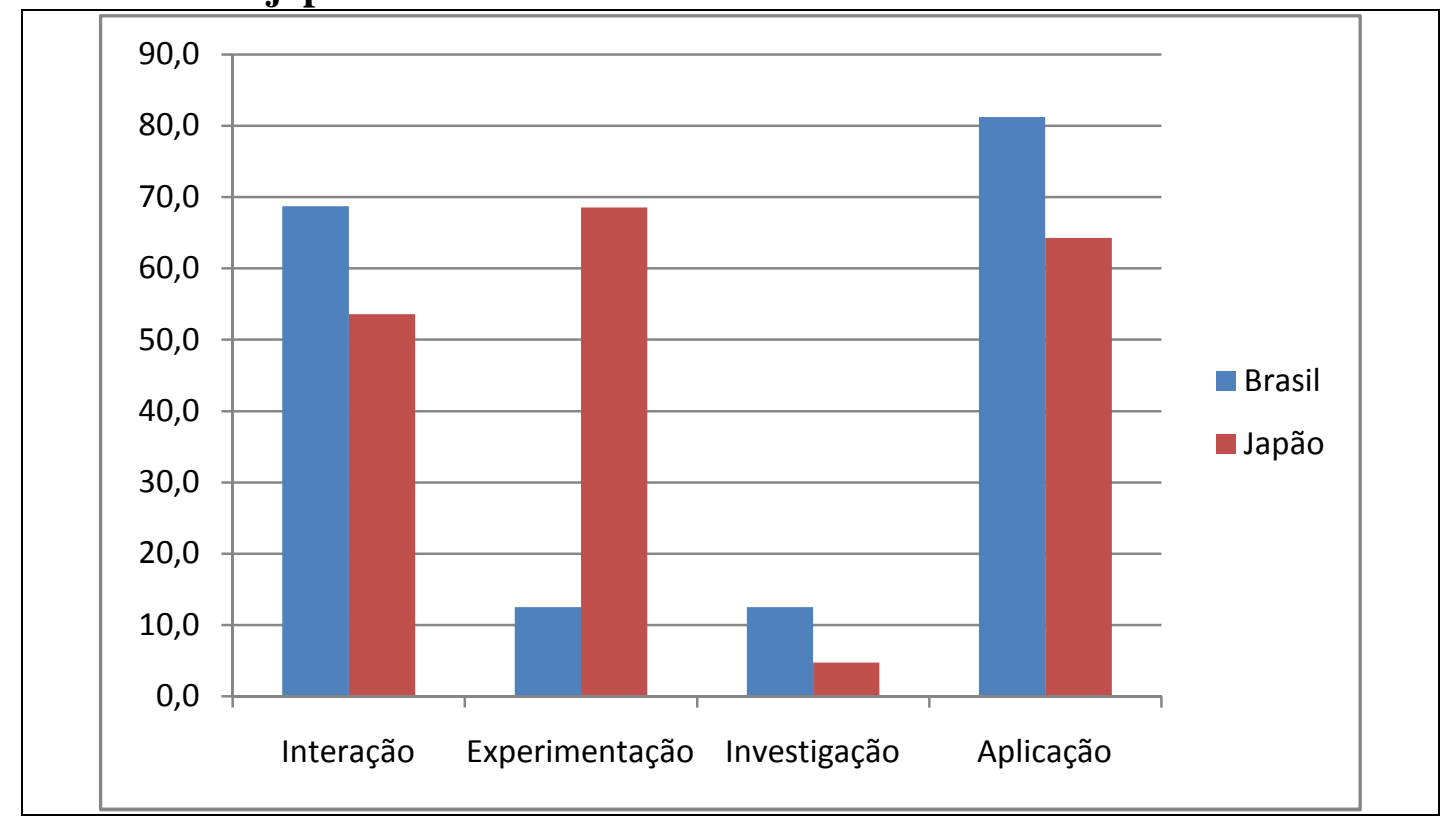

Fonte: elaboração própria, a partir dos resultados da pesquisa. 2016.

Os valores exibidos na figura acima representam o percentual de aulas em que cada conjunto de atividades ocorreu. Como se pode observar, na perspectiva dos professores japoneses, as atividades adotadas de forma mais recorrente na sua prática pedagógica são aquelas relacionadas à experimentação, aplicação e interação, nesta ordem e na maioria das aulas (mais de 50\% delas). No Brasil, os professores afirmam recorrer mais às atividades interação e aplicação (mais de $60 \%$ delas).

$\mathrm{Na}$ perspectiva dos próprios professores, as atividades de experimentação, reconhecidas por seu poder de atrair o interesse dos estudantes pela Ciência, é a menos utilizada pelos professores brasileiros. Eles admitem utilizá-las em pouco 
mais de $10 \%$ das aulas. Ao contrário dos professores brasileiros, os japoneses afirmam fazer uso dessas atividades em cerca de $70 \%$ das aulas.

Atividades investigativas são igualmente pouco frequentes nas aulas dos professores brasileiros e japoneses. Esta percepção dos professores participantes da pesquisa é corroborada nas respostas dos estudantes participantes do PISA no Brasil e no Japão (Figura 22) e em nossa percepção a partir das aulas observadas. Atividades de "investigação" foram menos frequentes nas aulas observadas tanto no Brasil quanto no Japão, ocorrendo em apenas $1 \%$ das aulas observadas no Brasil e em 6\% das observadas no Japão (Figura 25).

Figura 25. Frequência de ocorrência de atividades nas aulas de Ciências observadas no Brasil e no Japão.

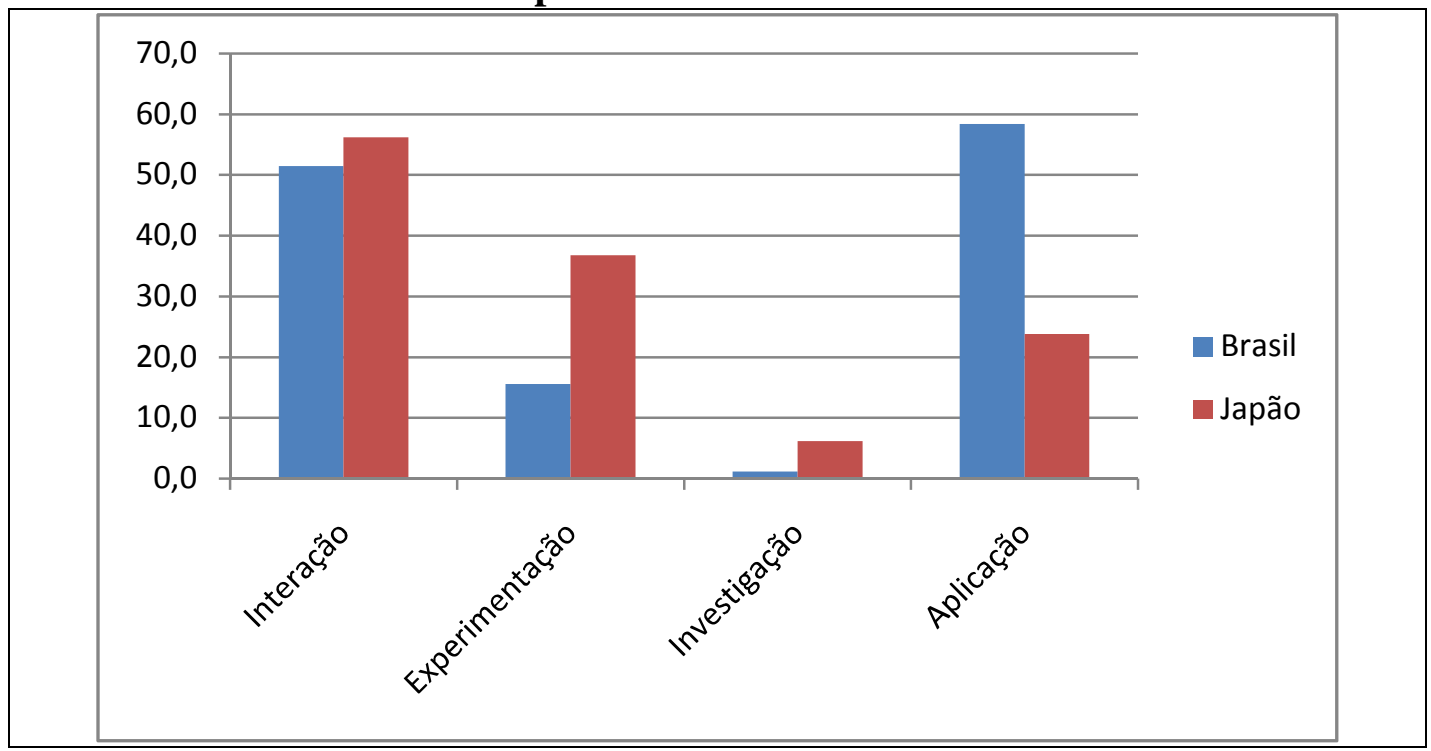

Fonte: elaboração própria, a partir dos resultados da pesquisa. 2016.

As atividades que compõem o índice "investigação" estão basicamente relacionadas ao nível de autonomia concedida aos estudantes para escolher seus temas de pesquisa, testar suas próprias ideias, fazer seus próprios experimentos etc. A questão da autonomia dos estudantes não é uma novidade e é amplamente discutida na literatura (DECHARMS, 1984; GUIMARÃES, 2003; BASTOS, 2006; REEVE; 2009; BZUNECK \& GUIMARÃES, 2010; BERBEL, 2011;).

Guimarães (2003) reforça a ideia de autonomia defendendo que os indivíduos são naturalmente propensos a realizar uma atividade por acreditar que o fazem por vontade própria e não por serem obrigados pela força de demandas externas. Em decorrência dessa percepção, seus comportamentos podem ser intrinsecamente motivados, fixando metas pessoais, demonstrando seus acertos e 
dificuldades, planejando as ações necessárias para viabilizar seus objetivos e avaliando adequadamente seu progresso, como explica a autora.

De outro lado, segundo Berbel (2011), encontramos estudantes que se percebem como "marionetes", e apresentam sentimentos negativos por serem guiados externamente, por pressão de outras pessoas. Essa situação promove sentimentos de fraqueza e ineficácia, afastamento de situações que envolvam desempenho e desenvolvimento precário das habilidades que possibilitariam uma melhor interação com eventos do ambiente (GUIMARÃES, 2003). Ao sentir-se obrigado a realizar algo por fatores externos, o indivíduo tem sua atenção desviada da tarefa, diminuindo as possibilidades de manifestar-se a motivação intrínseca (BERBEL, 2011).

Reeve (2009) enfatiza que estudantes que se percebem autônomos em suas interações escolares apresentam resultados positivos em relação:

1. à motivação (apresentando motivação intrínseca, a percepção de competência, pertencimento, curiosidade, internalização de valores);

2. ao engajamento (com emoções positivas, persistência, presença nas aulas, não reprovam ou se evadem da escola);

3. ao desenvolvimento (evidenciando autoestima, autovalor, preferência por desafios ótimos, criatividade);

4. à aprendizagem (melhor entendimento conceitual, processamento profundo de informações, uso de estratégias autorreguladas);

5. à melhoria do desempenho (em notas, nas atividades, nos resultados em testes padronizados); e

6. ao estado psicológico (apresentando indicadores de bem-estar, satisfação com a vida, vitalidade).

O autor, apesar de focalizar de maneira geral a educação, fornece algumas pistas que ajudam a pensar novos rumos para o Ensino de Ciências. Será que aulas mais investigativas e que promovam a autonomia dos estudantes contribuiriam de alguma forma para enfrentar o problema motivacional dos estudantes japoneses? Será que agregariam valor ao desempenho do Brasil em Ciências?

Segundo Berbel (2011) cabe ao professor organizar-se, para obter o máximo de benefícios das metodologias ativas para a formação de seus estudantes. Além disso, segundo a autora, um desafio interessante é o dos registros dos modos como as experiências docentes e discentes são realizadas com essas metodologias e seus 
efeitos junto aos estudantes, de modo a ampliar as reflexões e as evidências de seus benefícios pedagógicos.

O objetivo das investigações sobre ensino e aprendizagem das Ciências é envolver os estudantes no amplo processo de investigação científica, incluindo, por exemplo, a formulação de questões científicas e a concepção de exames científicos. Essas atividades de ensino dão aos estudantes a oportunidade de desenvolver as três competências centrais ("identificar questões científicas", "explicar fenômenos cientificamente" e "usar evidência científica") para o quadro de Ciências do PISA (KOBARG et al., 2011).

Revisão da literatura recente fornece evidências positivas do impacto das atividades investigativas sobre o conhecimento científico dos estudantes. Dos 29 estudos investigados, 25 apresentam evidências positivas (SCHEERENS et al., 2005). A qualidade de como a Ciência é representada por inquéritos e investigações científicas é mais importante do que a implementação de experiências de estudantes (HARLEN, 1999). Argumentos semelhantes podem ser derivados do American Lab report (SINGER, HILTON \& SCHWEINGRUBER, 2005). Nesta publicação, os autores enfatizam a idéia de que os experimentos podem apoiar o desenvolvimento do Letramento Científico quando integrados em unidades de ensino com o objetivo de melhorar a capacidade dos estudantes para pensar e raciocinar cientificamente. Assim, deve-se ressaltar que atividades práticas isoladas não promovem o Letramento Científico dos estudantes; eles precisam aprender sobre o processo mais amplo de investigações científicas para desenvolver uma profunda compreensão do conteúdo científico (KOBARG et al., 2011).

Foi maior a frequência de atividades do índice "experimentação" nas aulas observadas no Japão, onde atividades relacionadas ao uso do laboratório e à realização de experimentos ocorreram em cerca de $40 \%$ das aulas. As atividades de experimentação também foram observadas de forma mais frequente entre os professores japoneses. Como vimos, eles afirmam fazer uso de atividades experimentais em aproximadamente $70 \%$ das aulas. Os resultados do TIMSS (ROTH et al., 2006) apontam que as atividades práticas consomem uma quantidade considerável das aulas no Japão (43\% do tempo) e corroboram nossos resultados. No Brasil, observamos tais atividades em apenas $16 \%$ das aulas. Os 
professores brasileiros afirmam serem estas as atividades a que menos recorrem na sua prática pedagógica.

As atividades práticas são um aspecto importante do Ensino de Ciências (HARLEN, 1999). Estas são atividades de ensino e aprendizagem que proporcionam aos estudantes a oportunidade de realizar tarefas como planejar e conduzir um experimento e tirar conclusões de seus resultados (KOBARG et al., 2011). As atividades práticas, portanto, proporcionam aos estudantes a oportunidade de coletar suas próprias evidências científicas, o que, por sua vez, pode ajudá-los a desenvolver a competência de usar evidências científicas. Mas as atividades práticas são muitas vezes limitadas à coleta de dados e não vão muito longe na sua interpretação.

George \& Kaplan (1998) investigaram o papel que as atividades científicas desempenham nas atitudes dos estudantes em relação à Ciência. Utilizando dados do levantamento do ano base do National Educational Longitudinal Study de 1988 os autores conseguiram mostrar que as atividades científicas têm um efeito positivo e diretamente significativo sobre as atitudes em relação às Ciências. Os resultados também mostraram que a disponibilidade de instalações como laboratórios de Ciências nas escolas estava fortemente associada à frequência com que eram realizadas experiências científicas.

O relatório do American Lab (SINGER, HILTON, \& SCHWEINGRUBER, 2005) também sublinhou a importância da experiência dos estudantes no laboratório de Ciências, onde eles manipulam materiais e usam as ferramentas e técnicas dos cientistas. No entanto, os autores ressaltam que atividades isoladas que não são sistematicamente incorporadas nas aulas de Ciências pouco ajudam os estudantes no desenvolvimento do Letramento Científico.

As atividades do índice "interação" podem ser usadas para envolver os estudantes no discurso da sala de aula. Por exemplo, os estudantes podem ser convidados a declarar sua própria opinião, explicar suas ideias, ou participar em discussões sobre questões científicas. A interação dos estudantes com o processo de ensino e aprendizagem de Ciências foi observada por nós e reconhecida pelos professores em mais de $50 \%$ do total de aulas, tanto no Brasil quanto no Japão. No entanto, se os estudantes brasileiros identificam essas atividades em mais de $50 \%$ das aulas, os japoneses as reconhecem como fazendo parte de pouco mais de $15 \%$ das aulas. Na maioria das aulas, a ocorrência de interação foi observada 
principalmente na oportunidade dada pelos professores aos estudantes para explicar as suas ideias. Essa foi a atividade mais frequentemente observada no Brasil e no Japão.

Atualmente, os educadores de Ciências concordam que o ensino desta disciplina deve enfatizar atividades de aprendizado interativas (HOFSTEIN \& LUNETTA, 2004). O Ensino de Ciências transmissivo tem um forte foco no ensino de conhecimentos científicos através de aula teórica, livros didáticos e demonstração de experiências enquanto que o ensino interativo de Ciências é, em contraste, orientado para a aprendizagem cooperativa, através de discussões e interações colaborativas de estudantes e professores (KOBARG et al., 2011).

O TIMSS (ROTH et al., 2006) mostrou que o grau em que o ensino interativo é implementado nas salas de aula difere entre os países e está fortemente relacionado com crenças culturais sobre boas práticas de ensino (OCDE, 1999). De acordo com o estudo, países como o Japão tem uma forte orientação para os métodos interativos de ensino e aprendizagem, enquanto outros dão ênfase maior aos métodos centrados no professor, métodos transmissivos. A Ciência ensinada de forma interativa tem um impacto positivo na motivação de aprendizagem dos estudantes, nas estratégias de desenvolvimento de competências científicas, bem como sobre atitudes positivas em relação à Ciência (KOBARG et al., 2011). Por outro lado, algumas revisões também apontaram os efeitos positivos do ensino direto e transmissivo sobre a aprendizagem dos estudantes (CHANG \& BARUFALDI, 1999, SEIDEL, 2003, STOLARCHUK \& FISHER, 2001). Esses resultados aparentemente contraditórios indicam que o ensino interativo e transmissivo deve ser considerado, de acordo com Kobarg et al. (2011), mais como complementar do que como abordagens opostas.

A estrutura de Ciências do PISA 2006 enfatiza que os estudantes devem demonstrar seu conhecimento de e sobre Ciências em uma variedade de contextos que são significativos para eles. Portanto, as aplicações da vida real também são consideradas um aspecto importante do ensino e da aprendizagem de Ciências. Os jovens encontram Ciência e Tecnologia em diferentes ambientes e o ensino tem que incorporar aplicações da vida real, a fim de ajudá-los no desenvolvimento da alfabetização científica (KOBARG et al., 2011).

No PISA as atividades do índice de "aplicação" se referem à área de aplicações na vida real e investigam se o ensino e a aprendizagem de Ciências se 
concentram na relação entre conceitos teóricos e o mundo fora da escola. As atividades relacionadas à aplicabilidade da Ciência, sobretudo, à aplicação de conhecimentos científicos a problemas quotidianos, mas também a aplicação de um conceito científico a vários fenômenos, a importância da Ciência na vida de todos e da sociedade, foram bem mais frequentemente observadas no Brasil (quase $60 \%$ das aulas) do que no Japão (menos de 30\% das aulas).

A pesquisa em educação científica de Bennett, Gräsel, Parchmann e Waddington (2005) abordou o uso de aplicações da vida real no ensino de Ciências em currículos tradicionais e em novos currículos e da adoção de abordagens de ensino integradas com foco em contextos autênticos e aplicações da vida real. Os diferentes enfoques de ensino construtivista enfatizam as aplicações da vida real como um meio de criar contextos autênticos e significativos para os estudantes (COLLINS, BROWN \& NEWMAN, 1989). Finalmente, foram realizados estudos de base tecnológica que também abordam o papel de contextos autênticos na construção do conhecimento (BRANSFORD, BROWN, \& COCKING, 2000).

Diferentemente do encontrado no Brasil e como observado no Japão, geralmente, as aplicações da vida real não representam um foco importante no ensino tradicional de Ciências (SEIDEL, 2003; TESCH, 2004; WIDODO, 2004). Seidel (2003), por exemplo, analisou as declarações de professores e estudantes de Física com respeito ao papel das aplicações da Ciência na vida real. A autora mostrou que as referências a aplicações da vida real ocorreram em apenas $9 \%$ do tempo de aula avaliado. Contudo, via de regra, os resultados de estudos sobre a inclusão de aplicações da vida real no ensino das Ciências mostram uma correlação positiva entre a motivação dos estudantes para aprender e suas atitudes em relação à Ciência (KOBARG et al., 2011).

Enfim, a literatura sobre o ensino e a aprendizagem de Ciências indica que o ensino científico bem sucedido não se caracteriza por práticas pedagógicas únicas (AEBLI, 1998, BAUMERT \& KÖLLER, 2000, PRENZEL et al., 2002). A orquestração de diferentes atividades de Ensino de Ciências, por exemplo, como elas são combinadas, incluindo a quantidade de tempo dedicada a cada tipo de atividade, é muito mais importante. 


\section{5 O uso dos resultados do PISA no Brasil e no Japão}

"O que é importante os cidadãos saberem e serem capazes de fazer?" Em resposta a essa questão e à necessidade de desenvolver evidências comparadas entre países com base no desempenho dos estudantes, a OCDE lançou o PISA em 1997 (BRASIL, 2016). O PISA não apenas estabelece o que os estudantes podem reproduzir de conhecimento, mas também examina quão bem eles podem extrapolar o que têm apreendido e aplicar o conhecimento em situações não familiares, ambos no contexto escolar ou não (OCDE, 2016).

Bauer (2010), tendo como referência informações obtidas de diversas fontes, analisa tendências de uso dos resultados das avaliações de sistemas educacionais da América ${ }^{39}$, a partir de seus objetivos declarados. A autora destaca a propensão da utilização das avaliações no âmbito do gerenciamento dos sistemas educacionais e da prestação de contas.

Klinger, DeLuca e Miller (2008) retomam alguns autores para discutir os objetivos da avaliação. De acordo com essa revisão, haveria três diferentes propósitos para as avaliações em larga-escala:

1. Accountability - refere-se às preocupações do público com relação ao sistema educacional e às competências dos estudantes. Essas avaliações são frequentemente associadas a avaliações de programas e de sistemas que intentam fornecer informações sobre escolas específicas, iniciativas escolares, programas e professores. Elas normalmente fornecem dados que apoiam modificações no programa ou refletem a saúde do sistema educacional provincial / territorial. A crença é que tais programas de avaliação efetuam mudanças na política, currículo e prática, especialmente em um clima de tomada de decisão impulsionada por dados (MADAUS \& KELLAGHAN, 1992).

2. Classificação e seleção gatekeeping - usado para conceder aos estudantes privilégios como graduação, admissão, ou promoção de grau. No extremo, os resultados das avaliações em larga escala tornam-se o único determinante do sucesso de um estudante.

\footnotetext{
${ }^{39}$ Notadamente: Argentina, Bolívia, Brasil, Canadá, Chile, Colômbia, Costa Rica, El Salvador, Equador, Estados Unidos, Guatemala, Honduras, México, Nicarágua, Panamá, Paraguai, Peru, Rep. Dominicana, Uruguai e Venezuela.
} 
3. Diagnóstico instrucional: buscam determinar o que os estudantes realmente sabem com relação a um conjunto de critérios, expectativas ou resultados de aprendizagem (NAGY, 2000). Os resultados da avaliação são fornecidos aos professores e estudantes de forma atempada, a fim de apoiar e orientar a instrução e aprendizagem.

Para organizar os dados relativos aos objetivos das avaliações obtidos no trabalho intitulado "Usos dos resultados das avaliações de sistemas educacionais: iniciativas em curso em alguns países da América", Bauer (2010) retoma a distinção entre objetivos gerais das avaliações de sistema, apresentada por Klinger, DeLuca e Miller (2008), adaptando-a a quatro categorias:

1) Objetivos da avaliação relacionados à accountability;

2) Objetivos da avaliação relacionados ao diagnóstico instrucional/das aprendizagens;

3) Objetivos da avaliação relacionados ao gerenciamento e ao controle educacionais; e

4) Objetivos da avaliação relacionados com a seleção, classificação, premiação ou certificação.

Dentro dessas quatro categorias, os objetivos declarados nos documentos oficiais ou em produções dos autores de referência, segundo Bauer (2010), poderiam relacionar-se a mais de uma categoria, a depender da interpretação que lhes fosse atribuída; nesses casos, a autora realizou sua opção baseada no contexto em que a informação foi fornecida no documento consultado. Ela apresenta uma série de quadros que ilustram a importância atribuída à avaliação para a melhoria da qualidade da educação e para a tomada de decisões acerca da política educacional. Optamos por adaptar os quadros de Bauer (2010) para observar especificamente os objetivos estabelecidos no Brasil (Quadro 11). 
Quadro 11. Objetivos da avaliação relacionados com a accountability, o diagnóstico instrucional/das aprendizagens, o gerenciamento e o controle educacional e com a premiação, seleção, classificação ou certificação, no Brasil.

\begin{tabular}{|c|c|}
\hline $\begin{array}{l}\text { Objetivos da avaliação } \\
\text { relacionados com: }\end{array}$ & Objetivos \\
\hline Accountability & - Medir e controlar a qualidade \\
\hline $\begin{array}{l}\text { Diagnóstico Instrucional/ } \\
\text { das aprendizagens }\end{array}$ & $\begin{array}{c}\text { - Promover uma cultura de avaliação; gerar } \\
\text { competência técnica na área e atitude positiva em } \\
\text { relação à avaliação. }\end{array}$ \\
\hline $\begin{array}{c}\text { Gerenciamento e o controle } \\
\text { educacional }\end{array}$ & $\begin{array}{c}\text { - Monitorar a qualidade; contribuir para o melhoramento } \\
\text { da qualidade; } \\
\text { - Subsidiar tomada de decisões políticas e tomada de } \\
\text { decisões para melhorar a qualidade; } \\
\text { - Produzir informação gerencial; melhorar a gestão } \\
\text { institucional. }\end{array}$ \\
\hline $\begin{array}{c}\text { Premiação, seleção, } \\
\text { classificação ou certificação }\end{array}$ & ---------- \\
\hline
\end{tabular}

Fonte: adaptação livre de Bauer, 2010.

Como se pode observar no Quadro 11, no Brasil, os objetivos da avaliação são relacionados a três das quatro categorias criadas por Bauer (2010). Não foram observados objetivos de alto impacto, como certificações, premiações, etc., o que, de acordo com a autora, não permite definir se tais objetivos estão excluídos das intenções dos programas de avaliação ou se, apenas, não são declarados nos documentos consultados.

Segundo o INEP (BRASIL, 2016), mais e mais gestores estão utilizando os resultados de avaliações para tomar decisões sobre a educação. No caso específico do PISA, por exemplo, o Plano Nacional de Educação (PNE) estabelece uma meta de melhoria do desempenho dos estudantes da Educação Básica nas avaliações da aprendizagem do Programa, tomado essa avaliação externa como referência internacionalmente reconhecida.

Meta 7: fomentar a qualidade da educação básica em todas as etapas e modalidades, com melhoria do fluxo escolar e da aprendizagem de modo a atingir as seguintes médias nacionais para o Ideb:

\begin{tabular}{|c|c|c|c|c|}
\hline IDEB & 2015 & 2017 & 2019 & 2021 \\
\hline $\begin{array}{c}\text { Anos iniciais do ensino } \\
\text { fundamental }\end{array}$ & 5,2 & 5,5 & 5,7 & 6,0 \\
\hline $\begin{array}{c}\text { Anos finais do ensino } \\
\text { fundamental }\end{array}$ & 4,7 & 5,0 & 5,2 & 5,5 \\
\hline Ensino médio & 4,3 & 4,7 & 5,0 & 5,2 \\
\hline
\end{tabular}

7.11) melhorar o desempenho dos estudantes da educação básica nas avaliações da aprendizagem no Programa Internacional de Avaliação de Estudantes - PISA, tomado como instrumento externo de referência, internacionalmente reconhecido, de acordo com as seguintes projeções: 


\begin{tabular}{|l|c|c|c|}
\hline PISA & 2015 & 2018 & 2021 \\
\hline $\begin{array}{l}\text { Média dos resultados em Matemática, } \\
\text { Leitura e Ciências }\end{array}$ & 438 & 455 & 473 \\
\hline
\end{tabular}

BRASIL, Lei n ${ }^{\circ} 13.005$, de 25 de junho de 2014.

É importante que atores do contexto escolar, especialistas e a sociedade em geral entendam a avaliação e o que sustenta seus objetivos, de modo a pensar como o campo educacional poderá fazer a diferença nos resultados dos estudantes brasileiros (BRASIL, 2016). No entanto, vale ressaltar que a utilização dos dados do PISA no Brasil, ainda que o país tenha participado do Programa desde a primeira edição em 2000, só foi prescrita 14 anos mais tarde no PNE atualmente vigente.

O uso dos resultados do PISA foi uma das questões que colocamos aos gerentes da avaliação no Brasil e no Japão. Em entrevista, Maria Helena Guimarães de Castro, atualmente secretária executiva do INEP e responsável pelo PISA no Brasil, nos relatou o seguinte:

Eu acho que o Brasil, ao longo desse processo, já poderia ter feito muito mais porque o PISA não é apenas divulgar, publicar o ranking na primeira página, e ressaltar que o Brasil está em último lugar. Não é esse o objetivo do PISA. O objetivo do PISA é subsidiar política pública de melhoria da qualidade. Então eu acho que com a experiência do país no PISA, nós já teríamos tido tempo suficiente pra melhorar os materiais didáticos, o livro didático, a formação de professores. Já teríamos tido tempo para ter um currículo melhor. Agora está em discussão uma base curricular, você pega esse documento da base curricular nacional, a versão dois, é uma tristeza! Sabe o que é uma tristeza? Aquilo não tem nada a ver com o PISA.

Castro deixa claro na sua fala um dos principais objetivos da avaliação posto na literatura: subsidiar política pública de melhoria da qualidade. Mas discute que o Brasil não teria, mesmo a partir de uma experiência de participação nas seis edições do PISA, dado muitos passos nessa direção. Apesar de muitos países, como o Brasil, por exemplo, declararem a intenção de medir as aprendizagens, avaliar a qualidade da aprendizagem, subsidiar política de melhoria da qualidade, Bauer (2010) afirma não ter encontrado muitas informações sobre a que serviria o diagnóstico realizado.

No Japão, Akiko Ono, diretora do Department for International Research and Co-operation do National Institute for Educational Research (NIER) e responsável pelo PISA naquele país, assim se referiu à utilização dos dados do PISA: 
Generally speaking, PISA impacts our policy development. We have an education council, a kind of policy maker committee to advise the Ministry and they use a lot of the PISA results or TALIS results, for example. PISA is very helpful to them to find what is the problem, still attitude problem, for example, self-efficacy. They discuss the results and how we can encourage students to feel more confident, for example. That is very important, I think. Actually, generally speaking, Japanese students are not so confident. Anyway, PISA is one of the sources we take when we think about policy development. ${ }^{40}$

Como podemos perceber, o Japão admite que os objetivos do PISA colocados pela OCDE (2016), no sentido seja de munir os responsáveis políticos com dados sobre os conhecimentos e as competências dos estudantes no seu próprio país em comparação com os de outros países participantes, seja de estabelecer padrões de melhoria na educação e/ou nos resultados da aprendizagem, seja de compreender as forças e fraquezas relativas de seus próprios sistemas educacionais, são colocados em prática e vão além do puro e simples diagnóstico. Diferente do que acontece no Brasil, onde ainda muito se questiona sobre o que é feito efetivamente com o diagnóstico realizado nas avaliações, no Japão os resultados da avaliação são diretamente empregados na tomada de decisões políticas e na tomada de decisões para melhorar a qualidade do ensino.

Diante dos resultados do primeiro ciclo de edições do PISA (2000, 2003 e 2006), por exemplo, três reformas educacionais foram realizadas no Japão. Akiko Ono descreve no seu depoimento essas reformas em detalhe:

Basically we had the PISA shock as our results in 2003 and 2006 were not so good. So, after that we did three reforms. The first one is about the national curriculum revision. Well, our curriculum is revised every ten years and this revision was after the PISA shock happened. So, we took some serious findings into consideration and then we changed a little bit our curriculum. (...) PISA is not only related to academic knowledge but also to its application. We did the reform in 2008 and actually after the PISA shock we increased the school hours for Science and Math in approximately $10 \%$, I think. We also increased verbal activities in every subject emphasizing group work, discussion, written skills, presentation skills or discussion skill. Those kinds of skills related to the verbal, language activities. Not only in, for example, Japanese language and English language lessons but in all subjects we emphasized it. That is one of our improvements in expressing opinion, writing ideas. Those were our revisions on the curriculum.

\footnotetext{
${ }^{40}$ Tradução livre: Em termos gerais, o PISA afeta o desenvolvimento de nossa política. Temos um conselho de educação, uma espécie de comitê de formuladores de políticas para aconselhar o Ministério e eles usam muitos dos resultados do PISA, ou resultados do TALIS, por exemplo. O PISA é muito útil para que eles identifiquem onde está e o que é o problema, por exemplo, a autoeficácia. Eles discutem os resultados e como podemos incentivar os alunos a se sentir mais confiantes, por exemplo. Isso é muito importante, eu acho. Na verdade, em geral, os estudantes japoneses não são tão confiantes. Enfim, o PISA é uma das fontes que tomamos quando pensamos no desenvolvimento de políticas.
} 
The second reform was the publishing of a teaching guide book. We published it in 2005. PISA questions were not so popular at that time. PISA questions are related to application of knowledge and not acknowledging knowledge itself. So, in this teaching guide book we analyze the PISA questions and how to teach it in classroom, how to face and solve PISA items. We published those kind of books and distributed to all boarder of education to be distributed to the schools.

The third one is about the national assessment. We did not have a national assessment until 2006. Actually, we had it very long ago, 40 or 50 years ago, but the trial was not so systematic. After PISA we again restarted in 2007, grades 6 and 9, Math and Reading, including A type questions to access knowledge and B type questions to access application skills. Now we do it every year and also a background questionnaire. This is a small national testing and we think that it makes every prefecture to be familiar with PISA questions and to make the necessary changing on the teacher styling classroom. (...)

I am not sure if it is the best but we think that is one of the reasons we make PISA better. Anyway those three reforms showed better scores on the later editions of PISA and the main reason of that recovery is the positive effects of the problem solving. I did not mention it before but we emphasize problem solving in every subject. For example in science, we do experiments or group work, presentation, and in those kind of works we put emphasis in problem solving skills. That is one of the reasons that we get better performance and the reasons for our high achievement.

I would like to mention another thing. We have increased period for integrated learning. Classes of integrated learning. Actually twice a week no textbook is used and that is not a kind of overreaching subject, not a project based learning, not Science or Math or Language activity. This is a kind of activity in which the students find their problem issue, sometimes they go to community and talk to the community people to find one issue, one topic. Students and teachers think together on how to solve community problems, for example. The students do not depend on textbooks, they are very active to learn and it is very successful, I think. We think so and also OECD thinks so. This is one of our keys. ${ }^{41}$

\footnotetext{
${ }^{41}$ Tradução livre: Basicamente, tivemos um choque no PISA dado que nossos resultados em 2003 e 2006 não foram tão bons. Então, depois disso fizemos três reformas. A primeira é sobre a revisão curricular nacional. Bem, nosso currículo é revisado a cada dez anos e essa revisão foi depois de o choque no PISA ter acontecido. Então, tiramos algumas conclusões, fizemos sérias considerações e depois mudamos um pouco o nosso currículo. (...) O PISA não está apenas relacionado com o conhecimento acadêmico, mas também com a sua aplicação. Fizemos a reforma em 2008 e, na verdade, após o choque do PISA, aumentamos as horas de aulas de Ciências e Matemática em aproximadamente $10 \%$, eu acho. Também aumentamos as atividades verbais em cada assunto enfatizando o trabalho de grupo, discussão, habilidades escritas, habilidades de apresentação ou habilidades de discussão. Esses tipos de habilidades relacionadas com as atividades verbais, de linguagem. Não só em, por exemplo, língua japonesa e língua inglesa, mas em todas as matérias elas foram enfatizadas. Essa é uma de nossas melhorias em expressar opinião, escrever idéias. Essas foram nossas revisões no currículo.

A segunda reforma foi a publicação de um guia de ensino. Nós o publicamos em 2005. As perguntas PISA não eram tão populares naquela época. Os itens do PISA estão relacionados à aplicação do conhecimento e não ao próprio conhecimento. Assim, neste livro guia de ensino analisamos os itens do PISA e como ensiná-las em sala de aula, como enfrentar e resolver itens PISA. Publicamos esse tipo de livro e distribuímos a todos os setores da educação para serem distribuídos às escolas.

A terceira é sobre a avaliação nacional. Não tínhamos uma avaliação nacional até 2006. Na verdade, tivemos muito tempo atrás, há 40 ou 50 anos, mas não era tão sistemático. Depois do PISA, reiniciamos em 2007, nos $6^{\circ}$ e $9^{\circ}$ anos, Matemática e Leitura, incluindo perguntas de tipo A para acessar o conhecimento e perguntas tipo B para acessar as habilidades de aplicação. Agora fazemos isso todos os anos e também um questionário contextual. Este é um teste nacional
} 
As reformas descritas na fala de Akiko Ono foram tema da apresentação do Japão - Analysis of PISA results and its impact on educational policy in Japan na Conferência Internacional da OCDE realizada na Coréia do Sul em 11 de Março de 2016, em razão do seu impacto na melhoria dos resultados japoneses no PISA.

O que Akiko Ono chama de choque do PISA é fruto dos resultados do país nas edições de 2003 e 2006. Aconteceu que o país caiu algumas posições no ranking dos países membros da OCDE e participantes do PISA. A Figura 26 é um dos slides apresentados por ela na Conferência ocorrida na Coréia e ilustra bem a evolução do Japão no PISA.

Como se pode perceber a partir da abaixo, nos resultados de 2000, primeira edição do PISA, o Japão ficou na $8^{\mathrm{a}}$ posição em Leitura, $1^{\mathrm{a}}$ posição em Matemática e $2^{\mathrm{a}}$ posição em Ciências entre todos os países participantes, incluindo os países membros da OCDE e países convidados. Em 2003, apesar de ter aumentado o número de países participantes, o Japão caiu seis posições em Leitura e cinco posições em Matemática, mantendo-se estável apenas em Ciências. O país passou a ocupar as posições 14, 6 e 2, respectivamente, em Leitura, Matemática e Ciências. Em 2006, com o novo aumento no número de países participantes, o Japão foi o $15^{\circ} \mathrm{em}$ Leitura, o $10^{\circ} \mathrm{em}$ Matemática e o $6^{\circ} \mathrm{em}$ Ciências. Houve, portanto, uma queda significativa em Leitura e Matemática de 2000 para 2003 e em Matemática e Ciências de 2003 para 2006.

pequeno e nós pensamos que faz cada prefeitura se familiarizar com os itens de PISA e fazer a mudança necessária na sala de aula do professor. (...)

Não tenho a certeza se é o melhor, mas pensamos que é uma das razões pelas quais nos saímos melhor no PISA. De qualquer forma essas três reformas mostraram melhores pontuações nas edições posteriores do PISA e a principal razão dessa recuperação é o efeito positivo da resolução de problemas. Eu não mencionei isso antes, mas enfatizamos a resolução de problemas em cada assunto. Por exemplo, em ciências, fazemos experimentos ou trabalho de grupo, apresentação, e nesse tipo de trabalhos colocamos ênfase nas habilidades de resolução de problemas. Essa é uma das razões pelas quais obtemos melhor desempenho e as razões para nosso forte desempenho.

Gostaria de mencionar outra coisa. Aumentamos o período de aprendizagem integrada. Classes de aprendizagem integrada. Na verdade, duas vezes por semana não é usado um livro didático e isso não é um tipo de assunto que excede o alcance dos estudantes, nem uma aprendizagem baseada em projetos, nem ciência ou matemática ou atividade de linguagem. Este é um tipo de atividade em que os alunos encontram seu problema, às vezes eles vão para a comunidade e falam com as pessoas da comunidade para encontrar uma questão, um tópico. Estudantes e professores pensam juntos em como resolver problemas comunitários, por exemplo. Os alunos não dependem de livros didáticos, eles são muito ativos para aprender e isso é um sucesso, eu acho. Pensamos assim e também a OCDE pensa assim. Esta é uma das nossas propostas chave. 
Figura 26. PISA 2003/2006 shock in Japan

\begin{tabular}{|c|c|c|c|c|c|c|}
\hline & & PISA2000 & & PISA2003 & & PISA2006 \\
\hline \multirow[t]{2}{*}{$\begin{array}{l}\text { Reading } \\
\text { literacy }\end{array}$} & $\begin{array}{c}\text { Ranking } \\
\text { within } \mathrm{OECD} \\
\text { member nations }\end{array}$ & $\begin{array}{l}8^{\text {th }} \text { of } 27 \\
\text { countries }\end{array}$ & & $\begin{array}{l}12^{\text {th }} \text { of } 29 \\
\text { countries }\end{array}$ & & $\begin{array}{l}12^{\text {th }} \text { of } 29 \\
\text { countries }\end{array}$ \\
\hline & $\begin{array}{c}\text { within participating } \\
\text { nations }\end{array}$ & $8^{\text {th }}$ of 31 countries & $\begin{array}{c}\text { Significant } \\
\text { drop }\end{array}$ & $14^{\circ}$ of 40 countries & $\begin{array}{c}\text { No } \\
\text { change }\end{array}$ & $16^{\circ}$ of 56 countries \\
\hline \multirow[t]{2}{*}{$\begin{array}{l}\text { Mathemati- } \\
\text { cal literacy }\end{array}$} & $\begin{array}{c}\text { Ranking } \\
\text { within OECD } \\
\text { member nations }\end{array}$ & $\begin{array}{l}1^{\text {st }} \text { of } 27 \\
\text { countries }\end{array}$ & \multirow{4}{*}{$\begin{array}{l}\text { No change } \\
\text { for correct } \\
\text { answers in } \\
\text { common } \\
\text { areas. } \\
(\% 1)\end{array}$} & $\begin{array}{l}4^{\text {th }} \text { of } 29 \\
\text { countries }\end{array}$ & & $\begin{array}{l}6^{\text {th }} \text { of } 30 \\
\text { countries }\end{array}$ \\
\hline & $\begin{array}{c}\text { within partipating } \\
\text { nations }\end{array}$ & $1^{3 t}$ of 31 countries & & $6^{\text {th }}$ of 40 countries & Significant & $10^{\text {th }}$ of 57 countrles \\
\hline \multirow[t]{2}{*}{$\begin{array}{l}\text { Scientific } \\
\text { literacy }\end{array}$} & $\begin{array}{c}\text { Ranking } \\
\text { within OECD } \\
\text { member nations }\end{array}$ & $\begin{array}{l}2^{\text {nd }} \text { of } 27 \\
\text { countries }\end{array}$ & & $\begin{array}{l}2^{\text {nd }} \text { of } 29 \\
\text { countries }\end{array}$ & \multirow{2}{*}{$\begin{array}{l}\text { No change } \\
\text { for correct } \\
\text { answers in } \\
\text { common } \\
\text { areas. } \\
(* 2)\end{array}$} & $\begin{array}{l}3^{\text {rd }} \text { of } 30 \\
\text { countries }\end{array}$ \\
\hline & $\begin{array}{c}\text { within participating } \\
\text { nations }\end{array}$ & $2^{\text {ns }}$ of 31 countries & & & & $6=$ of 57 countries \\
\hline
\end{tabular}

Fonte: NIER, 2016.

O NIER (2016) acrescenta que, além do declínio nos níveis de Letramento nos três domínios do PISA, foi também possível observar, a partir dos resultados do Programa, que os estudantes japoneses apresentavam alta taxa de não resposta aos itens de resposta aberta nos três domínios, que havia um aumento do número de estudantes ocupando níveis de proficiência mais baixos e que estava lançado um desafio no que diz respeito às suas atitudes, por exemplo, baixa confiança e motivação, altos níveis de ansiedade etc. A partir dessas constatações feitas em função do diagnóstico realizado com os resultados das três primeiras edições do Programa que fecharam um ciclo de ênfases nos diferentes domínios, surgiram as três grandes reformas político-educacionais comentadas por Akiko Ono acima.

A primeira reforma, conforme depoimento de Akiko Ono, foi a revisão do currículo nacional. Como vimos, no Japão, o currículo nacional (Cursos de Estudo) é revisado a cada 10 anos. Na década de 1990, segundo o NIER (2016), a crítica era que a educação escolar enfatizava demais o conhecimento. Em seguida, a revisão de 1998/99 adotou a ideia de desenvolver o zest for living, um currículo baseado na aprendizagem autônoma e no pensamento (o que significa mais espaço para os estudantes pensarem por si mesmos), com seleção rigorosa dos conteúdos educacionais (o que significou uma redução de $30 \%$ do conteúdo) e o estabelecimento do "período de aprendizagem integrada" (classes para a aprendizagem orientada para a resolução de problemas entre sujeitos) (NIER, 2016). 
Com base no relatório final do PISA publicado em 2008, a revisão de 2008/09 teve a ideia de continuar o desenvolvimento de zest for living com a aquisição de conhecimentos básicos e fundamentais e de habilidades alinhados ao desenvolvimento equilibrado da capacidade de pensar, tomar decisões e expressar-se (NIER, 2016). Além disso, as mudanças ocorridas no que tange à reforma do currículo nacional do Japão incluíram o aumento de $10 \%$ no número de aulas de Língua Japonesa, Matemática, Ciências, Estudos Sociais e Educação Física/Saúde; o incentivo à leitura; e o aprimoramento de atividades verbais, de Ciências e Matemática, de educação cultural/tradicional, de educação moral, de atividades de experimentação, e de língua estrangeira (NIER, 2016).

A segunda reforma, conforme explicou Akiko Ono, é mais relacionada à prática pedagógica do professor. Segundo ela, após a publicação dos resultados do PISA 2003, um grupo de trabalho foi criado com membros do NIER e do MEXT. Eles analisaram os tipos de itens e áreas do teste que não seriam familiares aos estudantes japoneses e, em seguida, publicaram os Teaching Guidebooks de Matemática e de Ciências que mostram como melhorar a prática pedagógica para a utilização dos itens do PISA e do TIMSS. De acordo com o NIER (2016), dessa forma, os itens do PISA se tornaram mais populares nas salas de aula do Japão e influenciaram a prática docente. Simultaneamente, o programa de aprimoramento da habilidade de leitura foi implementado de forma a garantir que os estudantes desenvolvessem não apenas habilidades de leitura e compreensão, mas também habilidades de escrita e expressão.

A terceira reforma está relacionada com retomada do Sistema Nacional de Avaliação. O Japão deu inicio ao National Assessment of Academic Ability em 2007, que avalia os estudantes do $6^{\circ}$ e $9^{\circ}$ anos (que representam o final dos primeiro e segundo ciclos do Ensino Fundamental, respectivamente) em Língua Japonesa e Matemática. Como explicou Akiko Ono, o teste contém itens de dois tipos, A e B, que avaliam o nível de conhecimento adquirido pelos estudantes e suas habilidades de aplicação desses conhecimentos em situações do dia-a-dia, respectivamente. Atualmente, a avaliação é implementada todos os anos e os resultados são publicados apenas por prefeitura. Segundo Akiko Ono, os resultados de cada escola não são públicos dada a controvérsia do tema que está relacionado à responsabilização e à excessiva competição colocada sobre as escolas. 
Essas três reformas levaram ao que, segundo Ono, foi reportado na mídia como V-character recovery of students' academic performance. A característica em $\mathrm{V}$ a que as manchetes se referiam tem relação com o comportamento das curvas mostradas na Figura 27.

Figura 27. Evolução das médias do Japão no PISA

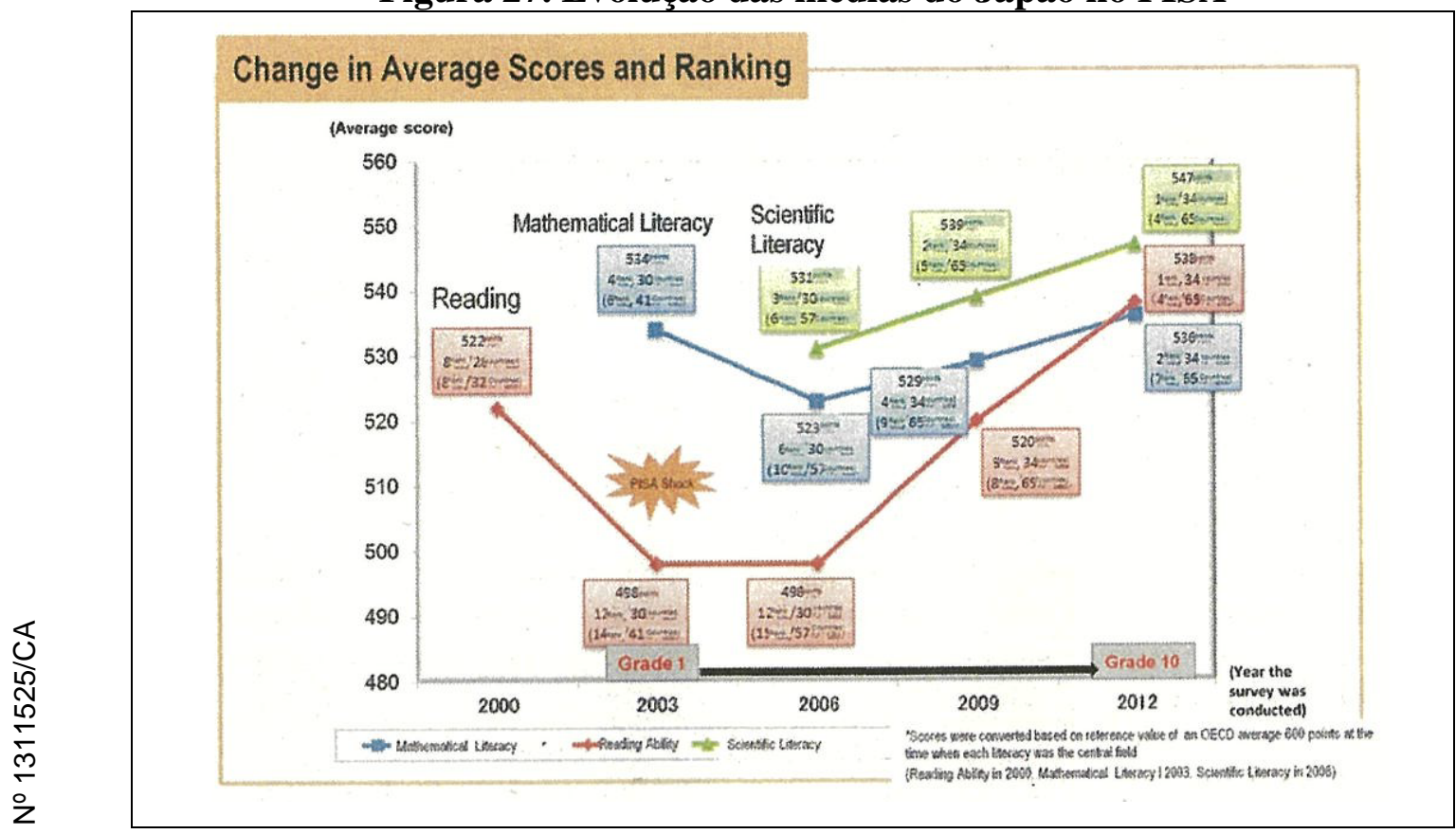

Fonte: NIER, 2016.

Como se pode observar, na edição de 2012 os estudantes japoneses atingiram as maiores médias comparadas as demais edições do PISA. De acordo com o NIER (2016), as razões para essa retomada do país estão relacionadas às reformas acima mencionadas, já que os estudantes que realizaram o teste em 2012 são fruto dessas reformulações curriculares que aconteceram ao longo do Ensino Fundamental. Em 2003, os estudantes que fizeram o teste em 2012 (Grade 10), estavam ingressando no $1^{\circ}$ ano (Grade 1) e, portanto, foram alvo da reforma curricular de 1998/99 nas séries iniciais e da de 2008/09 nas séries finais do Ensino Fundamental.

Por fim, Akino Ono comentou, também, durante a entrevista a nós concedida, sobre a extensão do período de tempo dedicado às classes integradas. Essa prática foi reconhecida pela OCDE como uma das principais razões para o alto desempenho do país no PISA. Segundo a OCDE (2013a; 2013b) o foco do Japão no desenvolvimento de habilidades de resolução de problemas por meio da participação dos estudantes em projetos transversais, conduzidos por eles 
próprios, tanto dentro das disciplinas como por meio de atividades de aprendizagem integradas é uma explicação plausível para os resultados do país.

No Brasil, segundo Santos e Greca (2006), os currículos e seus programas, os livros didáticos e os materiais de ensino pouco mudaram nos últimos anos. Houve, de fato, poucas mudanças significativas, inclusive no ensino de Ciências nos últimos anos que pudessem trazer expectativas positivas a respeito da melhora da qualidade educacional no país.

Na década de 1960, a Lei 4.024 - Diretrizes e Bases da Educação, de 21 de dezembro de 1961, ampliou substancialmente a participação das Ciências no currículo escolar, que passaram a figurar desde o $1^{\circ}$ ano do Ensino Fundamental. No Ensino Médio, houve também significativo aumento da carga horária de Física, Química e Biologia. Segundo Krazilchik (2000), essas disciplinas passavam a ter a função de desenvolver o espírito crítico com o exercício do método científico, preparando, assim, o cidadão para pensar lógica e criticamente e para ser capaz de tomar decisões com base em informações e dados.

Na década de 1970, as disciplinas científicas foram novamente alvo de reformas. No entanto, de forma contrária à reforma ocorrida na década anterior, com a promulgação da Lei de Diretrizes e Bases da Educação no 5.692, de 1971, e dadas as transformações políticas no país pela imposição da ditadura militar, em 1964, as disciplinas científicas passaram a ter característica profissionalizante, descaracterizando as funções sociais e pedagógicas assumidas anteriormente no currículo.

A nova Lei de Diretrizes e Bases da Educação, no 9.394/96, estabelece, no seu artigo $26^{\circ}$, que "os currículos do ensino fundamental e médio devem ter uma base nacional comum, a ser complementada pelos demais conteúdos curriculares especificados nesta Lei e em cada sistema de ensino". Dessa forma, em 1998, o MEC colocou à disposição da comunidade escolar, no documento intitulado PCN, uma proposta de reorganização curricular coerente com o ideário presente nesta Lei. Os PCNs procuram oferecer fundamentação aos professores para cada uma das áreas do conhecimento, ou seja, subsídios para a implementação da proposta de reforma neles contida. Contudo, ainda há uma distância substancial entre o que está prescrito e a prática pedagógica, e a superação desta dificuldade tem se mostrado bastante difícil. Segundo Ricardo \& Zylbersztajn (2003), essa dificuldade vai desde problemas com a formação inicial e continuada dos 
professores, passando pela escassa disponibilidade de materiais didáticos e pedagógicos que estejam em consonância com os fundamentos da proposta de reforma, e chegando até a estrutura verticalizada dos sistemas de ensino e à incompreensão dos pressupostos da lei, das DCNs e dos PCNs.

Esta incompreensão se relaciona com a dificuldade dos professores de entender alguns conceitos centrais presentes nos documentos do MEC e ausentes no contexto escolar como, por exemplo, o ensino por competências, a interdisciplinaridade e a contextualização (RICARDO \& ZYLBERSZTAJN, 2003). Assim também acontece com os estudantes brasileiros no PISA. Segundo Maria Helena Guimarães de Castro, a falta de familiaridade com o teste é uma das principais dificuldades e problemas encontrados pelos estudantes brasileiros no Programa.

Porque o problema do PISA é o desenho da prova. A prova é uma prova de alta qualidade técnica. Difícil para um estudante brasileiro, porque ela exige muita leitura. É uma prova basicamente de leitura. Cada item tem um enunciado enorme e a partir desses enunciados você vai derivando perguntas de problem solving, essas coisas, que exigem um raciocínio dos estudantes, de uma capacidade de leitura, de compreensão do texto, de análise do texto, que os nossos estudantes não têm. Os nossos estudantes leem pouco; estão acostumados a ler textos muito curtos. Uma das hipóteses que havia, de uma pesquisa que nós fizemos para o primeiro PISA aplicado em 2000, é que o Brasil tinha ido muito mal porque os estudantes brasileiros começavam a ler o texto, achavam muito chato e chutavam. Então, eles não liam. Eu acredito que ainda continue assim. Por quê? Porque lá na OCDE eles insistiram muito na preparação dos estudantes para a prova do PISA. Alguém prepara estudante? Tipo assim: "olha, daqui a um mês nós vamos fazer a prova do PISA e a nossa escola foi sorteada. Nós vamos então fazer agora alguns testes tipo o PISA que já foram divulgados e tal, pra vocês entenderem qual é o formato, qual é o desenho, que tipo de pergunta é feita, o que vai ser exigido de vocês. Isso não é feito nas nossas escolas. Muitos estudantes chegam sem ter a menor ideia do que é o PISA. Não tem um esclarecimento. Então, esse é um ponto que eu acho que a escola podia melhorar. O MEC poderia, inclusive, ter uma campanha de esclarecimento; o INEP poderia envolver as equipes estaduais que aplicam a Prova Brasil e tudo, para que eles entendam. Olha, vamos preparar o estudante, vai chegar a prova do PISA. Tem aqui um conjunto de testes. Imagina que o próximo teste do PISA, em 2018, vai ser tudo online. O de 2015 foi 100\% no computador, mas podendo usar pen drive. Podia ser off-line. Agora não é mais off-line, é online. Não tem como! Quem garante que as escolas sorteadas terão acesso a internet? Tem até universidade pública que não tem acesso. Não tem banda larga garantida pra todo mundo, entendeu? Eu não sei como vai ser. Porque não só a prova será online como vai ser aquele tipo de prova de adaptative learning que o estudante, se ele der uma resposta errada, ele pode ser eliminado da primeira resposta. Eles estavam discutindo isso lá. Inclusive tem o framework que se chama "competências globais para o século 21 " que procura avaliar tanto as competências cognitivas quanto as competências sócio emocionais, os valores éticos e morais e uma série de coisas. Bom, na medida em que você tem uma prova online, que o estudante respondeu errado, daí pula não sei quantas pra ir pra uma pergunta mais fácil, sei lá. É uma prova que é interativa, que ela interage com o estudante. Não 
consigo imaginar os estudantes brasileiros fazendo isso. Por que vem cá. Nem o estudante brasileiro que entra na USP ou na UNICAMP faz prova desse tipo. Qual é a escola privada brasileira que tem uma prova interativa online? Nenhuma. Como é que o Brasil vai participar?

Maria Helena chega a apontar algumas saídas para tornar os itens do PISA mais familiares para os professores e estudantes brasileiros, como a proposta de implementação de uma campanha do MEC, com envolvimento pelo INEP das equipes estaduais que aplicam a Prova Brasil promovendo uma maior divulgação do PISA, por exemplo. Essa também foi uma questão enfrentada pelo governo japonês, e resolvida com o auxílio da publicação dos livros guia para os professores. Será que a experiência japonesa, nesse sentido, não seria um bom ponto de partida para o Brasil? Maria Helena acrescentou ainda que

não há nenhuma evidência pior do que os levantamentos sobre os cursos de formação de professores e sobre as licenciaturas no Brasil. Eles não identificaram nenhum curso de pedagogia, nenhum curso de licenciatura no Brasil, que tivesse na sua bibliografia obrigatória os relatórios do PISA. Você entende? Quer dizer, os professores futuros estão saindo das faculdades sem conhecer o relatório do PISA, o framework, toda a questão da avaliação de competências. O PISA tem um trabalho conceitual muito bem feito e tem os melhores especialistas e consultores do mundo.

A falta de infraestrutura escolar no Brasil, que foi apontada por Maria Helena Guimarães de Castro, há muito tempo deixou de ser um problema para o Japão. De fato, estamos longe de conseguir resolvê-lo. As desigualdades escolares são muito acentuadas no Brasil, mesmo em termos de infraestrutura.

Há inúmeros fatores que influenciam e permanecerão influenciando as novas políticas educacionais mundo a fora, mas o Japão tem experimentado grande impacto do PISA nas mudanças ocorridas no seu currículo nacional e nas práticas docentes. O Brasil, com uma experiência maior em avaliação educacional do que o Japão, parece encontrar muita dificuldade para superar a barreira do uso apenas diagnóstico. Até porque, segundo Bauer (2010), não existem muitas informações sobre a que propósito atenderia o diagnóstico realizado em inúmeros países da América. Essa é, aparentemente e diante dos resultados encontrados aqui, a realidade do Brasil.

O que explicaria, então, o desempenho do Brasil e do Japão no PISA? O alto desempenho japonês, de acordo com Akiko Ono, estaria ligado às reformas ocorridas após o choque provocado pela divulgação dos resultados das edições do PISA de 2003 e de 2006 que implicaram na queda de algumas posições do Japão 
no ranking da OCDE. Segundo ela, o PISA impacta e continuará impactando as mudanças ocorridas no currículo e nas práticas pedagógicas do Japão.

Mas e o baixo desempenho do Brasil? Estaria sob o efeito da falta de familiaridade dos estudantes brasileiros com o teste? À falta de infraestrutura? À baixa frequência com que são realizadas atividades de experimentação e investigação nas aulas de Ciências? Maria Helena Guimarães de Castro completou assim seu depoimento:

Eu acho assim... Existe primeiro um problema muito grande na formação inicial dos nossos professores. Esse para mim é o fator mais importante para explicar o baixo desempenho do Brasil. Não é exclusivo. Não existe um fator isolado capaz de justificar o nosso baixo desempenho, mas os nossos professores saem absolutamente despreparados das faculdades para enfrentar as salas de aula e as secretarias de educação, em geral, têm baixa competência técnica para oferecer um programa de formação continuada. Elas não têm! Pelo menos a maioria, agora algumas já têm, mas normalmente não tinham um currículo definido. E, além disso, as secretarias têm falta de um corpo técnico bem qualificado para serem, digamos assim, professores tutores, professores supervisores, coordenadores, para você ter uma cadeia de trabalho que realmente possa chegar até a escola, até a sala de aula com base numa qualificação docente e numa qualificação na sala de aula.

Segunda coisa, a avaliação. Embora a gente tenha o SAEB desde 1995, com TRI, escala de proficiência e tal, ele foi muito pouco explorado pelas escolas públicas brasileiras. Os resultados do SAEB já apontaram, desde o primeiro momento, os principais problemas: o atraso escolar era um grande problema, o fato dos estudantes não saberem ler um texto. $\mathrm{O}$ estudante chegava ao final da oitava série na época sem saber ler um texto de baixo grau de complexidade. Isso estava lá. Eu sei, eu era presidente do INEP. Em matemática, os estudantes não sabiam fazer operações com decimais, como não sabem até hoje, e era um problema. Tudo isso não foi bem aproveitado pelos sistemas estaduais e municipais. O INEP, a partir de 2000, começou a fazer um trabalho mais de uso pedagógico dos resultados. Tanto é que o relatório do SAEB de 2001 foi um trabalho primoroso de análise pedagógica dos resultados, orientação para os professores. É um relatório de uma qualidade... Foi o último relatório de análise e interpretação pedagógica de resultados do SAEB 2001 eu era presidente do INEP, depois nunca mais teve. Desde 2001, o INEP continua fazendo mil coisas. O ENEM é para oito milhões de estudantes, Prova Brasil em tudo que é escola, mas daí faz um monte de provas, publica o ranking e já começa a preparar outra prova, entendeu? É sempre uma corrida contra o tempo. Ninguém entende que a avaliação, em larga escala e externa, é para melhorar o aprendizado. Então, é melhor ter uma avaliação a cada três anos do que esse monte de avaliação infernal e não chegar nada na ponta. Tá certo? Daí seria obrigação. Por que eu acho que num sistema nacional como o Brasil tem, deveria estar mais... Agora que a escola sabe qual é o numero no IDEB. Daí você pergunta: mas qual o seu maior problema na prova Brasil de língua portuguesa? Ah não sei, mas o meu IDEB precisa melhorar. Cadê a analise do erro da prova, entendeu? Então, eu acho o nosso problema é que nós não soubemos aproveitar. Há uma baixíssima tradição de política com base em evidência; os governos em geral valorizam mais as coisas de curto prazo, que têm impacto imediato... E então, vamos fazer; Pronto, é oito milhões, entendeu? Ninguém está muito preocupado com a qualidade do aprendizado, com a qualidade da formação do estudante e com a qualidade da formação do professor. 
Então, eu acho que formação de professor e falta de uso das evidências, tudo bem que o Brasil é um país desigual, que o background socioeconômico é determinante, tudo bem, mas tem fatores que são absolutamente internos à escola e que não foram resolvidos. E, mesmo do ponto de vista da infraestrutura básica da escola, ainda tem problemas absurdos que já deveriam ter sido resolvidos, ainda mais considerando a quantidade de dinheiro que esse ministério joga fora. Estou espantada com o desperdício de recursos do MEC. É uma coisa de chorar, entendeu? É um orçamento muito grande, é tudo fragmentado, superposição, não tem objetivo claro, entendeu?

Sobressaem na fala da gestora do PISA no Brasil, Maria Helena Guimarães de Castro, as questões relativas à formação dos professores e o desuso dos resultados das avaliações externas. Assim como ela própria, e como Bauer (2010), acreditamos que, principalmente em um momento em que já se passaram mais de 20 anos da implantação dos primeiros sistemas de avaliação, o debate técnico aliado ao pedagógico poderia ser retomado para que ajustes sejam realizados em prol da consolidação de avaliações mais significativas, cujos resultados possam alimentar debates e impulsionar práticas pedagógicas para a melhoria efetiva do nosso sistema educacional.

\section{6 \\ Em suma, o que podemos aprender da experiência do Japão?}

O Japão está no topo do ranking internacional de pesquisas educacionais desde o início. A OCDE (2010) dedicou um capítulo do relatório Strong Performers and Successful Reformers in Education: Lessons from PISA for the United States para explorar como o Japão tinha alcançado essa posição consistente e o que outros países podem contemplar da experiência japonesa. Segundo a OCDE,

the Japanese education system is grounded in a deep commitment to children that is concrete and enduring. The research also attributes Japan's success to a first-rate teaching force, superb family support for Japanese students at home, the way resources are focused on instruction and the strong incentives the system provides for students to take tough courses and study hard in school. The school curriculum in Japan appears very coherent, carefully centred on core topics, with a clear goal of fostering deep conceptual understanding. The academic programme follows a logical sequence and is set at a very high level of cognitive challenge. Though it is applied nationwide, Japanese teachers have a remarkable level of autonomy in its application. The entire approach is aided by the shared belief that effort and not ability is what primarily explains student achievement. There is no tracking in Japanese schools, classes are heterogeneous and no student is held back or promoted on account of ability. The system has a great deal of inherent accountability - to one's parents, one's peers and so on. While entrance exams are 
deeply important for progression to Japanese higher education, the system of teacher accountability in schools is interestingly not based on student assessments. These, and many other factors, have combined to produce one of the world's besteducated and most productive workforces. ${ }^{42}$ OCDE, 2010. P. 137.

As principais características do sistema educacional japonês que, de acordo com a OCDE (2010), servem de lição para outros países e economias do mundo são as seguintes:

1. Um currículo nacional padrão

2. Abordagens de ensino: ênfase no envolvimento dos estudantes

3. Longas horas de escolaridade e escolaridade adicional

4. Qualidade do professor

5. Recursos financeiros cuidadosamente direcionados

6. Um foco na equidade

7. Uma abordagem diferente da responsabilização e dos testes

Nesta tese, observamos empiricamente algumas dessas características e mostramos como, de fato, elas têm relação com o alto desempenho do Japão nas avaliações externas de larga escala, como é o caso do PISA. No entanto, a partir da nossa experiência com o estudo com aspectos do sistema educacional daquele país, gostaríamos de apontar algumas das lições aprendidas.

A primeira lição que podemos extrair da experiência japonesa reside na política de promoção dos estudantes. O Japão é um dos poucos países do mundo onde não há reprovação, recurso este com implicações pedagógicas frequentemente negativas para os estudantes e a sociedade em inúmeros países do globo, inclusive no Brasil.

\footnotetext{
${ }^{42}$ Tradução livre: O sistema de educação japonês é fundamentado em um profundo compromisso com as crianças, que é concreto e duradouro. A pesquisa também atribui o sucesso do Japão a uma força de ensino de primeira classe, excelente apoio familiar para estudantes japoneses em casa, a forma como os recursos são focados na instrução e os fortes incentivos que o sistema oferece aos alunos para tomar cursos difíceis e estudar duro na escola. O currículo escolar no Japão parece muito coerente, cuidadosamente focado em tópicos centrais, com um objetivo claro de promover uma profunda compreensão conceitual. O programa acadêmico segue uma sequência lógica e é definido em um nível muito elevado de desafio cognitivo. Embora seja aplicado em todo o país, os professores japoneses têm um notável nível de autonomia na sua aplicação. Toda a abordagem é auxiliada pela crença compartilhada de que o esforço e não a capacidade é o que explica o desempenho do aluno. Não há rastreamento nas escolas japonesas, as aulas são heterogêneas e nenhum aluno é impedido ou promovido por causa da habilidade. O sistema tem uma grande responsabilidade inerente - para os pais, os pares e assim por diante. Embora os exames de admissão sejam profundamente importantes para a progressão para o ensino superior japonês, o sistema de responsabilização dos professores nas escolas não é baseado nas avaliações dos alunos. Estes, e muitos outros fatores, se combinaram para produzir uma das forças de trabalho mais bem educadas e produtivas do mundo.
} 
A segunda lição está relacionada com as características do currículo nacional comum. Revisado a cada dez anos, levando em conta os resultados da avaliação, o currículo nacional e único é bastante coerente, cuidadosamente focado em tópicos essenciais e na exploração conceitual, logicamente sequenciada, que define um nível altamente elevado de desafio cognitivo. Segundo depoimento de Ryo Watanabe, presidente do conselho administrativo do PISA em 2006, a OCDE (2010), os estudantes japoneses têm se saído muito bem no PISA por conta do currículo que tem padrões nacionais; dos cursos de estudo que definem claramente o conteúdo a ser ensinado em cada ano escolar e disciplina; e dos professores que ensinam com base nesses padrões. O resultado é que os japoneses graduados do ensino médio têm um nível de domínio dos temas que rivaliza com graduados da faculdade em muitos países ocidentais (OCDE, 2010).

A lição de número 3 refere-se à formação e qualidade dos professores. Essa é, a nosso ver, uma das características mais importantes que definem a qualidade da educação no Japão. O Lesson Study japonês é apontado por especialistas e gestores o fator que provavelmente mais agregue valor ao alto desempenho dos estudantes japoneses nas avaliações externas de larga escala. Como vimos, o aspecto mais interessante dessa formação de professores é que ela ocorre em serviço, aliado ao fato de que quando os professores participam do Lesson Study, observam as salas de aula uns dos outros e trabalham juntos para refinar lições individuais, acelerando a disseminação das melhores práticas em toda a escola ou comunidade.

A lição de número quatro refere-se à utilização do tempo de aula. $\mathrm{O}$ uso do tempo escolar se entrelaça com outras práticas, como aquelas que envolvem o comprometimento dos professores com os estudantes e destes com aqueles. Praticamente não há atrasos nem tempos mortos. Há resultados de pesquisa (STEVENSON \& STIGLER, 1992) que demonstram que os estudantes japoneses se mostram mais engajados em aula do que estudantes de outros países e que isto está relacionado ao uso do tempo. Por um lado, os estudantes japoneses estudam em tempo integral. Por outro lado, embora como na maioria dos países do mundo, uma hora de aula no Japão tenha duração de aproximadamente 50 minutos, entre as aulas há um intervalo de 10 minutos destinado à locomoção/troca de sala, distribuição de tarefas corrigidas etc., o que ajuda a que não se desperdice o tempo 
de instrução com questões outras que não aquelas diretamente relacionadas com o processo de ensino-aprendizagem.

Por fim, e não menos importante, a quinta lição se refere ao uso dos resultados das avaliações externas. O Japão implementou a avaliação nacional muito recentemente, em 2007. Contudo, muito além do puro e simples diagnóstico, esse país faz uso dos resultados dessas avaliações para tomar decisões políticas e para melhorar a qualidade da educação no país. Os resultados das avaliações não são publicados no nível da escola, por entenderem que essa é uma questão controversa que envolve responsabilização e muita competitividade institucional. No Japão, os testes são utilizados como forma de monitoramento e de diagnóstico do desempenho do sistema educacional. 


\section{Conclusão}

Esse estudo teve por finalidade comparar os desempenhos alcançados pelos estudantes brasileiros e japoneses, em Ciências, no PISA. De uma maneira geral, os resultados mostram um enorme descompasso entre os países estudados e reproduzem os achados usuais da literatura que retrata os indicadores educacionais bastante desfavoráveis do Brasil e o bom desempenho do Japão em avaliações externas de larga escala.

Inicialmente, buscando responder nossa primeira questão de pesquisa, que indagava se haveria diferenças de competência cognitiva em Ciências entre os estudantes brasileiros e dos outros países, sobretudo os do Japão e também como se expressariam especificamente essas diferenças em termos das habilidades contempladas pelas subescalas do PISA, comparamos os resultados do Brasil e do Japão nas duas edições do PISA cujo foco foi a área de Ciências: a de 2006 e a de 2015. Essa comparação coloca o Brasil em situação de desvantagem em relação a quase todos os países que participam do PISA e não apenas em relação ao Japão. O Brasil foi o $52^{\circ}$ país em competência científica dentre os 57 participantes do PISA em 2006 e o $63^{\circ}$ entre os cerca de 70 países participantes do programa em 2015. O Japão foi o $6^{\circ}$ colocado em 2006 e o $2^{\circ}$ em 2015.

Na escala de desempenho do PISA, o Brasil permanece alocado no nível 1, enquanto o Japão, alocado no nível 3 em 2006, ascendeu ao nível 4 em 2015. Isso quer dizer que: a) a maioria dos estudantes brasileiros participantes do PISA tem limitado conhecimento científico, de forma tal que só consegue aplicá-lo em algumas poucas situações familiares. Eles são capazes de apresentar explicações científicas óbvias e tirar conclusões de evidências explicitamente apresentadas; b) a maioria dos estudantes japoneses participantes do PISA em 2006 é capaz de identificar questões científicas claramente definidas em uma série de contextos. Eles podem selecionar fatos e conhecimentos para explicar fenômenos e aplicar modelos simples e estratégias de pesquisa. Podem interpretar e usar conceitos científicos de diferentes disciplinas e aplicá-los diretamente. Podem, ainda, dissertar sobre os fatos e tomar decisões baseadas em conhecimento científico; c) a maioria dos estudantes japoneses em 2015 consegue usar conhecimento de conteúdo mais complexo e mais abstrato, proporcionado ou recordado, para 
construir explicações de eventos e processos mais complexos ou pouco conhecidos. Eles podem conduzir experimentos que envolvam duas ou mais variáveis independentes em contextos restritos. Conseguem justificar um projeto experimental recorrendo a elementos de conhecimento procedimental e epistemológico. Podem interpretar dados provenientes de um conjunto moderadamente complexo ou de contex to pouco conhecido, e chegar a conclusões adequadas que vão além dos dados e justificar suas escolhas.

Neste estudo, a comparação dos resultados do PISA obtidos por estudantes brasileiros e japoneses deixou claro também que a defasagem idade-série continua a constituir uma das dimensões mais importante das desigualdades educacionais, apesar de ser um dos problemas mais visados pelas políticas públicas federais, estaduais e municipais. Conduzimos nossas análises a partir das médias gerais da OCDE, do Japão, e do Brasil em quatro dimensões: a) geral, incluindo todos os estudantes participantes do teste; b) estudantes defasados matriculados no Ensino Fundamental; c) estudantes em fase - matriculados na primeira série do Ensino Médio; e d) estudantes adiantados - matriculados nas segunda e terceira séries do Ensino Médio.

Somente os estudantes brasileiros matriculados nas séries finais do Ensino Médio e, portanto, com escolaridade maior do que os estudantes japoneses conseguem atingir os patamares iniciais considerados pela OCDE como essenciais para uma participação ativa na sociedade. Os estudantes brasileiros defasados apresentam um desempenho inferior em Ciências ao dos estudantes brasileiros da amostra geral. No entanto, a diferença entre os estudantes brasileiros defasados e os estudantes japoneses chega a alcançar significativos 200 pontos em algumas competências, corroborando os achados da literatura especializada que mostra que a reprovação não é a melhor solução para os problemas de ensino-aprendizagem no Brasil, além de se mostrar uma medida que incide negativamente no desempenho em Ciências no PISA, porque priva esses estudantes da oportunidade de aprender o que é tipicamente avaliado pelo PISA entre jovens de 15 anos de idade que deveriam estar frequentando o último ano do Ensino Fundamental ou a primeira série do Ensino Médio.

De maneira geral, os países que apresentam menor média em avaliações internacionais são justamente aqueles que apresentam os maiores índices de defasagem escolar. Os altos índices de não aprovação escolar saem caro para 
países como o Brasil, por implicar em expressivos custos educacionais e socais decorrentes do prolongamento do tempo de frequência à escola motivada pela repetência, com o consequente adiamento da conclusão da escolaridade básica e do acesso ao mundo do trabalho.

No Japão, não há reprovação e 100\% dos estudantes japoneses que participaram em ambas as edições do Programa estavam devidamente matriculados no $10^{\circ}$ ano escolar, ou seja, no $1^{\circ}$ ano do Ensino Médio.

A comparação de resultados em testes educacionais, entendido como o resultado dos escores que medem a proficiência dos estudantes, foi possível graças à utilização da TRI que usa modelos estatísticos em que a dificuldade dos itens é parametrizada na mesma escala de proficiência das habilidades cognitivas dos estudantes. Além disso, é necessário empregar itens comuns aos diferentes testes e esses itens devem apresentar o mesmo funcionamento nos diferentes grupos de estudantes para que uma boa comparabilidade seja alcançada.

Em resposta a nossa segunda questão de pesquisa, que indagava se existiriam itens do PISA 2006 que apresentam DIF, tendo o Brasil como referência, podemos assumir que as análises comparativas realizadas demonstram que, não obstante os cuidados que cercam a elaboração e seleção de itens dessa avaliação internacional de grande porte, há grande presença de DIF nos itens de Ciências do PISA 2006, comparativamente, entre o Brasil e o Japão. Ainda assim, cabe lembrar que, mesmo os itens diagnosticados com DIF, nem sempre são capazes de comprometer o processo avaliativo ao privilegiar um grupo em detrimento do outro.

Neste estudo, no total de 96 itens analisados, foram identificados 62 apresentando DIF, oito dos quais com DIF tanto no parâmetro a quanto no parâmetro $b$. As características observadas desses itens foram traduzidas em variáveis aplicadas à estrutura do modelo Bayesiano para uma confirmação rigorosa e formal das hipóteses levantadas. As conclusões a que chegamos, após os resultados estimados pelo modelo, podem ser assim expressas:

1. Considerando o número de itens, a prova de Ciências foi mais fácil para o Japão. 28 dos 50 itens com DIF apenas no parâmetro $b$ foram mais fáceis para os estudantes japoneses. Contudo, o DIF encontrado nesses itens não afeta significativamente os resultados gerais do teste, tendo em vista que ele está localizado em uma parte dos itens e que alguns são mais fáceis 
para o Japão e outros para o Brasil. Por outro lado, sob o mesmo critério de número de itens, a prova discrimina mais os estudantes brasileiros. Dos 20 itens com DIF no parâmetro $a, 14$ discriminam mais a "população" de estudantes do Brasil.

2. No que diz respeito às competências:

a. Itens que mobilizam a competência "Usar evidência científica" tendem a apresentar menos DIF no parâmetro $a$ quando comparada às demais competências.

b. Os itens de Ciências apresentam mais DIF nas discriminações favoráveis ao Brasil. Isso significa que a maior parte dos itens que apresentam DIF no parâmetro de discriminação é favorável ao nosso país, ou seja, que esses itens são capazes se separar mais estudantes de proficiências mais altas daqueles estudantes de proficiências mais baixas no Brasil.

c. As diferenças no parâmetro $b$ estão distribuídas quase que uniformemente entre os grupos de itens das diferentes competências, e indicam que, considerando-se a dificuldade do item, praticamente não há comportamento diferencial dos itens que favoreça ou prejudique algum dos dois grupos analisados. Ou seja, a proporção de itens que favorece um grupo e outro se distribui igualmente entre os diferentes grupos de itens formados pelas diferentes competências. Assim, não há uma competência em que o DIF se concentre ou que apresente menos DIF do que o achado no teste como um todo. Isso aponta para a possibilidade de todas as competências apresentam a mesma prevalência de DIF.

3. De acordo com a área de conhecimento do item não se pode afirmar que os itens dos testes de Ciência privilegiem o Brasil ou o Japão. Apesar de terem sido identificados itens com DIF em todos os descritores avaliados, não há evidência estatística que mostre que um ou outro descritor concentre maior prevalência de DIF, nem tampouco que esses comportamentos diferenciais tomem um sentido único.

4. Quanto à área de aplicação dos itens:

a. Há uma tendência de maior ocorrência de DIF no parâmetro $a$ em itens alocados nas áreas de "meio ambiente" e "limites da Ciência 
e da Tecnologia" do que nas demais áreas avaliadas pelo PISA em 2006. No entanto, essa tendência não é definida, ou seja, o DIF observado, ora indica maior discriminação entre os estudantes do Japão ora entre os do Brasil.

b. No que diz respeito à dificuldade (parâmetro $b$ ), os itens se comportam de maneira diferente para estudantes brasileiros e japoneses. Itens em três das áreas avaliadas, "Meio Ambiente", "Saúde" e "Recursos Naturais", tendem a apresentar valores de $d . b$ negativos e, assim, são mais fáceis para os estudantes brasileiros. Nas demais áreas, "Limites da Ciência e da Tecnologia" e "riscos", tendem a apresentar valores de $d . b$ positivos e mostramse, portanto, mais fáceis para os estudantes japoneses que para os brasileiros.

5. Itens que medem habilidades nos contextos Global e Pessoal tendem a concentrar mais DIF no parâmetro de dificuldade que itens relacionados ao contexto Social.

6. Os DIF encontrados na dificuldade e na discriminação dos itens não se mostraram associados ao formato do item, de tal forma que este aspecto não torna um item mais ou menos discriminante, mais fácil ou mais difícil, para os estudantes de nenhum dos dois países. Embora existam itens com DIF, não há indícios suficientes de que o DIF esteja privilegiando um grupo em detrimento do outro, facilitando ou discriminando mais, por exemplo, o desempenho dos estudantes brasileiros ou dos japoneses.

7. Embora os itens sejam elaborados em diferentes idiomas e, posteriormente, traduzidos para o idioma de cada país avaliado, o vocabulário e os termos utilizados não se constituem, a priori, num obstáculo à resolução do item seja para os estudantes japoneses, seja para os estudantes brasileiros.

Os modelos mais tradicionais da TRI pressupõem que os itens apresentem o mesmo funcionamento em diferentes grupos. Uma boa e justa comparação entre resultados de grupos diferentes de estudantes requer, portanto, que os itens que compõem o teste não apresentem comportamento diferencial, pois, do contrário, isso significaria que um grupo em particular estaria sendo privilegiado em detrimento de outro. Frente a este pressuposto, usualmente busca-se produzir 
itens de teste que não apresentem DIF, ainda que esta seja uma tarefa muito difícil quando as populações avaliadas são tão distintas como é o caso de estudantes de diferentes países. Essa tarefa quase impossível de se construir instrumentos de avaliação sem DIF, para grupos muito diferentes, pode ser revertida a favor do avaliador. O DIF pode ajudar a conhecer as diferenças, e esse é o primeiro passo para as ações educacionais que visam superá-las ou, ao menos, minimizá-las.

Nossa terceira e última questão de pesquisa indagava se seria possível, a partir dos dados do PISA e da adoção complementar de uma abordagem qualitativa, identificar diferentes ênfases curriculares e/ou práticas pedagógicas no Ensino de Ciências de Brasil e Japão que contribuam para a compreensão das diferenças de desempenho entre estudantes brasileiros e japoneses. Para respondêla, procuramos complementar as análises de DIF com um estudo qualitativo, que buscou refinar e ampliar o potencial de interpretação dos resultados quantitativos, notadamente pela agregação da percepção dos sujeitos - estudantes, professores e especialistas - ao desenho da pesquisa. Observamos, no Japão e no Brasil, entre os meses de Novembro de 2015 e Outubro de 2016, um total de 147 aulas de Ciências dos três últimos anos do Ensino Fundamental (64 horas-aula no Japão e 83 no Brasil) em três escolas no Brasil e três no Japão. Foram acompanhados 16 professores no total, oito em cada país. As conclusões a que chegamos, após os resultados da pesquisa de campo, podem ser assim expressas:

1. No Japão, a maioria dos professores observados é do sexo masculino (cinco de oito) e, no Brasil, a maioria é do sexo feminino (seis de oito). Os professores brasileiros participantes da pesquisa são mais jovens e, no geral, têm maior grau de escolaridade do que os japoneses. Todos os professores brasileiros são formados em Biologia, enquanto no Japão há professores formados também em Química, Física e Geociências. A formação continuada dos professores brasileiros enfatiza aquelas iniciativas diretamente relacionadas à pesquisa e à extensão. Normalmente, essas atividades estão também relacionadas com a frequência a cursos de pós-graduação. A formação continuada dos professores japoneses se constitui de iniciativas relacionadas à interação com os pares, ou seja, aquelas que só podem ser implementadas quando a formação é realizada em e no serviço. No Japão, o trabalho colaborativo e os grupos de pesquisa de professores, como partes constituintes do 
desenvolvimento profissional, têm sido aspectos considerados bemsucedidos na formação de professores.

2. O tempo de aula é um indicador chave das oportunidades de aprendizagem de Ciências oferecidas aos estudantes. Tanto no Brasil quanto no Japão, nas escolas observadas, a hora-aula é composta por 50 minutos. Dado que observamos 64 horas-aula no Japão e 83 horas-aula no Brasil, nosso Tempo Oficial (TO) total foi de exatos 7350 minutos. Aproximadamente uma hora e meia de aula dentre as 64 observadas no Japão foi destinada a questões outras que não o ensino e a aprendizagem de Ciências. Isso não representa sequer $2 \%$ do total das horas observadas. No Brasil, das horasaula observadas (83) chega-se a perder pelo menos 15 horas-aula, quase que $20 \%$ do tempo total. Assim, as escolas brasileiras que observamos desperdiçam 10 vezes mais tempo de aula do que as escolas japonesas.

3. No Brasil, é possível observar a ênfase dos PCN nas Ciências Naturais e Biológicas. Via de regra, no Brasil, apenas no $9^{\circ}$ ano os estudantes são expostos a conteúdos escolares relacionados aos sistemas físicos, químicos e tecnológicos. Nossas observações e o conteúdo da maioria expressiva dos livros didáticos brasileiros apoiam esta conclusão. No Japão, apesar de haver uma maior prescrição de conteúdos relacionados às Ciências Naturais e Biológicas em cada ano escolar, foi possível observar uma distribuição mais equilibrada dos conteúdos. Nesse país, a cada ano, os estudantes recebem conteúdos relacionados à Química, à Física e à Biologia. Desde muito cedo, os estudantes japoneses têm contato com temas relacionados ao avanço da Ciência e da Tecnologia e à sua importância na vida de todos.

1. Os estudantes brasileiros, apesar de não apresentarem um desempenho satisfatório em Ciências no PISA, admitem serem expostos mais frequentemente às abordagens construtivistas que envolvem "investigação", "interação", "aplicação" e "experimentação" que os estudantes japoneses. A literatura sobre o tema sinaliza que essas abordagens do Ensino de Ciências são extremamente importantes para o desenvolvimento das habilidades no âmbito do Letramento Científico. No entanto, apesar de o Japão apresentar um dos melhores resultados em Ciências no PISA, quando comparado a outros países da OCDE, os 
estudantes japoneses raramente admitem uma utilização frequente dessas estratégias pedagógicas por parte de seus professores. Eles afirmam que, de modo geral, tais atividades ocorrem em pouco mais de $15 \%$ das aulas. Já os estudantes brasileiros responderam que a experimentação, atividade com menor frequência, ocorre, pelo menos, em $30 \%$ das aulas.

2. As perspectivas dos professores brasileiros e japoneses se assemelham em relação à sua percepção de as atividades mais frequentemente realizadas em suas aulas serem as de "interação" e "aplicação". De acordo com os professores participantes estas atividades são implementadas em mais de 50\% das aulas. Já as atividades de "experimentação", reconhecidas por seu poder de atrair o interesse dos estudantes pela Ciência, são as menos utilizadas pelos professores brasileiros e a mais utilizada pelos professores japoneses. Por último, os professores japoneses e brasileiros tendem a se aproximar quanto à menor frequência com que ocorrem as atividades investigativas nas suas aulas.

3. Atividades relacionadas à "experimentação" foram mais frequentemente observadas nas aulas das escolas japonesas, nas quais atividades como uso do laboratório e realização de experimentos ocorreram em cerca de $40 \%$ das aulas. Os professores japoneses assumiram fazer uso dessa prática em cerca de $70 \%$ das suas aulas. No Brasil, observamos tais atividades em apenas $16 \%$ das aulas e os professores brasileiros afirmaram ser esta a prática a que menos recorrem nas suas aulas (pouco mais de 10\% das aulas). A interação dos estudantes com o processo de ensino e aprendizagem de Ciências foi observada por nós e reconhecida pelos professores em mais de $50 \%$ do total de aulas, tanto no Brasil quanto no Japão. No entanto, se os estudantes brasileiros identificam essas atividades em mais de $50 \%$ das aulas, os japoneses as reconhecem como fazendo parte de pouco mais de $15 \%$ das aulas. Durante a pesquisa em sala de aula, esta foi a atividade mais frequentemente observada no Brasil e no Japão. As atividades relacionadas à aplicabilidade da Ciência, sobretudo, à aplicação de conhecimentos científicos a problemas quotidianos e a aplicação de um conceito científico a vários fenômenos, bem como a importância da Ciência na vida de todos e da sociedade, foram bem mais frequentemente observadas no Brasil (quase 60\% das aulas) que no Japão 
(menos de 30\% das aulas). Atividades investigativas, menos frequentes na percepção de estudantes e professores, foram também as menos observadas nas aulas no Brasil e no Japão. Ocorreram em apenas 1\% das aulas observadas no Brasil e em 6\% das aulas observadas no Japão.

4. Para ambas as gerentes do PISA, no Brasil e no Japão, o objetivo da avaliação é subsidiar política pública de melhoria da qualidade do ensino. No entanto, diferente do que acontece no Brasil, onde ainda muito se questiona sobre o que é feito, efetivamente, com o diagnóstico realizado pelas avaliações, no Japão, os resultados da avaliação são diretamente empregados na tomada de decisões para melhorar a qualidade da educação. Diante dos resultados do primeiro ciclo de edições do PISA (2000, 2003 e 2006), por exemplo, três reformas educacionais e curriculares foram realizadas no Japão. No Brasil, a gestora da avaliação discute que o país não teria, nem mesmo com a experiência de participação nas seis edições do PISA, dado muitos passos na direção de, por exemplo, o melhoramento dos materiais didáticos, do livro didático, da formação de professores, do currículo etc.

5. Na perspectiva da gerente do PISA no Japão, o bom desempenho do país pode ser explicado pelas reformas realizadas no ensino daquele país a partir dos resultados dessa avaliação internacional. Em breves palavras, o currículo foi revisto, os professores receberam uma publicação com instruções sobre o PISA e o sitema nacional de avaliação foi retomado com itens que, assim como o PISA, avaliam habilidades. O que a OCDE e a gerente do PISA no Japão, Akiko Ono, apontaram como as razões do alto desempenho dos estudantes japoneses, aparecem na fala da gerente do PISA no Brasil como as principais dificuldades e problemas encontrados pelos estudantes brasileiros no Programa e que podem ser fatores explicativos do baixo desempenho dos nossos estudantes e escolas. São eles: a qualidade técnica do teste, a não familiaridade e a falta de preparo dos estudantes com e para o teste, falta de infraestrutura, má formação de professores e falta de uso das evidências oriundas das avaliações externas.

6. O Japão está no topo do ranking internacional desde a origem das avaliações educacionais e há características do sistema educacional desse país das quais é possível retirar algumas lições. No desenvolvimento da 
pesquisa, observamos algumas dessas características e verificamos como, de fato, elas têm relação como alto desempenho do Japão nas avaliações externas em larga escala, como é o caso do PISA. São elas: a) a política de promoção dos estudantes; considerando que $100 \%$ dos estudantes estão em fase e que o Japão é um dos poucos países do mundo onde não há reprovação; b) o currículo nacional comum revisado a cada dez anos; c) a formação continuada de professores feita em serviço; d) a utilização do tempo reservado à ação pedagógica; e e) o uso dos resultados da avaliação para monitorar e diagnosticar o desempenho do sistema educacional.

Diante dos resultados e conclusões a que este estudo nos permitiu chegar, acreditamos que o desenvolvimento social, científico e tecnológico do Brasil passa também, mas não exclusivamente, por uma reformulação profunda da estrutura educacional. A necessidade de melhorar o ensino básico no Brasil e, em particular, o Ensino de Ciências, deve ser encarada com mais veemência, afinal, o ensino adequado de Ciências estimula o raciocínio lógico e a curiosidade, ajuda a formar cidadãos mais aptos a enfrentar os desafios da sociedade contemporânea e fortalece a democracia, dando à população, em geral, melhores condições para participar dos debates cada vez mais comuns sobre temas científicos que afetam nosso cotidiano.

Num momento em que a cidadania enfrenta novos desafios, busca novos espaços de atuação e abre novas áreas por meio das grandes transformações pelas quais passa o mundo contemporâneo, é importante ter o conhecimento de realidades que, no passado, significaram e, no presente, ainda significam passos relevantes no sentido da garantia de um futuro melhor para todos (CURY, 2002). O direito à educação escolar e uma educação de qualidade são os passos que não perderam e nem perderão tão cedo sua atualidade. 


\section{Referências bibliográficas}

ABADZI, H. Absenteeism and Beyond: Instructional Time Loss and Consequences. Policy Research Working Paper 4376. The World Bank Independent Evaluation Group Sector, Thematic, and Global Evaluation Division, 2007.

ABADZI, H. Instructional Time Loss in Developing Countries: Concepts, Measurement, and Implications. The World Bank Research Observer, v.24, n.2, p. 267-90, 2009.

ABELL, S.; LEDERMAN, N. Handbook of research on science education. Mahwah: Lawrence Erlbaum Associates, 2007.

ACADEMIA BRASILEIRA DE CIÊNCIAS [ABC]. O ensino de ciências e a educação básica: propostas para superar a crise. Rio de Janeiro, 2007.

AEBLI, H. Zwölf Grundformen des Lehrens (10 ed.). Stuttgart: Klett-Cotta, 1998.

AGIN, M. L. Education for scientific literacy: A conceptual frame of reference and some applications. Science Education, n.58, v.3, p. 403-415, 1974.

AGUIAR, G. S. Estudo comparativo entre Brasil e Portugal, sobre diferenças nas ênfases curriculares de Matemática, a partir da análise do Funcionamento Diferencial do Item (DIF) do PISA 2003. 2008. 246f. Tese (Doutorado em Educação). Pontifícia Universidade Católica do Rio de Janeiro, Rio de Janeiro, 2008.

AIKENHEAD, G. The humanistic and cultural aspects of science \& technology education. In: XI IOSTE (international organization for science and technology education) symposium: science and technology education for a diverse world. Anais... Lublin: IOSTE, 2004.

ALVES, F.; ORTIGÃO, M. I. R.; FRANCO, C. Origem social e risco de repetência: interação entre raça-capital econômico. Cadernos de Pesquisa. São Paulo, v.37, n.130, p. 161-180, jan./abr., 2007.

ALVES, L.; BATISTA, A. A. G.; ÉRNICA, M. Processos ocultos de seleção e evitação de estudantes em escolas públicas. Informe de Pesquisa n. 6. São Paulo: CENPEC, 2012.

AMERICAN ASSOCIATION FOR THE ADVANCEMENT OF SCIENCE [AAAS]. Project 2061. Science for all Americans. Washington: AAAS, 1989. AMERICAN ASSOCIATION FOR THE ADVANCEMENT OF SCIENCE [AAAS]. Science for All Americans. New York: Oxford University Press. 1990. AMERICAN ASSOCIATION FOR THE ADVANCEMENT OF SCIENCE [AAAS]. Vision and Change: A Call to Action. Washington: AAAS, 2010.

ANASTASI, A. Psychological testing. New York: MacMillan. 1988.

ANDRIOLA, W. B. Descrição dos principais métodos para detectar o funcionamento diferencial dos itens (DIF). Psicologia: Reflexão e Crítica, Rio Grande do Sul, v. 14, n. 3, p. 643-652, 2001.

ANGOFF, W. H. Perspectives on differential item functioning. In: P. W. HOLLAND, P. W.; WAINER, H. (Orgs.), Differential item functioning. New Jersey: Lawrence Erlbaum. 1993. P. 3-24.

ATKIN, J. M.; HELMS, J. Getting serious about priorities in science education. Studies in Science Education, v.21, p.1-20, 1993.

BABBIE, E. Métodos de Pesquisas de Survey. Belo Horizonte: UFMG, 1999. 
BARAM-TSABARI, A.; SETHI, R.; BRY, L.; YARDEN, A. Asking scientists: A decade of questions analyzed by age, gender, and country. Science Education, v. 93, n. 1, p. 131-160, jan. 2009.

BARROSO, M. F.; FRANCO, C. Avaliações Educacionais: o PISA e o Ensino de Ciências. XI Encontro de Pesquisa em Ensino de Física. Curitiba, 2008. Disponível em: http://www.if.ufrj.br/ marta/artigosetal/2008-epef11-PISA.pdf. Acesso em 27 de Julho de 2014.

BASTOS, C. C. Metodologias ativas. 2006. Disponível em: <http://educacaoemedicina.blogspot.com.br/2006/02/metodologias-ativas.html>. Acesso em: 14 fev. 2010.

BAUER, A. Usos dos resultados das avaliações de sistemas educacionais: iniciativas em curso em alguns países da América. R. bras. Est. pedag., Brasília, v. 91, n. 228, p. 315-344, maio/ago. 2010.

BAUMERT, J.; KÖLLER, O. Unterrichtsgestaltung, verständnisvolles Lernen und multiple Zielerreichung im Mathematik- und Physikunterricht der gymnasialen Oberstufe. In: J. BAUMERT, W. BOS \& R. LEHMANN (Eds.), TIMSS/III. Dritte Internationale Mathematik- und Naturwissenschaftsstudie. Mathematisch und naturwissenschaftliche Bildung am Ende der Schullaufbahn. Band 2(p. 271-315). Opladen: Leske + Budrich. 2000.

BENNETT, J.; GRÄSEL, C.; PARCHMANN, I.; WADDINGTON, D. Contextbased and Conventional Approaches to Teaching Chemistry: Comparing teachers' views. International Journal of Science Education, v.27, n.13, p.1521-1547, 2005.

BERBEL, N. A. N. As Metodologias Ativas e a Promoção da Autonomia de Estudantes. Semina: Ciências Sociais e Humanas, Londrina, v. 32, n. 1, p. 2540, jan./jun., 2011.

BERBEROGLU, G. Differential item functioning (DIF) analysis of computation, word problem and geometry questions across gender and SES groups. Studies in Educational Evaluation, v.21, p.439-456, 1995.

BERLINER, D.C. The Nature of Time in Schools: Theoretical Concepts, Practitioner Perceptions. New York: Teachers College Press; Rosenshine, 1990. BERLINER, D.C. Time to learn. Research Points (AERA), v.5, n.2, p.1-4, 2007. BIRNBAUM, A. Some Latent Traits Models and Their Use in Inferring an Examinee's Ability. In: F.M. LORD AND M.R. NOVICK (eds). Statistical Theories of Mental Test Scores. Addison-Wesley: Reading, MA, 1968.

BLANCHARD, M. R. Is inquiry possible in light of accountability? A quantitative comparison of the relative effectiveness of guided inquiry and verification laboratory instruction. Science Education, v.94, n.4, p. 577-616, 2010.

BLANK, R. K. What is the impact of decline in science instructional time in elementary school? Paper prepared for the Noyce Foundation, 2012. Disponível em: http://www.csss-science.org/downloads/NAEPElemScienceData.pdf. Acesso em: 15/11/2016.

BOCK, R. D. Multivariate Statistical Methods in Behavioral Research. NewYork: McGraw-Hill Book Co. 1975.

BRANDAO, Z.; BAETA, A. M. B.; ROCHA, A. D. Evasão e repetência no Brasil: a escola em questão. Rio de Janeiro: Achiamé, 1983.

BRANSFORD, J. D.; BROWN, A. L.; COCKING, R. R. How people learn: Brain, mind, experience, and school. Washington, DC: National Academy Press, 2000. 
BRASIL. INSTITUTO NACIONAL DE ESTATÍSTICAS EDUCACIONAIS. Brasil no PISA 2015: análises e reflexões sobre o desempenho dos estudantes brasileiros. Brasília, 2016.

BRASIL. INSTITUTO NACIONAL DE ESTATÍSTICAS EDUCACIONAIS. Resultados nacionais - PISA 2000: Programa Internacional de Avaliação de Estudantes (PISA). Brasília, 2001.

BRASIL. INSTITUTO NACIONAL DE ESTATÍSTICAS EDUCACIONAIS. Resultados nacionais - PISA 2006: Programa Internacional de Avaliação de Estudantes (PISA). Brasília, 2008.

BRASIL. MINISTÉRIO DA EDUCAÇÃO. Orientações curriculares para o ensino médio: ciências da natureza, matemática e suas tecnologias. Brasília, 2006.

BRASIL. MINISTÉRIO DA EDUCAÇÃO. PCN+ ensino médio: orientações educacionais complementares aos Parâmetros Curriculares Nacionais: ciências da natureza, matemática e suas tecnologias. Brasília, 2002.

BRASIL. MINISTÉRIO DA EDUCAÇÃ̃O. Parâmetros Curriculares Nacionais: Ciências: $5^{\mathrm{a}}$ a $8^{\mathrm{a}}$ séries. Brasília, 1998.

BRUEL, A. Distribuição de oportunidades educacionais: o programa de escolha da escola pela família na rede municipal de ensino do Rio de Janeiro. Tese (Doutorado em Educação) -Universidade Federal do Rio de Janeiro, Rio de Janeiro, 2014.

BRUNS, B.; JAVIER, L. Great Teachers: How to Raise Teacher Quality and Student Learning in Latin America and the Caribbean. Overview booklet. Washington, D.C.: Banco Mundial. 2014.

BYBEE, R. W. Achieving Scientific Literacy: From Purposes to Practices, Heinemann, Portsmouth, 1997a.

BYBEE, R. W. Toward an understanding of scientific literacy. In: Graber W. \& Bolte C. Scientific Literacy. Kiel, Germany, Institute for Science Education, 1997b. P.37-68.

BYBEE, R. W. Reforming Science Education: Social Perspectives and Personal Reflections. New York: Teachers College Press. 1993.

BZUNECK, J. A.; GUIMARÃES, S. E. R. A promoção da autonomia como estratégia motivacional na escola: uma análise teórica e empírica. In: BORUCHOVITCH, E.; BZUNECK, J. A.; GUIMARÃES, S. E. R.(Org.). Motivação para aprender: aplicações no contexto educativo. Petrópolis: Vozes, 2010. P. 43-70

CARNOY, M.; COM GOVE, A. E ; MARSHALL, J. A vantagem acadêmica de Cuba: por que seus estudantes vão melhor na escola. São Paulo: Ediouro, 2009.

CARROLL, J. A Model of School Learning. Teachers College Record, v.64, p.723-33, 1963.

CARVALHO, J. Segregação escolar e burocracia educacional: uma análise da composição do alunado nas escolas municipais do Rio de Janeiro. Dissertação (Mestrado em Educação) -Universidade Federal do Rio de Janeiro, Rio de Janeiro, 2014.

CHANG, C.Y. \& BARUFALDI, J.P. The use of a problem-solving-based instructional model in initiating change in students' achievement and alternative frameworks. International Journal of Science Education, v.21, n.4, p.373-388, 1999. 
CHASSELS, C. ; MELVILLE, W. Collaborative, reflective, and interactive Japanese Lesson Study in an initial teacher education program: benefits and challenges. Canadian Journal of Education, v. 32, n.4, p.734-763, 2009.

CHASSOT, A. Alfabetização científica: questões e desafios para a educação. Ijuí: Editora UNIJUÍ, 2000.

CHASSOT, A. Alfabetização científica: uma possibilidade para a inclusão social.

Revista Brasileira de Educação, ANPEd, n. 26, p. 89-100, 2003.

ÇIMER, A. Effective teaching in Science: a review of literature. Journal of Turkish Science Education, v.4, n. 1, May, p. 20-44, 2007.

CLAUSER, B. E.; MAZOR, K. M. Using statistical procedures to identify differential item functioning test items. Educational Measurement: Issues and Practice, v.17, p.31-44, 1998.

COLE, N.S. History and development of DIF. In: HOLLAND, P.W.; WAINER, H. (eds). Differential Item Functioning. Hilldsdale, NJ: Lawrence Erlbaum associates, Publishers, 1993.

COLLINS, A., BROWN, J. S., \& NEWMAN, S. E. Cognitive apprenticeship: Teaching the craft of reading, writing, and mathematics. In: L. B. RESNICK (Ed.), Knowing, learning and instruction. Essays in honor of Robert Glaser (pp. 453-494). Hillsdale, N.J.: Erlbaum, 1989.

CONFEDERACION DE SOCIEDADES CIENTIFICAS DE ESPAÑA. Informe ENCIENDE. Enseñanza de las Ciencias en la Didáctica Escolar para edades tempranas en España. Madrid. 2011.

CORREA, E.V.; BONAMINO, A.; SOARES, T.M. Evidências do efeito da repetência nos primeiros anos escolares. Est. Aval. Educ., São Paulo, v. 25, n. 59, p. 242-269, set./dez. 2014.

COSTA, M.; KOSLINSKI, M. Escolha, estratégia e competição por escolas públicas. Pro-Posições, Campinas, v. 23, n. 2, p. 195-213, 2012.

COSTA-RIBEIRO, S. A Pedagogia da repetência. Estudos Avançados, São Paulo, v.5, n.12, p. 7-21, maio/ago.1991.

CRAHAY, M. Poderá a Escola ser Justa e Eficaz? Da igualdade das Oportunidades à Igualdade dos Conhecimentos. Instituto Piaget, 2002.

CURY, C. R. J. Direito à educação: direito à igualdade, direito à diferença. São Paulo: Cadernos de Pesquisa, n. 116, p. 245-262, Jul. 2002.

DANIELSON, C. Enhancing Professional Practice: A Framework for Teaching. Alexandria, VA: Association for Supervision and Curriculum Development, 2007.

DARLING-HAMMOND, CHUNG WEI \& ANDREE. How High-Achieving Countries Develop Great Teachers. Stanford Center for Opportunity Policy in Education, 2010. Disponível em: https://edpolicy.stanford.edu/sites/default/files/publications/how-high-achievingcountries-develop-great-teachers.pdf. Acesso em 15/01/2017.

DARLING-HAMMOND, L.; WISE, A. E.; KLEIN, S. P. A license to teach: raising standards for teaching. San Francisco, CA: Jossey-Bass, 1999.

DEBOER G.E. Scientific literacy: another look at its historical and contemporary meanings and its relationship to science education reform. J Res Sci Teach: 37: 582-601. 2000.

DEBOER G.E. A history of ideas in science education. New York: Teachers College Press, 1991. 
DECHARMS, R. Motivation enhancement in educational settings. In: AMES, C., AMES, R. (eds.) Research on Motivation in Education, Student Motivation. New York: Academic Press, v.1, 1984. P.275-310.

DORANS, N. J. ; HOLLAND, P. W. DIF detection and description: MantelHaenszel and Standardization. In: P. W. HOLLAND \& H. WAINER (eds.). Differential item functioning. New Jersey: Lawrence Erlbaum. 1993. P. 35-66. DUFOUR, R., ; EAKER, R. Professional Learning Communities at Work: Best Practices for Enhancing Student Achievement. Bloomington, 1998. DURANT, J. R. What is scientific literacy? In J. R. DURANT \& J. GREGORY (Eds.) Science and culture in Europe. London: Science Museum, 1993.

ERMELING, B. A. ; GRAFF-ERMELING, G. Teaching between desks. Educational Leadership, v.72, n.2, p.55-60. Alexandria, VA: ASCD, 2014.

EUROPEAN COMMISSION [EU]. Science Education Now: A Renewed Pedagogy for the Future of Europe. Brussels: European Commission Directorate-General for Research, 2007.

EUROPEAN COMMISSION [EU]. Europe Needs More Scientists! European Commission, Directorate-General for Research, High Level Group on Human Resources for Science and Technology in Europe, Brussels, 2004.

FARBMAN, D. The Case for Improving and Expanding Time in School: A Review of Key Research and Practice. Boston, Mass.: National Center on Time and Learning, 2012.

FENSHAM, P.J. Increasing the relevance of science and technology education for all students in the 21st Century. Science Education International, v. 15, n. 1, p. 7-26, 2004.

FENSHAM, P.J. Time to change drivers for Scientific literacy. Canadian Journal of Science, Mathematics, and Technology Education, v.2, p.9-24, 2000.

FENSHAM, P.J. Science for all: A reflective essay. Journal of Curriculum Studies, 17(4), 415-435, 1985.

FERNANDEZ, C. ; YOSHIDA, M. Lesson study. New Jersey: Lawrence, 2004. FIELDING, N.; SCHREIER, M. Introduction: On the Compatibility between Qualitative and Quantitative Research Methods. Forum Qualitative Sozialforschung / Forum: Qualitative Social Research, v.2, n.1, p. 1-21, 2001. FITZPATRIK, F.L. Policies for Science education. The Saturday Review, v.19, November, p.74-81, 1960.

FLEISCHMAN, S. Before choosing, ask three questions. Better Evidence-based Education, v.4, n.2, p.20-21, 2012.

FLICK, U. Métodos Qualitativos na Investigação Científica. (2a ed.). São Paulo: Monitor, 2005a.

FLICK, U. Triangulation in Qualitative Research. In: FLICK, U., KARDORFF, E.; STEINKE, A. Companion to Qualitative Research. London: Sage, 2005b. P. 178-183.

FLICK, U. Qualitative Research in Sociology in Germany and the US - State of the Art, Differences and Developments. Forum Qualitative Sozialforschung / Forum: Qualitative Social Research, v.6, n.3, p.1-21, 2005c.

FORQUIN, J. C. As abordagens sociológicas do currículo: orientações teóricas e perspectivas de pesquisa. Educação e Realidade. Porto Alegre, v.21, n.1, p. 187198, 1995.

FORQUIN, J. C. Saberes escolares, imperativos didáticos e dinâmicas sociais. Teoria \& Educação. Porto Alegre, n.5, p. 28-49, 1992. 
FRACALANZA, H. O que sabemos sobre os livros didaticos para o ensino de ciencias no Brasil. 1992. 301f. Tese (Doutorado) - Universidade Estadual de Campinas, Faculdade de Educação, Campinas, SP.

FRACALANZA, H.; MEGID NETO, J. O Livro Didático de Ciências no Brasil. Campinas: Komedi, 2006.

FRANCO, C. Eficácia escolar em Brasil: investigando prácticas y políticas escolares moderadoras de desigualdades educacionales. In: CUETO, S. Educación y brechas de equidad em América Latina. Santiago: Fondo de Investigaciones Educativas / PREAL, 2007. Tomo I, p. 223-249.

FREITAS, M.A.T. A Escolaridade média no ensino primário brasileiro. Revista Brasileira de Estatística, Rio de Janeiro, v.8, n.30-31, p. 295-474, 1947.

FURTAK, E.M. Experimental and quasi-experimental studies of inquiry-based science teaching: a meta-analysis. Review of Educational Research, v. 82, n.3, p. 300-329, 2012.

GAMERMAN, D.; LOPES, H. Markov Chain Monte Carlo: Stochastic Simulation for Bayesian Inference. New York: Chapman \& Hall / CRC, 2006.

GAMERMAN, D.; SOARES, T.M.; GONÇALVES, F.B. Bayesian analysis in item response theory applied to a large-scale educational assessment. In: O'HAGAN, A.; WEST, M. The Oxford handbook of applied Bayesian analysis. New York: Oxford University Press, p.624-652, 2010.

GEORGE, R. \& KAPLAN, D. A structural model of parent and teacher influences on science attitudes of eighth graders: Evidence from NELS: 88. Science Education, v.82, n.1, p.93-109, 1998.

GETTINGER, M.; SEIBERT, J. Best practices in increasing academic learning time. Best Practices in School Psychology, v.IV, n. 1, p. 773-787, 2002.

GIERL, M. J., BISANZ, J., BISANZ, G., \& BOUGHTON, K. Identifying content and cognitive skills that produce gender differences in mathematics: A demonstration of the DIF analysis framework. Journal of Educational Measurement, v.40, p.281-306, 2003.

GORARD, S.; FITZ, J.; TAYLOR, C. School choice impacts: What do we know? Educational Researcher, v. 30, n. 7, p. 18-23, 2001.

GOUW, A. M. S. Os interesses e posturas de jovens estudantes frente às ciências: uma avaliação em âmbito nacional. 2013. 242 p. Tese (Doutorado em Educação) - Faculdade de Educação, Universidade de São Paulo, São Paulo, 2013.

GOUW, A. M. S.; BIZZO, N. M. V. A percepção dos jovens brasileiros sobre suas aulas de Ciência. Educar em Revista, Curitiba, Brasil, n. 60, p. 277-292, abr./jun, 2016.

GOUW, A. M. S.; MOTA, H. S.; BIZZO, N. O currículo de Ciências e o interesse dos estudantes brasileiros: uma aproximação necessária. Cadernos Cenpec. São Paulo, v.3, n.2, p.7-34, jun. 2013.

GRÄBER, W.; C. BOLTE (eds.). Scientific Literacy: An International Symposium. Institute for Science education at the University of Kiel, Kiel, 1997.

GRAUBARD, S. R. Nothing to fear, much to do. Daedalus, v.112, n.2, p.231248, 1983.

GUIMARÃES, S. E. R. Avaliação do estilo motivacional do professor: adaptação e validação de um instrumento. 2003. Tese (Doutorado em Educação) - Programa de Pós-Graduação em Educação, Universidade Estadual de Campinas, Campinas. 
GUSKEY, T.; HUBERMAN, M. (Eds.). Professional Development In Education: New Paradigms and Practices. NY: Teachers College, Columbia University, 1995.

GUSKEY, T.; YOON, K. What works in Professional Development? The Leading Edge/Professional Learning. Phi Delta Kappan, v.90, n.7, p.495-500, 2009.

HAMBLETON, R. K.; SWAMINATHAN, H.; ROGERS, H.J. Fundamentals of item response theory. Newburry Parks: Sage Publications, 1991.

HANUSHEK, E. Teacher quality. In I, Lance \& E. Williams. (Ed). Teacher Quality. Hoover Press, 2002.

HANUSHEK, E.; WOESSMANN, L. Education and Economic Growth. In: D. BREWER; P. MCEWAN. Economics of Education. Amsterdam: Elsevier, 2010. P.60-67.

HARLEN, W. Effective Teaching of Science. Edinburgh: The Scottish Council for Research in Education (SCRE), 1999.

HARRISON, D. Meta-analysis of selected studies of staff development. Tese de doutoramento, University of Florida, 1980.

HATTIE, J. Visible Learning for Teachers: Maximizing Impact on Learning. London and New York: Routledge, 2012.

HATTIE, J. Visible Learning. A synthesis of over 800 meta-analyses relating to achievement. London and New York: Routledge, 2009.

HATTIE, J. Teachers Make a Difference: What is the Research Evidence? 2003.

Disponível

em:

http://research.acer.edu.au/cgi/viewcontent.cgi?article=1003\&context

=research_conference_2003. Acesso em 30/11/2016.

HATTIE, J.; TIMPERLEY, H. The Power of Feedback. Review of Educational Research, v.77, n.1, p.81-112, 2007.

HOFSTEIN, A.; LUNETTA, V. N. The laboratory in science education: Foundations for the twenty-first century. Science Education, v.88, n.1, p.28-54, 2004.

HOLLAND, P. W.; THAYER, D. T. Differential item performance and the Mantel-Haenszel procedure. In: WAINER, H. ; BRAUN, H. (Eds.), Test validity. Hillsdale, NJ: Lawrence Erlbaum Associates, 1988.

HORD, S. Professional Learning Communities: Communities of Continuous Inquiry and Improvement. Austin, TX: Southwest Educational Development Laboratory, $1997 . \quad$ Disponível em: http://cms.press.jhu.edu/journals/better_evidence_based_education/online_article _access/archive/BetterWin12\%20US\%20WEB1.pdf. Acesso em: 02/01/2017.

HURD, P. Science literacy: Its meaning for American schools. Educational Leadership, v.16, p.13-16, 1958.

JENKINS, E. W. The student voice and school science education. Studies in Science Education, v. 42, n. 1, p. 49-88, 2006.

JENKINS, E. W. Scientific literacy. In: T. HUSEN \& T. N. POSTLETHWAITE, (Eds.), The international encyclopedia of education (Volume 9, 2nd ed., pp. 5345-5350). Oxford, UK: Pergamon Press, 1994.

JENKINS, E. W. School science education: Towards a reconstruction. Journal of Curriculum Studies, v.24, n.3, p.229-246,1992.

JENKINS, E. W.; NELSON, N. W. Important but not for me: students' attitudes towards secondary school science in England. Research in Science \& Technological Education, v. 23, n. 1, p. 41-57, 2005. 
JOHNSON, P.G. The goals of Science Education. Theory into practice, v.1, n.5, p.239-244, 1962.

JOSLIN, P. Inservice teacher education: a meta-analysis of the research. Tese de doutoramento, University of Minnesota, MN, 1980.

KARWEIT, N. L. Time on Task: A Research Review. Report No. 332. Baltimore, MD: Johns Hopkins University, Center for Social Organization of Schools, 1983. Disponível em: http://www.eric.ed.gov/PDFS/ED228236.pdf. Acesso em 15/11/2016.

KATO, Y. Professional Development: Fostering Integrative Knowledge and Pedagogy of Japanese Language Teachers through e-Portfolio. International Journal for Educational Media and Technology, v.8, n. 1, p. 24-40, 2014.

KIRCHER, P. A.; SWELLERJ; CLARK, R. E. Why minimal Guidance During Instruction does not work: an analysis of the failure of constructivist, discovery, problem-based, experiential, and inquiry-based teaching. Educational Psychologist, v.4, n.2, p.75-86, 2006.

KLEIMAN, A. (Org.). Os significados do letramento. Campinas, SP: Mercados de Letras, 1995.

KLEIN, R. Uma re-análise dos resultados do PISA: problemas de comparabilidade. Ensaio: Avaliação e Políticas Públicas em Educação, v.19, n.73, p.717-768, 2011.

KLINGER, D. A.; DE LUCA, C.; MILLER, T. The evolving culture of largescale assessments in Canadian education. Canadian Journal of Educational Administration and Policy, n. 76, July 3, 2008.

KOBARG, M.; PRENZEL, M.; SEIDEL, T.; WALKER, M.; MCCRAE, B.; CRESSWELL, J.; WITTWER, J. An International Comparison of Science Teaching and Learning. Further results from PISA 2006. Münster / New York / München / Berlin: Waxmann, 2011.

KOSLINSKI, M. Movimentação de estudantes em um sistema educacional: padrões de "tracking", rotulagem e reprodução da estratificação social. Educação em Foco, Juiz de Fora(MG), v. 18, n. 3, p. 83-115, 2014.

KRASILCHIK, M. Reformas e Realidade: o caso do ensino das Ciências. São Paulo em perspectiva, São Paulo,v.14,n. 1, p. 85-93, 2000.

KRASILCHIK, M. O professor e o currículo das Ciências. São Paulo: Pedagógica e Universitária /EDUSP, 1987.

KRASILCHIK, M.; MARANDINO, M. Ensino de Ciências e cidadania. São Paulo: Moderna, 2004.

KUSCH, P. Educating for scientific literacy in physics. School and Society, v.88, April, p.198-201, 1960.

LAUGKSCH, R. C. Scientific Literacy: a conceptual overview. Science Education, v. 84, n. 1, p. 71-94, 2000.

LAW, N. Scientific literacy: charting the terrains of a multifaceted enterprise. Canadian Journal of Science, Mathematics, and Technology Education, v.2, p.151-176, 2002.

LEDERMAN, N.; ABELL, S. (eds). Handbook of research on science education. Volume II. New York: Routledge, 2014.

LEWIS, C. Teachers and teaching in Japan: Professional Mecca or pressure cooker? In Y. Zhao (Ed.), Handbook of Asian Education (pp. 231-246). New York: Routledge, 2011.

LEWIS, C.; TSUCHIDA, I. Planned educational change in Japan: The case of elementary science instruction. Journal of Educational Policy, v.12, n.5, p.313-331, 1997. 
LEWIS, C.; PERRY, R.; MURATA, A. How should research contribute to instructional improvement? The case of lesson study. Educational Researcher, v. 35, n.3, p.3-14, 2006.

LINN, R. L.; DRASGOW, F. Implications of the golden rule settiemernt for test construction. In: HOLLAND, P. W.; WAINER, H. (eds). Differential Item Functioning. Hilldsdale: Lawrence Erlbaum associates, Publishers, 1993.

LOPES, J.; SILVA, H. O Professor Faz a Diferença. Na aprendizagem dos estudantes. Na realização escolar dos estudantes. No sucesso dos estudantes. Lisboa: LIDEL-Edições Técnicas, Lda, 2010.

LORD, F. Applications of Item Response Theory to Practical Testing Problems. Hillsdale, NJ: Lawrence Erlbaum, 1980.

MADAUS, G. F.; KELLAGHAN, T. Curriculum evaluation and assessment. In: P. W. JACKSON (Ed.). Handbook of Research on Curriculum. New York: Maxwell Macmillan International, 1992. P. 119-154

MAIENSCHEIN, J. Scientific literacy. Science, v.281, p.917-917, 1998.

MAMEDE, M.; ZIMMERMANN, E. Letramento Científico e CTS na formação de professores para o Ensino de Ciências. Enseñanza de Las Ciencias, número extra, 2005.

MARTIN, M. O. (eds.). TIMSS 1999: International Science Report. Boston College, Chestnut Hill, MA, 2000.

MARZANO, R. What works in schools: Translating research in action. Alexandria, VA: Association for Supervision and Curriculum Development, 2003. MAYER, V. J. (ed.). Global Science Literacy. Kluwer Academic Publishers, Dordrecht, 2002.

MAYER, V. J.; KUMANO, Y. The Philosophy of Science and global Science literacy. In: MAYER, V. J. (ed.), Global Science Literacy. Kluwer: Academic Publishers, 2002.

MEGID NETO, J.; FRACALANZA, H. O livro didático de ciências: problemas e soluções. Ciência \& Educação, São Paulo, v.9, n.2, p.147-157, 2003.

MEXT. Improvement of Academic Abilities (Courses of Study). Disponível em: http://www.mext.go.jp/english/elsec/1303755.htm. Acesso em 18/08/2016.

MILLAR, R. Towards a science curriculum for public understanding. School Science Review, v. 77, n. 280, p. 7-18, 1996.

MILLAR, R.; LUBBEN, F.; GOTT, R.; DUGGAN, S. Investigating in the school science laboratory: conceptual and procedural knowledge and their influence on performance. Research Papers in Education, v.9, n.2, p.207-248, 1995.

MILLAR R.; OSBORNE J.; NOTT, M. Science education for the future. School Sci. Rev, v.80, p.19-24, 1998.

MOREIRA, M. A.; AXT, R. O livro didático como veículo de ênfases curriculares. Revista de Ensino de Física, v.8, n. 1, p.33-48. 1986a.

MOREIRA, M. A. A questão das ênfases curriculares e a formação do professor de ciências. Cad. Cat. Ens. Fis., Florianópolis, v.3, n.2, p.66-78, ago., 1986b.

MURI, A. F. A formação científica no Brasil e o PISA: um estudo a partir do PISA 2006. Novas Edicões Acadêmicas. Berlin: Schaltungsdienst Lange o.H.G., 2015.

NAGY, P. The three roles of assessment: Gatekeeping, accountability, and instructional diagnosis. Canadian Journal of Education, v.25, p.262-279, 2000.

NATIONAL CENTER ON TIME AND LEARNING [NCTL]. The Relationship Between Time and Learning: A Brief Review of the Theoretical Research. 
2010. Disponível em: http://s384478517.onlinehome.us/sites/default/files/A Brief Review of the Theoretical Framework FINAL.pdf. Acesso em: 15/11/2016.

NATIONAL INSTITUTE FOR EDUCATIONAL RESEARCH [NIER]. Analysis of PISA results and its impact on educational policy in Japan. Korea-OCDE International Conference. March 11, 2016.

NATIONAL INSTITUTE FOR EDUCATIONAL RESEARCH [NIER]. International Comparison of Math and Science Education: TIMSS-R Research Report. Tokyo: Gyosei, 2001.

NATIONAL INSTITUTE FOR EDUCATIONAL RESEARCH [NIER].

National Survey on School Curricula 2001. Tokyo: Gyosei, 2002.

NATIONAL RESEARCH COUNCIL. A Framework for K-12 Science Education: Practices, Crosscutting Concepts, and Core Ideas. Washington, DC.: Committee on a Conceptual Framework for New K-12 Science Education Standards. Board on Science Education, Division of Behavioral and Social Sciences and Education. 2012.

NATIONAL SCIENCE TEACHERS ASSOCIATION [NSTA]. NSTA position statement on school science education for the 70's. The Science Teacher, v.38, p.46-51, 1971.

NATIONAL SCIENCE TEACHERS ASSOCIATION [NSTA]. Theory into Action. Washington: National Science Teachers Association.1964.

O'NEIL, K. A.; MCPEEK, W. M. Item and test characteristics that are associated with differential item functioning. In P. W. HOLLAND \& $\mathrm{H}$. WAINER (Eds.), Differential item functioning (pp. 255-276). Hillsdale, NJ: Lawrence Erlbaum Associates, 1993.

OGAWA, M.; SHIMODE, S. Three distinctive groups among japanese students in terms of their school science preference: from preliminary analysis of japanese data of an international survey 'The Relevance of Science Education' (ROSE). Journal of Science Education in Japan, v.28, n.4, p. 279-291. 2004.

OGURA, Y. Comparison of attitudes toward science between grade 9 and 10 japanese students by using the PISA questions and its implications on science teaching in Japan. Paper presented at the PISA research conference in Kiel, Germany, September 14-16. 2009.

OLIVER, R.; WEHBY, J.; RESCHLY, D. Teacher classroom management practices: effects on disruptive or aggressive student behavior. Campbell Systematic Reviews, n. 4, 2011.

ORGANIZATION FOR ECONOMIC CO-OPERATION AND DEVELOPMENT [OCDE]. PISA 2015 Assessment and Analytical Framework. Paris: OECD Publishing, 2016.

ORGANIZATION FOR ECONOMIC CO-OPERATION AND DEVELOPMENT [OCDE]. Education Policy Outlook 2015: Making Reforms Happen. Paris: OECD Publishing, 2015.

ORGANIZATION FOR ECONOMIC CO-OPERATION AND DEVELOPMENT [OCDE]. PISA 2012 Results: What Makes Schools Successful (Volume IV): Resources, Policies and Practices. Paris: OECD Publishing, 2013a.

ORGANIZATION FOR ECONOMIC CO-OPERATION AND DEVELOPMENT [OCDE]. PISA 2012 Results: Excellence through Equity (Volume II): Giving Every Student the Chance to Succeed. Paris: OECD Publishing, 2013b. 
ORGANIZATION FOR ECONOMIC CO-OPERATION AND DEVELOPMENT [OCDE]. TALIS 2013 Results: An International Perspective on Teaching and Learning. Paris: OECD Publishing, 2013c.

ORGANIZATION FOR ECONOMIC CO-OPERATION AND DEVELOPMENT [OCDE]. PISA 2015 draft science framework. Paris: OECD Publishing, 2013d.

ORGANIZATION FOR ECONOMIC CO-OPERATION AND DEVELOPMENT [OCDE]. PISA 2009 Technical Report, OECD Publishing. Paris: OECD Publishing, 2012.

ORGANIZATION FOR ECONOMIC CO-OPERATION AND DEVELOPMENT [OCDE]. When students repeat grades or are transferred out of school: What does it mean for education systems? Paris: PISA in Focus,2011.

ORGANIZATION FOR ECONOMIC CO-OPERATION AND DEVELOPMENT [OCDE]. Strong Performers and Successful Reformers in Education: Lessons from PISA for the United States. Paris: OECD Publishing, 2010.

ORGANIZATION FOR ECONOMIC CO-OPERATION AND DEVELOPMENT [OCDE]. PISA data analysis manual: SPSS (2nd edition). Paris: OECD Publishing, 2009.

ORGANIZATION FOR ECONOMIC CO-OPERATION AND DEVELOPMENT [OCDE]. Competências em ciências para o mundo de amanhã. Volume 1: Análise. Paris: OECD Publishing, 2007.

ORGANIZATION FOR ECONOMIC CO-OPERATION AND DEVELOPMENT [OCDE]. The PISA 2006 Assessment Framework for Science, Reading and Mathematics. Paris: OECD Publishing, 2006.

ORGANIZATION FOR ECONOMIC CO-OPERATION AND DEVELOPMENT [OCDE]. The PISA 2003 Assessment Framework: Mathematics, Reading, Science and Problem Solving Knowledge and Skills. Paris: OECD Publishing, 2003.

ORGANIZATION FOR ECONOMIC CO-OPERATION AND DEVELOPMENT [OCDE]. Measuring Student Knowledge and Skills: A New Framework for Assessment. Paris: OECD Publishing, 1999.

OSBORNE, J. Message from the president. E-NARST News, v. 49, n. 2, p. 1-2, 2006.

OSBORNE, J.; DILLON, J. Science education in Europe: Critical reflections. A report to the Nuffield Foundation. London: The Nuffield Foundation, 2008. OSBORNE, J.; SIMON, S.; COLLINS, S. Attitudes towards science: a review of the literature and its implications. International Journal of Science Education, v. 25, n. 9, p. 1049-1079, set. 2003.

PASQUALI, L. Psicometria: Teoria dos testes psicológicos. Brasília: Prática. 2000.

PATTO, M. H. A produção do fracasso escolar: histórias de submissão e rebeldia. São Paulo: Casa do Psicólogo, 1996.

PELLA, M. O. The place or function of science for a literate citizenry. Science Education, v.60, n.1, p.97-101, 1976.

PELLA, M. O. Scientific Literacy and the H. S. Curriculum. School Science and Mathematics, v.67, n.4, p.346-356. 1967.

PELLA, M. O.; O'HEARN, G. T.; GALE, C. G. Referents to scientific literacy. Journal of Research in Science Teaching, v.4, p.199-208, 1966. 
PRENZEL, M.; SEIDEL, T.; LEHRKE, M.; RIMMELE, R.; DUIT, R.; EULER, M. Lehr-Lern-Prozesse im Physikunterricht - eine Videostudie. Zeitschrift für Pädagogik, p.139-156, 2002.

RASCH, G. Probabilistic Models for Some Intelligence and Attainment Tests. Institute for Educational Research, Copenhagen, Danish, 1960.

RATCLIFFE, M.; GRACE, M. Science education for citizenship: teaching socio-scientific issues. Maidenhead: Open University Press, 2003.

REEVE, J. Why teachers adopt a controlling motivating style toward students and how they can become more autonomy supportive. Educational Psychologist, Hillsdale, v. 44, n. 3, p. 159-175, 2009.

RICARDO, E. C.; ZYLBERSZTAJN, A. A reforma educacional e as ciências do ensino médio: dificuldades de implementação e conceitos fundamentais. Atas IV Encontro nacional de Pesquisas em Educação em Ciências. Bauru, 2003.

RICHARDSON, J. Lesson study: Japanese method benefits all teachers. 2000. Disponível em: http://www.nsdc.org/news/results/ res12-00rich.cfm. Acesso: 14/01/2017.

ROBERTS, D. A. Scientific Literacy/Science Literacy. In: ABELL, S.; LEDERMAN, N. Handbook of research on science education. Mahwah: Lawrence Erlbaum Associates, 2007.

ROBERTS, D. A. Junior high school science transformed: analyzing a science curriculum policy change. International Journal of Science Education, v.17, n.4, p.493-504, 1995.

ROBERTS, D. A. Scientific literacy. Towards a balance for setting goals for school science programs. Ottawa: Minister of Supply and Services, 1983.

ROBERTS, D. A. Developing the concept of curriculum emphases in science education. Sci. Educ., v.66, n.2, p. 243-260, 1982.

ROBERTS, D. A.; BYBEE, R. W. Scientific Literacy, Science Literacy and Science Education. In: LEDERMAN, N.; ABELL, S. (eds). Handbook of research on science education. Volume II. New York: Routledge, 2014.

ROGERS, H. J.; SWAMINATHAN, H. A comparison of logistic regression and Mantel-Haenszel procedures for detecting differential item functioning. Applied Psychological Measurement, v.17, p.105-116, 1993.

ROGERS, J.; MIRRA, N.; SELTZER, M.; JUN, J. It's About Time: Learning Time and Educational Opportunity in California High Schools. Los Angeles: UCLA IDEA, 2014.

ROTH, K. J.; DRUKER, S. L.; GARNIER, H. E.; LEMMENS, M.; CHEN, C.; KAWANAKA, T. Teaching science in five countries. Results from the TIMSS 1999 Video Study. Statistical analysis report. Washington: US Department of Education, 2006.

RUTHERFORD, J. F.; AHLGREN, A. Science for All Americans. New York: Oxford University Press, Inc. 1989.

SANTOS, F. M. T.; GRECA, I. M. (orgs). A pesquisa em ensino de Ciências no Brasil e suas metodologias. Ijuí: Ed. Ijuí, 2006.

SANTOS, W. L. P. Educação científica na perspectiva de letramento como prática social: funções, princípios e desafios. Revista Brasileira de Educação, v.12, n.36, p.474-492, 2007.

SCHEERENS, J.; SEIDEL, T.; WITZIERS, B.; HENDRIKS, M.; DOORNEKAMP, G. Positioning the supervision frameworks for primary and secondary education of the Dutch Educational Inspectorate in current educational discourse and validating core indicators against the knowledge 
base of educational effectiveness research. Enschede / Kiel: University of Twente / Institute for Science Education (IPN), 2005.

SCHIBECI, R. A. Attitudes to Science: An Update. Studies in Science Education v.11, 1984.

SCHMITT, A. P.; BLEISTEIN, C. A. Factors affecting differential item functioning for black examinees on scholastic aptitude test analogy items (ETS RR-87-23). Princeton, NJ: Educational Testing Service. 1987.

SCHMITT, A. P.; HOLLAND, P. W.; DORANS, N. J. Evaluating hypotheses about differential item functioning. In P. W. HOLLAND \& H. WAINER (Eds.), Differential item functioning (pp. 281-316). Hillsdale, NJ: Lawrence Erlbaum Associates. 1993.

SCHNEIDER, R.; KRAJICK, J.; MARX, R.; SOLOWAY, E. Journal of Research in Science Teaching, v.39, n.5, p.410-422, 2002.

SCHREINER, C.; SJØBERG, S. Science education and youth's identity construction - two incompatible projects? In: CORRIGAN, D.; DILLON, J.; GUNSTONE, R. (Eds.). The Re-emergence of Values in the Science Curriculum. Rotterdam: Sense Publishers, 2007.

SCHREINER, C.; SJØBERG, S. Sowing the seeds of ROSE. Acta Didactica, v.4, p. $120,2004$.

SCHUH MOORE, A.; DESTEFANO, J.; ADELMAN, E. Time Misspent, Opportunities Lost: Use of time in School and Learning. In: HAWKINS, J.; JACOB, W. (eds.). Policy Debates in Comparative, International, and Development Education. London: Palgrove, 2011.

SCHUMER, G. Mathematics education in Japan. Journal of Curriculum Studies, London, v. 31, n. 4, p. 399 - 427, 1999.

SECKER, C. Effects of Inquiry-based teacher Practices on Science Excellence and Equity. The Journal of Educational Research, v.95, n.3, p.151-160, 2002.

SEIDEL, T. Lehr-Lernskripts im Unterricht. Münster: Waxmann, 2003.

SEKRETARIAT DER STÄNDIGEN KONFERENZ DER KULTUSMINISTER DER LÄNDER IN DER BUNDESREPUBLIK DEUTSCHLAND $[\mathrm{KMK}]$.Bildungs standards im Fach Biologie für den Mittleren Schulabschluss (Jahrgangsstufe 10). 2005.

SHAMOS, M. H. The myth of scientific literacy. New Brunswick: Rutgers University Press, 1995.

SHAMOS, M.; HOWES, R. The myth of scientific literacy. Physics Today, v. 49, n. 3, p. 89, 1996.

SILVA, H. S.; LOPES, J. P. O professor faz a diferença no desempenho escolar dos seus estudantes. O que nos diz a investigação educativa. Revista Eletrónica de Educação e Psicologia, n.2, p. 62-81, 2015.

SINGER, S. R.; HILTON, M. L.; SCHWEINGRUBER, H. A. American Lab Report: Investigations in High School Science. Washington: National Academies Press, 2005.

SOARES, M. B. Letramento e alfabetização: as muitas facetas. Revista Brasileira de Educação, Rio de Janeiro, n. 25, p. 5-17, jan. /abr. 2004.

SOARES, M. B. Novas práticas de leitura e escrita: letramento na cibercultura. Educação \& Sociedade, Campinas, SP, v. 23, n. 81, p. 143-160, 2002.

SOARES, M. B. Letramento, um tema em três gêneros. Belo Horizonte: Autêntica, 1998. 
SOARES, T. M. Utilização da Teoria de Resposta ao Item na produção de indicadores socioeconômicos. Pesquisa Operacional, Rio de Janeiro, v. 25, n. 1, p. 83-112, jan./abr. 2005.

SOARES, T. M.; GENOVEZ, S. F. M.; GALVÃO, A. F. Análise do Comportamento Diferencial dos Itens de Geografia: estudo da $4^{\mathrm{a}}$ série avaliada no Proeb/Simave, 2001. Estudos em avaliação educacional, São Paulo, v. 16, n. 32, p. 81-110, jul./dez. 2005.

SOARES, T. M.; GONÇALVES, F.B.; GAMERMAN, D. An integrated Bayesian model for DIF analysis. Journal of Educational and Behavioral Statistics, v. 34, n. 3, p. 348-377, September. 2009.

STEVENSON, H.; STIGLER, J. The Learning Gap. New York: Summit Books, 1992.

STIGLER, J.; HIEBERT, J. The teaching gap: Best ideas from the world's teachers for improving education in the classroom. New York: Free Press, 1999.

STOLARCHUK, E.; FISHER, D. An investigation of teacher-student interpersonal behavior in science classrooms using laptop computers. Journal of Educational Computing Research, v.24, n.1, p.41-55, 2001.

STREET, B. Literacy in theory and practice.Cambridge: Cambridge University Press, 1984.

SWAMINATHAN, H.; ROGERS, H. J. Detecting differential item functioning using logistic regression procedures. Journal of Educational Measurement, v.27, p.361-370, 1990.

TAIWAN MINISTRY OF EDUCATION. Curriculum outlines for "Nature Science and Living Technology". Taipei, Taiwan: Ministry of Education. 1999.

TASHAKKORI, A.; TEDDLIE, C. Mixed methodology: combining qualitative and quantitative approaches. Social Research Methods Series, London, v.46, 1998.

TAYLOR, J.; ROEHRIG, A.; HENSLER, B.; CONNOR, C.; SCHATSCHNEIDER, C. Teacher quality moderators the genetic effects on early reading. Science, v.328, n.5977, p.512-514, 2010.

TESCH, M. Experimentieren im Physikunterricht - Ergebnisse einer Vide ostudie.

Zeitschrift für Didaktik der Naturwissenschaften, v.10, p.51-69, 2004.

THE LEARNING CURVE. Lessons in country perfomance in education. Economist Intelligence Unit. Report. Londres: Pearson, 2012.

THISSEN, D. IRTLRDIF v.2.0.b: Software for the computation of the statistics involved in item response theory Likelihood-Ratio Tests for differential item functioning. 2001.

THISSEN, D.; STEINBERG, L.; WAINER, H. Detection of differential item functioning using the parameters of item response models. In: HOLLAND, P. W.; WAINER, H. (Eds.), Differential item functioning. Hillsdale: Lawrence Erlbaum Associates. 1993.

TIMPERLEY, H.; WILSON, A.; BARRAR, H.; FUNG, I. Teacher Professional Learning and Development: Best Evidence Synthesis Iteration (BES). 2007. Disponível em: http://www.oecd.org/edu/school/48727127.pdf. Acesso em: 03/01/2017.

TOLENTINO NETO, L. C. B. Os interesses e posturas de jovens estudantes frente às ciências: resultados do Projeto Rose aplicado no Brasil. 2008. 172 p. Tese (Doutorado em Educação) - Faculdade de Educação, Universidade de São Paulo, São Paulo, 2008. 
TOMEI, A. Foreword. In: OSBORNE, J.; DILLON, J. (Eds.). Science education in Europe: Critical reflections. A report to the Nuffield Foundation. London: The Nuffield Foundation, 2008.

TRAPHAGEN, K. Strengthening Science Education: The Power of More Time to Deepen Inquiry and Engagement. Washington, DC: National Center on Time and Learning, 2011.

UBRIACO, F. E. C. A. Interpretação de escalas de medida da competência matemática.2009. 123 f. Dissertação (Mestrado em Educação) - Universidade Federal de Minas Gerais, Minas Gerais, 2009.

UNITED NATIONS EDUCATIONAL, SCIENTIFIC AND CULTURAL ORGANISATION [UNESCO]. International Forum on Scientific and Technological Literacy for All. Final Report. Paris, 1993.

VALLE, R. C. A construção e a interpretação das escalas de conhecimento: considerações gerais e uma visão do que vem sendo feito no SARESP. Estudos em avaliação educacional, São Paulo, n. 23, p. 71-92, jan./jun. 2001.

VÁZQUEZ, A.; MANASSERO, M. A. El declive de las actitudes hacia la ciencia de los estudiantes: un indicador inquietante para la educación científica. Rev. Eureka Enseñ. Divul. Cien., v. 5, n. 3, p. 274-292, 2008.

VON GLASERSFELD, E. Cognition, construction of knowledge, and teaching. Synthese, v.80, p.121-140. 1989.

WADE, R. What Makes a Difference in In-service Teacher Education? A MetaAnalysis of Research. Educational Leadership, v.42, n.4, 48-54, 1985.

WANG, W. C.; YEH, Y. L. Effects of anchor item methods on differential item functioning detection with the likelihood ratio test. Applied Psychological Measurement, v.27, p.1-20. 2003.

WATERMAN, A. T. National Science Foundation: A ten-year resume. Science, v.131, n.3410, p.1341-1354, 1960.

WENGER, E. Communities of Practice: Learning as a Social System. The Systems Thinker, v.9, n.5. 1998. Disponível em: http://www.co-i1.com/coil/knowledge-garden/cop/lss.shtml. Acesso em: 30/12/2016.

WIDODO, A. Constructivist oriented lessons. Frankfurt a. M.: Peter Lang, 2004.

ZIMOWSKI, M. F.; MURAKI, E.; MISLEVY, R. J.; BOCK, R. D. BILOG-MG: Multiple Group IRT Analysis and test maintenance for binary items. Chicago: Scientific Software International Inc., 1996.

ZUMBO, B. D. A handbook on the theory and methods of differential item functioning (DIF). Logistic regression modeling as a unitary framework for binary and Likert-type (ordinal) item scores. Ottawa: Directorate of Human Resources Research and Evaluation, Department of National Defense of Canada. 1999. 


\section{9 \\ Anexos}

9.1

Anexo A

\section{Pontifícia Universidade Católica $_{\text {a }}$ DO RIO DE JANEIRO}

Câmara de Ética em Pesquisa da PUC - Rio

PARECER DA COMISSÃO DE ÉTICA EM PESQUISA DA PUC-RIO (2016-33)

B)

A Câmara de Ética em Pesquisa da PUC-Rio foi constituída como uma Câmara específica do Conselho de Ensino e Pesquisa conforme decisão deste órgão colegiado com atribuição de avaliar projetos de pesquisa do ponto de vista de suas implicações éticas.

\section{Identificação:}

Título: Estudo Comparativo entre Brasil e Japão: o Letramento Científico a partir da Análise do Funcionamento Diferencial do Item (DIF) do PISA 2006 (Departamento de Educação da PUC-Rio)

Autora: Andriele Ferreira Muri (Doutoranda do Departamento de Educação da PUC-Rio)

Orientadora: Alicia Maria Catalano de Bonamino (Orientadora do Departamento de Educação da PUC-Rio)

Co-Orientador: Tufi Machado Soares (Professor da UFJF)

Apresentação: Estudo comparativo que visa conhecer o posicionamento e a evolução do desempenho dos estudantes brasileiros em relação aos estudantes japoneses, do segmento final da educação fundamental, na área de Ciências, participantes do Programa Internacional de Avaliação de Alunos - PISA 2006. Bem como identificar itens que apresentam o funcionamento diferencial (Differential Item Functioning - DIF) entre os estudantes dos dois países. Pretende, ainda, identificar aspectos culturais, linguísticos e, sobretudo, curriculares que possam explicar tal funcionamento diferencial. Utilizará como referencial a Teoria de Resposta ao Item (TRI) e a ferramenta estatística o DIF. Complementarmente desenvolverá uma abordagem qualitativa envolvendo análise documental, observação e entrevistas no Brasil e no Japão. O estudo de campo no Japão é viabilizado por meio de acesso do estágio de Doutorado Sanduíche.

Aspectos éticos: 0 projeto e os Termos de Consentimento Livre e Esclarecido (Professor, Diretor, Responsável, Estudante) apresentados estão de arordo com os princípios e valores do Marco Referencial, Estatuto e Regimento da Universidade no que se refere às responsabilidades de seu corpo docente e discente. Os Termos de Consentimento Livre e Esclarecido expõem com clareza os objetivos da pesquisa, os procedimentos a serem seguidos e a garantia do sigilo e da confidencialidade dos dados coletados e da identidade dos participantes. Informam sobre a possibilidade de interrupção na pesquisa sem aplicação de qualquer penalidade ou constrangimento.

Parecer: Considerando os elementos expostos acima somos de parecer Favorável à aprovação do projeto quanto aos princípios e critérios estabelecidos pela Comissão de Ética em Pesquisa da PUC-Rio.

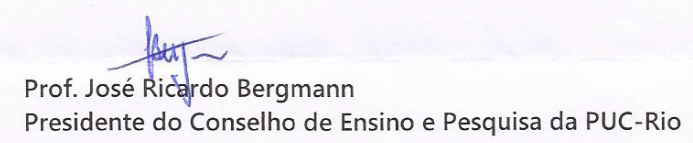

Rio de Janeiro, 29 de junho de 2016. 


\section{2}

\section{Anexo B}

Número da Observação:

Data da filmagem: '

Data do preenchimento: I__

Nome da Escola:

Nome do Professor (a):

Série/Ano:

Ficha de Observação

\section{Parte A - Aspectos preliminares da sala e dos atores sociais diretamente envolvidos}

1. Horário de Início da observação:

2. Horário de término da observação:

3. Número de estudantes matriculados na turma: sendo:

4. do sexo masculino (

5. do sexo feminino (

6. No. de estudantes presentes: sendo:

7. do sexo masculino (

8. do sexo feminino ( )

9. Número de estudantes que chegaram após iniciada a aula:

10. Número de estudantes que saíram antes do término da aula:

\section{Parte B - Aspectos organizacionais ou de gestão da sala de aula}

1) Tempo de ensino-aprendizagem de: (a) Ciências (b) Física (c) Química (d) Biologia
a) Início oficial:
b) Início efetivo da aula (*):
c) Término oficial:
d) Término efetivo:
e) Número de interrupções:
f) Tempo real total:
g) Número de aulas semanais:

(*) Por início efetivo, considerar atividades como: professor coloca a data no quadro negro, verifica a realização de tarefas, começa a explicar matéria, pede aos estudantes que abram o livro na página tal etc.

2) $\mathrm{O}(\mathrm{A})$ professor(a) se ausenta da sala? ( ) $\operatorname{sim} /$ ( ) não - Se sim, quantas vezes e por quanto tempo? 


\section{Parte C - Atividades didáticas ou situações de ensino-aprendizagem}

1) Sobre o desenvolvimento da aula:

1.1) Descreva a sequência de atividades e temas tratados do início ao término da observação (Por exemplo: Ciências Naturais e Biológicas/Seres Vivos; Física/Temperatura; Química/Ligações Químicas;)

\begin{tabular}{|l|l|}
\hline \multicolumn{1}{|c|}{ Atividades e temas de ensino } & Tempo investido (em minutos) \\
\hline a) & \\
\hline b) & \\
\hline c) & \\
\hline d) & \\
\hline e) & \\
\hline
\end{tabular}

2) Assinale as estratégias metodológicas adotadas pelo(a) professor(a).

\begin{tabular}{|c|c|c|}
\hline & Sim & Não \\
\hline \multicolumn{3}{|l|}{ Os estudantes são convidados a expor as suas ideias } \\
\hline \multicolumn{3}{|l|}{ Os estudantes fazem experiências no laboratório } \\
\hline \multicolumn{3}{|l|}{$\begin{array}{c}\text { O professor pede aos estudantes que imaginem como } \\
\text { determinada questão científica poderia ser investigada em } \\
\text { laboratório }\end{array}$} \\
\hline \multicolumn{3}{|l|}{$\begin{array}{l}\text { O professor pede aos estudantes que apliquem um conceito } \\
\text { científico a problemas quotidianos }\end{array}$} \\
\hline \multicolumn{3}{|l|}{$\begin{array}{c}\text { Os estudantes são convidados a dar a sua opinião acerca dos } \\
\text { temas tratados }\end{array}$} \\
\hline \multicolumn{3}{|l|}{$\begin{array}{l}\text { O professor pede aos estudantes que tirem conclusões de uma } \\
\text { experiência por eles realizada }\end{array}$} \\
\hline \multicolumn{3}{|l|}{$\begin{array}{l}\text { O professor explica como uma noção científica se pode aplicar a } \\
\text { vários fenômenos (por ex., ao movimento dos corpos ou a } \\
\text { substâncias com propriedades idênticas) }\end{array}$} \\
\hline \multicolumn{3}{|l|}{$\begin{array}{l}\text { Os estudantes têm permissão para conceber as suas próprias } \\
\text { experiências }\end{array}$} \\
\hline \multicolumn{3}{|l|}{ Há um debate ou troca de ideias na aula } \\
\hline $\begin{array}{c}\text { As experiências são feitas pelo professor, a título de } \\
\text { demonstração }\end{array}$ & & \\
\hline Os estudantes podem escolher os seus trabalhos de pesquisa & & \\
\hline
\end{tabular}




\begin{tabular}{|c|c|}
\hline Os estudantes debatem os temas tratados & \\
\hline $\begin{array}{r}\text { Os estudantes fazem experiências seguindo as instruções do } \\
\text { professor }\end{array}$ & \\
\hline $\begin{array}{r}\text { O professor explica de modo claro a importância dos conceitos } \\
\text { científicos na vida de todos }\end{array}$ & \\
\hline $\begin{array}{r}\text { O professor pede aos estudantes que façam uma pesquisa para } \\
\text { testarem as suas próprias ideias }\end{array}$ & \\
\hline $\begin{array}{c}\text { O professor dá exemplos de aplicações tecnológicas para mostrar } \\
\text { como a ciência é importante para a sociedade }\end{array}$ & \\
\hline
\end{tabular}

3) As atividades e conteúdos trabalhados pelo professor em sala de aula estão claramente relacionados a conteúdos de Ciências?

( ) Sim, durante toda a aula.

( ) Em grande parte da aula, perdendo pouco tempo com outras questões.

( ) Apenas parte da aula, gastando muito tempo com outras questões.

( ) Não, as atividades trabalhadas em aula não estão relacionadas com Ciências. (Por exemplo, apenas distribuiu material ou discutiu questões administrativas, de disciplina/indisciplina ou obediência/desobediência dos estudantes). 


\section{3 \\ Anexo C}

\section{Prezado(a) Professor(a),}

Muito obrigada por sua colaboração ao responder a este questionário. As perguntas que se seguem foram desenvolvidas para que possamos melhor conhecer a formação profissional e as práticas pedagógicas dos professores de Ciências dos anos finais do Ensino Fundamental. Turmas essas que antecedem a faixa etária dos 15 anos de idade que é a população amostrada no PISA (Programa Internacional de Avaliação de Estudantes). Não há respostas certas ou erradas.

A sua colaboração ao preencher este questionário será de grande valia para o êxito desta pesquisa no campo educacional e para o aprimoramento das discussões a cerca do processo de Letramento Científico.

Todas as informações coletadas neste estudo serão mantidas em sigilo. Garantimos que você, a escola ou qualquer outro membro da equipe docente não serão identificados em qualquer relatório ou produto resultante do estudo.

Se tiver dúvida sobre qualquer aspecto do questionário, ou se quiser informações adicionais sobre o estudo, por favor, entre em contato com Andriele Muri, enviando um e-mail para andrielemuri@hotmail.com.

Questionário do Professor

\section{Bloco I - Sobre você}

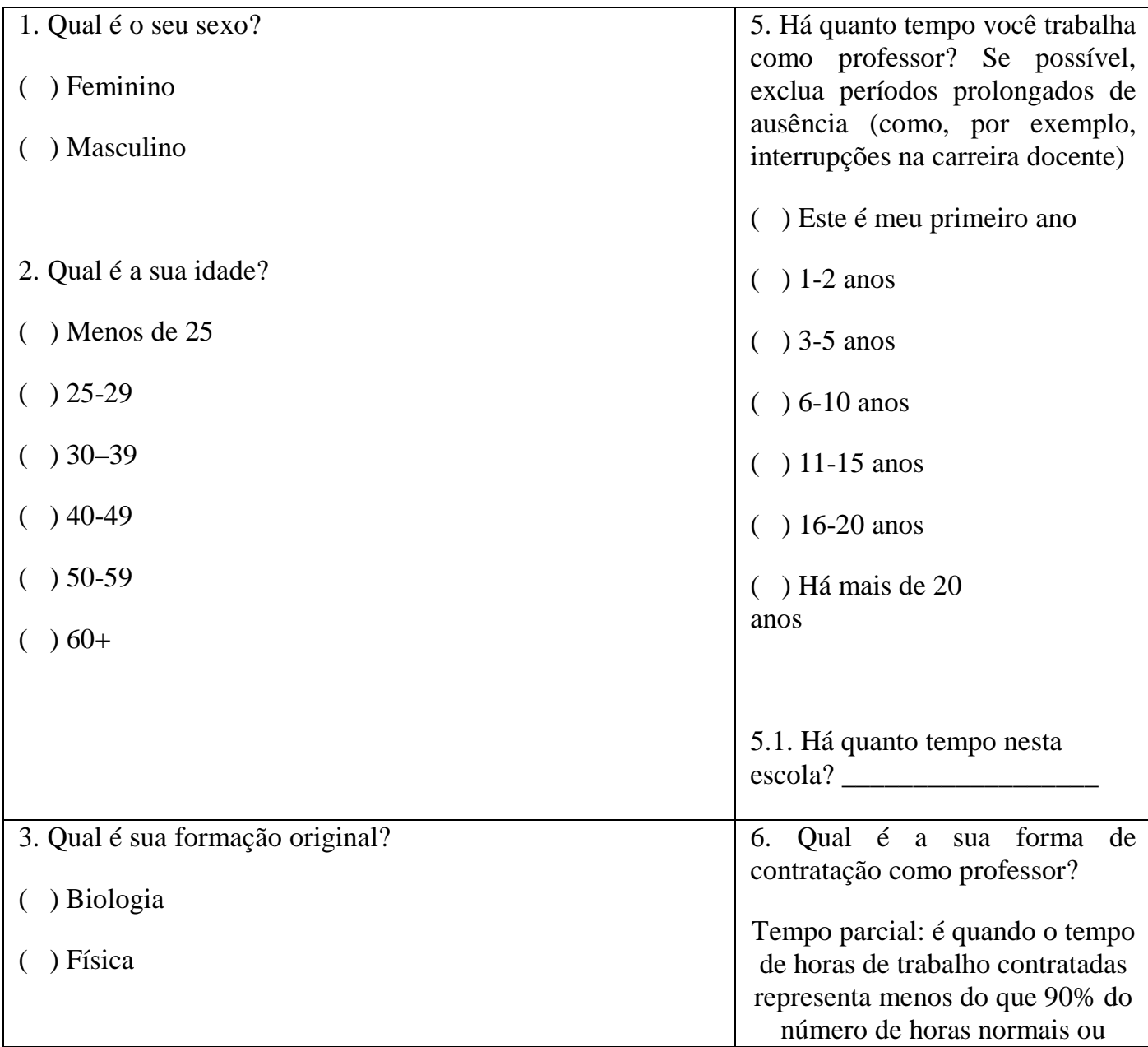




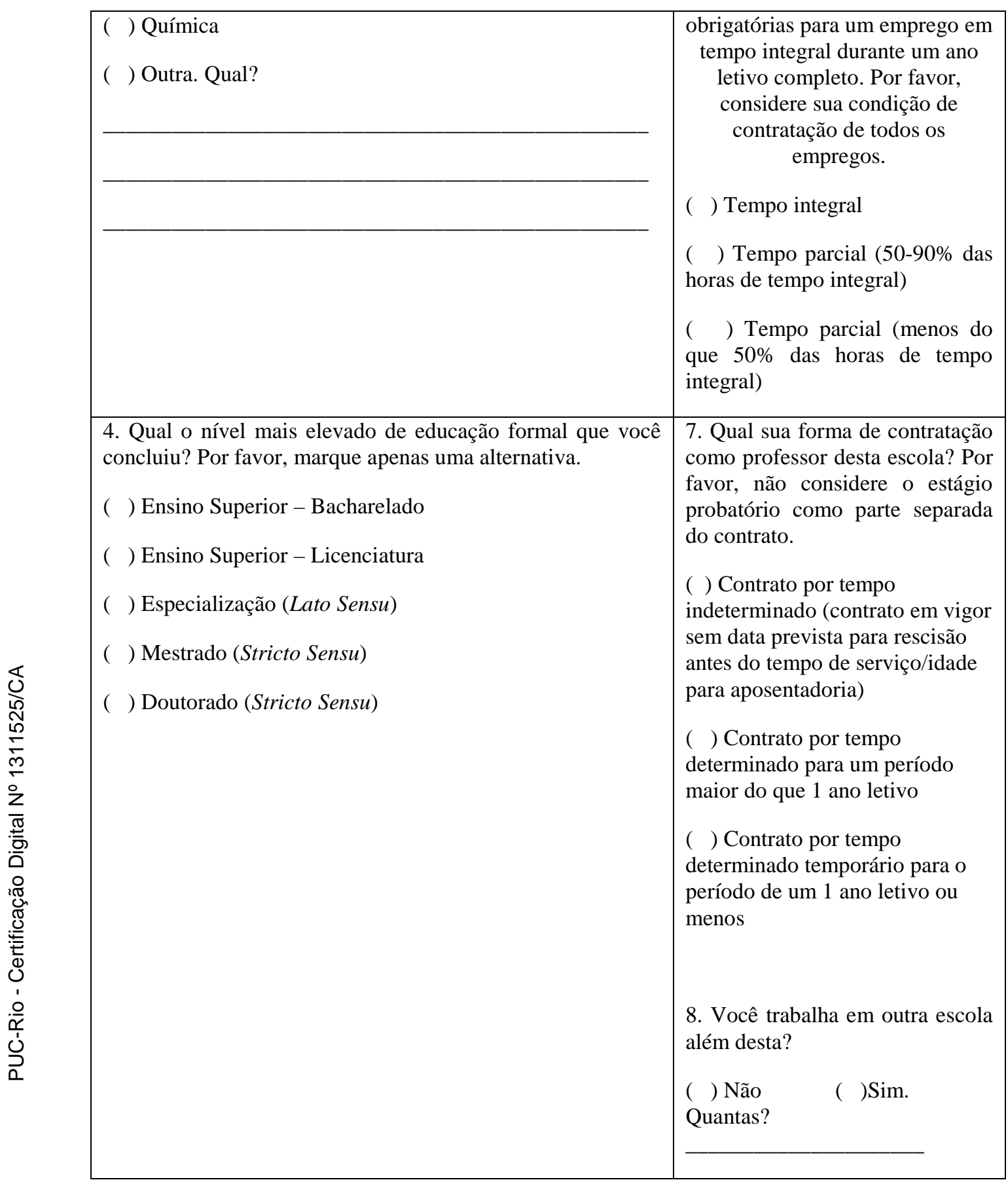

\section{Bloco II - Sobre sua formação continuada}

9. Nos últimos 18 meses, você participou de qualquer um dos seguintes tipos de atividades de desenvolvimento profissional e qual foi o impacto dessas atividades no seu aprimoramento profissional como professor?

Para cada item abaixo, por favor, marque uma alternativa na parte (A). Se a resposta foi "Sim" na parte (A), então marque uma alternativa na parte (B) para indicar o impacto que isto teve em seu aprimoramento profissional como professor.

\begin{tabular}{|l|l|l|}
\hline & Participação & Impacto \\
\hline
\end{tabular}




\begin{tabular}{|c|c|c|c|c|c|c|}
\hline & Sim & Não & Nenhum & Pequeno & Moderado & Grande \\
\hline $\begin{array}{l}\text { Cursos/ oficinas de trabalho } \\
\text { (por exemplo, sobre } \\
\text { disciplinas ou métodos e/ou } \\
\text { outros tópicos relacionados } \\
\text { à educação científica/ensino } \\
\text { de ciências) }\end{array}$ & ( ) & ( ) & ( ) & ( ) & ( ) & ( ) \\
\hline $\begin{array}{l}\text { Conferências ou seminários } \\
\text { sobre educação } \\
\text { científica/ensino de ciências } \\
\text { (quando os professores e/ou } \\
\text { os pesquisadores } \\
\text { apresentam resultados de } \\
\text { suas pesquisas e discutem } \\
\text { problemas educacionais) }\end{array}$ & ( ) & ( ) & ( ) & ( ) & ( ) & ( ) \\
\hline $\begin{array}{l}\text { Programa de qualificação } \\
\text { (como, por exemplo, um } \\
\text { curso em nível de graduação } \\
\text { ou pós-graduação que } \\
\text { ofereça diploma ou } \\
\text { certificado) }\end{array}$ & ( ) & ( ) & ( ) & ( ) & ( ) & ( ) \\
\hline $\begin{array}{l}\text { Visitas de observação a } \\
\text { outras escolas }\end{array}$ & ( ) & ( ) & ( ) & ( ) & ( ) & ( ) \\
\hline $\begin{array}{l}\text { Participação em uma rede } \\
\text { de professores (network) } \\
\text { formada especificamente } \\
\text { para o desenvolvimento } \\
\text { profissional dos professores }\end{array}$ & ( ) & ( ) & ( ) & ( ) & ( ) & ( ) \\
\hline $\begin{array}{c}\text { Pesquisa individual ou em } \\
\text { colaboração sobre um } \\
\text { tópico de seu interesse } \\
\text { profissional }\end{array}$ & ( ) & ( ) & ( ) & ( ) & ( ) & ( ) \\
\hline $\begin{array}{l}\text { Orientação e/ou observação } \\
\text { feita por um colega e } \\
\text { supervisão, organizadas } \\
\text { formalmente pela escola }\end{array}$ & ( ) & ( ) & ( ) & ( ) & ( ) & ( ) \\
\hline
\end{tabular}

\section{Bloco III - Sobre sua prática}

10. Que disciplina(s) especificamente você leciona nesta escola?

( ) Ciências

( ) Biologia

( ) Física

( ) Química

11. Com que frequência ocorrem as seguintes atividades nas suas aulas de ciências? (Por favor, assinale com X um item em cada linha.) 


\begin{tabular}{|c|c|c|c|c|}
\hline & $\begin{array}{l}\text { Em todas } \\
\text { as aulas }\end{array}$ & $\begin{array}{c}\mathrm{Na} \\
\text { maioria } \\
\text { das aulas }\end{array}$ & $\begin{array}{c}\text { Em } \\
\text { algumas } \\
\text { aulas }\end{array}$ & $\begin{array}{l}\text { Nunca ou } \\
\text { quase } \\
\text { nunca }\end{array}$ \\
\hline $\begin{array}{l}\text { Os estudantes são convidados a expor as } \\
\text { suas ideias }\end{array}$ & $($ ) & $($ ) & $($ ) & $($ ) \\
\hline $\begin{array}{l}\text { Os estudantes fazem experiências no } \\
\text { laboratório }\end{array}$ & $($ ) & $($ ) & $($ ) & $($ ) \\
\hline $\begin{array}{l}\text { Você pede aos estudantes que imaginem } \\
\text { como determinada questão científica } \\
\text { poderia ser investigada em laboratório }\end{array}$ & ( ) & ( ) & $($ ) & $($ ) \\
\hline $\begin{array}{l}\text { Você pede aos estudantes que apliquem } \\
\text { um conceito científico a problemas } \\
\text { quotidianos }\end{array}$ & $($ ) & ( ) & $($ ) & $($ ) \\
\hline $\begin{array}{l}\text { Os estudantes são convidados a dar a sua } \\
\text { opinião acerca dos temas tratados }\end{array}$ & $($ ) & $($ ) & $($ ) & $($ ) \\
\hline $\begin{array}{l}\text { Você pede aos estudantes que tirem } \\
\text { conclusões de uma experiência por eles } \\
\text { realizada }\end{array}$ & ( ) & $($ ) & $($ ) & ( ) \\
\hline $\begin{array}{l}\text { Você explica como uma noção científica } \\
\text { pode se aplicar a vários fenômenos (por } \\
\text { ex., ao movimento dos corpos ou a } \\
\text { substâncias com propriedades idênticas) }\end{array}$ & ( ) & ( ) & ( ) & ( ) \\
\hline $\begin{array}{l}\text { Os estudantes têm permissão para } \\
\text { conceber as suas próprias experiências }\end{array}$ & ( ) & ( ) & ( ) & $($ ) \\
\hline Há um debate ou troca de ideias na aula & $($ ) & $($ ) & $($ ) & $($ ) \\
\hline $\begin{array}{l}\text { As experiências são feitas por você, a } \\
\text { título de demonstração }\end{array}$ & ( ) & ( ) & ( ) & ( ) \\
\hline $\begin{array}{l}\text { Os estudantes podem escolher os seus } \\
\text { trabalhos de pesquisa }\end{array}$ & $($ ) & $($ ) & $($ ) & $($ ) \\
\hline Os estudantes debatem os temas tratados & ( ) & ( ) & ( ) & ( ) \\
\hline $\begin{array}{l}\text { Os estudantes fazem experiências } \\
\text { seguindo as suas instruções }\end{array}$ & $($ ) & $($ ) & $($ ) & $($ ) \\
\hline $\begin{array}{l}\text { Você explica de modo claro a } \\
\text { importância dos conceitos científicos na } \\
\text { vida de todos }\end{array}$ & $($ ) & ( ) & $($ ) & $($ ) \\
\hline $\begin{array}{l}\text { Você pede aos estudantes que façam } \\
\text { uma pesquisa para testarem as suas } \\
\text { próprias ideias }\end{array}$ & $($ ) & $($ ) & $($ ) & $($ ) \\
\hline $\begin{array}{l}\text { Você dá exemplos de aplicações } \\
\text { tecnológicas para mostrar como a } \\
\text { ciência é importante para a sociedade }\end{array}$ & ( ) & ( ) & $($ ) & $($ ) \\
\hline
\end{tabular}

Aqui termina o questionário. Muito obrigada por sua cooperação! 


\section{4}

Anexo D

Planilha 1. Características dos Itens de Ciências do PISA 2006.

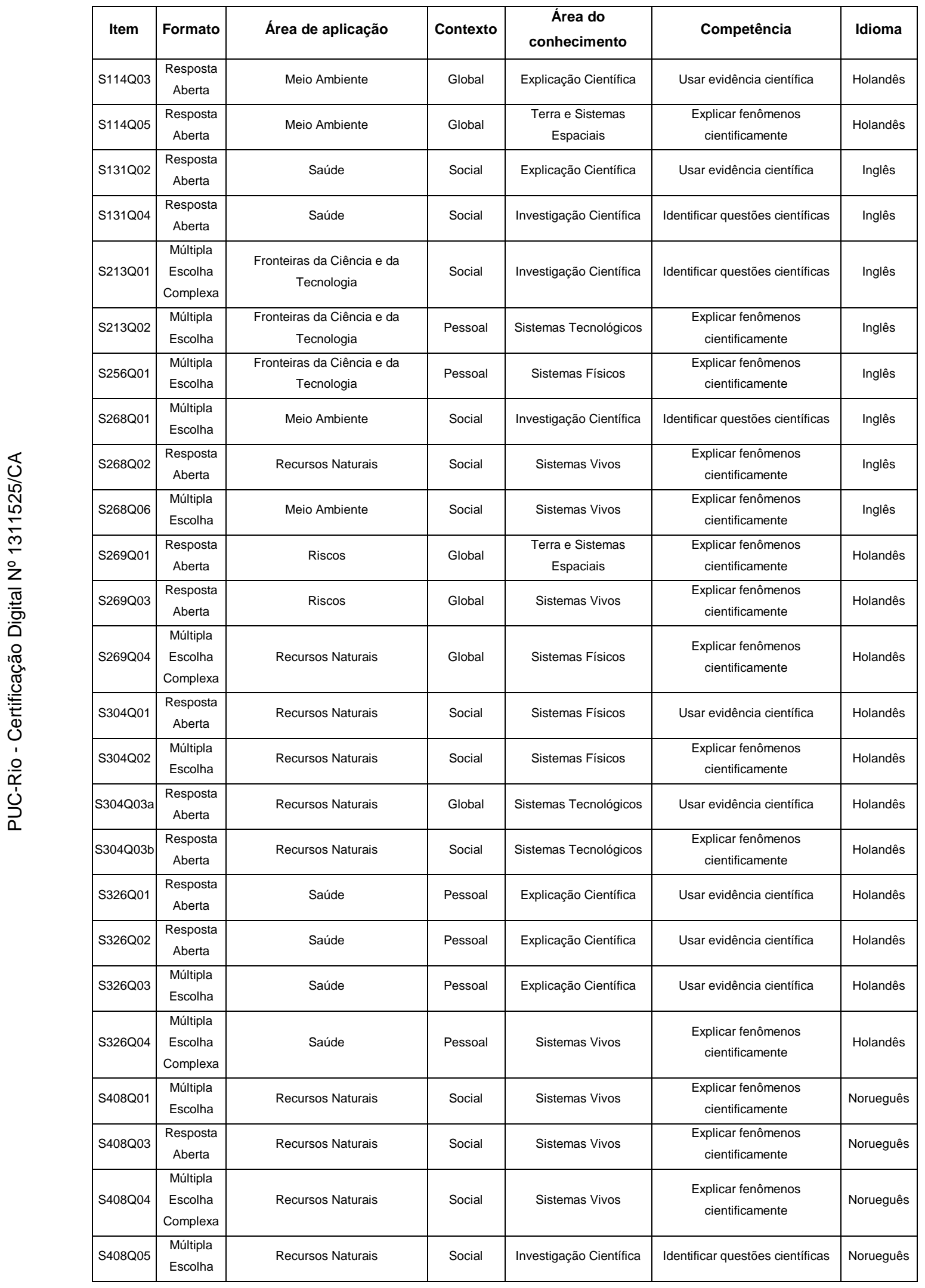




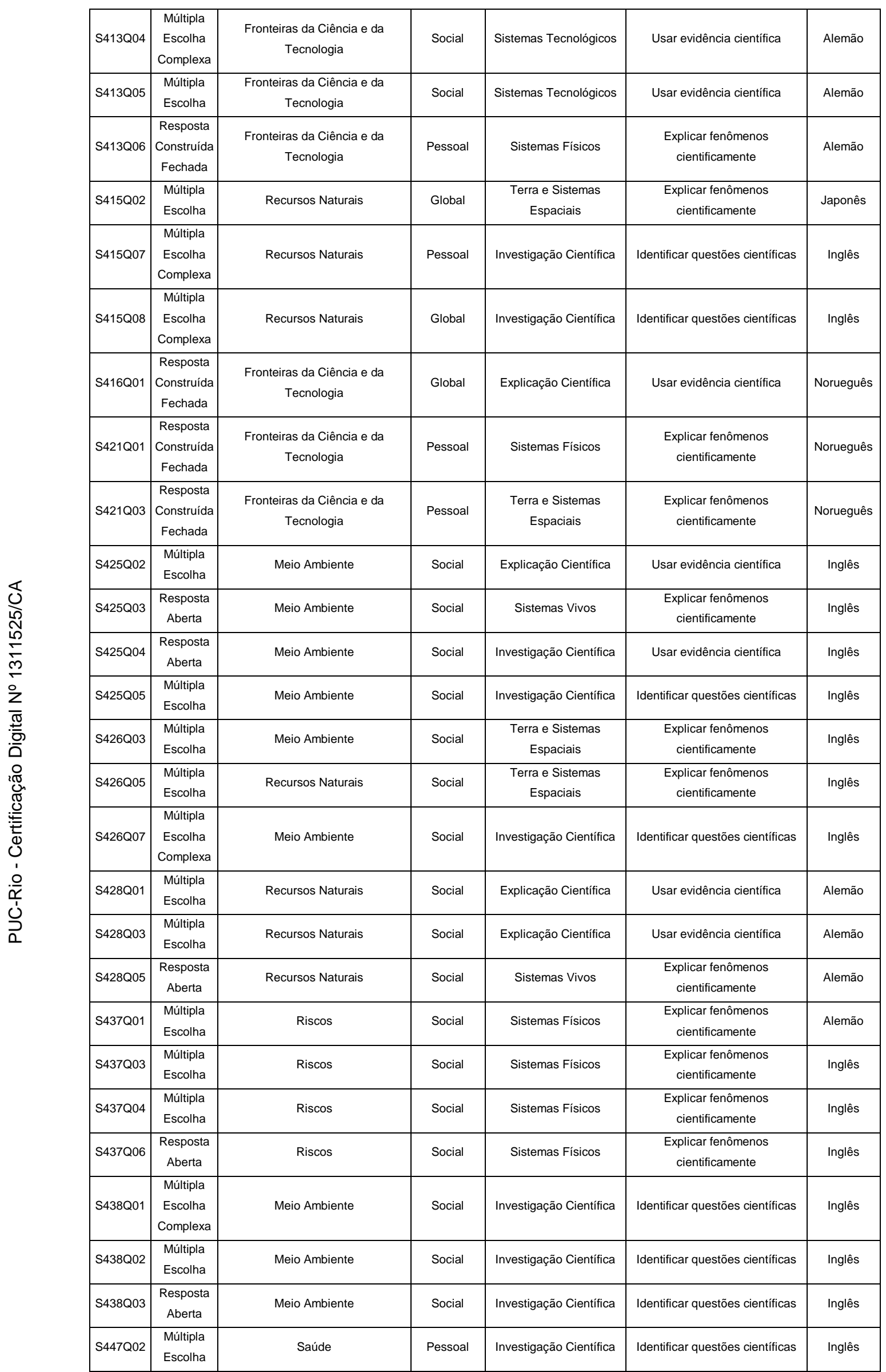




\begin{tabular}{|c|c|c|c|c|c|c|}
\hline S447Q03 & $\begin{array}{l}\text { Múltipla } \\
\text { Escolha }\end{array}$ & Saúde & Pessoal & Investigação Científica & Identificar questōes científicas & Inglês \\
\hline S447Q04 & $\begin{array}{l}\text { Múltipla } \\
\text { Escolha }\end{array}$ & Saúde & Pessoal & Investigação Científica & Identificar questões científicas & Inglês \\
\hline S458Q01 & $\begin{array}{l}\text { Resposta } \\
\text { Aberta }\end{array}$ & $\begin{array}{l}\text { Fronteiras da Ciência e da } \\
\text { Tecnologia }\end{array}$ & Global & Sistemas Vivos & $\begin{array}{l}\text { Explicar fenômenos } \\
\text { cientificamente }\end{array}$ & Norueguês \\
\hline S458Q02 & $\begin{array}{l}\text { Múltipla } \\
\text { Escolha } \\
\text { Complexa }\end{array}$ & $\begin{array}{l}\text { Fronteiras da Ciência e da } \\
\text { Tecnologia }\end{array}$ & Global & Sistemas Vivos & Usar evidência científica & Norueguês \\
\hline S465Q02 & $\begin{array}{l}\text { Múltipla } \\
\text { Escolha }\end{array}$ & Meio Ambiente & Global & $\begin{array}{c}\text { Terra e Sistemas } \\
\text { Espaciais }\end{array}$ & $\begin{array}{l}\text { Explicar fenômenos } \\
\text { cientificamente }\end{array}$ & Norueguês \\
\hline S465Q04 & $\begin{array}{l}\text { Múltipla } \\
\text { Escolha }\end{array}$ & Meio Ambiente & Global & $\begin{array}{c}\text { Terra e Sistemas } \\
\text { Espaciais }\end{array}$ & $\begin{array}{l}\text { Explicar fenômenos } \\
\text { cientificamente }\end{array}$ & Norueguês \\
\hline S466Q05 & $\begin{array}{l}\text { Múltipla } \\
\text { Escolha }\end{array}$ & Riscos & Social & Explicação Científica & Usar evidência científica & Norueguês \\
\hline S466Q07 & $\begin{array}{l}\text { Múltipla } \\
\text { Escolha } \\
\text { Complexa }\end{array}$ & Riscos & Social & Investigação Científica & Identificar questōes científicas & Norueguês \\
\hline S476Q01 & $\begin{array}{l}\text { Múltipla } \\
\text { Escolha }\end{array}$ & Saúde & Pessoal & Sistemas Vivos & $\begin{array}{l}\text { Explicar fenômenos } \\
\text { cientificamente }\end{array}$ & Inglês \\
\hline S476Q02 & $\begin{array}{l}\text { Múltipla } \\
\text { Escolha }\end{array}$ & Saúde & Pessoal & Sistemas Vivos & $\begin{array}{l}\text { Explicar fenômenos } \\
\text { cientificamente }\end{array}$ & Inglês \\
\hline S476Q03 & $\begin{array}{l}\text { Múltipla } \\
\text { Escolha }\end{array}$ & Saúde & Pessoal & Sistemas Vivos & $\begin{array}{l}\text { Explicar fenômenos } \\
\text { cientificamente }\end{array}$ & Inglês \\
\hline S477Q02 & $\begin{array}{l}\text { Múltipla } \\
\text { Escolha }\end{array}$ & Saúde & Social & Sistemas Vivos & $\begin{array}{l}\text { Explicar fenômenos } \\
\text { cientificamente }\end{array}$ & Norueguês \\
\hline S477Q03 & $\begin{array}{l}\text { Múltipla } \\
\text { Escolha }\end{array}$ & Saúde & Social & Sistemas Vivos & $\begin{array}{l}\text { Explicar fenômenos } \\
\text { cientificamente }\end{array}$ & Norueguês \\
\hline S477Q04 & $\begin{array}{l}\text { Resposta } \\
\text { Aberta }\end{array}$ & Saúde & Social & Sistemas Vivos & $\begin{array}{l}\text { Explicar fenômenos } \\
\text { cientificamente }\end{array}$ & Norueguês \\
\hline S478Q01 & $\begin{array}{l}\text { Múltipla } \\
\text { Escolha }\end{array}$ & Saúde & Pessoal & Sistemas Vivos & $\begin{array}{l}\text { Explicar fenômenos } \\
\text { cientificamente }\end{array}$ & Francês \\
\hline S478Q02 & $\begin{array}{l}\text { Múltipla } \\
\text { Escolha } \\
\text { Complexa }\end{array}$ & Saúde & Pessoal & Explicação Científica & Usar evidência científica & Francês \\
\hline S478Q03 & $\begin{array}{l}\text { Múltipla } \\
\text { Escolha } \\
\text { Complexa }\end{array}$ & Saúde & Pessoal & Sistemas Vivos & $\begin{array}{l}\text { Explicar fenômenos } \\
\text { cientificamente }\end{array}$ & Francês \\
\hline S485Q02 & $\begin{array}{l}\text { Resposta } \\
\text { Aberta }\end{array}$ & Riscos & Social & Sistemas Físicos & $\begin{array}{l}\text { Explicar fenômenos } \\
\text { cientificamente }\end{array}$ & Inglês/Grego \\
\hline S485Q03 & $\begin{array}{l}\text { Múltipla } \\
\text { Escolha }\end{array}$ & Riscos & Pessoal & Sistemas Físicos & Usar evidência científica & Inglês \\
\hline S493Q01 & $\begin{array}{l}\text { Múltipla } \\
\text { Escolha } \\
\text { Complexa }\end{array}$ & Saúde & Pessoal & Sistemas Vivos & $\begin{array}{l}\text { Explicar fenômenos } \\
\text { cientificamente }\end{array}$ & Francês \\
\hline S493Q03 & $\begin{array}{l}\text { Múltipla } \\
\text { Escolha } \\
\text { Complexa }\end{array}$ & Saúde & Pessoal & Sistemas Vivos & $\begin{array}{l}\text { Explicar fenômenos } \\
\text { cientificamente }\end{array}$ & Francês \\
\hline S493Q05 & $\begin{array}{c}\text { Resposta } \\
\text { Aberta }\end{array}$ & Saúde & Pessoal & Sistemas Vivos & $\begin{array}{l}\text { Explicar fenômenos } \\
\text { cientificamente }\end{array}$ & Francês \\
\hline S495Q01 & $\begin{array}{l}\text { Múltipla } \\
\text { Escolha } \\
\text { Complexa }\end{array}$ & Saúde & Social & Explicação Científica & Usar evidência científica & Francês \\
\hline S495Q02 & $\begin{array}{l}\text { Múltipla } \\
\text { Escolha } \\
\text { Complexa }\end{array}$ & Saúde & Social & Explicação Científica & Usar evidência científica & Francês \\
\hline S495Q03 & $\begin{array}{l}\text { Resposta } \\
\text { Aberta }\end{array}$ & Saúde & Social & Explicação Científica & Usar evidência científica & Francês \\
\hline S495Q04 & $\begin{array}{l}\text { Múltipla } \\
\text { Escolha } \\
\text { Complexa }\end{array}$ & Saúde & Social & Investigação Científica & Identificar questōes científicas & Francês \\
\hline S498Q02 & $\begin{array}{l}\text { Múltipla } \\
\text { Escolha } \\
\text { Complexa }\end{array}$ & Outra & Social & Investigação Científica & Identificar questōes científicas & Francês \\
\hline
\end{tabular}




\begin{tabular}{|c|c|c|c|c|c|c|}
\hline S498Q03 & $\begin{array}{l}\text { Múltipla } \\
\text { Escolha }\end{array}$ & Outra & Social & Investigação Científica & Identificar questões científicas & Francês \\
\hline S508Q02 & $\begin{array}{l}\text { Múltipla } \\
\text { Escolha } \\
\text { Complexa }\end{array}$ & $\begin{array}{c}\text { Fronteiras da Ciência e da } \\
\text { Tecnologia }\end{array}$ & Social & Investigação Científica & Identificar questões científicas & Inglês \\
\hline S508Q03 & $\begin{array}{l}\text { Múltipla } \\
\text { Escolha }\end{array}$ & $\begin{array}{c}\text { Fronteiras da Ciência e da } \\
\text { Tecnologia }\end{array}$ & Social & Investigação Científica & Identificar questões científicas & Inglês \\
\hline S510Q01 & $\begin{array}{l}\text { Múltipla } \\
\text { Escolha } \\
\text { Complexa }\end{array}$ & $\begin{array}{c}\text { Fronteiras da Ciência e da } \\
\text { Tecnologia }\end{array}$ & Social & Sistemas Físicos & $\begin{array}{l}\text { Explicar fenômenos } \\
\text { cientificamente }\end{array}$ & Holandês \\
\hline S510Q04 & $\begin{array}{c}\text { Resposta } \\
\text { Aberta }\end{array}$ & $\begin{array}{c}\text { Fronteiras da Ciência e da } \\
\text { Tecnologia }\end{array}$ & Pessoal & Sistemas Físicos & $\begin{array}{c}\text { Explicar fenômenos } \\
\text { cientificamente }\end{array}$ & Holandês \\
\hline S514Q02 & $\begin{array}{l}\text { Resposta } \\
\text { Aberta }\end{array}$ & Riscos & Social & Sistemas Tecnológicos & Usar evidência científica & Japonês \\
\hline S514Q03 & $\begin{array}{l}\text { Resposta } \\
\text { Aberta }\end{array}$ & Riscos & Social & $\begin{array}{c}\text { Terra e Sistemas } \\
\text { Espaciais }\end{array}$ & $\begin{array}{l}\text { Explicar fenômenos } \\
\text { cientificamente }\end{array}$ & Japonês \\
\hline S514Q04 & $\begin{array}{l}\text { Múltipla } \\
\text { Escolha } \\
\text { Complexa }\end{array}$ & Riscos & Social & Sistemas Tecnológicos & Usar evidência científica & Japonês \\
\hline S519Q02 & $\begin{array}{l}\text { Múltipla } \\
\text { Escolha } \\
\text { Complexa }\end{array}$ & $\begin{array}{l}\text { Fronteiras da Ciência e da } \\
\text { Tecnologia }\end{array}$ & Social & Sistemas Físicos & $\begin{array}{l}\text { Explicar fenômenos } \\
\text { cientificamente }\end{array}$ & Francês \\
\hline S519Q03 & $\begin{array}{c}\text { Resposta } \\
\text { Aberta }\end{array}$ & $\begin{array}{c}\text { Fronteiras da Ciência e da } \\
\text { Tecnologia }\end{array}$ & Social & Investigação Científica & Identificar questões científicas & Francês \\
\hline S521Q02 & $\begin{array}{l}\text { Múltipla } \\
\text { Escolha }\end{array}$ & $\begin{array}{c}\text { Fronteiras da Ciência e da } \\
\text { Tecnologia }\end{array}$ & Pessoal & Sistemas Físicos & $\begin{array}{l}\text { Explicar fenômenos } \\
\text { cientificamente }\end{array}$ & Inglês \\
\hline S521Q06 & $\begin{array}{l}\text { Múltipla } \\
\text { Escolha }\end{array}$ & $\begin{array}{c}\text { Fronteiras da Ciência e da } \\
\text { Tecnologia }\end{array}$ & Pessoal & Sistemas Físicos & $\begin{array}{l}\text { Explicar fenômenos } \\
\text { cientificamente }\end{array}$ & Inglês \\
\hline S524Q06 & $\begin{array}{c}\text { Múltipla } \\
\text { Escolha } \\
\text { Complexa }\end{array}$ & $\begin{array}{c}\text { Fronteiras da Ciência e da } \\
\text { Tecnologia }\end{array}$ & Social & Sistemas Tecnológicos & Usar evidência científica & Alemão \\
\hline S524Q07 & $\begin{array}{l}\text { Resposta } \\
\text { Aberta }\end{array}$ & $\begin{array}{l}\text { Fronteiras da Ciência e da } \\
\text { Tecnologia }\end{array}$ & Social & Explicação Científica & Usar evidência científica & Alemão \\
\hline S527Q01 & $\begin{array}{l}\text { Múltipla } \\
\text { Escolha } \\
\text { Complexa }\end{array}$ & $\begin{array}{c}\text { Fronteiras da Ciência e da } \\
\text { Tecnologia }\end{array}$ & Global & Explicação Científica & Usar evidência científica & Coreano \\
\hline S527Q03 & \begin{tabular}{|c|} 
Múltipla \\
Escolha \\
Complexa
\end{tabular} & $\begin{array}{c}\text { Fronteiras da Ciência e da } \\
\text { Tecnologia }\end{array}$ & Global & $\begin{array}{c}\text { Terra e Sistemas } \\
\text { Espaciais }\end{array}$ & $\begin{array}{l}\text { Explicar fenômenos } \\
\text { cientificamente }\end{array}$ & Coreano \\
\hline S527Q04 & $\begin{array}{l}\text { Múltipla } \\
\text { Escolha } \\
\text { Complexa }\end{array}$ & $\begin{array}{c}\text { Fronteiras da Ciência e da } \\
\text { Tecnologia }\end{array}$ & Global & $\begin{array}{c}\text { Terra e Sistemas } \\
\text { Espaciais }\end{array}$ & $\begin{array}{l}\text { Explicar fenômenos } \\
\text { cientificamente }\end{array}$ & Coreano \\
\hline
\end{tabular}




\section{5}

\section{Anexo E}

Planilha 2. Parâmetros e percentual válido de acerto dos itens de Ciências do PISA

2006.

\begin{tabular}{|c|c|c|c|c|c|c|c|c|c|c|c|c|}
\hline & & & & & & & & & & $\begin{array}{r}\text { Perce } \\
\text { Ac } \\
\end{array}$ & $\begin{array}{l}\text { tual Vál } \\
\text { to ao it }\end{array}$ & $\begin{array}{l}\text { do de } \\
\text { em }\end{array}$ \\
\hline Item & $\mathrm{Za}$ & a1 & a2 & d.a & $\mathrm{Zb}$ & b1 & b2 & d.b & c & Brasil & Japão & OCDE \\
\hline S114Q03 & 0,115 & 1,277 & 1,272 & $-0,003$ & 0,093 & 0,734 & 0,732 & 0,002 & 0,079 & 29,9 & 69,9 & 51,9 \\
\hline S114Q05 & 0,118 & 0,713 & 0,704 & $-0,015$ & 1,000 & 1,897 & 3,226 & $-1,329$ & 0,035 & 16,6 & 18,0 & 19,2 \\
\hline S131Q02 & 0,365 & 1,200 & 1,353 & 0,126 & 0,118 & 1,531 & 1,536 & $-0,005$ & 0,131 & 23,0 & 50,2 & 44,1 \\
\hline S131Q04 & 0,137 & 0,884 & 0,880 & $-0,005$ & 0,805 & 1,625 & 1,966 & $-0,341$ & 0,071 & 19,4 & 39,9 & 31,4 \\
\hline S213Q01 & 0,824 & 1,444 & 0,945 & $-0,418$ & 0,118 & 1,520 & 1,522 & $-0,002$ & 0,049 & 16,3 & 52,9 & 47,4 \\
\hline S213Q02 & 0,988 & 1,004 & 0,499 & $-0,704$ & 1,000 & 0,555 & $-0,692$ & 1,247 & 0,143 & 44,9 & 81,2 & 77,6 \\
\hline S256Q01 & 0,885 & 0,250 & 0,454 & 0,587 & 0,505 & $-1,866$ & $-2,099$ & 0,233 & 0,302 & 73,9 & 93,7 & 86,7 \\
\hline S268Q01 & 0,146 & 1,128 & 1,128 & 0,000 & 0,186 & 0,791 & 0,815 & $-0,024$ & 0,257 & 46,1 & 75,6 & 71,4 \\
\hline S268Q02 & 0,296 & 1,086 & 1,169 & 0,078 & 0,442 & 1,460 & 1,572 & $-0,112$ & 0,069 & 21,6 & 49,7 & 37,2 \\
\hline S268Q06 & 0,732 & 1,543 & 0,947 & $-0,447$ & 0,086 & 1,336 & 1,337 & $-0,002$ & 0,170 & 29,0 & 59,1 & 53,2 \\
\hline S269Q01 & 0,123 & 1,295 & 1,284 & $-0,009$ & 0,979 & 0,587 & 0,115 & 0,472 & 0,077 & 33,9 & 84,1 & 56,5 \\
\hline S269Q03 & 0,078 & 1,127 & 1,127 & $-0,001$ & 1,000 & 1,526 & 0,160 & 1,366 & 0,028 & 13,7 & 80,6 & 39,9 \\
\hline S269Q04 & 0,411 & 0,748 & 0,609 & $-0,188$ & 1,000 & 2,312 & 1,247 & 1,066 & 0,101 & 18,6 & 57,4 & 33,9 \\
\hline S304Q01 & 0,364 & 1,148 & 1,287 & 0,119 & 0,200 & 1,170 & 1,151 & 0,019 & 0,071 & 21,9 & 58,5 & 41,9 \\
\hline S304Q02 & 0,301 & 1,142 & 1,029 & $-0,093$ & 0,165 & 0,907 & 0,891 & 0,016 & 0,225 & 35,3 & 72,3 & 61,1 \\
\hline S304Q03a & 0,109 & 1,201 & 1,198 & $-0,002$ & 1,000 & 1,002 & 1,668 & $-0,666$ & 0,033 & 21,5 & 42,4 & 38,7 \\
\hline S304Q03b & 0,108 & 1,680 & 1,676 & $-0,003$ & 0,097 & 0,997 & 0,990 & 0,006 & 0,024 & 17,1 & 65,5 & 49,3 \\
\hline S326Q01 & 0,508 & 0,786 & 0,991 & 0,235 & 0,874 & 0,888 & 1,265 & $-0,377$ & 0,133 & 40,7 & 64,7 & 60,0 \\
\hline S326Q02 & 0,186 & 1,168 & 1,203 & 0,030 & 1,000 & 0,573 & 1,236 & $-0,663$ & 0,113 & 40,4 & 64,8 & 63,1 \\
\hline S326Q03 & 0,230 & 1,346 & 1,243 & $-0,072$ & 0,836 & 1,330 & 1,037 & 0,293 & 0,159 & 26,8 & 68,4 & 56,4 \\
\hline S326Q04 & 0,546 & 1,359 & 1,057 & $-0,254$ & 0,219 & 2,399 & 2,445 & $-0,046$ & 0,058 & 7,6 & 26,1 & 22,4 \\
\hline S408Q01 & 0,215 & 0,774 & 0,731 & $-0,050$ & 0,196 & 0,972 & 0,952 & 0,020 & 0,202 & 43,0 & 72,8 & 59,9 \\
\hline S408Q03 & 0,203 & 0,745 & 0,767 & 0,035 & 0,964 & 2,644 & 3,541 & $-0,898$ & 0,060 & 12,9 & 16,2 & 31,2 \\
\hline S408Q04 & 0,300 & 0,626 & 0,571 & $-0,110$ & 1,000 & 0,852 & 2,009 & $-1,157$ & 0,147 & 40,6 & 44,8 & 47,7 \\
\hline S408Q05 & 0,144 & 0,896 & 0,895 & $-0,002$ & 0,3 & 1,529 & 1,635 & $-0,107$ & 0,131 & 28,4 & 45,3 & 40,0 \\
\hline S413Q04 & 0,376 & 1,149 & 0,842 & $-0,243$ & 0,889 & 2,116 & 1,497 & 0,619 & 0,129 & 16,5 & 52,9 & 40,3 \\
\hline S413Q05 & 0,220 & 0,640 & 0,615 & $-0,039$ & 0,188 & 0,810 & 0,831 & $-0,021$ & 0,140 & 37,9 & 66,0 & 62,9 \\
\hline S413Q06 & 0,147 & 1,430 & 1,390 & $-0,029$ & 0,107 & 1,531 & 1,523 & & 0,035 & 11,3 & 45,6 & 35,7 \\
\hline S415Q02 & 0,116 & 0,989 & 0,998 & 0,009 & 0,229 & 0,465 & 0,500 & $-0,034$ & 0,201 & 48,4 & 78,5 & 76,8 \\
\hline S415Q07 & 0,305 & 0,691 & 0,608 & $-0,125$ & 0,953 & 0,719 & 1,406 & $-0,688$ & 0,233 & 53,8 & 63,6 & 72,8 \\
\hline S415Q08 & 0,219 & 0,915 & 0,862 & $-0,060$ & 0,755 & 1,161 & 0,799 & 0,362 & 0,194 & 36,9 & 73,0 & 57,7 \\
\hline S416Q01 & 0,971 & 1,479 & 0,817 & $-0,588$ & 1,000 & 1,613 & 0,874 & 0,738 & 0,040 & 14,1 & 64,3 & 44,7 \\
\hline S421Q01 & 0,419 & 1,432 & 1,122 & $-0,226$ & 0,316 & 1,744 & 1,817 & $-0,073$ & 0,107 & 18,4 & 43,9 & 38,9 \\
\hline S421Q03 & 0,878 & 1,474 & 0,806 & $-0,600$ & 0,129 & 0,982 & 0,987 & $-0,005$ & 0,080 & 26,6 & 60,7 & 61,5 \\
\hline S425Q02 & 0,675 & 1,631 & 1,116 & $-0,366$ & 0,295 & 1,581 & 1,520 & 0,060 & 0,181 & 26,2 & 60,0 & 44,9 \\
\hline S425Q03 & 0,196 & 0,672 & 0,702 & 0,041 & 0,204 & 1,481 & 1,499 & $-0,018$ & 0,075 & 28,7 & 50,1 & 39,9 \\
\hline S425Q04 & 0,087 & 0,917 & 0,917 & 0,000 & 0,133 & 2,401 & 2,408 & $-0,006$ & 0,034 & 9,3 & 26,1 & 29,2 \\
\hline S425Q05 & 0,174 & 0,679 & 0,656 & $-0,036$ & & 0,912 & $-0,085$ & 0,997 & 0,197 & 48,4 & 84,4 & 69,4 \\
\hline S426Q03 & 0,627 & 1,302 & 0,675 & $-0,527$ & 1,000 & 2,235 & 1,001 & 1,234 & 0,270 & 31,0 & 68,0 & 66,3 \\
\hline S426Q05 & 0,862 & 0,848 & 1,315 & 0,441 & 0,191 & 0,289 & 0,262 & 0,027 & 0,163 & 46,0 & 83,8 & 73,7 \\
\hline S426Q07 & 0,209 & 0,319 & 0,328 & $\begin{array}{ll}0,024 \\
\end{array}$ & 0,892 & 1,294 & 2,176 & $-0,882$ & 0,221 & 50,5 & 53,6 & 62,4 \\
\hline S428Q01 & 0,123 & 1,323 & 1,309 & $-0,010$ & 0,089 & 0,599 & 0,602 & $-0,002$ & 0,129 & 35,4 & 73,7 & 60,1 \\
\hline S428Q03 & 0,173 & 1,238 & 1,278 & 0,033 & 0,103 & 0,400 & 0,397 & 0,003 & 0,117 & 44,1 & 81,6 & 70,0 \\
\hline S428Q05 & 0,299 & 1,233 & 1,133 & $-0,083$ & 0,251 & 0,956 & 0,990 & $-0,034$ & 0,051 & 25,5 & 60,7 & 41,6 \\
\hline S437Q01 & 0,129 & 0,867 & 0,854 & $-0,012$ & 1,000 & 1,251 & 0,417 & 0,835 & 0,276 & 46,1 & 82,5 & 70,6 \\
\hline S437Q03 & 0,221 & 0,756 & 0,727 & $-0,041$ & 1,000 & 1,052 & 1,839 & $-0,787$ & 0,133 & 37,3 & 51,1 & 48,2 \\
\hline S437Q04 & 0,479 & 1,112 & 0,808 & $-0,286$ & 0,204 & 1,509 & 1,528 & $-0,019$ & 0,259 & 34,4 & 60,3 & 54,1 \\
\hline S437Q06 & 1,000 & 1,508 & 0,715 & $-0,747$ & 0,127 & 0,634 & 0,633 & 0,001 & 0,061 & 31,9 & 21,1 & 72,3 \\
\hline S438Q01 & 0,891 & 1,052 & 0,658 & $-0,485$ & 0,474 & 0,017 & 0,195 & $-0,178$ & 0,130 & 50,6 & 79,2 & 81,6 \\
\hline S438Q02 & 0,998 & 0,566 & 1,315 & 0,848 & 0,129 & 0,839 & 0,827 & 0,012 & 0,166 & 39,8 & 71,6 & 65,3 \\
\hline S438Q03 & 0,506 & 1,065 & 1,255 & 0,170 & 0,334 & 1,438 & 1,499 & $-0,061$ & 0,049 & 16,4 & 44,1 & 38,2 \\
\hline S447Q02 & 0,981 & 0,365 & 0,866 & 0,866 & 0,297 & 1,855 & 1,807 & 0,049 & 0,147 & 35,1 & 45,1 & 40,7 \\
\hline S447Q03 & 0,174 & 0,935 & 0,925 & $-0,011$ & 1,000 & 0,672 & 1,361 & $-0,689$ & 0,173 & 41,5 & 60,4 & 55,8 \\
\hline S447Q04 & 0,224 & 0,875 & 0,841 & $-0,035$ & 0,359 & 2,067 & 1,936 & 0,131 & 0,209 & 24,9 & 49,9 & 40,7 \\
\hline S458Q01 & 0,125 & 1,098 & 1,102 & 0,003 & 1,000 & 1,620 & 2,812 & $-1,192$ & 0,044 & 14,8 & 16,0 & 15,9 \\
\hline S458Q02 & 0,173 & 0,819 & 0,788 & $-0,036$ & 0,844 & 1,278 & 0,878 & 0,400 & 0,133 & 26,0 & 66,0 & 57,1 \\
\hline S465Q02 & 0,162 & 1,180 & 1,187 & 0,008 & 0,205 & 1,148 & 1,118 & 0,030 & 0,282 & 38,0 & 70,8 & 60,7 \\
\hline S465Q04 & 0,370 & 2,153 & 3,897 & 0,330 & 0,277 & 2,773 & 2,706 & 0,067 & 0,195 & 19,7 & 29,7 & 35,1 \\
\hline S466Q07 & 0,128 & 0,880 & 0,864 & $-0,019$ & 1,000 & 0,987 & $-0,145$ & 1,132 & 0,085 & 26,8 & 86,6 & 75,0 \\
\hline S476Q01 & 0,353 & 0,746 & 0,652 & $-0,134$ & 0,719 & 0,649 & 0,271 & 0,378 & 0,188 & 46,5 & 79,4 & 70,7 \\
\hline S476Q02 & 0,161 & 0,745 & 0,772 & 0,037 & 0,190 & 0,559 & 0,580 & $-0,021$ & 0,268 & 51,3 & 73,1 & 69,9 \\
\hline
\end{tabular}




\begin{tabular}{|c|c|c|c|c|c|c|c|c|c|c|c|c|}
\hline S476Q03 & 0,149 & 0,977 & 0,941 & $-0,039$ & 0,804 & 0,848 & 0,521 & 0,327 & 0,110 & 36,5 & 75,0 & 58,7 \\
\hline S477Q02 & 0,323 & 0,769 & 0,694 & $-0,104$ & 0,998 & 0,079 & 0,922 & $-0,843$ & 0,252 & 61,4 & 71,9 & 76,8 \\
\hline S477Q03 & 0,303 & 1,130 & 1,231 & 0,083 & 1,000 & 0,051 & 0,806 & $-0,755$ & 0,182 & 58,8 & 76,0 & 74,5 \\
\hline S477Q04 & 0,208 & 0,928 & 0,898 & $-0,031$ & 0,991 & 0,710 & 0,070 & 0,640 & 0,098 & 37,1 & 85,1 & 60,1 \\
\hline S478Q01 & 0,836 & 0,686 & 0,335 & $-0,717$ & 0,862 & 2,215 & 3,591 & $-1,376$ & 0,142 & 26,8 & 36,0 & 43,1 \\
\hline S478Q02 & 0,219 & 1,221 & 1,162 & $-0,050$ & 0,506 & 1,313 & 1,156 & 0,157 & 0,189 & 28,3 & 64,3 & 48,7 \\
\hline S478Q03 & 0,163 & 0,622 & 0,629 & 0,010 & 1,000 & 0,194 & 1,154 & $-0,960$ & 0,188 & 57,6 & 66,4 & 66,1 \\
\hline S485Q02 & 0,973 & 1,545 & 0,875 & $-0,566$ & 1,000 & 0,593 & 1,263 & $-0,670$ & 0,078 & 32,4 & 54,6 & 57,8 \\
\hline S485Q03 & 0,470 & 0,856 & 1,042 & 0,195 & 0,999 & 0,702 & 0,125 & 0,576 & 0,148 & 43,5 & 83,4 & 66,1 \\
\hline S493Q01 & 0,618 & 0,650 & 0,419 & $-0,446$ & 0,669 & 2,009 & 2,618 & $-0,609$ & 0,126 & 27,3 & 37,9 & 50,4 \\
\hline S493Q03 & 0,190 & 0,727 & 0,751 & 0,032 & 0,992 & $-0,397$ & 0,309 & $-0,706$ & 0,250 & 71,0 & 79,9 & 82,7 \\
\hline S493Q05 & 0,511 & 1,126 & 0,882 & $-0,229$ & 0,903 & 1,907 & 1,482 & 0,425 & 0,038 & 13,8 & 51,2 & 44,6 \\
\hline S495Q01 & 0,207 & 1,095 & 1,100 & 0,007 & 0,670 & 1,699 & 1,443 & 0,256 & 0,094 & 18,0 & 51,4 & 42,1 \\
\hline S495Q02 & 0,188 & 0,758 & 0,722 & $-0,044$ & 0,344 & 1,335 & 1,417 & $-0,082$ & 0,140 & 28,5 & 59,3 & 55,9 \\
\hline S495Q03 & 0,234 & 1,419 & 1,501 & 0,059 & 1,000 & 0,993 & 1,414 & $-0,422$ & 0,031 & 20,6 & 48,5 & 39,3 \\
\hline S495Q04 & 0,160 & 0,957 & 0,975 & 0,019 & 0,625 & 1,569 & 1,332 & 0,238 & 0,119 & 24,4 & 58,5 & 54,4 \\
\hline S498Q02 & 0,189 & 0,750 & 0,743 & $-0,008$ & 0,978 & 1,406 & 2,051 & $-0,646$ & 0,181 & 37,1 & 46,4 & 46,5 \\
\hline S498Q03 & 0,855 & 0,500 & 0,925 & 0,603 & 0,338 & 2,144 & 2,296 & $-0,152$ & 0,223 & 32,6 & 44,6 & 42,0 \\
\hline S508Q02 & 0,255 & 0,859 & 0,919 & 0,075 & 0,178 & 0,769 & 0,781 & $-0,012$ & 0,265 & 42,7 & 75,1 & 60,6 \\
\hline S508Q03 & 0,957 & 0,668 & 1,187 & 0,589 & 0,181 & 0,581 & 0,565 & 0,017 & 0,146 & 44,0 & 78,4 & 71,3 \\
\hline S510Q01 & 0,664 & 0,731 & 0,484 & $-0,424$ & 0,704 & 1,569 & 1,124 & 0,445 & 0,154 & 30,6 & 62,4 & 52,1 \\
\hline S510Q04 & 0,460 & 0,895 & 1,070 & 0,195 & 0,571 & 1,937 & 2,135 & $-0,198$ & 0,106 & 19,5 & 35,4 & 38,7 \\
\hline S514Q02 & 0,289 & 0,988 & 1,113 & 0,107 & 0,509 & $-0,063$ & 0,117 & $-0,181$ & 0,121 & 55,8 & 83,6 & 83,4 \\
\hline S514Q03 & 0,218 & 1,009 & 1,061 & 0,061 & 0,735 & 1,561 & 1,255 & 0,306 & 0,094 & 24,2 & 60,8 & 46,3 \\
\hline S514Q04 & 0,097 & 1,136 & 1,132 & $-0,004$ & 1,000 & 1,496 & 0,954 & 0,542 & 0,052 & 22,5 & 68,4 & 52,2 \\
\hline S519Q02 & 0,312 & 1,345 & 1,160 & $-0,127$ & 0,206 & 1,980 & 1,993 & $-0,013$ & 0,414 & 45,2 & 61,5 & 52,1 \\
\hline S519Q03 & 0,149 & 0,707 & 0,696 & $-0,017$ & 0,151 & 2,185 & 2,183 & 0,002 & 0,042 & 12,8 & 35,6 & 26,7 \\
\hline S521Q02 & 0,218 & 0,724 & 0,708 & $-0,020$ & 0,741 & 2,337 & 1,789 & 0,548 & 0,250 & 31,4 & 57,6 & 55,1 \\
\hline S521Q06 & 0,142 & 1,055 & 1,067 & 0,012 & 1,000 & $-0,468$ & 0,419 & $-0,888$ & 0,226 & 68,3 & 80,1 & 88,9 \\
\hline S524Q06 & 0,105 & 0,816 & 0,821 & 0,006 & 0,999 & 1,152 & 0,641 & 0,511 & 0,105 & 36,4 & 72,2 & 64,5 \\
\hline S524Q07 & 0,086 & 1,082 & 1,079 & $-0,002$ & 0,283 & 1,964 & 1,897 & 0,067 & 0,034 & 8,1 & 34,5 & 35,7 \\
\hline S527Q01 & 0,180 & 0,915 & 0,903 & $-0,013$ & 0,404 & 2,682 & 2,814 & $-0,132$ & 0,027 & 5,1 & 18,4 & 15,9 \\
\hline S527Q03 & 0,676 & 0,969 & 0,564 & $-0,495$ & 1,000 & 1,974 & 0,441 & 1,533 & 0,256 & 32,3 & 74,6 & 57,4 \\
\hline S527Q04 & 0,369 & 0,884 & 0,734 & $-0,147$ & 0,639 & 1,947 & 1,598 & 0,349 & 0,230 & 28,9 & 56,8 & 53,7 \\
\hline
\end{tabular}

